UNIVERSIDADE ESTADUAL PAULISTA

FACULDADE DE MEDICINA VETERINÁRIA E ZOOTECNIA

CAMPUS DE BOTUCATU

\title{
ANTICORPOS POLICLONAIS E MONENSINA SÓDICA NA ALIMENTAÇÃO DE BOVINOS JOVENS CONFINADOS COM DIETAS DE ALTO CONCENTRADO
}

DANILO DOMINGUES MILLEN

Tese apresentada ao Programa de Pós-Graduação em Zootecnia como parte das exigências para obtenção do Titulo de Doutor.

BOTUCATU - SP

ABRIL / 2010 
UNIVERSIDADE ESTADUAL PAULISTA

FACULDADE DE MEDICINA VETERINÁRIA E ZOOTECNIA

CAMPUS DE BOTUCATU

\section{ANTICORPOS POLICLONAIS E MONENSINA SÓDICA NA ALIMENTAÇÃO DE BOVINOS JOVENS CONFINADOS COM DIETAS DE ALTO CONCENTRADO}

DANILO DOMINGUES MILLEN

Zootecnista

ORIENTADOR: Prof. Dr. MÁRIO DE BENI ARRIGONI

Tese apresentada ao Programa de Pós-Graduação em Zootecnia como parte das exigências para obtenção do Titulo de Doutor.

BOTUCATU - SP

ABRIL / 2010 
FICHA CATALOGRÁFICA ELABORADA PELA SEÇÃO TÉCNICA DE AQUISIÇÃO E TRATAMENTO DA INFORMAC̄ĀO - SERVIÇO TÉCNICO DE BIBLIOTECA E DOCUMENTAC̄ĂO - UNESP - FCA LAGE.ADO - BOTUCATU (SP)

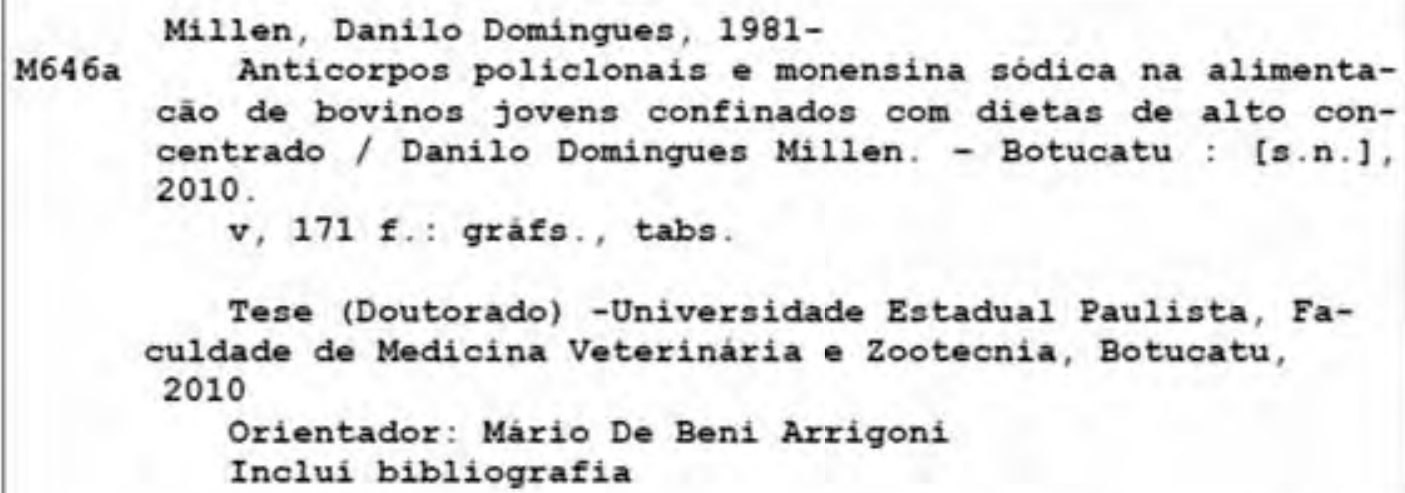

1. Brangus. 2. Nelore. 3. Rumenites. 4. Abscesso hepápatico. 5. Carcaça. I. Arrigoni, Mário De Beni. II. Universidade Estadual Paulista "Júlio de Mesquita Filho" (Campus de Botucatu). Faculdade de Medicina Veterinária e Zootecnia. III. Título. 


\section{Dedicatória}

Aos meus pais, TALIBA e DALVA, que são tudo na minha vida e por terem me dado as maiores heranças que pais podem passar para os filhos: amor, educação e incentivo para obtenção contínua do conhecimento. Todo meu esforço e dedicação são para retornar a confiança e investimento que vocês depositaram em mim por todo esse tempo. 


\section{Agradecimentos}

Em primeiro lugar gostaria de deixar explícito o meu muito obrigado ao meu orientador e amigo Prof. Dr. Mário De Beni Arrigoni pela extrema confiança, abertura, companheirismo, atenção, aconselhamentos e idéias partilhadas a tudo relacionado ao desenvolvimento do projeto dessa tese e pelos 5 anos de orientação durante a pósgraduação.

Ao meu "companheiro de aventuras" e amigo de ontem, hoje e sempre Rodrigo Dias Lauritano Pacheco por compartilharmos sempre os estudos, as pesquisas, as idéias com e sem fundamento, e os momentos difíceis e de satisfação. Divido os méritos de planejamento, condução e conclusão deste e de todos os outros trabalhos que conduzimos com você.

A Prof. Dra. Cyntia Ludovico Martins pelo contínuo auxílio durante as etapas desse projeto, principalmente na resolução de problemas burocráticos, logísticos e financeiros relacionados aos projetos.

Ao Prof. Dr. Alfredo DiCostanzo da Universidade de Minnesota, EUA, pela co-

orientação e sem o qual não teríamos a oportunidade e nem o incentivo para começarmos a desenvolver as pesquisas com anticorpos policlonais no Brasil.

Ao amigo e grande colaborador Dr. Nicolas DiLorenzo, antes na Universidade de Minnesota, agora na Texas Tech University nos EUA, pelas constantes participações e idéias visando sempre melhorar os resultados desse projeto.

Aos amigos de pós-graduação e nossos "braços direitos" na condução das pesquisas: Luis Marcelo Nave Sarti, Robson Sfaciotti Barducci, Samira Rodrigues Baldin, João Paulo Sigolo Teixeira Bastos, Taenna Martins Mariani, João Ricardo Ronchesel e Fernando Salvador Parra.

À Carolina Tobias Marino pela amizade, ajuda, colaboração durante este projeto e força de vontade para conduzir os experimentos de anticorpos policlonais no campus da USP/Pirassununga.

Ao Prof. Dr. Paulo Henrique Mazza Rodrigues da USP/Pirassununga pela colaboração e engajamento junto com todo o restante da equipe pelos projetos envolvendo anticorpos policlonais no Brasil. 
Aos funcionários do setor de Confinamento de Bovinos de Corte: Cido, Dinho, Claudemir e Sidnei pela dedicação e vontade constante de fazer com que tudo desse certo.

À Prof. Dra. Suzane Beier pelo auxílio, extrema dedicação e atenção nas análises do perfil metabólico sanguíneo.

À Prof. Dra. Ana Maria Lopes pela orientação, dedicação e paciência na condução das análises das lipoproteínas sanguíneas.

À Maria Antônia pelo auxílio e ao Prof. Dr. Dante Pazzanese Lanna por ceder o laboratório da ESALQ/USP, para que pudéssemos realizar as análises de perfil de ácidos graxos.

Ao Prof. Dr. Gerson Barreto Mourão, da ESALQ/USP pelos conhecimentos transmitidos e idéias propostas com relação a análise estatística dos dados.

Aos funcionários da UNESP responsáveis pelo setor de importação na reitoria, Vladimir e Lílian, pelo extremo profissionalismo e atenção para fazer com que o produto fosse recebido no Brasil e desembaraçado no tempo necessário para não faltar a nossos animais.

À Cilene e Luis Carlos, funcionários do Departamento de Melhoramento e Nutrição Animal pelo constante suporte em questões burocráticas e entraves dentro da universidade.

À Camas Incorporated americana por fornecer sem custo nenhum para universidade o produto contendo o preparado de anticorpos policlonais. Um obrigado especial aos senhores Brad Mitteness e Scott Simplot.

À Fundação de Amparo à Pesquisa do Estado de São Paulo, FAPESP, pela bolsa de estudo (Processo 07/58108-0) e auxílio regular à pesquisa (Processo 07/58993-4), concedidos.

À todos que não foram citados aqui, e que de alguma forma ou outra deram sua contribuição para que essa tese fosse concluída. 
SUMÁRIO

CAPÍTULO 1

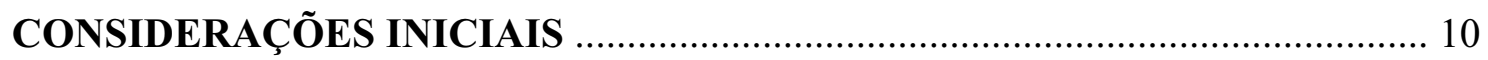

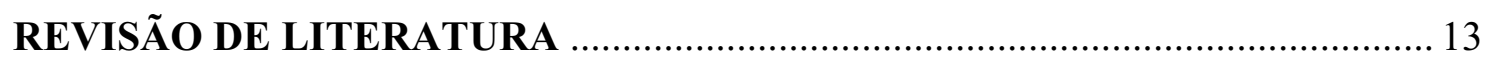

Caracterização do Ambiente Ruminal ...................................................... 13

Acidose Ruminal ...................................................................................... 14

Flutuação na Ingestão de Matéria Seca ............................................. 20

Rumenites e Abscessos Hepáticos ..................................................... 21

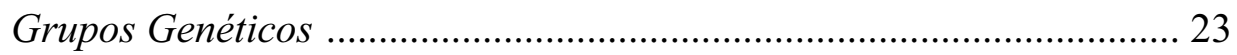

Manipulação da Fermentação Ruminal ....................................................... 25

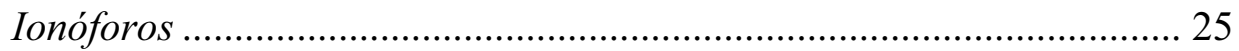

Preparado de Anticorpos Policlonais ............................................... 32

Perfil de Ácidos Graxos ...................................................................... 42

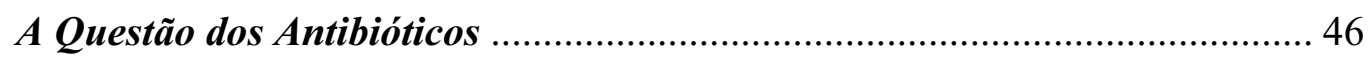

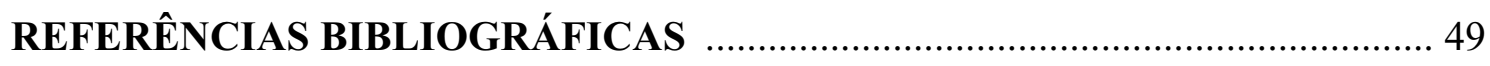

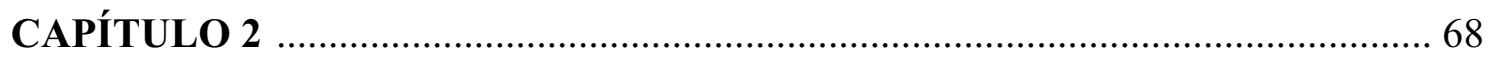

ANTICORPOS POLICLONAIS OU MONENSINA SÓDICA NA ALIMENTAÇÃO DE BOVINOS JOVENS CONFINADOS COM DIETAS DE ALTO CONCENTRADO: DESEMPENHO, PARÂMETROS METABÓLICOS E

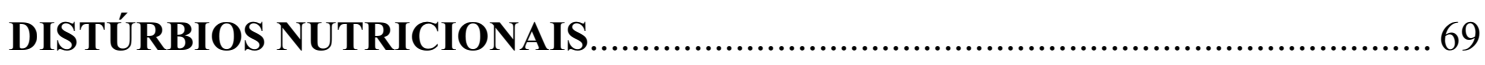

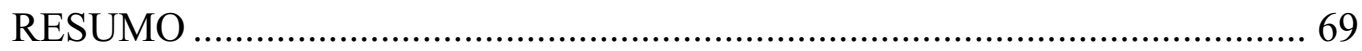

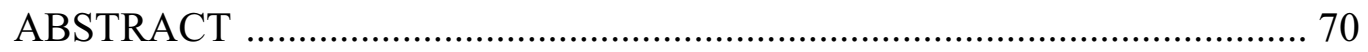

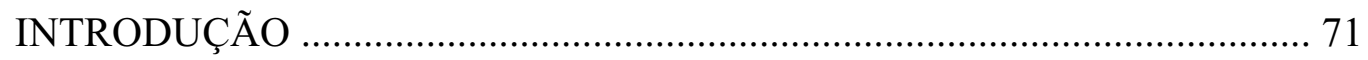

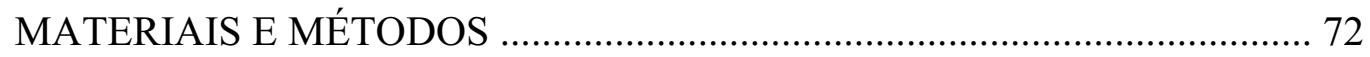

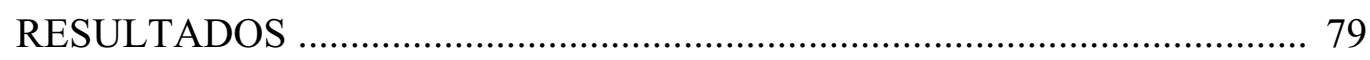

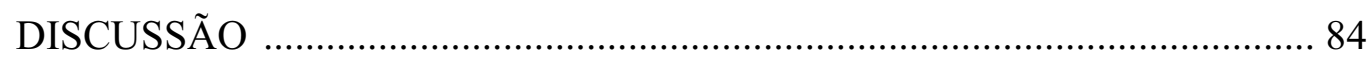

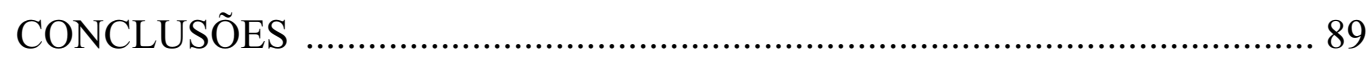

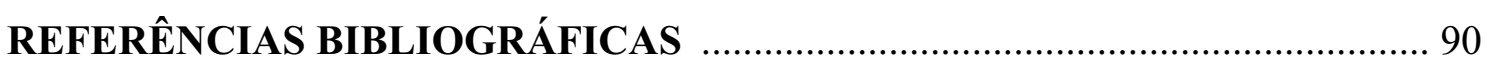


ANTICORPOS POLICLONAIS OU MONENSINA SÓDICA NA ALIMENTAÇÃO DE BOVINOS JOVENS CONFINADOS COM DIETAS DE ALTO CONCENTRADO: LIPOPROTEÍNAS SANGUÍNEAS E PERFIL DE ÁCIDOS GRAXOS DA GORDURA DA CARCAÇA DE BOVINOS

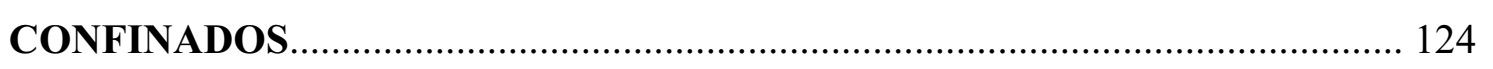

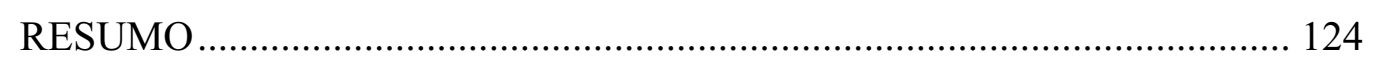

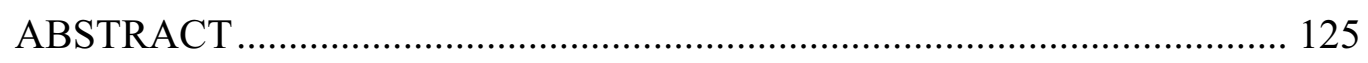

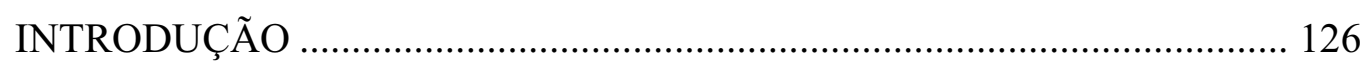

MATERIAIS E MÉTODOS ................................................................. 127

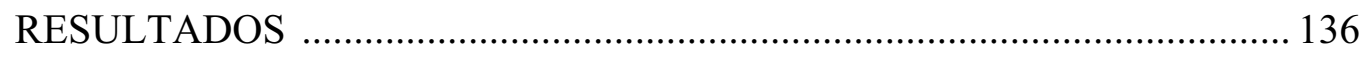

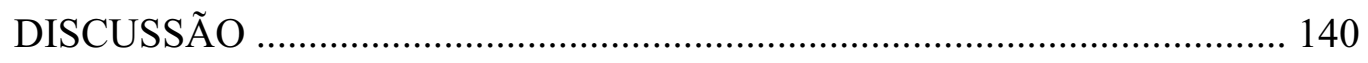

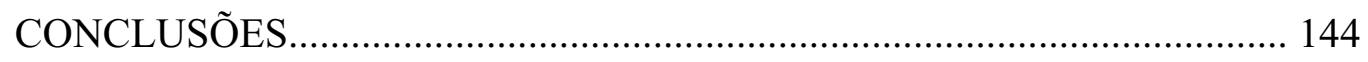

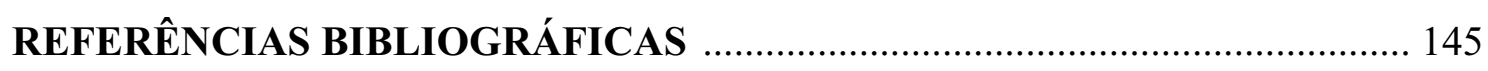

CAPÍTULO 4

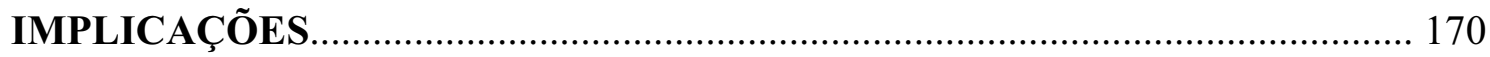




\section{CAPÍTULO 1}




\section{CONSIDERAÇÕES INICIAIS}

O mundo enfrentará, nos próximos anos, dois grandes problemas. Primeiramente a deterioração ambiental e o esgotamento de recursos naturais e, segundo, a crescente pressão sobre a capacidade de alimentar uma população em rápido crescimento (Makiya e Traballi, 2009). Para solucionarmos estes problemas temos como missão o desenvolvimento de sistemas agroindústrias sustentáveis, ecologicamente equilibrados, sanitariamente corretos e socialmente responsáveis, além de éticos e rentáveis ao longo de toda sua cadeia.

Nas últimas cinco décadas a oferta de alimentos aumentou substancialmente devido ao uso de novas tecnologias de produção (irrigação, maquinários agrícolas desenvolvidos, aditivos alimentares, promotores de crescimento, drogas eficazes ao combate de doenças e parasitas na produção animal, entre outros), maior profissionalização dos produtores, melhores canais de comercialização e apoio mais intenso dos governos (Scolari, 2005), tendo sido eficiente em atender a demanda mundial por alimento.

Segundo projeções do Comitê de Agricultura da FAO, haverá nos próximos 20 anos, aumento de aproximadamente 1,4 bilhões de habitantes no mundo, passando de 6,5 para 7,9 bilhões, devendo a produção mundial de carnes mais que dobrar até o ano de 2050, passando de 229 para 465 milhões de toneladas, representando aumento de 103\% (FAO, 2009).

$\mathrm{O}$ atendimento dessa nova demanda por alimentos deverá ser feito somente com aplicação de tecnologias, com ajustes para intensificar o sistema, aumentando a produtividade por área mas sempre de modo sustentável. Apesar da grande necessidade em atender essa demanda por alimento nos próximos anos, poucos são os países que possuem áreas agricultáveis não utilizadas. Nesse cenário, o Brasil se destaca por possuir ferramentas necessárias para se firmar como líder mundial na produção de alimentos e pesquisas nesta área.

Em um comunicado oficial emitido pela FAO em 2007 é citada a potencialidade de crescimento do agronegócio brasileiro, especialmente em relação à produção mundial de carne. O Brasil possui hoje, o maior rebanho bovino comercial do mundo com aproximadamente 173 milhões de cabeças (IBGE, 2008b), sendo o maior exportador em volume, com 2.000 mil toneladas em equivalentes carcaça. O Brasil é 
ainda o segundo maior produtor mundial de carne bovina com uma estimativa de 9.180 mil toneladas em equivalente carcaça, além de apresentar o terceiro maior consumo interno e quarto maior consumo per capita deste produto (ABIEC, 2008).

Millen et al. (2009) com o objetivo de traçar perfil dos confinamentos brasileiros realizaram levantamento com 31 nutricionistas, responsáveis pelo atendimento de um total de 3.163.750 milhões animais em confinamentos brasileiros, 547\% a mais que seis anos atrás (Cavalcanti e Camargo, 2007), e demonstraram que em relação à participação de ingredientes volumosos nas dietas, a inclusão média foi de $28,8 \%$. De acordo com Cervieri (2005), a terminação de bovinos confinados representou em 2004 cerca de 5\% do total de animais abatidos (1,9 milhão de animais). Em 2008, aproximadamente 36 milhões de bovinos foram abatidos (IBGE, 2008b), e de acordo com Millen et al. (2009) $8,7 \%$ desses animais foram terminados em confinamentos. Isto indica o crescente aumento no número de bovinos confinados no Brasil, o qual é reflexo da crescente demanda mundial por carne bovina e aonde, a inclusão de grãos e subprodutos da agroindústria nas dietas para aumentar a eficiência do sistema de produção, se tornou uma necessidade.

Por isso, tanto pelo decorrente aumento das exportações quanto da exigência dos consumidores (Fapri, 2005), os sistemas de produção de bovinos de corte no Brasil estão passando por intensificação, e assim faz-se necessário recorrer a ferramentas que permitam ajustes no sistema para que se possa explorar o máximo potencial produtivo do animal.

Dentre estas ferramentas, a manipulação da fermentação ruminal para melhorar o desempenho produtivo de ruminantes tem sido o objetivo de alguns nutricionistas por décadas (DiLorenzo, 2004). A manipulação da fermentação tem levado a extensa pesquisa na área de microbiologia ruminal nos últimos anos, com o objetivo de melhorar a eficiência de utilização dos nutrientes (Nagaraja, 2003). O impacto da manipulação dos micro-organismos do rúmen na moderna produção animal é visto como nova linha de pesquisa. Alguns dos objetivos da manipulação da fermentação ruminal, segundo Nagaraja et al. (1997), incluem: melhorar processos benéficos e minimizar, alterar ou eliminar processos ineficientes que causem prejuízos tanto para os micro-organismos do rúmen quanto para o hospedeiro. 
Nas últimas décadas, a utilização de ionóforos como aditivos alimentares para bovinos confinados se tornou imprescindível na manipulação da fermentação ruminal, aumentando, assim, a eficiência no aproveitamento das dietas empregadas e também prevenindo desordens digestivas como a acidose, que costumam aparecer com maior freqüência, quanto maior o teor energético das dietas fornecidas ao gado confinado. No entanto, se o Brasil quiser continuar a solidificar sua posição de liderança dentro do agronegócio mundial no segmento de produção de carne bovina, além da preocupação quanto à necessidade de aumentos na produção e nos índices produtivos, há também a preocupação com o atendimento das novas exigências que os mercados consumidores têm apresentado quanto àquilo que consomem e desejam consumir. Dentre estas, podemos destacar a crescente preocupação da Europa com relação a resistência ao uso de antibióticos na produção animal. Como os ionóforos são classificados atualmente como antibióticos, na União Européia o uso deste aditivo como promotor de crescimento está banido desde 2006 (OJEU, 2003). Entretanto, continua permitido o uso de ionóforos como medicamentos terapêuticos, desde que recomendados e assinados por médico veterinário.

Como o Brasil destinou em 2009 cerca de 29,3\% de suas exportações para União Européia (Beefpoint, 2010), e de acordo com Millen et al. (2009) os ionóforos são os principais aditivos alimentares utilizados em 100\% dos confinamentos brasileiros, a busca de novas alternativas para substituir os ionóforos pode levar a descoberta de novas técnicas que melhorem os processos de fermentação ruminal, e apresentem a mesma eficiência e economicidade dos ionóforos, sem trazer qualquer tipo risco para a saúde humana (DiLorenzo, 2004).

Desta forma, surge a oportunidade de pesquisa e desenvolvimento de novos aditivos que desempenhem funções semelhantes aos ionóforos e que sejam seguros à saúde humana (Newbold, 2007). Alguns autores (Hardy, 2002; Berghman e Waghela, 2004) têm citado a utilização do conceito de imunidade como potencial ferramenta na manipulação da fermentação ruminal. Anticorpos de origem aviária contra bactérias específicas seriam adicionados à alimentação de ruminantes, aumentando a eficiência produtiva através da imunidade passiva. No caso dos bovinos, os anticorpos seriam contra os micro-organismos Streptococcus bovis, Fusobacterium necrophorum 
relacionados com a ocorrência de acidose ruminal e abscessos hepáticos, respectivamente.

O interesse em compreender os efeitos da utilização de um preparado de anticorpos policlonais contra bactérias ruminais específicas como aditivo alimentar levou a realização desta pesquisa. O tema foi tratado em dois capítulos, 2 e 3 da presente tese:

O Capítulo 2, denominado "Anticorpos policlonais ou monensina sódica na alimentação de bovinos jovens confinados com dietas de alto concentrado: desempenho, parâmetros metabólicos e distúrbios nutricionais", apresenta-se de acordo com as normas para publicação no periódico Journal of Animal Science. O objetivo deste estudo foi avaliar os efeitos do preparado de anticorpos policlonais contra as bactérias Streptococcus bovis, Fusobacterium necrophorum, Escherichia coli, Clostridium aminophilum, Clostridium sticklandii, Peptostreptococcus spp. ou monensina sódica sobre o desempenho, características de carcaça, incidências de rumenites e abscessos hepáticos, perfil metabólico sanguíneo e flutuação da ingestão de matéria seca de bovinos Brangus e Nelore confinados.

O Capítulo 3, denominado "Anticorpos policlonais ou monensina sódica na alimentação de bovinos jovens confinados com dietas de alto concentrado: lipoproteínas sanguíneas e perfil de ácidos graxos da gordura da carcaça de bovinos confinados”, também apresenta-se de acordo com as normas para publicação no periódico Journal of Animal Science. O objetivo deste estudo foi avaliar os efeitos do preparado de anticorpos policlonais contra as bactérias Streptococcus bovis, Fusobacterium necrophorum, Escherichia coli, Clostridium aminophilum, Clostridium sticklandii, Peptostreptococcus spp. ou monensina sódica sobre a concentração de lipoproteínas sanguíneas e perfil de ácidos graxos da gordura da carcaça coletadas de três distintas regiões de bovinos Brangus e Nelore confinados.

\section{REVISÃO DE LITERATURA}

\subsection{CARACTERIZAÇÃO DO AMBIENTE RUMINAL}

No interior do rúmen há condições ambientais ideais para o desenvolvimento de micro-organismos como bactérias, protozoários e fungos que compõem a flora 
microbiana. Estas condições são temperatura entre $38-41^{\circ} \mathrm{C}$, $\mathrm{pH}$ entre 5,5-7,2, umidade entre 85-90\%, osmolaridade entre 260-340 mOsm e ambiente anaeróbico. Além disso, há presença constante de substratos para fermentação oriundos da alimentação e um padrão de motilidade ruminal que permite a mistura do conteúdo e remoção periódica dos subprodutos de fermentação não utilizados pela flora microbiana através de absorção pelo epitélio ruminal (Carvalho et al., 2003).

O objetivo do ruminante é manter as condições ruminais descritas acima para assegurar que o metabolismo dos micro-organismos mantenha-se ativo para fermentar os nutrientes da dieta. A não manutenção destas condições poderá acarretar distúrbios metabólicos, como a acidose ruminal. O principal diferencial entre ruminantes e outras espécies de mamíferos é que através da relação simbiótica com os micro-organismos é possível o aproveitamento dos nutrientes contidos nos carboidratos estruturais e nos compostos nitrogenados não-protéicos. Isto deve-se à presença de enzimas no metabolismo dos micro-organismos, as quais permitem degradar estes compostos (Valadares Filho et al., 2006).

\subsection{ACIDOSE RUMINAL}

O sucesso dos ruminantes pode ser largamente explicado pela habilidade destes em digerir materiais fibrosos. $\mathrm{O}$ fato destes animais hospedarem micro-organismos que produzem enzimas que degradam fibra dá a eles uma vantagem competitiva em relação aos outros animais na natureza (Russel e Richlik, 2001). No entanto, altos níveis de produtividade não podem ser sustentados por forragens apenas, e frequentemente grãos e seus subprodutos são empregados na produção de ruminantes.

No Brasil, o aumento da demanda de carne bovina no mercado internacional tem estimulado o crescimento da produção deste tipo de carne no país. Este aumento tem ocorrido devido a diversos fatores, entre eles: melhoria no manejo das pastagens, suplementação protéica na época das secas e crescimento do número de confinamentos e semi-confinamentos. O surgimento de grandes unidades de confinamento no Brasil, assim como maior disponibilidade de grãos e subprodutos tem estimulado o uso de rações com altos teores de concentrado.

Quando consideramos que o Brasil produziu 30 bilhões de litros de leite (CNA, 2007) e abateu 36 milhões de cabeças de gado (IBGE, 2008b) em 2008, a inclusão de 
ingredientes para aumentar a densidade energética das dietas se torna uma necessidade. Neste caso, quando bovinos são abruptamente submetidos a dietas de alto concentrado (grãos em geral), uma série de processos fisiológicos é ativada resultando num distúrbio metabólico conhecido como acidose (DiLorenzo, 2004). Devido ao acentuado crescimento do número de animais confinados nos últimos anos (Cavalcanti e Camargo, 2007), faz-se necessário a preocupação com este tipo de distúrbio digestivo. Portanto, o aparecimento de distúrbios digestivos como esse aumentam conforme os níveis de produtividade se elevam. Em levantamento realizado por Millen et al. (2009) com nutricionistas de gado confinado no Brasil, foi reportado que 52\% dos nutricionistas entrevistados responderam que a acidose ou problemas ligados à acidose (laminites e timpanismo) são o segundo maior problema relacionado à saúde de bovinos confinados, ficando atrás apenas de problemas respiratórios (56\%).

Segundo Nocek (1997), as perdas econômicas são mais acentuadas em quadros de acidose subclínica do que em acidose clínica, pois os sintomas na maioria dos casos não são evidentes como em casos clínicos. Pesquisadores da Universidade de Nebraska calcularam que as perdas econômicas devido à acidose subclínica resultando em redução do desempenho animal, causada pela reduzida ingestão de matéria seca nos confinamentos, estão entre US\$10 e US\$13 por cabeça. Se a esses valores fossem adicionados perdas devido a abscessos de fígado, o qual é associado à acidose subclínica, as perdas atingiriam US\$16 por animal. Esse cálculo foi realizado considerando $15 \%$ de incidência de abscesso hepático (Stock e Britton, 1996). Consumos de matéria seca e desempenho reduzidos são comumente observados como resultados de acidose subclínica (Koers et al., 1976; Owens et al., 1998).

Acidose pode ser definida como redução do conteúdo alcalino do fluído corporal em relação ao conteúdo ácido (Owens et al., 1998). Quando o suprimento de carboidratos não fibrosos é aumentado abruptamente, ácidos graxos de cadeia curta produzidos pelos micro-organismos no rúmen e a proporção de ácido lático, aumentam como resultado da maior taxa de fermentação. O lactato não está geralmente presente no rúmen em altas concentrações; no entanto, quando o rúmen é abruptamente suprido com altas quantidades de carboidratos não fibrosos, o acúmulo de ácido lático ocorrerá (Owens et al., 1998). O lactato apresenta maior $\mathrm{pK}_{\mathrm{a}}$ (constante de dissociação) e portanto maior força que ácidos graxos de cadeia curta comumente produzidos no 
rúmen (acetato, propionato, butirato), promovendo maior efeito na redução do $\mathrm{pH}$ ruminal (Dawson et al., 1997).

$\mathrm{O}$ processo de acidose se inicia quando o ruminante consome grandes quantidades de amido ou outros carboidratos rapidamente fermentáveis. A hidrólise do amido leva ao aumento da concentração de glicose ruminal, a qual normalmente é muito baixa, até o ponto onde esta excede a concentração de glicose sanguínea (Galyean e Rivera, 2003). O aumento da concentração de glicose ruminal causa várias conseqüências negativas no ambiente ruminal como: o crescimento de microorganismos produtores de lactato, principalmente Streptococcus bovis (Dawson et al., 1997); aumento da osmolaridade (quantidade de sólidos dissolvidos no fluído ruminal), o qual colabora com a acidez ruminal e inibe a absorção de ácidos graxos de cadeia curta do rúmen (Owens et al., 1998); e crescimento de micro-organismos coliformes e aminoácido decarboxilantes, os quais produzem endotoxinas que contribuem para o desenvolvimento de laminites (Galyean e Rivera, 2003).

O ácido lático é acumulado durante acidose como resultado da proliferação de micro-organismos ruminais que fermentam glicose a lactato, os quais são insensíveis ao pH reduzido. Por outro lado, a maior parte das bactérias utilizadoras de lactato são sensíveis a baixos valores de $\mathrm{pH}$ (Owens et al., 1998). Essa situação favorece a produção e o acúmulo mais rápido de ácido lático no rúmen. $\mathrm{O}$ acúmulo de ácido lático no rúmen é frequentemente observado quando ruminantes são abruptamente mudados de dietas com alta proporção de forragem para outras com altos teores de concentrado. Se bovinos são gradualmente adaptados a dietas com alto teor de concentrado, o acúmulo de ácido lático é prevenido; no entanto, o $\mathrm{pH}$ ruminal poderá ainda permanecer baixo devido a maior produção de ácidos graxos de cadeia curta (Nagaraja, 2003). O pH de 5,5 é considerado por alguns autores (Slyter, 1976; Nagaraja, 2003) o limite, abaixo do qual, bactérias produtoras de lactato como Streptococcus bovis e Lactobacillus spp. proliferam. Simultaneamente, o crescimento de bactérias utilizadoras de lactato (Megasphera elsdenii e Selenomonas ruminantium) é inibido nessa faixa de $\mathrm{pH}$ (Russel e Hino, 1985). Assim sendo, independentemente do tipo de dieta, quando o pH ruminal cai abaixo de 5,5; o acúmulo de ácido lático é esperado.

Dois tipos de acidose podem afetar bovinos confinados: clínica e subclínica. $\mathrm{Na}$ acidose clínica, bovinos que consumiram grandes quantidades de carboidratos não 
fibrosos, como grãos, apresentaram maiores produções de ácidos graxos de cadeia curta (Galyean e Rivera, 2003). A concentração de ácido lático ruminal também é abruptamente elevada com o aumento da produção de ácidos graxos de cadeia curta, resultando em drástica redução do pH ruminal. Concentrações de ácido lático no rúmen maiores que $40 \mathrm{mM}$ (ambas as formas isômeras D e L) são consideradas reflexos de acidose clínica (Owens et al., 1998). O pH menor que 5,2 é considerado o limite para acidose clínica (Owens et al., 1998; Galyean e Rivera, 2003). Acidose ruminal causa migração de ácido lático para a corrente sanguínea devido à diferença de osmolaridade entre o rúmen e o sangue, derrubando, desse modo, a capacidade do bicarbonato de tamponar o sangue (Galyean e Rivera, 2003).

A absorção de ácidos graxos de cadeia curta pela remoção de ácidos não ionizados e pela troca de ácidos graxos ionizados por bicarbonato durante o processo de absorção (Stevens, 1970), ajuda a manter o pH ruminal próximo à neutralidade. Consequentemente, a redução da taxa de absorção de ácidos graxos de cadeia curta leva à queda do $\mathrm{pH}$ do rúmen por duas razões: acúmulo dos mesmos no rúmen e redução da entrada de bicarbonato provindo do sangue para dentro do meio ruminal. Aproximadamente metade do bicarbonato que entra no rúmen vem da saliva durante mastigação e ruminação; a outra metade chega ao ambiente ruminal provindo da corrente sanguínea na troca com os ácidos ionizados enquanto estes estão sendo absorvidos.

Com dietas contendo altos teores de concentrado e reduzida contribuição de saliva, maior proporção de bicarbonato deve ser derivada do sangue. Isso reduz os excessos de base no sangue e no fluídos extra-celulares, e se o animal não conseguir restabelecer a homeostase, isso poderá causar a chamada acidose metabólica (Owens et al., 1998). Faverdin et al. (1999) relataram que as concentrações de bicarbonato e excessos de base no sangue foram negativamente correlacionadas com a concentração ruminal de ácidos graxos de cadeia curta quando altas quantidades de grãos de trigo foram adicionadas ao rúmen de vacas de leite canuladas. Esses resultados foram acompanhados de transitória redução no consumo de matéria seca. Outros estudos também têm reportado reduções nas concentrações sanguíneas de bicarbonato e excessos de base durante acidose subclínica em novilhos confinados (Goad et al., 1998). Outra resposta do organismo dos ruminantes em decorrência de acidose metabólica 
seria a taxa respiratória compensada levando à baixos valores de pressão e total de gás carbônico e aumento na pressão e saturação de oxigênio sanguíneos (Hill, 1990). Sob condições normais, o pH do sangue é altamente regulado e raramente flutua, porque este está saturado com bicarbonato. Durante acidose clínica, no entanto, a produção excessiva de ácidos pode exaurir a capacidade do bicarbonato tamponar o sangue e então o pH sanguíneo pode diminuir (Owens et al., 1998).

Den Hartog et al. (1989) e Jackson et al. (1992) observaram pH, bicarbonato e pressão de gás carbônico reduzidos no sangue quando novilhos confinados foram alimentados com dietas contendo maiores teores de concentrado. No entanto, Bevans et al. (2005) não encontraram diferenças entre animais adaptados rapidamente (5 dias) ou gradualmente (17 dias) no tocante ao $\mathrm{pH}$, pressão parcial de $\mathrm{CO}_{2}$ e volume das células sanguíneos. Valores de referência de gases e metabólitos sanguíneos de bovinos podem ser encontrados na Tabela 1.

Tabela 1. Valores referência de gases e metabólitos de sangue venoso de bovinos.

\begin{tabular}{cc}
\hline $\mathrm{pH}$ & $7,35-7,50$ \\
$\mathrm{pO}_{2}(\mathrm{~mm} \mathrm{Hg})$ & $*$ \\
$\mathrm{pCO}_{2}(\mathrm{~mm} \mathrm{Hg})$ & $35-44$ \\
Bicarbonato $(\mathrm{mmol} / \mathrm{L})$ & $20-30$ \\
$\mathrm{CO}_{2}$ Total $(\mathrm{mmol} / \mathrm{L})$ & $24-29$ \\
Excessos de Base $(\mathrm{mmol} / \mathrm{L})$ & $0 \pm 2$ \\
\hline
\end{tabular}

* Não há um padrão de referência em sangue venoso de bovinos.

Carlson (1997)

Mudanças na osmolaridade sanguínea levam ao endurecimento das pernas e laminites (Nocek, 1997), assim como lesões na parede do rúmen que podem ser mais tarde colonizadas por micro-organismos patogênicos como Fusobacterium necrophorum ou Actinomyces pyogenes, ambos agentes etiológicos de abscessos de fígado (Nagaraja e Chengappa, 1998). Desse modo, a eficiência hepática é prejudicada, levando à diminuição do desempenho animal. Outros eventos que acontecem simultaneamente estão associados com a diminuição do volume extracelular, resultando em desidratação, batimentos cardíacos inconstantes, diminuição da circulação sanguínea periférica, redução do fluxo de sangue para os rins, choque e morte (Huntington, 1988). Assim sendo, se o ruminante não for capaz de restabelecer a homeostase, o resultado pode ser a morte do animal. 
O perfil de micro-organismos no rúmen também sofre mudança: há um aumento na população de bactérias da espécie Streptococcus bovis e das bactérias que produzem ácido lático. Concomitantemente, há redução no número dos micro-organismos consumidores de ácido lático (Megasphera elsdenii e Selenomonas ruminantium) causando acúmulo ruminal deste (Strobel e Russel, 1986). A partir do momento que o pH ruminal cai abaixo de 5,2, o crescimento de bactérias Streptococcus bovis é inibido, mas bactérias do gênero Lactobacillus encontram ambiente favorável para se proliferar, preenchem este nicho e continuam a produzir ácido lático em pH menor que 5,2 (Russel e Hino, 1985).

No caso de acidose subclínica, ruminantes não mostram sintomas ou sinais externos da doença, mas com freqüência a ingestão de matéria seca e, consequentemente, o desempenho animal são diminuídos. $\mathrm{O}$ pH de 5,6 é considerado o limite para a acidose subclínica (Owens et al., 1998; Galyean e Rivera, 2003). A acidose subclínica ocorre mais frequentemente e a identificação de um animal doente dentro da baia se torna mais difícil mesmo ocorrendo severa redução no consumo de matéria seca. De acordo com Stock e Britton (1996), todos os animais submetidos a dietas com altos teores de concentrado vão passar por acidose subclínica no mínimo uma vez durante o confinamento.

Várias ferramentas de manejo e aditivos alimentares podem ser utilizadas com o intuito de prevenir ou controlar acidose, e a eficácia dessas ferramentas é dependente da extensão da doença e da natureza do produto. Tamponantes como o bicarbonato, óxido de magnésio e carbonato de cálcio foram adicionados a dietas para neutralizar ácidos nos anos 70 (Russell e Rychlik, 2001). No entanto, o efeito do bicarbonato sozinho como agente tamponante não é suficiente para conter acidose em confinamentos. Carbonato de cálcio e óxido de magnésio são mais efetivos em $\mathrm{pH}$ reduzidos; mas, seria necessário o fornecimento desses produtos várias vezes ao dia para se obter o efeito desejado de tamponamento ruminal, pois esses produtos agem no rúmen no mesmo momento em que são consumidos, não restando, por exemplo, poder tampão suficiente no pico de produção de ácidos graxos de cadeia curta que ocorre em geral quatro horas após a alimentação, tornando o uso desses produtos inviável. Indubitavelmente, o uso de ionóforos é um dos métodos mais efetivos para controle e prevenção da acidose. Ionóforos modificam a composição da microflora ruminal e reduzem a ingestão, 
aliviando assim a acidose. Stock et al. (1995) relataram menores flutuações no consumo de matéria seca em novilhos confinados alimentados com monensina sódica.

\subsubsection{Flutuação na Ingestão de Matéria Seca}

Em geral, é assumido que variações na ingestão de alimentos por bovinos confinados podem causar acidose e reduzir a ingestão de matéria seca (Britton e Stock, 1987). Essa crença, abraçada por vários confinadores, é suportada pelo estudo de Galyean et al. (1992), no qual deliberadamente 10\% de flutuação na dieta fornecida aos animais reduziu o ganho em $6 \%$ e a eficiência alimentar em $7 \%$ quando comparados a animais que receberam a dieta de acordo com programação constante com base no peso vivo. Neste estudo, o desempenho reduzido foi atribuído à acidose subclínica devido à variação na ingestão, mesmo com o pH ruminal não sendo mensurado. Esta teoria permanece prevalente, mesmo após aparecimento de alguns estudos que a contradizem (Zinn et al., 1994; Stock et al., 1995; Cooper et al., 1999, Soto-Navarro et al., 2000).

Em animais que estão sendo acometidos por quadros de acidose subclínica principalmente, a alta osmolaridade no ambiente ruminal, faz com que a digestão de fibra e amido sejam prejudicadas (osmolaridades $>350 \mathrm{mOsm}$ ) e a motilidade do abomaso cesse, prejudicando a remoção dos ácidos produzidos e exacerbando ainda mais a acidificação ruminal, podendo causar o aparecimento de rumenites e abscessos de fígado. Desta forma, a alterada motilidade ou tonicidade pode causar flutuações na ingestão de matéria seca (Owens et al., 1998).

Muitos estudos têm concluído que grandes variações ou flutuações na ingestão de matéria seca por bovinos alimentados com dietas contendo altos teores de concentrado, podem causar desordens digestivas como a acidose (Fulton et al., 1979; Britton e Stock, 1987) e reduzir o desempenho animal em confinamento (Stock et al., 1995) com este efeito sendo maior no início do período de alimentação (Krehbiel et al., 1995; Soto-Navarro et al., 2000). Schwartzkopf-Genswein et al. (2004) observaram que bovinos que foram impostos à ingestões flutuantes apresentaram maior tempo de $\mathrm{pH}$ ruminal abaixo de 5,5; valor este que já pode ser considerado como acidose subclínica (Owens et al., 1998; Galyean e Rivera, 2003) e ainda inibir severamente a digestão de fibra (Yang et al., 2002). Ainda, Cooper et al. (1999) relataram que animais que apresentaram ingestões flutuantes despenderam menor tempo com alimentação. Em 
levantamento recente realizado por Millen et al. (2009), foi relatado que mais de 50\% dos confinamentos brasileiros atendidos pelos nutricionistas entrevistados não controlavam a quantidade de alimento fornecido para cada baia, adotando o sistema de "bica corrida", o que pode colaborar com o aumento da variação do consumo de matéria seca.

Stock et al. (1995) avaliaram a monensina em bovinos alimentados individualmente e observaram menor variação na ingestão de alimentos, especialmente quando os teores de concentrado foram de $85 \%$ ou mais na dieta. Em estudos similares, novilhos adaptados à dietas de $85 \%$ de concentrado contendo monensina consumiram menos alimento, porém com refeições mais frequentes do que novilhos não alimentados com monensina. A monensina tendeu a fazer com que os animais reduzissem a taxa de ingestão e quantidade de alimento por refeição, aumentando com isso o número de refeições diárias, não afetando a ingestão de matéria seca total do dia (Fanning et al., 1999).

\subsubsection{Rumenites e Abscessos Hepáticos}

A população microbiana ruminal normalmente não inclui patógenos. Entretanto, quando as condições se tornam favoráveis, certos micro-organismos, como o Aspergillus spp. ou o Fusobacterium necrophorum invadem o epitélio ruminal e podem causar rumenites. A partir desse quadro de rumenite o $F$. necrophorum consegue atravessar a parede ruminal e atingir a circulação portal, alcançando e se alojando no fígado, gerando abscessos hepáticos. Entre as bactérias ruminais, o Fusobacterium necrophorum é aquele mais freqüentemente encontrado nas rumenites e nos abscessos hepáticos (Nagaraja e Chengappa, 1998).

A rumenite causada por fungos oportunistas, particularmente espécies do Aspergillus, é quase sempre secundária à acidose ruminal. A estrutura micelial dos fungos permite a invasão e a dispersão do fungo na parede ruminal, resultando em lesões hemorrágicas no rúmen (Nagaraja et al., 1996).

Seqüela comum em muitas doenças, a rumenite é uma condição com desenvolvimento de alterações inflamatórias no epitélio ruminal e nos tecidos subjacentes do gado alimentado com dietas ricas em cereais e com níveis de forragem inadequados. $\mathrm{Na}$ maioria dos casos, a infecção do epitélio ruminal ocorre após dano 
mecânico ou químico. A causa mais comum de dano mecânico é a perfuração do retículo e do rúmen por objetos metálicos pontiagudos que ficam presos no retículo. Estes casos de reticulite e rumenite são esporádicos e têm pouca importância econômica. A causa química mais freqüente é a alta concentração dos ácidos produzidos no rúmen. A rumenite induzida por ácidos pode ser aguda, verificada após um episódio de acidose láctica; ou crônica ou subaguda, decorrente de prolongada alimentação com dieta rica em cereais com forragem inadequada. Esta última condição é também chamada de hiperqueratose ruminal, onde as papilas ruminais se tornam escuras, maiores, grossas, irregulares e comprimidas umas contra as outras devido à formação de camada anormal de queratina depositada nas superfícies papilares. Na rumenite crônica ou aguda, o epitélio inflamado se torna susceptível a invasões de micróbios ruminais oportunistas, tais como o Fusobacterium necrophorum, o Arcanobacterium pyogenes e outras espécies de fungos. A rumenite micótica também pode ocorrer em conseqüência do uso intenso de antibióticos orais ou da ingestão de alimentos com fungos, sendo que seu grau de perturbação é dependente de sua extensão e localização da lesão no rúmen (Nagaraja e Chengappa, 1998).

Os abscessos hepáticos ocorrem esporadicamente na maior parte dos animais, mas são mais comuns nos ruminantes, especialmente no gado alimentado com dietas contendo altos níveis de concentrado. Pode ocorrer em todas as idades e em todos os tipos de gado, incluindo leiteiro, porém tem seu maior impacto econômico no gado de corte confinado, no qual a incidência vai de $2 \%$ até 90 ou $95 \%$, apresentando médias de 20 a 30\% na maior parte dos animais confinados nos EUA (Nagaraja et al., 1996), sendo a maior causa de condenação do fígado. No Brasil, até pouco tempo atrás não se dava tanta atenção à lesões ruminais e incidência de abscessos de fígado, no entanto, a maioria dos nutricionistas de gado confinado no Brasil recomendaram em 2009 nível de inclusão de grãos de mais de 50\% nas dietas (Millen et al., 2009), o que pode tornar esses tipos de patologia uma preocupação econômica ainda em 2010.

Entretanto, o principal efeito econômico dos abscessos hepáticos está relacionado com a redução no desempenho animal e com a diminuição do rendimento de carcaça. Em geral, os abscessos hepáticos são resultados diretos das práticas alimentares, portanto, a dieta desempenha papel fundamental em sua incidência. Práticas, tais como brusca elevação energética da dieta ou manejo nutricional errôneo, 
caracterizadas por refeições irregulares (em termos de volume ou freqüência), podem promover acidose ruminal e rumenites, bem como levar a maior incidência de abscessos hepáticos (Nagaraja et al., 1996).

Quase todos os estudos bacteriológicos de abscessos hepáticos concluíram que o Fusobacterium necrophorum, um habitante regular do rúmen, é o agente causador primário e o segundo patógeno isolado mais freqüente é o Arcanobacterium (Actinomyces) pyogenes (Nagaraja e Chengappa, 1998).

Os abscessos hepáticos são secundários aos focos primários de infecção na parede ruminal. A relação entre patologia ruminal e abscessos hepáticos em gado de corte confinado já foi bem documentada (Jensen et al., 1954). O termo "complexo rumenite - abscesso hepático" vem sendo muito utilizado devido à alta correlação entre abscessos hepáticos e lesões ruminais. A rumenite induzida por ácido e os danos à superfície protetora estão geralmente associados à alta ingestão de ingredientes concentrados (Jensen et al., 1954; Fell et al., 1972).

Assim sendo, a parede ruminal danificada por acidez ou por penetração de corpos estranhos se torna suscetível à invasão e colonização pelo F. necrophorum. Uma vez que a colonização ocorreu, o $F$. necrophorum pode chegar à corrente sangüínea ou causar abscessos na parede ruminal e, consequentemente, liberar êmbolos bacterianos na circulação portal. As bactérias na circulação portal são filtradas pelo fígado, levando a infecções e à formação de abscessos.

\subsubsection{Grupos Genéticos}

É bem documentado na literatura internacional (Ferrell et al., 2006; Krehbiel et al., 2000; Sherbeck et al., 1996) o melhor desempenho de bovinos com alguma proporção de genótipos europeus na sua composição em dietas de alta energia, quando estes são comparados com bovinos Bos indicus. Putrino (2002) encontrou ganho de peso diário em torno de $20 \%$ maior para animais Brangus em relação a bovinos Nelore em todas as dietas do período experimental (20,40, 60 e 80\% de concentrado). Observações fornecidas por nutricionistas de bovinos confinados no Brasil sugerem maior ingestão de matéria seca para bovinos cruzados em relação a animais Nelore (Millen et al., 2009). Melhor desempenho de bovinos confinados com maior proporção de genótipo europeu em relação ao genótipo Zebu têm sido relatado também por vários 
outros autores brasileiros (Cucki, 2006; Cruz et al., 1995; Leme et al., 2000). Lanna et al. (1998) encontraram redução no desempenho esperado de zebuínos quando o nível de concentrado na dieta foi superior a $50 \%$ da matéria seca total. Neste mesmo trabalho, a revisão de dados sobre digestibilidade de zebuínos no Brasil, indicou que concentrações maiores que $67 \%$ de NDT, devido a maior inclusão de ingredientes concentrados pareceu não aumentar a digestibilidade ou valor energético da dieta (a maior parte dos trabalhos indicados na revisão utilizou o milho como fonte de energia). Por outro lado, é difícil tirar algum tipo de conclusão em relação ao teor máximo de energia que animais zebuínos podem consumir, pois ainda não existem na literatura estudos conduzidos com adaptação desses animais à dietas que contém altos teores de concentrado, ainda mais com a variedade de subprodutos da agroindústria que são incluídos com freqüência nas dietas dos confinamentos brasileiros.

Fossa et al. (2008) encontraram maior concentração de ácidos graxos insaturados, incluindo o CLA, na gordura subcutânea de animais Nelore em relação a animais Canchim e Tri-Cross ( $1 / 2$ Brangus, $1 / 4$ Angus, 1/4 Nelore) e inferiram que estes achados poderiam ser devidos a maior incidência de lesões na parede do rúmen que estes animais apresentaram em estudo conduzido por Millen et al. (2007), no qual foi encontrado maior incidência de rumenites em bovinos Nelore quando estes foram comparados a animais Canchim e Tri-Cross, indicando maior sensibilidade de bovinos Nelore a dietas de alto concentrado quando comparados a animais que possuem alguma proporção de sangue europeu nas suas composições. Em estudo conduzido na Austrália, Bigham e McManus (1975) observaram menores ganhos de peso diário e ingestão de matéria seca em animais com maior incidência de rumenites.

Provavelmente a acidose que ocorre em confinamentos brasileiros seja do tipo subclínica devido ao grande uso de subprodutos da agroindústria nas dietas, e por isso, a redução do $\mathrm{pH}$ acontece apenas pelo acúmulo de ácidos graxos de cadeia curta, sendo que ingestões menores e mais espaçadas poderiam evitar esse acúmulo (Erickson et al., 2003). De acordo com levantamento realizado por Millen et al. (2009), nutricionistas de bovinos confinados no Brasil recomendaram níveis de inclusão de 15\%, 33,8\% e 28\% para subprodutos como o caroço de algodão, polpa cítrica e casca de soja, respectivamente. Enfim, na atual conjuntura de intensificação dos sistemas de produção de bovinos, é preciso cada vez mais efetuar ajustes para que se possa explorar ao 
máximo a eficiência dos animais, sem haver problemas de distúrbios como a acidose. $\mathrm{O}$ uso de estratégias ou produtos comerciais, que de alguma forma manipulam ou modificam os padrões de fermentação do rúmen, podem ajudar a solucionar ou aliviar problemas de acidificação ruminal em bovinos de genótipos Bos indicus.

\subsection{MANIPULAÇÃO DA FERMENTAÇÃO RUMINAL}

No final do século XVIII, Tappeiner (1884; citado por Bergman, 1990) demonstrou que os microrgasnimos presentes no rúmen fermentavam celulose e como produtos obtinham ácidos graxos de cadeia curta, metano e dióxido de carbono. Desde esta época, a comunidade científica busca entender os processos metabólicos que ocorrem neste órgão e suas interações, e procura por estratégias de manipulação da fermentação ruminal com intuito de melhorar a eficiência energética destas reações. Esta energia disponível pode ser utilizada para incremento dos fins produtivos do animal, como ganho de peso ou produção leiteira.

\subsubsection{Ionóforos}

De todos os aditivos alimentares disponíveis no mercado brasileiro, os ionóforos são os mais comumente usados na indústria de bovinos de corte. Millen et al. (2009) através de levantamento realizado com nutricionistas de bovinos confinados no Brasil, reportaram que $100 \%$ dos confinamentos atendidos pelos nutricionistas entrevistados utilizam ionóforos como principal aditivo alimentar. Os ionóforos mais usados pela indústria de bovinos de corte, atualmente, incluem salinomicina, monensina sódica, e lasalocida.

Ionóforos são substâncias químicas produzidas por micro-organismos como o Streptococcus cinnamonensis (Haney e Hoehn, 1967), que aumentam a permeabilidade de membranas lipídicas biológicas ou artificiais a íons específicos. A maior parte dos ionóforos são moléculas orgânicas pequenas que agem como carreadores móveis dentro das membranas ou formam um canal íon permeável através das mesmas. Ionóforos são quimicamente classificados como antibióticos poliéteres (Hirohiko et al., 1994), e muitos deles agem como agentes causadores de "curto circuito" no gradiente de prótons através das membranas das mitocôndrias.

Russel (1987) propôs uma explicação para a desorganização no transporte de 
íons da membrana pela monensina, culminando na inibição do crescimento microbiano. Vale a pena conhecer essa hipótese para permitir melhor compreensão dos fatores que podem interferir na ação de ionóforos.

A maioria das células expele prótons ativamente (via ATPase) através da membrana celular e mantém o interior mais alcalino. As bactérias mantêm, internamente, concentrações de $\mathrm{K}+$ muito altas, maiores que no meio externo (culturas de S. bovis mantêm a concentração de $\mathrm{K}+$ interna cerca de 70 vezes maior que a externa). As concentrações internas elevadas de $\mathrm{K}+$ são necessárias não só para a síntese de proteína, como também o gradiente de $\mathrm{K}+$ que se forma é importante para tamponar o $\mathrm{pH}$ intracelular por meio do mecanismo de troca de $\mathrm{K}+/ \mathrm{H}+$.

É necessário que o excesso de prótons $(\mathrm{H}+)$ seja expulso da bactéria para que o $\mathrm{pH}$ interno se estabilize. Esse gradiente de $\mathrm{pH}$ cria um gradiente químico de prótons; como o interior da membrana é mais negativo que o exterior, é criado também um potencial elétrico. $\mathrm{O}$ gradiente químico de prótons e o potencial elétrico são responsáveis pela formação da força motriz de prótons, que pode ser utilizada para importar solutos para dentro da membrana.

A monensina desorganiza o transporte de íons segundo o modelo em que um cátion monovalente é trocado por outro durante a passagem pela membrana plasmática. A monensina tem cerca de dez vezes maior afinidade por $\mathrm{Na}+/ \mathrm{H}+$ que por $\mathrm{K}+/ \mathrm{H}+$. Entretanto, o gradiente de $\mathrm{K}+$ é cerca de 25 vezes maior que o gradiente de $\mathrm{Na}+$, tornando o efluxo de $\mathrm{K}+$ via monensina mais favorável que o efluxo de $\mathrm{Na}+$. $\mathrm{O}$ efluxo de $\mathrm{K}+$ resulta em acúmulo de $\mathrm{H}+$, levando ao decréscimo no $\mathrm{pH}$ intracelular.

Assim, por exemplo, culturas de $S$. bovis mantêm $\mathrm{pH}$ interno próximo a 7,08 quando o pH externo é de 6,65 , gerando um potencial próton-químico de $-26 \mathrm{mV}$. Quando a monensina é adicionada ao meio de cultura, a bactéria parece perder a capacidade de expelir prótons e o interior da membrana passa a ser mais ácido que o ambiente externo. Embora o gradiente elétrico não seja afetado (deve haver compensação da entrada de cátions por meio de saída de cátions ou entrada de ânions), a inversão do $\mathrm{pH}$ provoca decréscimo na força motriz de prótons.

A redução de $\mathrm{K}+$ intracelular pela adição de monensina levou o gradiente de $\mathrm{K}+$ a apresentar queda para cerca de $1 / 3$ do valor original ( 25 vs. 70 ), ao mesmo tempo em que o gradiente de sódio se elevou. A entrada de $\mathrm{Na}+$ pode ter sido gerada por saída de 
$\mathrm{H}+$, devido ao menor pH intracelular. A dissipação do gradiente de $\mathrm{K}+$ deve ter sido apenas parcialmente compensada pelo aumento no gradiente de $\mathrm{Na}+$. A inibição de crescimento observada nas bactérias, provavelmente, deve-se ao incremento do transporte ativo (dependente de energia) de $\mathrm{H}+$ para fora da célula.

Bactérias ruminais Gram-positivas são, em muitos casos, mais sensíveis aos ionóforos do que espécies Gram-negativas, mas esse modo de resistência não é sempre bem definido, sendo que o argumento mais aceito parece estar relacionado à presença de uma segunda membrana que é impermeável a grandes partículas formadas por proteínas, lipoproteínas e lipopolissacarídeos. Essa membrana possui canais de proteínas através da membrana com tamanho limite de aproximadamente 600 Dalton, denominadas porinas. A maioria dos ionóforos possui tamanho maior que 600 Dalton, e consequentemente não passam através das porinas, o que torna as células impermeáveis aos ionóforos. Por outro lado, as bactérias Gram-positivas possuem apenas uma camada espessa de peptidioglicano que, por ser porosa, não impede a ação dos ionóforos (Morais et al., 2006). No entanto, os ionóforos podem aumentar o fluxo de íons em algumas bactérias Gram-negativas tornando-as inicialmente sensíveis fazendo com que se comportem como Gram-positivas, principalmente em altas doses de ionóforos. Como exemplo, a bactéria Gram-negativa Fibrobacter succinogenes, que degrada a celulose, é mais sensível aos ionóforos do que outras bactérias Gram-negativas. Além disso, com o passar do tempo, bactérias originalmente resistentes aos ionóforos podem tornar-se sensíveis e certas bactérias sensíveis, como as Gram-positivas podem desenvolver resistência aos ionóforos.

Alguns dos efeitos benéficos dos ionóforos incluem: aumento da produção de propionato ruminal pela modificação dos padrões de fermentação (Perry et al., 1976); redução das perdas de energia devido à redução da produção de metano (Russell e Strobel, 1989); prevenção de desordens digestivas como a acidose (Owens et al., 1998); redução da proteólise ruminal (Bergen e Bates, 1984); diminuída desaminação no rúmen (Chalupa, 1980); e aumento do fluxo de ácidos graxos insaturados para o intestino delgado (Clary et al., 1993).

Todos os processos citados acima levam ao aumento do desempenho animal pelo aumento da eficiência do metabolismo energético dentro do rúmen, melhorando o metabolismo de nitrogênio e reduzindo desordens digestivas em confinamento, 
especialmente acidose lática e timpanismo (Bergen e Bates, 1984). O aumento da proporção molar de ácido propiônico no rúmen com redução na proporção de ácidos acético e butírico ocorrem quando ionóforos são oferecidos (Nagaraja et al., 1981). Propionato é o único ácido graxo de cadeia curta que pode ser convertido à glicose, a qual então pode ser utilizada como fonte de energia pelos ruminantes. A redução na relação acetato/propionato leva a menor incremento calórico pois o ácido propiônico produz menor quantidade de calor que o ácido acético durante o seu processo de formação (Bergen e Bates, 1984). Enfim, a redução na produção de metano também melhora a retenção de carbono e energia (Chalupa, 1980).

Em relação aos efeitos da administração de ionóforos, mais especificamente à monensina, sobre a digestibilidade aparente em ruminantes, os resultados são bem variados. Em novilhos alimentados com dietas de alto concentrado, foi observado melhora na digestibilidade da matéria seca com a suplementação de monensina (Wedegaertner e Johnson, 1983). Com o aumento da suplementação de monensina (0 $1,2 \mathrm{mg} / \mathrm{kg}$ de peso vivo) para bezerros em crescimento, em sistema de confinamento, Salles e Lucci (2000) relataram aumento linear para os coeficientes de digestibilidade aparente da matéria seca. Beede et al. (1986) descreveram aumento da digestibilidade da matéria seca em dietas de baixa inclusão de proteína para novilhos (8,7\% na base seca), com suplementação de monensina. Em dietas com baixo ou alto teor de fibra fornecidas a novilhos mestiços Holandês $\times$ Brahman, a suplementação com monensina promoveu aumento da digestibilidade da matéria seca e do FDN (Araújo-Febres et al., 1991). Este aumento na digestibilidade da fibra com a suplementação de monensina foi relacionado com o maior tempo de retenção ruminal do alimento, promovido pelo ionóforo, permitindo assim mais tempo para a digestão microbiana (Spears, 1990).

Spears (1990), em revisão bibliográfica dos efeitos da utilização de ionóforos na digestibilidade aparente da energia, citou que em 17 experimentos houve melhora na digestibilidade de 2 pontos percentuais em média com suplementação de monensina, em relação ao grupo controle, com variação de $-0,9$ a $9,2 \%$. A suplementação com monensina melhorou o coeficiente da energia digestível em novilhos (Wedegaertner e Johnson, 1983) e bezerros (Salles e Lucci, 2000) alimentados com dietas de alto concentrado. Acredita-se que a melhora na digestibilidade com a utilização de ionóforos esteja relacionada com sua afinidade em transportar cátions monovalentes através das 
membranas, aumentando a concentração intracelular de cátions. Este incremento estimularia a atividade da bomba sódio-potássio e afetaria a taxa de absorção do trato gastrointestinal, já que a absorção de diversos nutrientes é dependente do transporte de sódio e da energia proveniente da bomba $\mathrm{Na}+/ \mathrm{K}+$-ATPase (Spears, 1990). Por outro lado, Sooden-Karamath e Youssef (1999), estudando os efeitos da suplementação de monensina em dieta à base de feno de arroz tratada com uréia mais concentrado e capim, para ovinos ou caprinos, observaram que não houve efeito do aditivo sobre a digestibilidade da matéria seca e suas frações. Resultados semelhantes foram observados por Oliveira et al. (2007), ao trabalharem com ovinos que recebiam dietas com distintos níveis de proteína bruta: 11,4 ou 16,0\% da matéria seca. Ainda, corroborando para estes achados, Ricke et al. (1984) observaram que a administração de monensina não influenciou a digestibilidade da matéria seca para cordeiros. No tratamento em que a monensina foi suplementada sozinha ou em combinação com levedura (Saccharomyces cerevisiae), o aditivo não afetou a digestibilidade da matéria seca em dietas com relação volumoso:concentrado de 50:50 para ovinos (García et al., 2000).

Com respeito à digestibilidade da proteína com a utilização de monensina, Beede et al. (1986) e Salles e Lucci (2000) observaram melhora neste coeficiente de digestibilidade com administração do ionóforo. Corroborando com estes achados, Rodrigues et al. (2001) verificaram que a utilização de monensina aumentou a digestibilidade total da proteína bruta, independentemente do nível de concentrado (25, 50 ou $75 \%$ da dieta) utilizado para ovinos. Vacas em lactação mantidas em pastagem apresentaram melhora na digestibilidade aparente do nitrogênio, quando foram suplementadas com monensina (Ruiz et al., 2001). Resultados semelhantes foram observados por Araújo-Febres et al. (1991) ao trabalharem com novilhos mestiços Holandês $\times$ Brahman, alimentados com dietas de baixo ou alto teor de fibra, suplementadas com monensina. Acredita-se que a melhora da digestibilidade da proteína bruta com a utilização de ionóforos esteja relacionada com sua capacidade de reduzir a deaminação (Russell et al., 1988). Dessa forma, peptídeos e aminoácidos que não sofreram deaminação podem ser convertidos em proteína microbiana por cepas resistentes aos ionóforos (Yang e Russell, 1993), melhorando o aproveitamento da proteína disponível (Rodrigues et al., 2001). 
A influência no metabolismo do nitrogênio de ruminantes alimentados com ionóforos poderia ser explicada, em parte, pelo efeito de diminuição na degradação da proteína. Esses achados são suportados por observações de mais baixas concentrações ruminais de amônia em bovinos alimentados com monensina (Chalupa, 1980). O fato da concentração de amônia ser reduzida poderia ser explicado pelo efeito de depressão causado pela monensina, resultando na redução de enzimas proteolíticas e deaminativas ou pelo efeito direto sobre as atividades de proteases e deaminases (Bergen e Bates, 1984). Aumentos de 22 a 55\% na quantidade de proteína bypass foram observados (Bergen e Bates, 1984) em cinco estudos quando a monensina sódica foi oferecida.

Um estudo demonstrou também que poliéteres ionóforos, monensina e lasalocida, foram efetivos em prevenir acidose lática em bovinos alimentados com grãos ou solução de glicose (Nagaraja et al., 1981). Nesse estudo, a alimentação com um ou outro ionóforo foi eficaz sobre o $\mathrm{pH}$ ruminal e preveniu o acúmulo de ácido lático. No entanto, a lasalocida além de demonstrar efeito de controle sobre o $\mathrm{pH}$ ruminal, inibiu mais severamente o crescimento de várias cepas de Streptococcus bovis quando comparada a monensina. Dennis et al. (1981) testaram o efeito de doses crescentes de lasalocida e monensina sobre as populações das bactérias que mais produzem e que mais utilizam lactato no rúmen. Bovinos alimentados com monensina ou lasalocida apresentaram reduções na populações de bactérias que mais produzem lactato no rúmen, enquanto que as populações das bactérias que mais utilizam o ácido lático no rúmen não foram afetadas.

Ainda, é comumente descrita na literatura, diminuição na ingestão de matéria seca com utilização de monensina em dietas de alto concentrado (Schelling, 1984), porém sem alterar o ganho de peso, melhorando a eficiência de utilização dos alimentos pelos ruminantes (Goodrich et al., 1984). Abe et al. (1994) ao utilizarem vacas leiteiras, Restle et al. (2001) ao trabalharem com novilhas e vacas de corte em confinamento, e Maas et al. (2001), com ovinos em regime de pasto, também observaram diminuição na ingestão de matéria seca com a administração de monensina. Oliveira et al. (2005) observaram que a adição de $28 \mathrm{mg}$ de monensina $/ \mathrm{kg}$ de matéria seca consumida para novilhos holandeses fistulados no rúmen reduziu a ingestão de alimentos. Acredita-se que a redução na ingestão observada com a suplementação de monensina esteja relacionada com um provável aumento no aporte de energia promovido pelo ionóforo. 
O maior aporte de energia, devido ao aumento do propionato disponível, resultante das mudanças na população microbiana ruminal provocada pelo ionóforo, pode contribuir com a diminuição na ingestão de matéria seca (Oliveira et al., 2007).

Ao analisar 228 ensaios que envolveram 11.274 bovinos alimentados com rações ricas em grãos suplementados ou não com monensina, Goodrich et al. (1984) observaram que a monensina sódica aumentou em 1,6\% o ganho de peso, reduziu o consumo em $6,4 \%$ e melhorou a conversão alimentar em 7,5\%, resposta que pode ser bastante variável de acordo com o tipo do animal suplementado. Observou-se que bovinos considerados ineficientes em converter alimento em ganho, responderam melhor à adição da monensina na dieta que animais com melhor conversão alimentar. Já para animais não confinados, ou seja, em regime de pastagens, a resposta ao uso de monensina pode alcançar aumentos de 15\% no ganho de peso diário. Raun et al. (1974a) relataram melhoras para o ganho de peso diário de 1,5 à 15\%. Farlin et al. (1975) relataram melhoras na taxa da conversão alimentar de 13,2; 9,4; 9,7 e 1,4\%. Todavia, em animais mantidos em regime de pastagem, a monensina não reduz a ingestão de matéria seca e, consequentemente, o ganho de peso é aumentado como reflexo do aumento na eficiência alimentar (Bergen e Bates, 1984). Em revisão realizada por Tedeschi et al. (2003), em 228 ensaios o fornecimento de monensina melhorou o ganho de peso diário de $1,6 \%$ a $1,8 \%$, o consumo diminuiu de $4 \%$ a $6 \%$ e a conversão alimentar melhorou de $6 \%$ a 7,5\% em bovinos em crescimento mantidos em condições de confinamento.

Em um outro estudo, Potter et al. (1985) forneceram monensina sódica $(33 \mathrm{mg} / \mathrm{kg}$ de matéria seca), tilosina (11 mg/kg de matéria seca) ou ambos a novilhos consumindo dietas de alto grão para determinar os efeitos sobre o ganho de peso diário e a eficiência alimentar. A suplementação com monensina melhorou a eficiência alimentar e reduziu a ingestão de matéria seca de novilhos confinados, mas não teve efeito sobre a incidência de abscesso hepático. Por outro lado, a suplementação com tilosina aumentou o ganho de peso diário e melhorou a eficiência alimentar sem afetar a ingestão de matéria seca. Bovinos alimentados com tilosina apresentaram reduzida incidência de abscesso hepático ( 9 vs. $27 \%$ para bovinos suplementados ou não com tilosina, respectivamente). 
De acordo com Goodrich et al. (1984), o uso de monensina afeta muito pouco as características de carcaça, tornando-as ligeiramente mais "magras", comparada a animais controle. Apenas a área de olho de lombo apresentou efeito positivo $(0,61 \%)$. O rendimento de carcaça, escore de marmoreio, deposição de gordura, "quality grade" e "yield grade" são afetados negativamente pelo uso de monensina $(-0,38 \%$; $-39 \%$; $0,24 \% ;-0,69 \%$ e $-0,31 \%$; respectivamente). Muitos estudos encontraram que características de carcaça não foram afetadas pelo fornecimento de monensina (Brown et al., 1974; Embry e Swan, 1974; Raun et al., 1974b; Farlin et al., 1975).

Em termos de dosagens, a quantidade da monensina a ser administrada afeta diretamente a ingestão de matéria seca. Goodrich et al. (1976) reuniram 29 experimentos incluindo dosagens de 11 a $33 \mathrm{~g} / \mathrm{t}$ de monensina adicionadas a ração. Foi relatado que a dose de $33 \mathrm{~g} / \mathrm{t}$ proporcionou taxa de ganho de peso mais lenta que as outras dosagens, sendo essa similar ao controle. A ingestão diária de matéria seca foi reduzida conforme aumentou-se a dose de monensina, passando de 7,89 $\mathrm{kg}$ de matéria seca/dia no grupo controle, para 7,23 kg com a dose de $33 \mathrm{~g} / \mathrm{t}$. No entanto, as dosagens de 22 a $33 \mathrm{~g} / \mathrm{t}$ apresentaram similares quantidades de alimento ingeridos $/ 100 \mathrm{~kg}$ de carcaça. De acordo com o levantamento realizado por Millen et al. (2009) com nutricionistas de gado confinado no Brasil, a dosagem media recomendada em relação aos ionóforos foi de $21,9 \mathrm{mg} / \mathrm{kg}$.

\subsubsection{Preparado de Anticorpos Policlonais (PAP)}

Uma das alternativas para substituir os ionóforos é a imunização por meio do uso de anticorpos na produção animal. O conceito de imunização como ferramenta para atingir maior eficiência na fermentação ruminal e assim melhorar o desempenho animal é relativamente recente (Newbold et al., 2001; Hardy, 2002; Berghman e Waguela, 2004).

A base desse mecanismo é o reconhecimento de corpos estranhos no organismo (antígenos), ativação dos leucócitos e engajamento do mecanismo direto para remoção do patógeno. Quando os macrófagos da corrente sanguínea do hospedeiro encontram moléculas estranhas (antígenos) estes respondem englobando-as. Este evento é mediado pelas células $\mathrm{T}$, que estabelecem uma corrente de respostas, resultando na estimulação das células B. As células B produzem proteínas chamadas anticorpos, os quais se ligam 
às moléculas estranhas. Esta ligação entre anticorpo e antígeno causa destruição do invasor por fagocitose (Goldsby et al., 2000).

O mecanismo de formação do produto com anticorpos para uso na alimentação de bovinos se dá da seguinte maneira: galinhas são vacinadas com pequenas doses de imunogenes de bactérias ruminais vivas ( $S$. bovis, $F$. necrophorum e várias cepas de bactérias proteolíticas) e logo desenvolvem anticorpos específicos contra essas bactérias. Esses anticorpos passam, através de mecanismos fisiológicos das aves para a gema do ovo. Esta é utilizada então para se fazer o produto batizado de Preparado de Anticorpos Policlonais (PAP) com anticorpos específicos, os quais têm como alvo eliminar do meio ruminal dos bovinos, bactérias cujos produtos da fermentação são indesejáveis (Shimizu et al., 1988). O PAP contendo anticorpos contra as bactérias $S$. bovis, F. necrophorum, E. coli e as três maiores proteolíticas Clostridium aminophilum e sticklandii e Peptostreptococcus spp é produzido pela Camas Incorporated (Le Center, Minnesota, EUA) e têm sido testado para provar sua eficiência em reduzir as populações das bactérias ruminais citadas acima.

O sistema imune das aves difere dos mamíferos em vários aspectos. Um dos aspectos mais distintos no sistema imune das aves é a imunidade passiva para os descendentes, a qual nos mamíferos é feita pela placenta ou pelo colostro e nas aves vem pelos componentes líquidos do ovo. Enquanto o ovo está ainda no ovário, as galinhas transferem suas imunoglobulinas séricas $\mathrm{Y}(\mathrm{IgY})$ para a gema do ovo. À medida que o ovo passa pelo oviduto, os anticorpos $\operatorname{IgM}$ e $\operatorname{IgA}$ são adicionados a albumina (Schade et al., 2001). Anticorpos IgG de galinhas imunizadas são transportados eficientemente e acumulados na gema do ovo (Shimizu et al., 1988). Altos níveis de atividade dos anticorpos podem ser mantidos por imunização periódica, fazendo com que a produção de IgY de ovos de galinhas imunizadas seja economicamente viável (Shimizu et al., 1988; Lee et al., 2002). Assim, as imunoglobulinas podem ser extraídas da gema do ovo por diversas técnicas, sendo que uma das mais utilizadas envolve precipitação protéica com sulfato de amônia. Este método de produção de anticorpos foi avaliado pelo Centro Europeu de Validação de Métodos Alternativos (Schade et al., 1996), órgão que promove a aceitação científica e regulamenta métodos laboratoriais alternativos, com fins de reduzir ou substituir a utilização de animais de laboratório. O uso desta técnica foi incentivado, pois reduz a 
necessidade de animais de laboratório, já que uma galinha produz em média 5 - 7 ovos por semana. Além disso, causa menor estresse aos animais por não haver sangria após a imunização.

O uso potencial de IgY de gemas de ovos como aditivo alimentar foi investigado por Shimizu et al. (1988). A estabilidade de IgY anti Escherichia coli foi testada sob várias condições de temperatura, $\mathrm{pH}$ e proteólise. A atividade da imunoglobulina $\mathrm{Y}$ foi testada por aglutinação de culturas vivas de bactérias alvo. A imunoglobulina Y também foi determinada como estável em calor, após alguns testes a temperaturas maiores que $70^{\circ} \mathrm{C}$. Além disso, a especificidade de IgY contra E. coli foi testada desafiando a aglutinação com IgY não específico (provindo de galinhas não imunizadas); mas nenhuma aglutinação foi observada. Congelamento ou congelamento a seco também não afetaram a atividade dos anticorpos. Imunoglobulina $\mathrm{Y}$ permaneceu ativa a $\mathrm{pH}$ em torno de 4; mas em pH menor que 4 foi inativada devido a mudanças na conformação do anticorpo, porém sem nenhuma avaria nos polipeptídios foi observada. Susceptibilidade a proteólise por enzimas gastrointestinais foi testada utilizando digestões com pepsina, tripsina e quimiotripsina. Apesar do fato de moléculas de anticorpo ter sido partidas pela pepsina e tripsina em pequenos polipeptídios, a atividade de ligação e aglutinação celular permaneceu inalterada. A digestão de quimiotripsina não produziu nenhuma alteração na molécula de IgY. Acredita-se que esta resistência à proteólise esteja relacionada a presença de ligações dissulfeto na composição das imunoglobulinas, mais difíceis de serem rompidas pelas enzimas proteolíticas (Santos, 2006). A estabilidade de IgY obtida de galinhas imunizadas provaram ser resistentes ao congelamento, calor, ao meio ácido e proteólise, indicando que esses tipos de compostos poderiam ter grande potencial como aditivos alimentares.

Ikemori et al. (1997) conduziram interessante estudo para avaliar a possibilidade do uso de imunização passiva contra o coronavírus bovino em bezerros recém nascidos. As fontes de imunização utilizadas foram: gemas de ovos secas de galinhas imunizadas ou colostros de vacas vacinadas contra o coronavírus bovino. A mortalidade foi reduzida em bezerros alimentados com o tratamento contendo gemas de ovos quando comparados àqueles alimentados com colostro ou placebo. Animais alimentados com gemas de ovos também apresentaram menores escores de fezes indicando melhora no controle da diarréia. Bezerros alimentados com colostro requereram mais que o dobro 
de anticorpos para atingir o mesmo resultado obtido em animais alimentados com gemas de ovos. Finalmente, bezerros suplementados com gemas de ovos apresentaram maior ganho de peso diário que aqueles não imunizados. Quando a concentração de anticorpos no colostro foi cinco vezes maior que a concentração presente nas gemas de ovos, bezerros apresentaram maiores ganhos de peso que bezerros não imunizados. Os autores concluíram que significante proteção contra o coronavírus bovino em bezerros foi atingida nos dois tratamentos, mas especialmente em gemas de ovos secas. $\mathrm{O}$ fato de concentrações mais altas de anticorpos no colostro serem necessárias para atingir o mesmo nível de proteção promovida pelas gemas de ovos pode levantar a possibilidade que menos anticorpos provindos de aves podem ter sido degradados e inativados pelo suco gástrico. Pesquisas prévias conduzidas por Shimizu et al. (1992) demonstraram que anticorpos de gemas de ovos apresentaram estabilidade similar quando comparados a anticorpos de mamíferos. Ikemori et al. (1997) concluíram que gemas de ovos em pó provindos de galinhas imunizadas contra coronavirus bovino apresentaram maior potencial preventivo que colostro em pó de vacas imunizadas, promovendo assim uma alternativa para imunização passiva contra o coronavírus bovino em bezerros.

Da mesma foram, anticorpos imunoglobulina Y contra Salmonella enteritidis e Salmonella typhimurium também foram testados (Lee et al., 2002) em uma série de estudos in vitro. IgY específica contra Salmonella inibiu o crescimento da bactéria no meio líquido. Também foi observada reatividade cruzada de 42 a 55\% entre os anticorpos das duas espécies de Salmonella testadas. Profundas avaliações microscópicas demonstraram que IgY específico contra Salmonella se ligam aos antígenos na superfície da bactéria causando alteração estrutural não permitindo mais o crescimento bacteriano. Já Sherman et al. (1983), observaram que a administração oral de anticorpos monoclonais de origem aviária contra o antígeno K99 da bactéria enterotoxinogênica Escherichia coli, foi eficaz em atenuar a severidade da enfermidade e o grau de desidratação dos animais acometidos por quadros de diarréia, reduzindo a taxa de mortalidade. Resultados semelhantes foram encontrados por Yokoyama et al. (1992), onde a imunização passiva em leitões neonatos contra a bactéria enterotoxigênica Escherichia coli foi alcançada com administração oral de anticorpos de origem aviária fornecidos logo após a exposição induzida aos antígenos. 


\section{PAP x Prevenção de Acidose e Abscessos Hepáticos}

Segundo DiLorenzo et al. (2006), a alimentação com o PAP contra Streptococcus bovis e Fusobacterium necrophorum teve sucesso em reduzir as populações dessas bactérias quando novilhos foram alimentados com dietas contendo altos teores de concentrado. A alta especificidade do anticorpo foi observada porque o mesmo não afetou as populações de outras bactérias testadas. Shu et al. (1999; 2000) também verificaram reduções nas populações de $S$. bovis e Lactobacillus spp. quando PAP formulado contra estas bactérias foram administrados.

No mesmo estudo de DiLorenzo et al. (2006), o PAP contra Streptococcus bovis e Fusobacterium necrophorum foi eficiente em aumentar o $\mathrm{pH}$ ruminal (6,08 vs. 5,67 para o grupo controle) 5,5h após a alimentação e, em estudo posterior, diminuir a incidência de abscessos hepáticos (DiLorenzo et al., 2008), propiciando aos animais imunizados melhor ambiente para fermentação e desenvolvimento de micro-organismos benéficos já que $S$. bovis e $F$. necrophorum são bactérias chave no desenvolvimento de acidose ruminal e abscessos de fígado, respectivamente. Shu et al. (1999) e Gill et al. (2000) também constataram aumento no pH ruminal e diminuição na concentração de lactato no rúmen quando vacas fistuladas foram submetidas ao tratamento com PAP e alimentadas com dieta contendo $90 \%$ de concentrado.

Blanch et al. (2009) estudando os efeitos do PAP contendo anticorpos contra as bactérias $S$. bovis, F. necrophorum, E. coli e as três maiores proteolíticas Clostridium aminophilum e sticklandii e Peptostreptococcus spp na adaptação de novilhos à dietas de alto concentrado relataram que o PAP foi efetivo em reduzir o risco de acidose, pois os animais suplementados, mesmo apresentando maior concentração total de ácidos graxos de cadeia curta $(147,1$ vs. 132,9), apresentaram maior $\mathrm{pH}$ ruminal $(6,54$ vs. 5,95) e maior concentração de ácido acético $(90,3$ vs. 81,8) que os não suplementados. Ainda, animais recebendo PAP, preveniram o acúmulo de lactato e mantiveram a relação acetato:propionato 1 dia após o desafio de acidose, o que não ocorreu com o grupo controle.

Em estudo brasileiro, com vacas Girolandas canuladas, Marino et al. (2007) relataram que a suplementação com PAP contendo anticorpos contra as bactérias $S$. bovis, F. necrophorum, E. coli e as três maiores proteolíticas Clostridium aminophilum e sticklandii e Peptostreptococcus spp foi tão efetiva em controlar o $\mathrm{pH}$ ruminal em 
dietas de alto concentrado quanto a monensina sódica $(5,95$ vs. 5,99$)$ 4h após a alimentação, sendo estes valores maiores que os apresentados pelo grupo controle $(5,65)$. Entretanto, ao longo do dia, a inclusão do PAP não alterou o tempo em que o $\mathrm{pH}$ ruminal permaneceu abaixo de 6,0. Em outro estudo, no entanto, Bastos et al. (2009) observaram que níveis crescentes do PAP $(0 ; 1,5 ; 3,0$ e 4,5 g/animal/dia) contra $S$. bovis, F. necrophorum, E. coli e várias cepas de bactérias proteolíticas, não alteraram o $\mathrm{pH}$ ruminal de vacas fistuladas alimentadas com dietas de alto concentrado.

Otero et al. (2007) observaram aumento na degradabilidade potencial do FDN quando o mesmo PAP utilizado por Marino et al. (2007) foi administrado em comparação com a monensina sódica. Ainda, Otero (2008) apontou aumento de 93,65\% na contagem relativa de protozoários Isotricha em relação ao grupo controle. $\mathrm{O}$ efeito do PAP no aumento de Isotricha pode demonstrar ação deste produto na diminuição do número de bactérias responsáveis pela acidificação do ambiente, tornando este favorável à proliferação de bactérias (fonte de substrato dos protozoários) e também destes protozoários.

Shu et al. (2000) observaram que ovinos imunizados contra S. bovis, apresentaram menores escores de diarréia severa, quando comparados aos animais controle (não-vacinados) e ainda relataram menor aumento no volume das células do sangue em animais que receberam PAP contra a S. bovis alimentados com $90 \%$ de concentrado. Isso representa menor perda de fluído intravascular, o que é associado a pH sanguíneo mais elevado, o qual reflete em maiores excesso de bases e bicarbonatos no sangue, que implica em controle homeostático mais eficiente e menor risco de acidose ruminal e metabólica.

Millen et al. (2008a) analisaram o perfil metabólico sanguíneo de bovinos confinados que receberam monensina ou PAP contra as bactérias ruminais S. bovis, F. necrophorum, E. coli e várias cepas de bactérias proteolíticas. As amostras foram coletadas 15 dias após a introdução de nova dieta. Não foram observadas diferenças entre os aditivos alimentares para o $\mathrm{pH}$, bicarbonatos, pressão parcial de $\mathrm{CO}_{2}$, total de $\mathrm{CO}_{2}$, excesso de bases no sangue e no fluído extra-celular quando os animais mudaram das dietas de adaptação até as de terminação $(58 \% \rightarrow 73 \% \rightarrow 82 \% \rightarrow 85 \%$ de concentrado). Do mesmo modo, não foram encontradas diferenças entre os aditivos 
alimentares em termos de flutuação na ingestão de matéria seca, mensurada nos 4 primeiros dias após a introdução de nova dieta (Millen et al., 2008b).

\section{PAP x Desempenho e Características de Carcaça e Carne}

Segundo DiLorenzo (2004), novilhos Angus alimentados com PAP contra as bactérias Streptococcus bovis ou Fusobacterium necrophorum apresentaram maiores pesos finais que aqueles não alimentados com aditivos alimentares ou alimentados com ambos os PAP. Efeitos sobre o peso final foram devido ao maior ganho de peso diário pelos novilhos alimentados com um ou outro PAP. Não foram observados efeitos em relação à ingestão de matéria seca quando o PAP foi consumido. Novilhos Angus alimentados com PAP contra Streptococcus bovis melhoraram a eficiência alimentar quando comparados àqueles que não receberam PAP ou àqueles que receberam ambos PAP. DiLorenzo (2004) também constatou que a alimentação com PAP contra Streptococcus bovis aumentou o peso da carcaça, espessura de gordura subcutânea e classificação da carcaça, provavelmente devido ao efeito sobre o ganho de peso diário.

No entanto, DiLorenzo et al. (2008) reportaram que bovinos que receberam o PAP contra $F$. necrophorum apresentaram menor rendimento de carcaça que àqueles que não receberam o PAP contra esta bactéria (62,2 vs. 62,7\%). Pacheco et al. (2008) encontraram também redução no rendimento de carcaça quando bovinos receberam PAP contra $S$. bovis, $F$. necrophorum e várias cepas de bactérias proteolíticas ao invés de monensina $(53,4$ vs. 54,5\%). As razões pelas quais a suplementação de PAP provoca este efeito negativo sobre o rendimento de carcaça, e se isto está de alguma forma ligado a bactéria $F$. necrophorum, ainda são desconhecidas.

Millen et al. (2007) testando PAP contra as bactérias ruminais S. bovis, F. necrophorum, E. coli e várias cepas de bactérias proteolíticas sobre o desempenho de bovinos jovens com diferentes graus de sangue Zebu, relataram que animais suplementados com PAP apresentaram ganho de peso diário (1,35 vs. 1,31 kg), ingestão de matéria seca em quilos $(8,37$ vs. $8,14 \mathrm{~kg})$ e eficiência alimentar $(0,159$ vs. 0,160$)$ similares aos de animais suplementados com monensina sódica. Já em porcentagem do peso vivo, animais suplementados com anticorpos policlonais aviários consumiram mais que aqueles suplementados com monensina sódica (2,20 vs. 2,14\%). O aumento da ingestão de matéria seca devido ao uso de PAP na alimentação de bovinos alimentados 
com dietas de alta energia tem sido relatado por diversos autores (Shu et al., 1999; Gill et al, 2000; Shu et al., 2000).

Barducci et al. (2009) estudaram a inclusão ou não de monensina sódica ou PAP contras as bactérias $S$. bovis, F. Necrophorum, Lactobacillus spp., E. coli e endotoxinas em dietas com altos teores de concentrado para bovinos jovens Brangus em confinamento. Os animais suplementados com monensina apresentaram melhor eficiência alimentar $(0,180$ vs. $0,173 \mathrm{~kg} / \mathrm{kg})$, maiores ganho de peso diário $(1,68 v s .1,57$ $\mathrm{kg})$ e peso de carcaça quente $(248,46$ vs. $240,20 \mathrm{~kg})$ que aqueles que não receberam monensina. Por outro lado, a adição de PAP na dieta não melhorou o desempenho dos bovinos confinados e nem afetou negativamente a ingestão de matéria seca $(9,16 v s$. $9,08 \mathrm{~kg})$ e o rendimento de carcaça $(52,38$ vs. $52,12 \mathrm{~kg})$.

Com relação as características de carne, Pacheco et al. (2008) não encontraram diferenças entre bovinos que receberam PAP (contra S. bovis, F. necrophorum, E. coli e várias cepas de bactérias proteolíticas) ou monensina sobre a maciez (mensurada pelos métodos da força de cisalhamento e pelo índice de fragmentação miofibrilar), concentração de colesterol no músculo Longissimus, lipídeos totais e quantidade de gordura visceral. Da mesma forma, de acordo com Fossa et al. (2008) bovinos jovens com diferentes graus de sangue Zebu alimentados com PAP (contra as bactérias ruminais $S$. bovis, F. necrophorum, E. coli e várias cepas de bactérias proteolíticas) ou monensina sódica, apresentaram algumas similaridades no perfil de ácidos graxos da gordura subcutânea do músculo Longissimus. Foram observados resultados similares para os ácidos mirístico (C14:0), esteárico (C18:0), oléico (C18:1), linoléico (C18:2) e linolênico (C18:3). No entanto, para os ácidos palmítico (C16:0) e margárico (C17:0), foram encontradas maiores concentrações dos mesmos na gordura subcutânea de animais suplementados com monensina. Ionóforos inibem o crescimento de bactérias gram positivas e muitas dessas bactérias gram positivas estão envolvidas na biohidrogenação no rúmen, incluindo a Butyrivibrio fibrisolvens (Van Nevel e Demeyer, 1995; Fellner et al., 1997). Assim, seria esperado que a monensina sódica aumentasse a proporção de pelo menos alguns ácidos graxos insaturados na gordura subcutânea de bovinos suplementados, como constatado anteriormente na literatura (Sauer et al., 1998; Eifert, 2004). 
Isso poderia estar ligado, de alguma forma, às lipoproteínas do sangue, as quais são responsáveis pelo transporte dos ácidos graxos saturados e insaturados até os tecidos alvos. No entanto, Ronchesel et al. (2009) mensuraram as concentrações de colesterol, triglicerídeos e das lipoproteínas VLDL, LDL e HDL no sangue de bovinos Brangus confinados que receberam dietas com inclusão ou não de monensina sódica ou PAP (contras as bactérias S. bovis, F. Necrophorum, Lactobacillus spp., E. coli e endotoxinas), e não encontraram efeito dos aditivos alimentares sobre as variáveis estudadas.

\section{PAP $x$ Comportamento Ingestivo}

Mariani (2010) reportou que animais suplementados com monensina apresentaram maior número de refeições/dia e menor tempo de alimentação/refeição que animais recebendo PAP (contra as bactérias ruminais $S$. bovis, F. necrophorum, $E$. coli e várias cepas de bactérias proteolíticas), indicando que como a ingestão de matéria seca/refeição foi numericamente menor, animais suplementados com monensina foram mais vezes ao cocho, aumentando com isso a taxa de passagem da digesta do rúmen para o omaso e, consequentemente, aumentando o tempo de ruminação desses animais, o qual foi observado apenas no período de terminação. $O$ menor tempo de alimentação/refeição e o maior número de refeições/dia em bovinos recebendo monensina, devem estar ligados a reduzida variação na ingestão de matéria seca. Burrin et al. (1988) e Stock et al. (1995) reportaram reduzida variação na ingestão de matéria seca quando monensina foi fornecida a bovinos confinados. Galyean et al. (1992) observaram que a reduzida variação na ingestão de matéria seca melhorou o desempenho de bovinos mantidos em confinamento; no entanto, no presente estudo e no estudo de Stock et al. (1995) nenhuma melhora em desempenho foi encontrada quando bovinos foram suplementados com monensina. Em relação às demais variáveis do comportamento ingestivo, e às eficiências de alimentação e ruminação da matéria seca e do FDN, animais suplementados com monensina e PAP apresentaram o mesmo padrão de comportamento e eficiências similares.

\section{PAP x Lesões Ruminais}


Millen et al. (2007) relataram menor incidência de rumenites em bovinos que receberam o PAP contra as bactérias $S$. bovis, F. necrophorum, E. coli e várias cepas de bactérias proteolíticas, quando estes foram comparados com animais que receberam monensina sódica. Sarti et al. (2009) observaram que a inclusão do PAP contras as bactérias $S$. bovis, F. Necrophorum, Lactobacillus spp., E. coli e endotoxinas na dieta não melhorou a superfície de absorção da parede ruminal; no entanto a suplementação com monensina sódica mostrou ser efetiva em aumentar a superfície de absorção por $\mathrm{cm}^{2}$ de parede do rúmen quando foram comparados aos animais que não receberam monesina $\left(24,92\right.$ vs. $\left.19,45 \mathrm{~cm}^{2}\right)$. A maior superfície de absorção do epitélio ruminal pode indicar maior absorção de ácidos graxos de cadeia curta e ainda menor extensão de lesões (rumenites).

\section{PAP na forma seca $x$ PAP na forma líquida}

Em relação aos trabalhos já citados anteriormente nesta revisão, os estudos mais antigos envolvendo a imunização passiva, foram conduzidos utilizando-se o PAP na forma liquida (DiLorenzo, 2004; DiLorenzo et al., 2006 e 2008; Marino et al., 2007; Otero et al., 2007; Otero, 2008; Millen et al., 2007, 2008a e 2008b; Pacheco et al., 2008; Fossa et al., 2008; Blanch et al., 2009). Os estudos publicados mais recentemente (Bastos et al., 2009; Barducci et al., 2009; Sarti et al., 2009; Ronchesel et al., 2009; Mariani, 2010) foram realizados com formulações do PAP na forma seca (em forma de pó).

Estudos com o PAP na forma líquida sugerem que apesar do efeito negativo sobre o rendimento de carcaça (DiLorenzo et al., 2008; Pacheco et al., 2008), animais recebendo PAP mostraram melhora no desempenho em relação a grupos controle (DiLorenzo, 2004) e em outros estudos apresentaram desempenho similar àqueles animais suplementados com monensina sódica (Millen et al., 2007). Ainda, a suplementação com PAP foi efetiva em: elevar o pH ruminal (DiLorenzo et al., 2006; Blanch et al., 2009) tanto quanto a monensina (Marino et al., 2007), e reduzir a incidência de lesões no rúmen quando comparado à suplementação de monensina (Millen et al., 2007).

Entretanto, quando observamos os estudos envolvendo o PAP na forma seca, os dados mostram que o PAP não foi mais tão efetivo quanto a monensina para melhorar o 
desempenho (Barducci et al., 2009) e reduzir a incidência de lesões (Sarti et al., 2009). Ainda, não foram detectados aumentos no $\mathrm{pH}$ ruminal quando diferentes doses foram testadas contra um tratamento controle (Bastos et al., 2009). No entanto, os dados de comportamento ingestivo mostraram algumas similaridades entre PAP e monensina quando estes são fornecidos a bovinos confinados (Mariani, 2010).

Vale ressaltar que os estudos com PAP na forma líquida, foram conduzidos nos EUA, Espanha e Brasil e os estudos envolvendo o PAP na forma seca, foram realizados somente no Brasil. Podem ser apenas experimentos "isolados", mas é no mínimo intrigante o fato de a mudança na forma de apresentação do produto fazer com que alguns efeitos constatados anteriormente deixassem de aparecer quando se forneceu o PAP na forma seca. No entanto, ainda não está claro se alguma etapa do procedimento utilizado para secar o produto prejudicou a atividade dos anticorpos ou os efeitos destes dentro do rúmen, de alguma maneira.

\subsubsection{Perfil de Ácidos Graxos}

Recentemente, a preocupação com a qualidade nutricional da carne vem ganhando força. A carne bovina, em especial, é considerada uma das com maior efeito maléfico à saúde humana, em razão de sua composição lipídica constituída de ácidos graxos principalmente saturados e trans. De acordo com Chiara et al. (2002), os ácidos graxos trans estão relacionados ao aumento de doenças coronárias e seu principal efeito metabólico seria sua ação hipercolesterolêmica, que eleva o colesterol total e a lipoproteína de baixa densidade (LDL), reduzindo a lipoproteína de alta densidade (HDL) e resultando em aumento da relação LDL/HDL. Essa relação é considerada o prognóstico mais importante para as doenças cardiovasculares, em razão dos níveis plasmáticos de lipídios (Chiara et al., 2002). De uma forma geral, ocorrem mudanças nas lipoproteínas do sangue durante o crescimento do animal, sendo os triglicerídeos transportados em maior concentração pelas VLDL (Ochoa e Marchello, 1991) e ácidos graxos saturados como os ácidos palmítico e mirístico pelas lipoproteínas VLDL e LDL. Por outro lado, os ácidos graxos insaturados [ácido linoléico, linolênico e o ácido linoléico conjugado (CLA)] são transportados na sua maior parte pela lipoproteína de alta densidade, ou seja, a HDL (Souza, 2005). 
Entretanto, tem sido amplamente demonstrado que ácidos graxos poliinsaturados de cadeia longa participam de vários processos metabólicos benéficos à saúde humana (Cook et al., 2001; Varela et al., 2004) e que as gorduras da carne de animais ruminantes, assim como do leite e a própria carne, são fontes naturais de alguns desses ácidos graxos para os humanos, como os isômeros do CLA, em particular o cis-9, trans-11 (French et al., 2000; Metz et al., 2009), o qual representa a mais ampla fonte natural de CLA na dieta humana (Chin et al., 1992). A suplementação de animais com CLA pode aumentar sua concentração no leite e assim produzir um alimento mais saudável que pode ser recompensado com maior valor de venda no mercado. A concentração de CLA é geralmente expressa em relação ao total de gordura, e produtos como leite e carne de ruminantes, tipicamente tem concentração numa extensão de três para sete mg/g de gordura (Chin et al., 1992; Lin et al., 1995; Banni e Martin, 1998).

Holmes et al. (1999) e Sugano e Hirahara (2000) têm demonstrado que o ácido linolênico ( $\omega$-3) age como elemento protetor contra o câncer de mama. A proteção do $\omega$-3 sobre este câncer pode estar associada a seus metabólitos, que são os eicosanóides com ação pró-inflamatórias menos potentes. Além disso, esse efeito parece ser devido a influência do $\omega$-3 na atividade de enzimas e proteínas relacionadas à sinalização intramuscular e à proliferação celular (Bartsch et al., 1999). Em relação a esse aspecto, a carne dos ruminantes seria particularmente benéfica a saúde humana, por apresentar baixa correlação $\omega-6 / \omega-3$, especialmente em animais que consomem gramíneas com alto níveis de C18:3. Segundo Wood et al. (2004), a carne dos ruminantes apresenta relação $\omega-6 / \omega-3$ mais favorável do que a carne de suínos.

Os ácidos graxos $\omega$-3 e $\omega$-6 são muitos diferentes quanto a sua ação no organismo humano. Enquanto os produtos metabólicos dos ácidos graxos $\omega-6$ promovem inflamações e tumores, os ácidos graxos $\omega-3$ atuam no sentido totalmente oposto. É importante manter o equilíbrio dietético entre as duas formas, uma vez que funcionam em conjunto, promovendo a saúde e equilíbrio orgânico (Simopoulos, 2002). O departamento de saúde da Inglaterra recomenda que para a saúde ideal, a razão $\omega$ 6/

Após anos de condenação dos produtos bovinos e lácteos, a existência de componentes potencialmente tão benéficos à saúde humana podem ser a chance para 
uma nova percepção por parte dos consumidores, e pela comunidade médica, em relação aos alimentos de origem animal.

Para se conseguir a deposição desses ácidos graxos benéficos a saúde humana, a biohidrogenação é obstáculo ao fornecimento desses ácidos graxos insaturados para a deposição no tecido adiposo ou incorporação pela glândula mamária, pois, em dietas convencionais, quase todo C18:2 e C18:3 são biohidrogenados. A biohidrogenação ruminal, definida como desaparecimento de linoléico e linolênico, costuma ser extensa. Em média, $80 \%$ do linoléico e $92 \%$ do linolênico são saturados, valores próximos aos encontrados por Fellner et al. (1995) e Ferlay et al. (1993), respectivamente. Em geral, todos os ácidos graxos poliinsaturados são extensivamente biohidrogenados $(86,6$ a 95,3\%) a ácidos graxos saturados pelos micro-organismos ruminais (Jenkins, 1993).

Todavia, pesquisas têm demonstrado que o perfil de ácidos graxos tanto da carne quanto do leite de ruminantes pode ser manipulado pelo nível e composição química da dieta oferecida aos animais. A relação volumoso:concentrado, adições de tampões, alimentação restrita e o estágio de crescimento das pastagens são fatores que podem influenciar o conteúdo de CLA e de ácidos graxos insaturados na carne e no leite de ruminantes. Outro fator bastante estudado para o aumento na concentração de CLA e de ácidos graxos insaturados na carne e no leite é a adição de óleos à dieta (Mir et al., 2004; Eifert, 2004).

Mir et al. (2004) adicionaram óleo de girassol à dieta de bovinos confinados, conseguindo aumentar em mais de cinco vezes a concentração de CLA na carne. Isso demonstra que a escolha de alimentos ricos em ácidos linoléico (C18:2), como o óleo de girassol, aumentam a quantidade de CLA na carne dos animais. Segundo Bauman e Griinari (2000) altas concentrações de ácido linoléico inibem o último passo da biohidrogenação, permitindo acúmulo de C18:1 trans-11 no rúmen, que pode ser reconfigurado no tecido adiposo em CLA cis-9 trans-11, através da enzima $\Delta^{9}$ desaturase. Esse processo é mais evidente na glândula mamária, o que justifica os maiores teores de CLA no leite em relação à carne (Chin et al., 1992). Por outro lado, essa maior relação C18:2 ( $\omega-6) / C 18: 3(\omega-3)$ na dieta leva ao aumento da relação $\omega-6 / \omega$ 3 na gordura intramuscular, conforme demonstrado por Raes et al. (2004). Demeyer e Doreau (1999) observaram que dietas com altos teores de concentrado diminuem o pH ruminal, o que reduz a lipólise e a biohidrogenação, resultando em carne com o perfil 
lipídico mais insaturado. De acordo com Lobato e Freitas (2006), foi observado que o aumento na proporção de ingredientes concentrados na dieta faz com que a relação $\omega$ 6/ $\omega$-3 aumente e a concentração de CLA diminua. Esse efeito é devido à diminuição da biohidrogenação ruminal.

Outro fator que pode alterar o padrão de fermentação ruminal, é a monensina sódica, pois dependendo da dose o seu fornecimento aumenta a produção de propionato, diminuindo a produção de metano e amônia. A monensina parece também alterar a atividade microbiana ruminal em relação aos lipídios da dieta. Estudos in vitro têm demonstrado que as taxas de hidrólise dos triglicerídios e de biohidrogenação dos ácidos graxos foram reduzidas na presença de monensina (Van Nevel e Demeyer, 1995; Fellner et al., 1997). Eifert (2004) por sua vez verificou que a proporção de ácidos graxos insaturados do leite foi mais alta em vacas recebendo dietas com monensina. A forma trans do ácido oléico origina-se durante o processo de biohidrogenação dos ácidos graxos insaturados pelas bactérias ruminais (Mansbridge e Blake, 1997) e, em estudos com vacas em lactação, foi verificado que o teor deste ácido graxo no leite foi mais alto em animais recebendo ionóforo (Cant et al., 1997; Sauer et al., 1998). No entanto, não foram encontradas na literatura, publicações em que tenham sido avaliados os efeitos da monensina sobre o perfil de ácidos graxos de cadeia longa depositados na carcaça de bovinos e, somente alguns poucos estudos, relacionaram a presença da monensina nas dietas.

Ionóforos inibem o crescimento de bactérias gram positivas. Muitas das bactérias gram positivas estão envolvidas no processo de biohidrogenação no rúmen, incluindo a Butyrivibrio fibrosolvens. Van Nevel e Demeyer (1995) observaram em estudos in vitro, que a inclusão de monensina sódica na dieta diminuiu a taxa e a extensão da biohidrogenação, possibilitando assim o acúmulo de CLA e C18:1 trans-11 no conteúdo ruminal. Vários outros fatores podem afetar a composição de ácidos graxos da carne de bovinos, entre eles o grupo genético (Nuernberg et al., 2005; Kuss et al., 2007), heterose (Menezes et al., 2008), condição sexual (Freitas et al., 2006), e idade (Duckett et al., 1993).

Havendo poucos estudos sobre a influência de aditivos alimentares, principalmente envolvendo o PAP e a monensina sódica na manipulação do perfil de 
ácidos graxos de cadeia longa depositados na gordura da carcaça de bovinos de corte, tornam-se necessários mais estudos nesta área.

\subsection{A QUESTÃO DOS ANTIBIÓTICOS}

Ionóforos, como a monensina e lasalocida, são classificados pela Food and Drug Administration (FDA), agência controladora dos Estados Unidos, como antibióticos. Em contrapartida, organizações como a National Cattlemen's Beef Association (NCBA) se esforçam para re-classificar como ionóforos, baseados no fato que os mesmos não funcionam como antibióticos terapêuticos ou subterapêuticos quando ofertados aos animais e porque também não são usados como agentes terapêuticos na medicina humana. Grupos científicos e a mídia vêm cada vez mais questionando o uso de antibiótico na alimentação animal por acharem que esses produtos poderiam contribuir para o desenvolvimento de organismos resistentes, criando risco à saúde humana.

Assim, a cada dia que passa os consumidores estão mais exigentes em relação ao uso de antibióticos como promotores de crescimento na indústria de alimentos de origem animal e preocupados com as consequências que estes podem provocar à saúde humana, conforme aponta pesquisa patrocinada pelo Whole Foods Market, a maior rede varejista de alimentos naturais e orgânicos dos Estados Unidos. A pesquisa foi realizada recentemente com 1.000 consumidores norte-americanos e apontou que $74 \%$ dos entrevistados se preocupam com a presença de resíduos de antibióticos deixados nos produtos finais. O trabalho norte-americano mostrou ainda que 59\% das pessoas preferem evitar o uso desses produtos e consumir carne cuja criação seja livre de antibióticos. A provável associação entre o uso de antibióticos na produção animal e a rápida disseminação de bactérias resistentes na população humana, bem como a proliferação dessas bactérias na cadeia produtiva dos alimentos tem recebido atenção especial da Organização Mundial da Saúde (OMS), Organização Mundial para a Saúde Animal (OIE) e o Codex Alimentarius.

No entanto, um recente encontro da FAO/WHO Expert Committee on Food Additives (JECFA) foi organizado em Genebra, Suíça, de 21 a 29 de Outubro de 2008. A tarefa diante do Comitê foi promover princípios elaborados para avaliar a segurança alimentar de resíduos de drogas veterinárias (entre esses os ionóforos) na alimentação e estabelecer níveis aceitáveis de consumos diários e limite máximo de resíduo 
recomendado para certos medicamentos, quando estes são administrados para produção de alimento de origem animal, em concordância com as boas práticas no uso de medicamentos veterinários. Segundo a Food and Agriculture Organization of the United Nations/World Health Organization (FAO/WHO) através do Codex Alimentarius Comission (2009), o limite máximo para presença de monensina sódica no leite é da ordem de $2 \mu \mathrm{g} / \mathrm{L}$. Para a carne bovina esse valor está torno de $10 \mu \mathrm{g} / \mathrm{kg}$, e em relação ao fígado, órgão de eleição para detecção de resíduos de monensina, o limite máximo é de $20 \mu \mathrm{g} / \mathrm{kg}$. Para muitos, um grande passo foi dado.

Bagg et al. (2005) suplementaram vacas leiteiras no início da lactação com doses crescentes de monenina: 72, 144, e $240 \mathrm{mg} / \mathrm{kg}$ de matéria seca, e observaram drástica redução na produção de leite e no consumo de matéria seca nas doses de 144 e 240 $\mathrm{mg} / \mathrm{kg}$ de matéria seca, mas não foram detectados resíduos de monensina que caracterizassem risco a saúde humana, apesar dos métodos de análise utilizados serem altamente sensíveis. O valor de resíduo detectado de monensina para a dose de 240 $\mathrm{mg} / \mathrm{kg}$, que representa aproximadamente 10 vezes a dose usual, foi na ordem de $5 \mathrm{ng} / \mathrm{L}$ $(<0,005 \mu \mathrm{g} / \mathrm{mL})$. Aparentemente, a utilização de monensina para vacas de leite não trás risco a saúde humana e os resíduos quando detectados são de valores baixíssimos, mesmo com dose muito elevada do ionóforo; além disso, esses resultados são obtidos em condições experimentais extremas, que geralmente não são utilizados nas rações em sistemas de produção de leite. Porém, no Brasil, apesar da monensina ser utilizada frequentemente em sistema de produção de leite, é desconhecido estudos que avaliaram riscos de resíduo de monensina sódica no leite.

Aliado a isso, ruminantes possuem: 1) enzimas hepáticas capazes de inativar ou degradar os compostos dos ionóforos, e 2) a habilidade da circulação entero-hepática de reciclar o ionóforo de volta para o trato gastrintestinal via bile, permitindo o animal a tolerar o uso dessa tecnologia como aditivo alimentar quando comparado aos eqüinos (Donoho, 1984). Talvez esse seja um dos motivos da dificuldade em se encontrar metodologias adequadas para determinar e com isso entender os níveis de monensina detectados nas carcaças.

Atualmente, não existem trabalhos na literatura que comprovem resistência de bactérias ao uso de ionóforos a partir do enfoque nutricional. A idéia de que a resistência aos ionóforos é uma seleção fenotípica (adaptação fisiológica), sustentada 
por medições do fluxo de potássio monensina dependente é mais aceita do que a mutação ou aquisição de genes externos (Russell e Houlihan, 2003). Além disso, genes responsáveis pela resistência das bactérias ruminais aos ionóforos não têm sido identificados e há uma pequena evidência de que a resistência aos ionóforos possa ser transferida de uma bactéria para outra. Devido a isso, o uso de ionóforos na alimentação animal, provavelmente não tem significativo impacto na transferência de resistência à antibióticos dos animais para os humanos (Russel e Houlihan, 2003).

Mesmo assim, pelo fato dos ionóforos serem tecnicamente considerados antibióticos pelo FDA (Foods and Drugs Administration, órgão americano que inspeciona o uso de drogas na produção de alimentos), o uso destes na produção animal é considerado pela Organização Mundial de Saúde um risco crescente para a saúde humana. Existem esforços de técnicos de órgãos oficiais e associações de consumidores em prol da restrição total ao uso de antibióticos como promotores de crescimento na Europa, e argumentam que a resistência aos ionóforos coloca em posição de ameaça a saúde pública mesmo com antibióticos convencionais. O uso dos ionóforos está proibidos na Europa, para o uso como promotores de crescimento, desde Janeiro de 2006.

Toda essa discussão sobre a proibição do uso de antibióticos na alimentação animal tem sido recomendada por uma questão de precaução. Essa nova legislação inclui também barreiras à importação de produtos de origem animal provenientes de países que utilizam essas substâncias, e agora mais do que nunca dos que os utilizam de forma errônea. Desta forma, principalmente na Europa, a eliminação do uso dos promotores de crescimento antibióticos, como a monensina, terá importantes implicações econômicas, esperando-se aumentos de 3 a 5\% nos custos de produção.

Mesmo que nunca ocorra alguma proibição efetiva de importação de carne por motivos relacionados a uso de antibióticos, a importância do desenvolvimento de novas tecnologias de aditivos que reduzam a inclusão de antibióticos na alimentação animal é grande ao se pensar na busca de maior valor agregado pago à carne brasileira. Cientistas e produtores devem-se atentar às tendências do mercado consumidor para o lançamento de novo produtos.

Em vista disso, mesmo com a comprovação científica de, até agora, não haver indícios de cooperarem com a resistência de micro-organismos nocivos a saúde humana, 
os pesquisadores têm concentrado esforços na busca de estratégias para evitar o uso de aditivos antibióticos na produção animal, lembrando que a opinião do consumidor é o que determinará o maior ou menor uso destes produtos na produção animal. Logo, tecnologias alternativas que possam suprir ao menos em equivalência o uso desses antibióticos no quesito produtividade, constituem-se em importante diferencial de qualidade, agregando valor ao produto.

\section{REFERÊNCIAS BIBLIOGRÁFICAS}

ABE, N.; LEAN, I. J.; RABIEE, A. et al. Effects of sodium monensin on reproductive performance of dairy cattle. II. Effects on metabolites in plasma, resumption of ovarian cyclicity and oestrus in lactating cows. Australian Veterinary Journal, v.71, n.4, p.277-282, 1994.

ABIEC. Associação Brasileira das Indústrias Exportadoras de Carne. Estatísticas: Volume das exportações entre Janeiro e Dezembro. ABIEC. 2008. Disponível em: $<$ www.abiec.com.br $>$. Acesso em 01/03/2009.

ARAÚJO-FEBRES, O.; FERNÁNDEZ, M. D. C.; DEL, C. F. M. et al. Efecto en novillos Del monensin y el nível de fibra de la dieta sobre el consumo y la disgestilidad de la materia seca. Revista de La Facultad de Agronomía, v.8, n.2, p.143-153, 1991.

BAGG, R.; VESSIE, G. H.; DICK, C. P. et al. Milk residues and performance of lactating dairy cows administered high doses of monensin. The Canadian Journal of Veterinary Research, v.69, p.180-185, 2005.

BANNI, S.; MARTIN J. C. Conjugated linoleic acid and metabolites. In: J. J. Sebedio e W. W. Christie (Ed.) Trans Fatty Acids in Human Nutrition. p.261-302. Oily Press, Dundee, Scotland. 1998.

BARDUCCI, R. S.; SARTI, L. M. N.; ARRIGONI, M. D. B. et al. Feedlot performance of Brangus cattle fed monensin or polyclonal antibody preparation against lactateproducing rumen bacteria. Journal of Animal Science, v.87, E-suppl.2, p.283$284,2009$. 
BARTSCH, H.; NAIR, J.; OWEN, R.W. Dietary polyunsaturated fatty acids and cancers of the breast and colorectum: emerging evidence for their role as risk modifiers. Carcinogenesis, v. 20, p. 2209-2218, 1999.

BAStOS, J. P. S. T.; MARINO, C. T.; RODRIGUES, P. H. M. et al. Efeito do preparado de anticorpos policlonais (PAP) sobre o $\mathrm{pH}$ ruminal de bovinos recebendo dieta de alto concentrado. II Simpósio Internacional de Nutrição de Ruminantes FMVZ-UNESP. Botucatu. p.273. CD-ROM. 2009.

BAUMAN, D. E.; GRIINARI, J. M. Historical perspective and recent developments in identifying the cause of diet-induced milk fat suppression. Cornell Nutrition Conference for Feed Manufacturers. Rochester, NY. p.191-202, 2000.

BEEDE, D. K.; SCHELlinG, G. T.; MITCHELL, G. E. et al. Nitrogen utilization and digestibility by growing steers and goats of diets that contain monensin and low crude protein. Journal of Animal Science, v.62, n.3, p.857-863, 1986.

BEEFPOINT. Ponto de Encontro da Cadeia da Carne. Notícias. 2010. Disponível em: http://www.beefpoint.com.br/?noticiaID=59748\&actA=7\&areaID=15\&secaD=16. Acesso em 17/01/2010.

BERGEN, W. G.; BATES, D. B. Ionophores: Their effect on production efficiency and mode of action. Journal of Animal Science, v.58, p.1465-1483, 1984.

BERGMAN, E. N. Energy contributions of volatile fatty acids from the gastrointestinal tract in various species. Physiological Reviews, v.70, n.2, p.567-590, 1990.

BERGHMAN, L. R.; WAGHELA, S. D. Antibodies: an alternative for antibiotics? Journal of Animal Science, v.82 (Suppl. 1), p.82, 2004.

BEVANS, D. W.; BEAUCHEMIN, K. A; SCHWARTZKOPF-GENSWEIN, K. S. et al. Effect of rapid or gradual grain adaptation on subacute acidosis and feed intake by feedlot cattle. Journal of Animal Science, v.83, p.1116 - 1132, 2005.

BIGHAM, M. L.; MCMANUS W. R. Whole Wheat Grain Feeding of Lambs. Effects of Roughage and Wheat Grain Mixtures. Australian Journal of Agricultural Research, v.26, p.1053-1062, 1975. 
BLANCH, M.; CALSAMIGLIA, S.; DILORENZO, N. et al. Physiological changes in rumen fermentation during acidosis induction and its control using a multivalent polyclonal antibody preparation in heifers. Journal of Animal Science, v.87, p.1722-1730, 2009.

BRITTON, R. A.; STOCK, R. A. Acidosis, rate of starch digestion and intake. In: Agricultural experiment station MP 121. Feed intake by beef cattle. Stillwater: Oklahoma State University, p.125-137, 1987.

BROWN, H.; CARROLL L. H.; ELLISTON N. G. et al. Field evaluation of monensin for improving feed efficiency in feedlot cattle. Proc. Western Sec. ASAS 25: p.300, 1974.

BURRIN, D. G.; STOCK, R. A.; BRITTON, R. A. et al. Monensin level during grain adaptation and finishingp erformance in cattle. Journal of Animal Science, v.66, p.513-521, 1988.

CANT, J. P.; FREDEEN. A. H.; MACINTYRE, T. et al. Effect of fish oil and monensin on milk composition in dairy cows. Canadian Journal of Animal Science, v.77, p.125-131, 1997.

CARLSON, G.P. Fluid, Electrolyte and Acid-Base Balance. In: KANEKO, J.J. (Ed.) Clinical biochemistry of domestic animals. 5.ed. New York: Academic Press. p.485-516, 1997.

CARVALHO, F.A.N.; BARBOSA, F. A.; MCDOWELL, E L.R. et al. Nutrição de Bovinos a Pasto. Carvalho, F.A.N. e F.A. Barbosa (Eds.). $2^{\mathrm{a}}$ ed. Belo Horizonte: Papelform. p.428, 2003.

CAVAlCANTI, M. R.; CAMARGO, A. Pesquisa top beef point em confinamentos. Beef Point. 2007. Disponível em: $<\underline{\mathrm{http}} / / / \mathrm{www}$.beefpoint.com.br $>$ Acesso em: 05/09/2007.

CERVIERI, R. C. Confinamento e produção de carne em escala. 2005. Disponível em: $<\mathrm{http}$ //www.beefpoint.com.br/bn/radarestecnicos/artigo.asp?nv=1\&area=20\&area _desc $=$ Sistemas + de + Produ\%E7\%E3o\&id_artigo=25850\&perM=12\&perA=2005 >. Acesso em: 19/10/2008. 
CHALUPA, W. Chemical control of rumen microbial metabolism. In: RUCKEBUSH, Y.; THIVEND, P. (Ed.) Digestive Physiology and Metabolism in Ruminants. AVI Publishing Co., Inc., Westport, CT, p.325, 1980.

CHIARA, V. L.; SILVA, R.; JORGE, R. et al. Ácidos graxos trans: doenças cardiovasculres e saúde materno-infantil. Revista de Nutrição, v.15, n.3, p.341$349,2002$.

CHIN, S. F.; LIU, W.; STORKSON, J. M. et al. Dietary sources of conjugated dienoic isomers of linoleic acid, a newly recognized class of anticarcinogens. Journal of Food Composition and Analysis, v.5, p.185-197, 1992.

CLARY, E. M.; BRANDT, R. T.; HARMON, D. L. et al. Supplemental fat and ionophores in finishing diets: Feedlot performance and ruminal digesta kinetics in steers. Journal of Animal Science, v.71, p.3115-3123, 1993.

C.N.A. Comissão Nacional de Pecuária de Leite da Confederação da Agricultura e Pecuária do Brasil. [2007]. Leite: produção deve chegar a 27 bilhões de litros. Disponível em: <http://www.pecuaria.com.br/info.php?ver=2819.>. Acesso em: $13 / 06 / 2009$.

COOK, M .E.; WHIGHAM, L. D.; YANG, M. et al. CLA inhibitis the induction of prostaglandin and leukotriene synthesis. A natural substitute for non-steroidal andti-inflammaory drugs? In: INTERNATIONAL CONFERENCE ON CLA, 1. Proceedings. Alesund: NATURAL ASA, 2001, p. 6-7, 2001.

COOPER, R. J.; KLOPFENSTEIN T. J.; STOCK R. A. et al. Effects of imposed feed intake variation on acidosis and performance of finishing steers. Journal of Animal Science, 77:1093-1099, 1999.

CRUZ, G. M.; TULLIO, R. R.; ESTEVES, S. N. et al. Peso ótimo de abate de machos cruzados para produção do bovino jovem. I - Desempenho em confinamento e características de carcaça. In: REUNIÃO ANUAL DA SOCIEDADE BRASILEIRA DE ZOOTECNIA, v.32., 1995, Brasília. Anais... Viçosa: Sociedade Brasileira de Zootecnia, p.223, 1995.

CUCKI, T. O. A eficiência do sistema superprecoce com bovinos de diferentes proporções do genótipo Bos indicus. Botucatu: Universidade Estadual Paulista, 
2006. p.99. Tese (Doutorado em Zootecnia) - Universidade Estadual Paulista, 2006.

DAWSON, K. A.; RASMUSSEN, M. A.; ALLISON, M. J. et al. Digestive disorders and nutritional toxicity. In: HOBSON, P.N.; STEWART, C.S. (Ed.). The rumen microbial ecosystem. p.633-660, 1997.

DEMEYER, D.; DOREAU M. Targets and procedures for altering ruminant meat and milk lipids. Proceedings of Nutrition Society, v.58, p.593-607, 1999.

DEN HARTOG, L. A.; SCHAMP, T. A. G.; MORS, R. A. B. et al. The effect of dietary electrolyte balance on blood parameters and the performance of veal calves. Livestock Production Science v.21, p.213, 1989.

DENNIS, S. M.; NAGARAJA, T. G.; BARTLEY, E. E.; et al. Effects of lasalocid or monensin on lactate-producing or using rumen bacteria. Journal of Animal Science, v.52, p.418-426, 1981.

DILORENZO, N. et al. Effects of feeding polyclonal antibody preparations against rumen starch and lactic-fermenting bacteria on target bacteria populations and steer performance. Saint Paul, Minnesota, USA: University of Minnesota, 2004, p.101. Master thesis submitted to the faculty of the graduate school of the University of Minnesota, 2004.

DILORENZO, N.; DIEZ-GONZALEZ, F.; DICOSTANZO, A. Effects of feeding polyclonal antibody preparations on ruminal bacterial populations and ruminal $\mathrm{pH}$ of steers fed high-grain diets. Journal of Animal Science, v.84, p.2178-2185, 2006.

DILORENZO, N.; DAHLEN, C.R.; DIEZ-GONZALEZ, F. et al. Effects of feeding polyclonal antibody preparations on rumen fermentation patterns, desempenho, and carcass characteristics of feedlot steers. Journal of Animal Science, v.86, p.30233032, 2008.

DONOHO, A. L. Biochemical studies on the fate of monensin action in animals and environment. Journal of Animal Science, v.58, 1528-1539, 1984.

DUCKETT, S. K.; WAGNER, D. G.; YATES, L. D.H. et al. Effects of time on feed on beef nutrient composition. Journal of Animal Science, v.71, p.2079-2088, 1993. 
EIFERT, E. C. Fontes de carboidratos, óleo de soja e monensina para vacas lactantes: Desempenho, digestibilidade, parâmetros ruminais e perfil de ácidos graxos do leite. 117f. Tese (Doutorado em Zootecnia) - Universidade Federal de Viçosa, 2004.

EMBRY, L. B. ; SWAN, W. S. Effects of monensin on feedlot performance of growing and finishing steers. South Dakota State University Agricultural Experimental Station A. S. Series 74-S, 1974.

ERICKSON, G. E.; MILTON, C. T.; FANING, K. C. et al. Interaction between bunk management and monensin concentration during an acidosis challenge with feedlot cattle. Journal of Animal Science, v.81, p.2869-2879, 2003.

FANNING, K.; MILTON T.; KLOPFENSTEIN T. et al. Effect of rumensin level and bunk management strategy on finishing steers. p.41. Nebraska Beef Report, University of Nebraska, Lincoln, 1999.

FAO, Food and Agriculture Organization of the United Nations. Statical Databases FAOSTATS. Agriculture, 2007. Disponivel em: http://www/fao.org/faostas. Acesso em 18/01/2010.

FAO/WHO Expert Committee on Food Additives (JECFA) Food and Agriculture Organization of the United Nations/World Health Organization. This report contains Codex Circular Letter CL 2009/7-FA. Codex Alimentarius Comission, 2009. Disponivel em: <www.codexalimentarius.net>. Acesso em 15/10/2009.

FAPRI. World agricultural outlook. Iowa State University - University of Missouri Columbia, 2005.

FARLIN, S. D.; CLANTON D. C.; HELDT J. D. A new feed additive for beef cattle. University of Nebraska Cattle Reports, p. 8, 1975.

FAVERDIN, P; BAREILLE, N. et al. Lipostatic regulation of feed intake in ruminants. In: HEIDE, D. et al. (Eds). Regulation of feed intake. CAB International, p.82 $102,1999$.

FELL B. F.; KAY, M.; ØRSKOV, E. R. et al. The role of ingested animal hairs and plant spicules in the pathogenesis of rumenitis. Research in Veterinary Science, v.13, p.30, 1972. 
FELLNER, V.; SAUER, F. D.; KRAMER, J. K. G. Effect of nigercin, monensin, and tetronasin on biohydrogenation in continuous flow-through ruminal fermenters. Journal of Dairy Science, 80:921-928, 1997.

FELLNER, V.; SAUER, F. D.; KRAMER, J. K. G.; Steady-State rates of linoleic acid biohydrogenation by ruminal bactéria in contínuos culture. Journal of Dairy Science, v.78, p.1815-1823, 1995.

FERLAY, A.; CHABROT, A. F.; ELMEDDAY, Y. et al. Ruminal lipid balance and intestinal digestion by dairy cows fed calcium salts of rapeseed oil fatty acids or rapeseed oil. Journal of Animal Science, v.71, p.2237-2245, 1993.

FERRELL, C. L.; BERRY, E. D.; FREETLY, H. C. et al. Influence of genotype and diet on steer performance, manure odor, and carriage of pathogenic and other fecal bacteria. I. Animal performance. Journal of Animal Science, v.84, p.2515 $2522,2006$.

FOSSA, M.V.; PACHECO, R.D.L.; MILLEN, D.D. et al. Fatty acid profile, meat cholesterol and total lipids of Bos indicus based types bullocks fed monensin or polyclonal antibodies against lactate-producing rumen bacteria. Journal of Animal Science, v.86 (E-suppl.2), p.200, 2008.

FREITAS, A. W. P.; PEREIRA, J. C.; ROCHA, F. C. et al. Avaliação da divergência nutricional de genótipos de cana-de-açúcar (Saccharum spp). Revista Brasileira de Zootecnia, v.35, n.1, p.229-236, 2006.

FRENCH, P.; STANTON C.; LAWLESS F. et al. Fatty acid composition, including conjugated linoleic acid, of intramuscular fat from steers offered grazed grass, grass silage, or concentrate-based, Journal of Animal Science, v.78, p.28492855,2000 .

FULTON, W. R.; KLOPFENSTEIN, T. J.; BRITTON, R. A. et al. Adaptation to high concentrate diets by beef cattle. I. Adaptation to corn and wheat diets. Journal of Animal Science, v.49, p.775-784, 1979.

GALYEAN, M. L.; MALCOLM, K. F.; DUFF, G. C. et al. Performance of feedlot steers fed diets containing laidlomycin propionate or monensin plus tylosin, and effects of laidlomycin propionate concentration on intake patterns and ruminal 
fermentation in beef steers during adaptation to a high concentrate diet. Journal of Animal Science, v.70, p. 2950 - 2958, 1992.

GALYEAN, M. L.; RIVERA, J. D. Nutritionally related disorders affecting feedlot cattle. Canadian Journal of Animal Science, v.83, p.13-20. 2003.

GARCÍA, C. C. G.; MENDOZA, M. G. D.; GONZÁLEZ, M. S. et al. Effect of a yeast culture (Saccharomyces cerevisiae) and monensin on ruminal fermentation and digestion in sheep. Animal Feed Science Technology, v.83, n.2, p.165-170, 2000.

GILL, H. S.; SHU, Q.; LENG, R. A. et al. Immunization with Streptococcus bovis protects against lactic acidosis in sheep. Vaccine, v.18, p.2541-2548, 2000.

GOAD, D. W.; GOAD, C. L.; NAGARAJA, T. G. et al. Ruminal microbial and fermentative changes associated with experimentally induced subacute acidosis in steers. Journal of Animal Science, v.76, p.234-241, 1998.

GOLDSBY, R. A.; KINDT, T. J.; OSBORNE, B. A. et al. Kuby Immunology. $4^{\text {th }}$ ed. Chapter 1. W. H. Freeman and Company, New York, 2000.

GOODRICH, R. D.; LINN, J. G.; SCHAFER, J. C. Influence of monensin on feedlot performance - A summary of university trials. Minnesota Cattle Feeder`s Reports, B-214, 1976.

GOODRICH, R. D.; GARRETT, J. E.; GAST, D. R. et al. Influence of monensin on the performance of cattle. Journal of Animal Science, v.58, n.6, p.1484-1498, 1984.

HANEY JR., M. E.; HOEHN, M. M. Monensin, a new biologically active compound. I. Discovery and isolation. Antimicrobial Agents Chemotherapy, v.7, p.349-352, 1967.

HARDY, B. The issue of antibiotic use in the livestock industry: what have we learned? Animal Biotechnology. v.13, p.129-147, 2002.

HILL, L. L. Body composition, normal electrolyte concentrations and the maintenance of normal volume, tonicity, and acid-base metabolism. Pediatric Clinics of North America, v.37, p.241, 1990. 
HIROHIKO, A.; HIDEAKI, M.; KENICHI, H. et al. Improvement of chemical analysis of antibiotics. 21. Simultaneous determination of three polyether antibiotics in feeds using High-Performance Liquid Chromatography with fluorescence detection. Journal of Agricultural and Food Chemistry. v.42, p.112-117, 1994.

HOLMES, M. D.; HUNTER, D. J.; COLDITZ, G. A. et al. Association of dietary intake of fat and fatty acids with risk of breast cancer. Journal of the American Medical Association, v.281(10), p.914-920, 1999.

HUNTINGtON, G. B. Acidosis. in the Ruminant Animal: Digestive Physiology and Nutrition. D. C. Church, ed. Prentice-Hall, Englewood Cliffs. p.474, 1988.

IBGE, Instituto Brasileiro de Geografia e Estatistica. 2008. Disponível em: $<\mathrm{http}: / /$ www.ibge.gov.br/home/presidencia/noticias/noticia_visualiza.php?id_noti cia $=1340 \&$ id_pagina $=.1>$. Acesso em 9/11/2009.

IBGE. Instituto Brasileiro de Geografia e EstatiÅLstica. 2008b. Disponível em: http:// www.ibge.gov.br/home/presidencia/noticias/noticia_visualiza.php?id_noticia=134 0\&id_pagina=1 Acesso em 9/11/2009.

IKEMORI, Y.; UMEDA, M. O. K.; ICATLO JR., F. C. et al. Passive protection of neonatal calves against coronavirus-induced diarrhea by administration of egg yolk or colostrum antibody powder. Veterinary Microbiology, v.58, p.105-111, 1997.

JACKSON, J. A.; HOPKINS, D. M.; XIN, Z. et al. Influence of cation-anion balance on feed intake, body weight gain, and humoral response of dairy calves. Journal of Dairy Science, v.75, p.1281, 1992.

JENKINS, T. C. Lipid metabolism in the rumen. Journal of Dairy Science, v.76, p.3851-3863, 1993.

JENSEN, R. ; DEANE, H. M. ; COOPER, L. J. et al. The rumenitis-liver abscess complex in beef cattle. American Journal of Veterinary Research, v.15, p.202, 1954.

KOERS, W. C.; BRITTON, R.; KLOPFENSTEIN, T. J. et al. Ruminal histamine, lactate and animal performance. Journal of Animal Science, v.43, p.684-691, 1976. 
KREHBIEL, C. R.; BRITTON, R. A.; HARMON, D. L. et al. The effects of ruminal acidosis on volatile fatty acid absorption and plasma activities of pancreatic enzymes in lambs. Journal of Animal Science, v.73, p.3111-3121, 1995.

KREHBIEL, C. R.; KREIKEMEIER, K. K.; FERRELL, C. L. et al. Influence of Bos indicus crossbreeding and cattle age on apparent utilization of a high grain diet. Journal of Animal Science, v.78, p.1641-1647, 2000.

KUSS, F.; RESTLE, J.; KOSLOSKI, G.V. et al. Perfil de ácidos graxos da gordura intramuscular da carne de vacas de descarte de diferentes grupos genéticos terminadas em confinamento, abatidas com distintos pesos. Ciência Rural, v.37, n.3, p.815-820, 2007.

LANNA, D. P.; FOX, D. G.; TEDESCHI, L. O. et al. Exigências nutricionais de gado de corte: O sistema NRC. Anais do Simpósio sobre Produção Intensiva de Gado de Corte - CBNA. p.138-167, Campinas, 1998.

LEE, E. N.; SUNWOO, H. H.; MENNINEN, K. et al. In vitro studies of chicken egg yolk antibody (IgY) against Salmonella enteritidis and Salmonella typhimurium. Poultry Science, v.81, p.632-641, 2002.

LEME, P.R.; BOIN, C.; MARGARIDO, R. C. C. et al. Desempenho em confinamento e características de carcaça de bovinos machos de diferentes cruzamentos abatidos em três faixas de peso. Revista Brasileira de Zootecnia, v.29, n.6, supl.2, p.2347 $-2353,2000$.

LIN, H.; BOYLSTON, T. D.; CHANG M. J. et al. Survey of the conjugated linoleic acid contents of dairy products. Journal of Dairy Science, 78:2358-2365, 1995.

LOBATO, J. F. P.; FReitAS, A. K. Carne Bovina: Mitos e Verdades. Pecuária Competitiva. Federacite, CD-ROM, 2006.

MAAS, J. A.; WILSON, G. F., MCCUTCHEON, S. N. et al. The effect of season and monensin sodium on the digestive characteristics of autumn and spring pasture fed to sheep. Journal of Animal Science, v.79, n.4, p.1052-1058, 2001.

MAKYIA, I. K.; TRABALLI, R. C. Infra-estrutura como fator chave para a sustentabilidade do escoamente da produção agrícola. In : $\mathbf{2}^{\text {nd }}$ International workshop advances in cleaner production. São Paulo - Brasil, 2009. 
MANSBRIDGE, R.J.; BLAKE, J.S. Nutritional factors affecting the fatty acid composition of bovine milk. British Journal of Nutrition, v.78, suppl.1, p.S37S47, 1997.

MARIANI, T. M. Suplementação de Anticorpos Policlonais ou Monensina Sódica sobre o Comportamento Ingestivo e Desempenho de Bovinos Brangus e Nelore Confinados. Dissertação (Programa de Pós-Graduação em Zootecnia), Universidade Estadual Paulista Júlio de Mesquita Filho, UNESP. Botucatu. 90p., 2010.

MARINO, C.; OTERO, W.; RODRIGUES, P. H. M. et al. Avaliação do preparado de anticorpos policlonais (PAP) nos parâmetros de fermentação ruminal em bovinos recebendo dietas de alto concentrado. In: Reunion Asociacion Latinoamericana de Produccion Animal (ALPA), 20., 2007, Cusco - Peru. Anais... Cusco, 2007, CDROM.

MENEZES, L. F. G.; RESTLE, J.; KUSS, F. et al. Medidas corporais de novilhos das gerações avançadas do cruzamento rotativo entre as raças Charolês e Nelore terminada em confinamento. Ciência Rural, v.38, n. 3, p.771-777, 2008.

METZ, P. A. M.; MENEZES, L. F. G.; SANTOS, A. P. et al. Perfil de ácidos graxos na carne de novilhos de diferentes categorias e grupos genéticos, terminados em confinamento. Revista Brasileira de Zootecnia, v. 38, p.523-531, 2009.

MILlEN, D. D.; PACHECO, R. D. L.; ARRIGONI, M. D. B. et al. Feedlot performance and rumen parakeratosis incidence in Bos indicus type bullocks fed high grain diets and monensin or polyclonal antibodies preparations against rumen bacteria. Journal of Animal Science, v.85, (supplement1), p.552, 2007.

MILlEN, D. D.; PACHECO, R. D. L.; ARRIGONI, M. D. B. et al. Blood metabolic profile of feedlot cattle supplemented with monensin or polyclonal antibodies preparations against lactate-producing rumen bacteria during diet step-up. Journal of Animal Science, v.86, (E-suppl.2), p.285, 2008a.

MILLEN, D. D.; PACHECO, R. D. L.; ARRIGONI, M. D. B. et al. Intake fluctuations of feedlot cattle supplemented with monensin or polyclonal antibodies preparations against lactate-producing rumen bacteria during diet step-up. 
Journal of Animal Science, v.86, (E-supp1.2), p.285, 2008b.

MILLEN, D. D. Desempenho, avaliação ruminal e perfil metabólico sanguíneo de bovinos jovens confinados suplementados com monensina sódica ou anticorpos policlonais. Botucatu: Universidade Estadual Paulista, 2008. Tese (Mestrado em Zootecnia) - Universidade Estadual Paulista, 2008.

MILLEN, D. D.; PACHECO, R D. L.; ARRIGONI, M. D. B. et al. A snapshot of management practices and nutritional recommendations used by feedlot nutritionists in Brazil. Journal of Animal Science, v.87, p.3427-3439, 2009.

MIR, P. S.; MCALliSTER, T. A.; SHANNON, S. et al. Conjugated linoleic acid enriched beef production. American Journal of Clinical Nutrition, v.79(Suppl), n.3, p.1207-1211, 2004.

MORAIS, J.A.S.; BERCHIELLI, T.T.; REIS, R.A. Aditivos. In: BERCHIELLI, T.T.; PIRES, A.V.; OLIVEIRA, S.G. Nutrição de ruminantes. Jaboticabal: Funep, p.539-563, 2006.

NAGARAJA, T. G.; AVERY, T. B.; BARTLEY, E. E. et al. Prevention of lactic acid acidosis in cattle by lasalocid or monensin. Journal of Animal Science, v.53, p.206-216, 1981.

NAGARAJA T. G.; LAUDERT, S. B.; PARROTT, J. C. et al. Liver abscesses in feedlot cattle. Part 1. Causes, pathogenesis, pathology, and diagnosis. Compendium on Continuing Education for the Practicing Veterinarian, v.18, p.S230-273, 1996.

NAGARAJA, T. G.; NEWBOLD, C. J.; VAN NEVEL, C. J. et al. Manipulation of ruminal fermentation. In: The rumen microbial ecosystem, p.523-632. P. N. Hobson and C. S. Stewart editors, 1997.

NAGARAJA, T. G.; CHENGAPPA, M. M. Liver abscesses in feedlot cattle: A review. Journal of Animal Science, v.76, p.287-298, 1998.

NAGARAJA, T. G. Response of the Gut and Microbial Populations to Feedstuffs: The ruminant story. In Proc. $64^{\text {th }}$ Minnesota Nutrition Conference. St. Paul, MN, p.64-77, 2003. 
NEWBOLD, C. J.; STEWART, C. S.; WALLACE, R. J. et al. Developments in rumen fermentation - The scientist's view. In Recent Advances in Animal Nutrition 2001. P. C. Garnsworthy and J. Wiseman ed. Nottingham University Press, Nottingham, United Kingdom. p.251-279, 2001.

NEWBOLD, C. J. New products for rumen manipulation. British Journal of Nutrition, v.98, n.1, p.15-16, 2007.

NOCEK, J. E. Bovine Acidosis: Implications on Laminitis. Journal of Dairy Science, v.80, p.1005-1028, 1997.

NUERNBERG, K.; DANNENBERGER, D.; NUERNBERG, G. et al. Effect of a Grassbased and a concetrate feeding system on meat quality characteristics and fatty acid composition of longissimus muscle in differente cattle breeds. Livestock Production Science, v.94, p.137-147, 2005.

OCHOA, M. F., MARCHELLO, J. A. Bovine lipoprotein and apolipoprotein profiles as influenced by sex and growth. Journal of Animal Science, 69: 4030-4038, 1991.

OJEU. Official Journal of the European Union. Regulation (EC) No 1831/2003 of the European Parliament and the Council of 22 of September of 2003 on Additives for Use in Animal Nutrition. Pages L268/29-L268/43 in OJEU of 10/18/2003.

OLIVEIRA, M. V. M.; LANA, R. P.; JHAM, G. N. et al. Influência da monensina no consumo e na fermentação ruminal em bovinos recebendo dietas com teores baixo e alto de proteína. Revista Brasileira de Zootecnia, v.34, n.5, p.1763-1774, 2005.

OLIVEIRA, M. V. M.; LANA, R. P.; EIFERT, E. C. et al. Influência da monensina sódica no consumo e na digestibilidade de dietas com diferentes teores de proteína para ovinos. Revista Brasileira de Zootecnia, v.36, n.3, p.643-651, 2007.

OTERO, W. G.; MARINO, C. T.; ALVES, F. R. et al. Degradabilidade in situ da canade-açúcar e do farelo de soja sob a influência de preparado de anticorpos policlonais e monensina. In: V Congreso Internacional de Ganadaria de doble propósito, Cuzco - Peru. Trabalho aceito para publicação em Outubro de 2007.

OTERO, W. G. Avaliação da diversidade microbiana e degradabilidade in situ em animais tratados com preparado de anticorpos policlonais contra bactérias 
produtoras de lactato e bactérias proteolíticas. Dissertação (Programa de PósGraduação em Medicina Veterinária), Universidade da São Paulo, USP. Pirassununga. p.85, 2008.

OWENS, F. N.; SECRIST, D. S.; HILL, W. J. et al. Acidosis in cattle: A review. Journal of Animal Science, v.76, p. 275-286, 1998.

PACHECO, R. D. L. Características físicas e químicas da carcaça de bovinos jovens suplementados com monensina sódica ou anticorpos policlonais aviários. Dissertação (Programa de Pós-Graduação em Zootecnia), Universidade Estadual Paulista Júlio de Mesquita Filho, UNESP. Botucatu. 82p., 2008.

PACHECO, R. D. L.; MILLEN, D. D.; CUNHA LEME, T. M. et al. Evaluation of growth, carcass characteristics and meat tenderness of bullocks fed monensin or polyclonal antibodies against lactate-producing rumen bacteria. Journal of Animal Science, v.86 (E-suppl.2), p.200, 2008.

PERRY, T. W.; BEESON, W. M.; MOHLER, M. T. et al. Effect of monensin on beef cattle performance. Journal of Animal Science, v.42, p.761-765, 1976.

POTTER, E. L.; WRAY, M. I.; MULLER, R. D. et al. Effect of monensin and tylosin on average daily gain, feed efficiency and liver abscesses incidence in feedlot cattle. Journal of Animal Science, v.61, p.1058-1065, 1985.

PUTRINO, S. M. Exigências de proteína e energia líquidas para o ganho de peso de tourinhos das raças Nelore e Brangus alimentados com dietas com diferentes proporções de concentrado. Pirassununga: Universidade de São Paulo, 2002. p.82. Dissertação (Mestrado em Zootecnia) - Universidade de São Paulo, USP, 2002.

RAES, K.; SMET, S.; DEMEYER, D. Effect of dietary fatty acids on incorporation of long chain polyunsaturated fatty acids and conjugated linoleic acid in lamb, beef, prok meat: A review. Animal Feed Science and Technology, v. 113, p. 199-221, 2004.

RAUN, A. P.; COOLEY C. O.; POTTER E. L. et al. Effect of monensin on feed efficiency of cattle. Journal of Animal Science, 39:250 (Abstr.), 1974. 
RAUN, A. P.; COOLEY C. O.; RATHMACHER R. P. et al. Effect of different levels of monensin on feed efficiency, ruminai and carcass characteristics of cattle. Proc. Western Sec. Journal of Animal Science, 25:346, 1974b.

RESTLE, J.; NEUMANN, M.; ALVES FILHO, D. C. et al. Terminação em confinamento de vacas e novilhas sob dietas com ou sem monensina sódica. Revista Brasileira de Zootecnia, v.30, n.6, p.1801-1812, 2001.

RICKE, S. C.; BERGER, L. L.; VAN DER AAR, P. J. et al. Effects of lasalocid and monensin on nutrient digestion, metabolism and rumen characteristics of sheep. Journal of Animal Science, v.58, n.1, p.194-202, 1984.

RODRIGUES, P. H. M.; MATtOS, W. R. S.; MElOTTI, L. et al. Monensina e digestibilidade aparente em ovinos alimentados com proporções de volumoso/concentrado. Scientia Agrícola, v.58, n.3, p.449-455, 2001.

ROCHESEL, J. R.; ARRIGONI, M. D. B.; MILLEN, D. D. et al. Efeito dos anticorpos policlonais ou da monensina sódica na concentração de lipoproteínas sanguíneas de bovinos jovens confinados. II Simpósio Internacional de Nutrição de Ruminantes FMVZ-UNESP. Botucatu. p.281. CD-ROM. 2009.

RUIZ, R.; ALBRECHT, G. L.; TEDESCHI, L. O. et al. Effect of monensin on the performance and nitrogen utilization of lactating dairy cows consuming fresh forage. Journal of Dairy Science, v.84, n.7, p.1717-1727, 2001.

RUSSELL, J. B. A proposed mechanism of monensin action in inhibiting ruminal bacterial growth: effects on ion flux and protonmotive force. Journal of Animal Science, Champaign, v. 64, n. 5, p. 1519-1525, 1987.

RUSSELL, J. B.; HOULIHAN, A. J. Ionophore resistance of ruminal bacteria and its potential impact on human helath. FEMS Microbiology Reviews, v.27, p.65-74, 2003.

RUSSELL, J. B.; STROBEL, H. J.; CHEN, G. The enrichment and isolation of a ruminal bacterium with a very high specific activity of ammonia production. Applied and Environmental Microbiology, v.54, n.4, p.872-877, 1988.

RUSSELL, J. B.; STROBEL, H. J. Mini-Review: the effect of ionophores on ruminal fermentations. Applied and Environmental Microbiology, v.55, p.1-6, 1989. 
RUSSELL, J. B.; HINO, T. Regulation of lactate production in streptococcus bovis: a spiraling effect that contributes to rumen acidosis. Journal of Dairy Science, v.68, p.1712, 1985.

RUSSELL, J .B.; RYCHLIK, J. L. Factors that alter rumen microbial ecology. Science, v.292, p.1119-1122, 2001.

SALLES, M. S. V.; LUCCI, C. S. Monensina para bezerros ruminantes em crescimento acelerado. 2. Digestibilidade e parâmetros ruminais. Revista Brasileira de Zootecnia, v.29, n.2, p.582-588, 2000.

SANTOS, F.A.P., 2006. Metabolismo de proteínas. In: BERCHIELLI, T.T.; PIRES, A.V.; OLIVEIRA, S.G. (Ed.) Nutrição de Ruminantes. 1. ed. Jaboticabal: Funep. p.151-179.

SARTI, L. M. N.; BARDUCCI, R. S.; MILLEN, D. D. et al. Rumen papillae measurements of feedlot cattle fed monensin or polyclonal antibody preparation against lactate-producing rumen bacteria. Journal of Animal Science, v.87, ESuppl.2, p.284, 2009.

SAUER, F. D.; FELLNER, V.; KINSMAN, R.; KRAMER, J. K. G. et al. Methane output and lactation response in Holstein cattle with Monensin or unsaturated fat added to the diet. Journal of Animal Science, v.76, p.906-914, 1998.

SCHADE, R.; BEHN, I.; ERHARD, M. et al. Chicken egg yolk antibodies, production and application. Chapter 1. Springer, Germany. 2001.

SCHADE, R.; STAAK, C.; HENDRIKSEN, C. et al. 1996. The production of avian (Egg Yolk) antibodies: IgY. Disponível em: http://altweb.jhsph.edu/publications/ECVAM/ecvam.21.htm Acesso 10/06/2009.

SCHELling, G. T. Monensin mode of action in the rumen. Journal of Animal Science, v.58, n.6, p.1518-1527, 1984.

SCHWARTZKOPF-GENSWEIN, K. S.; BEAUCHEMIN, K. A.; MCALLISTER, T. A. et al. Effect of feed delivery fluctuations and feeding time on ruminal acidosis, growth performance, and feeding behavior of feedlot cattle. Journal of Animal Science, v.82, p.3357-3365, 2004. 
SCOLARI, D. D. G. Produção agrícola mundial: O potencial do Brasil. - Embrapa Roraima. 2005. Disponível em: <http://www.cpafrr.embrapa.br. Acesso em $11 / 12 / 2009$.

SHERBECK, J. A.; TATUM, J. D.; FIELD, T. G. et al. Effect of phenotypic expression of Brahman breeding on marbling and tenderness traits. Journal of Animal Science, v.74, p.304 - 309, 1996.

SHERMAN, D. M.; ACRES, S. D.; SADOWSKI, P. L.; et al. Protection of calves against fatal enteric colibacillosis by orally administered Escherichia coli K99specific monoclonal antibody. Infection and Immunity, v.42, n.2, p.653-658, 1983.

SHIMIZU, M.; FITZSIMMONS, R. C.; NAKAI, S. et al. Anti-E. coli immunoglobulin $\mathrm{Y}$ isolated from egg yolk of immunized chickens as a potential food ingredient. Journal of Food Science, v.53, p.1360-1366, 1988.

SHIMIZU, M.; NAGASHIMA, H.; SANO, K. et al. Molecular stability of chicken and rabbit immunoglobulin G. Bioscience, Biotechnology and Biochemistry, v.56, p.270-274, 1992.

SHU, Q.; GILL, H. S.; HENNESSY, D. W. et al. Immunization against lactic acidosis in cattle. Research of Veterinary Science, v.67, p.65-71, 1999.

SHU, Q.; GILL, H. S.; LENG, J. B. et al. Immunization with a Streptococcus bovis vaccine administered by different routes against lactic acidosis in sheep. The Veterinary Journal, v.159, p.262-269, 2000.

SIMOPOULOS, A.P. The importance of the ratio of omega-6/omega-3 essential fatty acids. Biomed Pharmacother, v.56, p.365-379, 2002.

SLYTER, L. L. Influence of acidosis on rumen function. Journal of Animal Science, v.43, p.910-929, 1976.

SOODEN-KARAMATH, S.; YOUSSEF, F. G. Effect of monensin, avoparcin and grass supplementation on utilization of urea-treated rice straw by sheep and goats. Small Ruminant Research, v.33, n.3, p.201-211, 1999.

SOTO-NAVARRO, S. A.; KREHBIEL, C. R.; DUFF, G. C. et al. Influence of feed 
intake fluctuation and frequency of feeding on nutrient digestion, digesta kinetics, and ruminal fermentation profiles in limit-fed steers. Journal of Animal Science, v.78, p.2215-2222, 2000.

SOUZA, A. A. Perfil de ácidos graxos e concentração de CLA no tecido adiposo de bovinos de corte de diferentes grupos genéticos no modelo biológico superprecoce. Botucatu. Tese (Doutorado)-Faculdade de Medicina Veterinária e Zootecnia, Universidade Estadual Paulista, Botucatu. 73p., 2005.

SPEARS, J. Ionophores and nutrient digestion and absorption in ruminants. Journal of Nutrition, Bethesda, v.120, n.6, p.632-638.1990.

STEVENS, C. E. Fatty acid transport through the rumen epithelium. In: A. T. Phillipson (Ed.) Physiology of Digestion and Metabolism in the Ruminant. Oriel Press, Newcastle upon Tyne, U.K, p.101-112, 1970.

STOCK, R. A.; LAUDERT, S. B.; STROUP, W. W. et al. Effects of monensin and monensin and tylosin combination on feed intake variation of feedlot steers. Journal of Animal Science, v.73, p.39-44, 1995.

STOCK, R. A.; BRITTON, R. A. Acidosis. University of Nebraska. NebGuide. On line. Disponível: http://ianrpubs.unl.edu/animaldisease/g1047.htm, 1996.

STROBEL, H. J.; RUSSELL, J. B. Effect of pH and energy spilling on bacterial protein synthesis by carbohydrate-limited cultures of mixed rumen bacteria. Journal of Dairy Science, v.69, p.2941, 1986.

SUGANO, M.; HIRAHARA, F. Polyunsaturated fatty acids in the food chain in Japan. American Journal of Clinical Nutrition, v.71(1 Suppl), p.189-196, 2000.

TEDESCHI, L. O.; FOX, D. G.; TYLUTKI, T. P. Potential environmetal benefits of ionophores in ruminantes diets. Journal of Environmental Quality, v.32, p.1591-1602, 2003.

VAlADARES FILHO, S. C.; AZEVEDO, J. A. G.; PINA, D. S. et al. Consumo de matéria seca de bovinos Nelore e mestiços. In: Exigências Nutricionais Zebuínos e Tabelas de Composição de Alimentos - BR Corte. VALADARES FILHO, S.C.; PAULINO, P.V.R.; MAGALHÃES, K.A. (Eds.). Universidade Federal de Viçosa. p.1 - 11, 2006. 
VAN NEVEL, C. J.; DEMEYER, D. I. Lipolysis and biohydrogenation of soybean oil in the rumen in vitro: Inhibition by antimicrobials. Journal of Dairy Science, 78:2797-2806, 1995.

VARELA, A.; OLIETE, B.; MORENO, T. et al. Effect of pasture finishing on the meat characteristics and intramuscular fatty acid profile of steers of the Rubia Gallega breed. Meat Science, v.67, p.515-522, 2004.

WEDEGAERTNER, T. C.; JOHNSON, D. E. Monensin effects on digestibility, methanogenesis and heat increment of a cracked corn-silage diet fed to steers. Journal of Animal Science, v.57, n.1, p.168-177, 1983.

WOOD, J. D.; RICHARDSON, R. I.; NUTE, G. R. et al. Effects of fatty acids on meat quality: a review. Meat Science, v.66, p.21-32, 2004.

YANG, W. Z.; BEAUCHEMIN, K. A.; VEDRES, D. D. Effects of pH and fibrolytic enzymes on digestibility, bacterial protein synthesis, and fermentation in continuous culture. Animal Feed Science and Technology, v.102, n.1, p.137$150,2002$.

YANG, C. M. J; RUSSELL, J. B. The effect of monensin supplementation on ruminal ammonia accumulation in vivo and the numbers of aminoacid38 fermenting bacteria. Journal of Animal Science, v.71, n.12, p.3470-3476,1993.

YOKOYAMA, H.; PERALTA, R. C.; DIAZ, R. et al. Passive protective effect of chicken egg yolk immunoglobulins against experimental enterotoxigenic Escherichia coli infection in neonatal piglets. Infection and Immunity, v.60, n.3, p.998-1007, 1992.

ZINN, R. A.; PLASCENCIA, A.; BORAJES, R. Interaction of forage level and monensin in diets for feedlot cattle on growth desempenho and digestive function. Journal of Animal Science, v.72, p.2209-2215. 1994. 
CAPÍTULO 2 


\section{Anticorpos policlonais ou monensina sódica na alimentação de bovinos jovens} confinados com dietas de alto concentrado: desempenho, parâmetros metabólicos e distúrbios nutricionais

O objetivo deste estudo foi estudar os efeitos da suplementação do preparado de anticorpos policlonais (PAP) ou monensina sódica (MON) sobre o desempenho, características de carcaça, perfil metabólico sanguíneo, flutuação da ingestão de matéria seca (IMS) e incidências de rumenites e abscessos de fígado. O delineamento experimental foi inteiramente casualizado em arranjo fatorial $2 \times 2$, com seis repetições por tratamento, nos quais 48 bovinos machos inteiros de cada grupo genético (GG) avaliado [Brangus (BR) ou Nelore (NE)] foram alimentados com dietas contendo MON ou PAP fornecidos diariamente nas doses de 30 e $300 \mathrm{mg} / \mathrm{kg}$ de MS, respectivamente. Os animais passaram por três fases durante o estudo: adaptação (ADAP), crescimento, e terminação. As dietas fornecidas nestes períodos continham 55, 70 e 85\% de concentrado, respectivamente. Não foi observado $(P>0,05)$ efeito principal dos aditivos alimentares (AA) sobre a maioria das características de desempenho, com exceção à IMS em quilos e em porcentagem do peso vivo, onde bovinos recebendo MON apresentaram $(P<0,05)$ menores IMS. Foi observado $(P<0,01)$ efeito principal dos AA e dos GG sobre as concentrações de bicarbonato, total de $\mathrm{CO}_{2}$ e excesso de base no fluído extra-celular, onde bovinos recebendo PAP, e aqueles da raça BR, apresentaram maiores concentrações desses metabólitos no sangue. Animais que receberam PAP e aqueles da raça $\mathrm{BR}$, apresentaram maiores $(P<0,01)$ valores de $\mathrm{pH}$ na fase de ADAP que animais suplementados com MON $(7,427$ vs. 7,400) e animais $\mathrm{NE}$, respectivamente. Bovinos BR apresentaram $(P<0,01)$ maior ganho de peso diário que bovinos NE em ambas as fases, contudo conversão alimentar similar $(P>0,05)$. Por outro lado, bovinos NE mostraram maior $(P<0,05)$ incidência de lesões ruminais. Assim sendo, a suplementação de PAP pode ser uma eventual alternativa à MON, já que bovinos que consumiram PAP neste estudo apresentaram desempenho similar àqueles que receberam MON sem afetar negativamente as características de carcaça e a saúde dos animais quando dietas de alta energia foram fornecidas. Bovinos BR apresentaram melhor desempenho e menor incidência de rumenites que animais NE.

Palavras-chave: abscesso hepático, Brangus, carcaça, Nelore, rumenites. 


\section{Polyclonal antibodies preparations against rumen bacteria or monensin in high- concentrate diets fed to feedlot cattle: performance, blood gas profile, and nutritional disorders}

This study, conducted at the São Paulo State University feedlot, Botucatu Campus, Brazil, was designed to test monensin (MON) and a polyclonal antibody preparation (PAP) against rumen bacteria on feedlot performance of Brangus (BR) and Nellore (NE) cattle. The experiment was designed as a $2 \times 2$ factorial arrangement using repeated measures over time, replicated 6 times (4 bullocks/pen), in which 48 8-mo-old bullocks of each of two breeds (BD) evaluated were fed diets containing either MON at $30 \mathrm{mg} \cdot \mathrm{kg}^{-1}$ or PAP at $300 \mathrm{mg} \bullet \mathrm{kg}^{-1}$ of dry matter (DM). Measures over time were taken according to the phase and level of concentrate fed during the study: 55,70 and $85 \%$. Phases were named adaptation (AD), growing (GR), and final (FN), respectively. No significant $(P>0.05)$ feed additives (FA) main effect was observed for any of the feedlot performance variables, with the exception $(P<0.05)$ of DM intake expressed in $\mathrm{kg}(\mathrm{PAP}=7.60 ; \mathrm{MON}=7.24)$ and in \% of body weight $(\mathrm{PAP}=2.11 ; \mathrm{MON}=2.03)$. Feeding MON led to greater $(P<0.05)$ subcutaneous fat deposition throughout the study, and decreased $(P<0.05)$ the final rib eye area (RBA). As a result a reduced $(P<$ 0.05) RBA deposition, mainly in GR phase, it was observed when feeding MON was compared to feeding PAP. A significant $(P<0.01)$ FA and BD main effects were found for bicarbonate, total $\mathrm{CO}_{2}$, and base excess in extracellular fluid, where bullocks receiving $\mathrm{PAP}$, and those $\mathrm{BR}$ cattle, presented greater concentrations of these metabolites in the blood. Likewise, BR cattle and bullocks receiving PAP had $(P<$ 0.01) higher blood $\mathrm{pH}$ in the AD phase than NE cattle and bullocks fed MON (7.427 vs. 7.400), respectively. BR had greater $(\mathrm{P}<0.01)$ average daily gain in GR and FN phases, but similar $(P>0.05)$ feed conversion was observed. On the other hand, NE bullocks presented greater $(P<0.05)$ incidence of rumenites. Thus, feeding PAP may be eventually an alternative to MON, because in this study bullocks fed PAP presented similar feedlot performance compared to those receiving MON without impacting negatively carcass traits and animal health when high concentrate diets were fed. BR bullocks presented better feedlot performance and lesser extent of rumen lesions.

Keywords: Brangus, carcass, liver abscess, Nellore, rumenites. 


\section{INTRODUÇÃO}

Ionóforos como a monensina (MON) são frequentemente incluídos nas dietas de bovinos confinados no intuito de promover crescimento e prevenir desordens digestivas como a acidose ruminal pela modificação da troca de íons através das membranas de bactérias Gram positivas. No entanto alguns países, particularmente os do continente europeu, baniram o uso de ionóforos como promotores de crescimento por que estes são classificados como antibióticos (OJEU, 2003), os quais despertam a percepção pública de que contribuem para emergência de micro-organismos resistentes a antibióticos (Newbold et al., 2001). Baseado nos fatos de que em 2009 o Brasil destinou cerca de 29,3\% de suas exportações para a União Européia (Beefpoint, 2010) e que os ionóforos são os principais aditivos alimentares, utilizados em 100\% dos confinamentos brasileiros (Millen et al., 2009), a busca de novas alternativas para substituir os ionóforos é relevante e pode levar a descoberta de novas técnicas que melhorem os processos de fermentação ruminal e apresentem mesma eficiência e economicidade dos ionóforos, sem trazer qualquer tipo risco para a saúde humana (DiLorenzo, 2004).

Uma alternativa aos ionóforos que foi avaliada in vivo recentemente é a imunização passiva (DiLorenzo et al., 2008; Blanch et al., 2009). Vacinação e doses orais de anticorpos contra bactérias ruminais produtoras de lactato têm levado a redução da concentração do lactato ruminal (Shu et al., 1999), maior pH do rúmen (DiLorenzo et al., 2006), menor incidência de rumenites e desempenho similar a bovinos recebendo MON (Millen et al., 2007) e aumentos na ingestão de matéria seca (Gill et al., 2000; Shu et al., 2000). Como bovinos Bos indicus predominam nos confinamentos brasileiros, e observações práticas e evidências científicas sugerem que animais Zebuínos podem ser mais susceptíveis a acidose que bovinos de genótipo Bos taurus (Millen et al., 2009), seria interessante o oferecimento de produtos ou alimentos que atuem de alguma forma na prevenção da acidificação do rúmen.

Assim sendo, o objetivo deste estudo foi estudar os efeitos do preparado de anticorpos policlonais (PAP), contra as bactérias ruminais Streptococcus bovis, Fusobacterium necrophorum, Escherichia coli, Clostridium aminophilum, Clostridium sticklandii, Peptostreptococcus spp., ou MON sobre o desempenho, características de carcaça, incidências de rumenites e abscessos hepáticos, perfil metabólico sanguíneo e flutuação da ingestão de matéria seca de bovinos Brangus e Nelore confinados. 


\section{MATERIAL E MÉTODOS}

O trabalho foi conduzido de acordo com as normas da comissão de ética no uso de animais (CEUA) da Faculdade de Medicina Veterinária e Zootecnia, UNESP - Univ. Estadual Paulista, campus de Botucatu.

\subsection{PAP}

Os PAP foram produzidos pela CAMAS Inc., Le Center, MN, EUA. O produto comercial contém imunoglobulinas contra Streptococcus bovis (ATCC 9809), Fusobacterium necrophorum (ATCC 27852), Clostridium sticklandii (ATCC 12662), Clostridium aminophilum (ATCC 49906), Peptostreptococcus anaerobius (ATCC 49031), e Escherichia coli O157:H7 (ATCC 43895). Streptococcus bovis é a bactéria que mais produz ácido láctico, Fusobacterium necrophorum é o causador de abscessos hepáticos em animais com acidose, Clostridium sticklandii, Clostridium aminophilum, e Peptostreptococcus anaerobius são bactérias produtoras de amônia, e Escherichia coli O157:H7 é patogênica em humanos e também causadora de acidose.

\subsection{Animais e Local Experimental}

O estudo foi conduzido na Faculdade de Medicina Veterinária e Zootecnia, UNESP - Univ. Estadual Paulista, campus de Botucatu no confinamento experimental de bovinos de corte, onde foram alocados 96 animais machos, não castrados, com oito meses de idade, pertencentes a dois grupos genéticos [48 da raça Nelore (NE) e 48 da raça Brangus (BR)] e distribuídos aleatoriamente em 24 baias (4 animais/baia). O peso vivo médio inicial foi de $272,60 \pm 9,07$ e $236,63 \pm 15,37 \mathrm{~kg}$ para $\mathrm{BR}$ e NE, respectivamente.

\subsection{Manejo, Arraçoamento e Cuidados com os Animais}

Todos os animais foram submetidos ao mesmo fornecimento de dietas ad libitum, tipo de alojamento e manejo. As baias eram cobertas, protegendo os animais e o alimento do sol e da chuva e com boa facilidade na circulação do ar. 
Antes do início do experimento os animais foram pesados, desverminados, vacinados contra doenças virais e bacterianas (rota e coronavírus, tétano, botulismo e sete tipos Clostridium spp.; Pfizer Animal Health, New York, NY) e adaptados às baias e às dietas por período de 28 dias.

Os ingredientes das dietas foram adicionados no próprio vagão distribuidor, no qual foram também misturados. Os animais receberam as dietas duas vezes ao dia: às $8 \mathrm{~h}$ (40\% do total) e $15 \mathrm{~h}$ ( $60 \%$ do total), sempre com água constante em bebedouros automáticos $\left(0,89 \mathrm{~m}^{2}\right)$. As dietas foram fornecidas em cada baia $\left(6,7 \mathrm{~m}^{2} /\right.$ animal $) \mathrm{em}$ cocho de $5 \mathrm{~m}$ (1,25 m/animal). A quantidade de ração fornecida diariamente foi ajustada com base na quantidade de sobras medidas antes do trato da manhã (8h), considerandose 3\% como nível de sobras (Cucki, 2006). A quantidade de ração fornecida e as sobras foram pesadas diariamente e amostradas semanalmente para determianção dos teores de matéria seca (MS), proteína bruta, extrato etéreo e matéria mineral, os quais foram avaliados segundo o AOAC (1997) e fibra detergente neutro (FDN) segundo Goering e Van Soest (1970). As concentrações de FDN (com $\alpha$-amilase estável sob calor e sulfito de sódio) e FDA foram determinadas usando-se um analisador de fibra (Modelo 200, Ankom Technology, Fairport, NY, EUA).

Os animais foram abatidos quando atingiram $5 \mathrm{~mm}$ de espessura de gordura subcutânea (EGS), mensurada por meio de ultrassonografia, para alcançar os requerimentos mínimos de gordura de cobertura do mercado brasileiro. A EGS do músculo Longissimus foi mensurada via ultra-som (Pie Medical Modelo 200), no início e no final de cada fase (crescimento e terminação), seguindo metodologia descrita por Perkins et al. (1992). Também foram mensurados por meio de ultra-som a área de olho de lombo (AOL) e a espessura de gordura do músculo Bíceps femoris (EGP8), sendo calculados posteriormente os ganhos diários de AOL, EGS e EGP8.

\subsection{Tratamentos e Dietas}

O delineamento experimental foi inteiramente casualizado em arranjo fatorial 2 $\times 2$, com seis repetições por tratamento, nos quais 48 bovinos machos inteiros de cada grupo genético avaliado (BR ou NE) foram alimentados com dietas contendo MON (Rumensin, Elanco Animal Health, Indianapolis, IN, EUA) ou PAP fornecidos 
diariamente misturado ao suplemento mineral em doses de 30 e $300 \mathrm{mg} / \mathrm{kg}$ de $\mathrm{MS}$, respectivamente.

Os animais passaram por três fases durante o estudo: adaptação (ADAP), crescimento (CRES), e terminação (TERM). As dietas fornecidas nestes períodos continham 55, 70 e $85 \%$ de concentrado na base da MS, respectivamente, e foram compostas por silagem de grãos úmidos de milho, grãos de milho seco quebrados, polpa cítrica peletizada, farelo de soja, bagaço de cana cru, feno de Coast Cross e suplemento mineral e protéico (Tabela 1). A dieta contendo 58\% de concentrado (ADAP) foi fornecida por período de 28 dias para adaptar os animais às dietas subsequentes. Com isso foi considerado o "dia 1" da fase de CRES para o início do experimento. O critério para as mudanças de dieta foi baseado na EGS mensurada por meio de ultrassonografia. Quando os animais atingiram média de $3 \mathrm{~mm}$ de EGS sobre o músculo Longissimus, a dieta foi alterada de 70\% (CRES) para 85\% (TERM) de concentrado. As dietas foram formuladas segundo o sistema Cornell Net Carbohydrate and Protein System 5.0.40 (CNCPS, 2000), cuja formulação está apresentada na Tabela 1, esperando-se ganhos de peso diários (GPD) de 1,300 a 1,600 kg/dia/animal. Os animais permaneceram no experimento por 140 dias antes de serem abatidos nas fases de ADAP (28 dias), CRES (56 dias) e TERM (56 dias). Os animais foram pesados após jejum de sólidos de 16 horas, no início e no final de cada fase (CRES e TERM). Foram calculados dados referentes ao desempenho, como o GPD, conversão alimentar (CA), ingestão de matéria seca em quilos (IMSKG) e em porcentagem do peso vivo (IMSPV) foram coletados.

A ingestão de matéria seca (IMS) foi medida para cada baia por meio da pesagem do alimento fornecido diariamente. A pesagem da sobra foi efetuada todos os dias em todas as baias antes do trato da manhã, fazendo-se, posteriormente, a média por animal. A conversão alimentar dos animais foi calculada dividindo-se a IMSKG pelo GPD.

\subsection{Perfil Metabólico Sanguíneo}

Foram coletadas amostras de sangue da veia jugular de todos os animais do estudo após 15 dias do início de uma nova fase ou introdução de nova dieta, seguindo a metodologia proposta por Brossard et al. (2003) utilizando-se seringas de dois mililitros para coleta de sangue (MONOVETTE®, Sarstedt, Nümbrecht, Germany). As amostras 
foram coletadas $3 \mathrm{~h}$ após o trato da manhã e analisadas em até $2 \mathrm{~h}$ de acordo com a recomendação de Beauchemin et al. (2003) utilizando-se um equipamento de análise de pH e perfil metabólico sanguíneo (BAYER Rapid Lab 865; Siemens Healthcare Diagnostics Inc., Deerfield, IL). Foram determinados os seguintes parâmetros sanguíneos: $\mathrm{pH}$, pressão parcial de $\mathrm{CO}_{2}$ (PCO2), pressão parcial de $\mathrm{O}_{2}$ (PO2), bicarbonatos $\left(\mathrm{HCO}_{3}{ }^{-}\right.$; BICARB), $\mathrm{CO}_{2}$ total (TCO2), excesso de bases no sangue (BEB) e excesso de bases no fluído extracelular (BEECF). Os valores referência de gases e metabólitos de sangue venoso de bovinos são mostrados na Tabela 1 do capítulo 1 (Carlson, 1997).

\subsection{Flutuação da Ingestão de Matéria Seca}

Para avaliar a flutuação na ingestão de matéria seca foi seguida metodologia proposta por Bevans et al. (2005). Nos quatro primeiros dias de cada nova fase (CRES e TERM), foram coletados dados de ingestão de matéria seca em quilos (IMS4D). Variações na ingestão de matéria seca (VIMS) foram calculadas pela diferença no consumo de matéria seca entre dois dias consecutivos (Dias: 0 e 1; 1 e 2; 2 e 3; 3 e 4).

\subsection{Coleta de Dados das Carcaças}

Logo após o abate, foram coletados os dados de peso de carcaça quente (PCQ) e o peso da gordura visceral (GVS), ambos em quilos. Posteriormente, pela divisão do PCQ pelo peso vivo final em jejum coletado no confinamento antes do embarque dos animais, foi obtido o rendimento de carcaça (REND). Ainda, pela divisão da GVS pelo PCQ, foi obtida a quantidade de gordura visceral expressa em porcentagem do PCQ (GVSP). A AOL final medida por meio de ultra-som foi relacionada ao PCQ através do parâmetro AOL/100 kg de PCQ.

\subsection{Incidência de Rumenites}

Para as avaliações das papilas ruminais todos os animais do estudo, logo após o abate, tiveram os rúmens lavados e então examinados. As papilas ruminais foram classificadas conforme a incidência de lesões (rumenites) seguindo a metodologia proposta por Bigham e McManus (1975), baseada numa escala de 0 a 10 pontos. Foi considerada na incidência de rumenites qualquer classificação na escala de 1 a 10 
pontos, sendo desconsiderada a incidência desta apenas em casos de classificação zero. Rúmens totalmente comprometidos com lesões ulcerativas, receberam nota 10. Como é uma classificação visual e, portanto subjetiva, o exame dos rumens foi realizado por dois técnicos treinados para este fim, e o escore final foi a média destes dois escores.

\subsection{Incidência de Abscesso Hepático}

No abate, os abscessos hepáticos foram classificados de acordo com a severidade destes em escala de 0 a 3. Essa classificação foi baseada no trabalho de Brink et al. (1990) e categorizada como segue: (0) - fígados sem abscessos; (A- = 1) fígados com um ou dois pequenos abscessos (bem menores que 2,5 cm de diâmetro) ou cicatrizes de abscessos; $(\mathrm{A}=2)$ - fígados com dois a quatro abscessos ativos (pouco menores que 2,5 cm de diâmetro); $\left(\mathrm{A}^{+}=3\right)$ - fígados com um ou mais, grandes abscessos (maiores que 2,5 cm de diâmetro) e porções do diafragma aderido à superfície do fígado. Foram consideradas ainda para a análise, a porcentagem de animais acometidos por abscessos dentro de cada tratamento, obtendo-se com isso a incidência de abscessos hepáticos propriamente dita.

\subsection{Delineamento Experimental e Análise Estatística}

O delineamento experimental foi inteiramente casualizado e as baias foram consideradas as unidades experimentais para todas as variáveis deste estudo. Foram realizados testes de normalidade e de heterogeneidade de variâncias antes de se proceder a análise de variância e quando necessário, os dados foram transformados. Para todas as variáveis respostas em que foram realizadas medidas repetidas no tempo, foram testadas as seguintes estruturas de covariância: $\operatorname{AR}(1), \operatorname{ARH}(1), \operatorname{ANTE}(1), \mathrm{CS}$, CSH, TOEP, TOEPH, UN, UNR e HF. A estrutura que rendeu o menor valor de AIC (Akaike Bayesian Criterion) para cada variável resposta, foi escolhida para análise por acomodar melhor os dados. Já para os dados de flutuação da ingestão de matéria de seca foram testadas as seguintes estruturas de covariância: UN@UN, UN@CS e UN@AR(1). Resultados foram considerados significantes a $\mathrm{P}<0,05$.

Os dados de PCQ, REND, GVIS, GVISP e AOL/100 kg de PCQ foram analisados como arranjo fatorial $2 \times 2$, em que o efeito de dois grupos genéticos $(\mathrm{BR} \mathrm{e}$ $\mathrm{NE}$ ), e de dois aditivos alimentares (PAP e MON) foram avaliados utilizando-se o 
PROC MIXED do SAS (2003) de acordo com o modelo 1 abaixo. Os dados referentes ao escore de rumenites foram analisados pelo mesmo modelo 1, mas utilizando-se o NPAR1WAY do SAS (2003) para dados não paramétricos e teste de Kruskal-Wallis para comparação entre médias. Os dados de incidência de abscesso hepático foram analisados pelo modelo 1 abaixo, porém, como diferenças em severidade não existiram, utilizou-se o PROC FREQ do SAS (2003) para testar as diferenças entre os tratamentos. Como a matriz tratamentos $x$ incidência de abscessos teve muitas células com valores zero, a opção EXACT foi escolhida para se realizar o teste exato de Fischer.

\section{MODELO 1:}

$Y_{i j k}=\mu+G G_{i}+T_{j}+G G^{*} T_{i j}+e_{i j k}$

em que:

- $\mathrm{Y}_{\mathrm{ijk}}$ é a observação na $\mathrm{k}^{\text {ésima }}$ baia, no $\mathrm{j}^{\text {ésimo }}$ tratamento e no $\mathrm{i}^{\text {ésimo }}$ grupo genético;

- $\mu$ é a média geral;

- $\mathrm{GG}_{\mathrm{i}}$ é o efeito do $\mathrm{i}^{\text {ésimo }}$ grupo genético, sendo $\mathrm{i}=1$ : NE e 2: BR;

- $\mathrm{T}_{\mathrm{j}}$ é o efeito do jésimo aditivo alimentar, sendo $\mathrm{j}=1$ : MON e 2: PAP;

- GG* $T_{\mathrm{ij}}$ é a interação entre o $\mathrm{i}^{\text {simo }}$ grupo genético e o jésimo aditivo alimentar;

- $\mathrm{e}_{\mathrm{ijk}}$ é o erro experimental associado a observação $\mathrm{Y}_{\mathrm{ijk}}\left(0 ; \sigma_{e}^{2}\right)$.

Os dados de desempenho e de ultrassonografia foram analisados como arranjo fatorial $2 \times 2$ com medidas repetidas no tempo, em que os efeitos de dois grupos genéticos (BR e NE) e de dois aditivos alimentares (PAP e MON) foram avaliados em duas fases de mensurações (CRES e TERM) utilizando-se o PROC MIXED do SAS (2003) de acordo com o modelo 2 abaixo e teste de Tukey para comparação entre médias. Para o perfil metabólico sanguíneo foi utilizado o mesmo modelo 2, porém foi incluído mais uma fase de mensuração: ADAP.

\section{MODELO 2:}

$Y_{i j k l}=\mu+G G_{i}+T_{j}+G G^{*} T_{i j}+\gamma_{i j l}+F_{k}+G G^{*} F_{i k}+T^{*} F_{j k}+G G^{*} T^{*} F_{i j k}+e_{i j k l} ;$ em que:

- $Y_{\mathrm{ijkl}}$ é a observação na $1^{\text {ésima }}$ baia, no $\mathrm{j}^{\text {ésimo }}$ tratamento, no $\mathrm{i}^{\text {ésimo }}$ grupo genético e $\mathrm{k}^{\text {ésima }}$ fase de mensuração; 
- $\mu$ é a média geral;

- $\mathrm{GG}_{\mathrm{i}}$ é o efeito do $i^{\text {ésimo }}$ grupo genético, sendo $\mathrm{i}=1$ : NE e 2: BR;

- $\mathrm{T}_{\mathrm{j}}$ é o efeito do jésimo aditivo alimentar, sendo $\mathrm{j}=1$ : MON e 2: PAP;

- GG* $T_{\mathrm{ij}}$ é a interação entre o $\mathrm{i}^{\text {ésimo }}$ grupo genético e o jésimo aditivo alimentar;

- $\gamma_{\mathrm{ijl}}$ é o erro experimental “a” associado a observação $\mathrm{Y}_{\mathrm{ijl}}\left(0 ; \sigma_{\gamma}^{2}\right)$;

- $\mathrm{F}_{\mathrm{k}}$ é o efeito da $\mathrm{k}^{\mathrm{e} s i m a}$ fase, sendo $\mathrm{k}=1$ : CRES e 2: TERM;

- GG* $\mathrm{F}_{\mathrm{ik}}$ é a interação entre o $\mathrm{i}^{\text {ésimo }}$ grupo genético e a $\mathrm{k}^{\text {ésima }}$ fase;

- $\mathrm{T}^{*} \mathrm{~F}_{\mathrm{jk}}$ é a interação entre o $\mathrm{j}^{\text {śimo }}$ aditivo alimentar e a $\mathrm{k}^{\text {ésima }}$ fase;

- GG* T* $F_{i j k}$ é a interação entre o $\mathrm{i}^{\text {śimo }}$ grupo genético, o jésimo aditivo alimentar e a $\mathrm{k}^{\text {ésima }}$ fase;

- $\mathrm{e}_{\mathrm{ijkl}}$ é o erro experimental "b" associado a observação $\mathrm{Y}_{\mathrm{ijkl}}\left(0 ; \sigma_{e}^{2}\right)$.

Os dados de flutuação da ingestão de matéria seca foram analisados como arranjo fatorial $2 \times 2$ com medidas repetidas no tempo, em que os efeitos de dois grupos genéticos (BR e NE) e de dois aditivos alimentares (PAP e MON) foram avaliados nos quatro primeiros dias das duas fases de mensurações (CRES e TERM) utilizando-se o PROC MIXED do SAS (2003) de acordo com o modelo 3 abaixo e teste de Tukey para comparação entre médias.

\section{MODELO 3:}

$Y_{i j k l m}=\mu+G G_{i}+T_{j}+G G^{*} T_{i j}+\gamma_{i j m}+F_{k}+G G^{*} F_{i k}+T^{*} F_{j k}+G G^{*} T^{*} F_{i j k}+\delta_{i j k m}+$ Dias $_{l}$ + Dias $^{*} G G_{i l}+$Dias$^{*} T_{j l}+$Dias$^{*} G G^{*} T_{i j l}+$Dias$^{*} F_{k l}+$ Dias $^{*} G G^{*} F_{i k l}+$ Dias $^{*} T^{*} F_{j k l}$ $+\operatorname{Dias}^{*} G G^{*} T^{*} F_{i j k l}+e_{i j k l m}$;

em que:

- $Y_{\mathrm{ijklm}}$ é a observação na $\mathrm{m}^{\text {ésima }}$ baia, no $\mathrm{j}^{\text {ésimo }}$ tratamento, no $\mathrm{i}^{\text {ésimo }}$ grupo genético, $\mathrm{k}^{\text {ésima }}$ fase de mensuração e $1^{\text {ésimo }}$ dias de mensuração;

- $\mu$ é a média geral;

- $\mathrm{GG}_{\mathrm{i}}$ é o efeito do $\mathrm{i}^{\text {ésimo }}$ grupo genético, sendo $\mathrm{i}=1$ : NE e 2: BR;

- $\mathrm{T}_{\mathrm{j}}$ é o efeito do jésimo aditivo alimentar, sendo $\mathrm{j}=1$ : MON e 2: PAP;

- GG* $\mathrm{T}_{\mathrm{ij}}$ é a interação entre o $\mathrm{i}^{\text {ésimo }}$ grupo genético e o jésimo aditivo alimentar;

- $\gamma_{\mathrm{ijm}}$ é o erro experimental “a” associado a observação $\mathrm{Y}_{\mathrm{ijm}}\left(0 ; \sigma_{\gamma}^{2}\right)$; 
- $\mathrm{F}_{\mathrm{k}}$ é o efeito da $\mathrm{k}^{\text {ésima }}$ fase, sendo $\mathrm{k}=1$ : CRES e 2: TERM;

- GG* $\mathrm{F}_{\mathrm{ik}}$ é a interação entre o $\mathrm{i}^{\text {śimo }}$ grupo genético e a $\mathrm{k}^{\text {ésima }}$ fase;

- T* $\mathrm{F}_{\mathrm{jk}}$ é a interação entre o jésimo aditivo alimentar e a $\mathrm{k}^{\mathrm{e} s i m a}$ fase;

- GG* $T^{*} F_{i j k}$ é a interação entre o $\mathrm{i}^{\text {śimo }}$ grupo genético, o jésimo aditivo alimentar e a $\mathrm{k}^{\text {ésima }}$ fase;

- $\boldsymbol{\delta}_{\mathrm{ijkm}}$ é o erro experimental "b" associado a observação $\mathrm{Y}_{\mathrm{ijkm}}\left(0 ; \sigma_{\delta}^{2}\right)$;

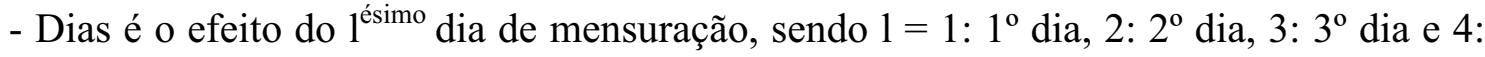
$4^{\circ}$ dia;

- Dias* $\mathrm{GG}_{\mathrm{il}}$ é a interação entre o $1^{\text {ésimo }}$ dia e o $i^{\text {ésimo }}$ grupo genético;

- Dias* $\mathrm{T}_{\mathrm{j} 1}$ é a interação entre o $\mathrm{l}^{\text {simo }}$ dia e o o jésimo aditivo alimentar;

- Dias* GG* $\mathrm{T}_{\mathrm{ijl}}$ é a interação entre o $1^{\text {ésimo }}$ dia, o $\mathrm{i}^{\text {ésimo }}$ grupo genético e o jésimo aditivo alimentar;

- Dias*Fase ${ }_{\mathrm{kl}}$ é a interação entre o $1^{\text {ésimo }}$ dia e a $\mathrm{k}^{\text {ésima }}$ fase;

- Dias* GG*Fase ${ }_{i k l}$ é a interação entre o $1^{\text {ésimo }}$ dia, o iésimo grupo genético e a $\mathrm{k}^{\text {ésima }}$ fase;

- Dias* $\mathrm{T}^{*} \mathrm{~F}_{\mathrm{jkl}}$ é a interação entre o $1^{\text {ésimo }}$ dia, o jésimo aditivo alimentar e a $\mathrm{k}^{\text {ésima }}$ fase;

- Dias*GG*T* $\mathrm{F}_{\mathrm{ijk}}$ é a interação entre o $1^{\text {ésimo }}$ dia, o $\mathrm{i}^{\text {ésimo }}$ grupo genético, o jésimo aditivo alimentar e a ${ }^{\text {ésima }}$ fase;

- $\mathrm{e}_{\mathrm{ijklm}}$ é o erro experimental "c" associado a observação $\mathrm{Y}_{\mathrm{ijklm}}\left(0 ; \sigma_{e}^{2}\right)$.

\section{RESULTADOS}

\subsection{Desempenho e Características de Carcaça}

Não foi observado $(P>0,05)$ efeito principal dos aditivos alimentares sobre a maioria das características de desempenho, com exceção à IMSKG e IMSPV, onde bovinos que receberam MON apresentaram $(P<0,05)$ menores ingestões (Tabela 2). Da mesma forma, com relação às características de carcaça, não foi encontrado $(P>$ $0,05)$ efeito principal dos aditivos alimentares sobre a maioria das variáveis respostas avaliadas, com exceção de: AOL/100 kg de PCQ e AOL final onde animais suplementados com PAP apresentaram $(P<0,05)$ maiores áreas por $\mathrm{cm}^{2}$; e Ganho de EGS (Tabela 2), onde animais que receberam MON apresentaram $(P<0,01)$ maior deposição diária média de gordura. 
Foi encontrada ainda interação $(\mathrm{P}<0,05)$ entre aditivos alimentares e fase de mensuração para AOL inicial (Figura 1) e Ganho de AOL (Figura 2). Animais que receberam tanto PAP quanto MON apresentaram $(P>0,05)$ AOL Inicial similares na fase de CRES, entretanto animais alimentados com PAP apresentaram $(P<0,05)$ maior AOL inicial na fase de TERM que animais que receberam MON. Isso refletiu nos animais alimentados com PAP, os quais apresentaram $(P<0,05)$ maior Ganho de AOL na fase de CRES, todavia nenhuma diferença foi encontrada $(P>0,05)$ entre os aditivos alimentares na fase de TERM.

Não foi observado $(\mathrm{P}>0,05)$ efeito principal dos grupos genéticos sobre as variáveis de desempenho avaliadas (Tabela 2). No entanto, foram encontradas interações $(P<0,01)$ entre grupos genéticos e fases de mensuração para GPD (Figura 3), Ganho de Peso Total (GPT; Figura 4), IMSKG (Figura 5) e IMSPV (Figura 6). Os animais BR mantiveram o GPD e GPT em ambas as fases $(P>0,05)$, todavia animais NE apresentaram $(P<0,01)$ redução do GPD e GPT na fase de TERM em relação a de CRES. Os bovinos BR também apresentaram $(P<0,01)$ maiores GPD e GPT que bovinos NE em ambas as fases. Com relação à ingestão de alimentos, animais BR e NE apresentaram aumento $(P<0,01)$ da IMSKG na fase de TERM em relação a de CRES, no entanto animais BR apresentaram $(P<0,01)$ maior aumento e ainda apresentaram $(P$ $<0,01)$ maiores IMSKG em ambas as fases quando comparados aos NE. No entanto, animais BR mantiveram a IMSPV em ambas as fases $(P>0,05)$, e animais NE apresentaram $(P<0,01)$ redução da IMSPV na fase de TERM em relação a de CRES. Ainda, bovinos BR apresentaram $(P<0,01)$ maior IMSPV que bovinos NE na fase de TERM, não sendo detectada diferença $(P>0,05)$ na fase de CRES.

Em termos de características de carcaça, não foi encontrado $(P>0,05)$ efeito principal dos grupos genéticos sobre a maioria das variáveis dependentes analisadas, com exceção do PCQ, GVS, AOL inicial e final (Tabela 2), onde maiores $(P<0,05)$ valores foram encontrados para bovinos BR. Foi observada ainda interação $(\mathrm{P}<0,01)$ entre grupos genéticos e fase de mensuração para EGS final (Figura 7), Ganho de EGS (Figura 8), EGP8 inicial (Figura 9), EGP8 final (Figura 10) e Ganho de EGP8 (Figura 11). Foram encontradas $(P>0,05)$ EGS final, Ganho de EGS, e EGP8 inicial similares na fase de CRES entre animais BR e NE, no entanto animais BR apresentaram $(P<$ 0,01) maiores EGS final, Ganho de EGS e EGP8 inicial na fase TERM. Foram 
encontradas ainda, maiores $(P<0,01)$ EGP8 final e Ganho de EGP8 tanto na fase de CRES quanto na de TERM para animais BR em relação aos NE.

Não foi observado $(P>0,05)$ efeito principal das fases de mensuração sobre a maioria das variáveis respostas referentes ao desempenho e as características de carcaça, com exceção da CA, AOL final e EGS inicial (Tabela 2), em que na fase de CRES foi observada melhor $(P<0,01) \mathrm{CA}$, e na fase de TERM maiores $(P<0,01)$ AOL final e EGS inicial.

\subsection{Perfil Metabólico Sanguíneo}

Foi observado $(P<0,01)$ efeito principal dos aditivos alimentares sobre o BICARB, TCO2 e BEECF, onde bovinos recebendo PAP apresentaram maiores concentrações desses metabólitos no sangue (Tabela 3). Foi encontrada interação entre aditivos alimentares e grupos genéticos para pH sanguíneo (Figura 12), onde animais BR que receberam PAP apresentaram maiores $(P<0,01)$ valores de $\mathrm{pH}$ que BR suplementados com MON; no entanto, não foi observada diferença $(P>0,05)$ entre NE que receberam PAP e MON. Ainda, quando foram alimentados com dietas que continham PAP, bovinos BR apresentaram maior $(P<0,01) \mathrm{pH}$ que $\mathrm{NE}$, porém nenhuma diferença foi constatada $(P>0,05)$ quando os animais foram alimentados com MON.

Foram encontradas também interações $(P<0,05)$ entre aditivos alimentares e fases de mensuração para pH do sangue (Figura 13), PCO2 (Figura 14), e BEB (Figura 15). Animais recebendo PAP apresentaram maiores $(P<0,01)$ valores de $\mathrm{pH}$ na fase de ADAP que animais suplementados com MON (7,427 vs. 7,400). No entanto, não foi observada diferença $(P>0,05)$ entre os aditivos alimentares nas fases de CRES e TERM. Para PCO2, os bovinos que foram suplementados com PAP apresentaram maiores $(P<0,05)$ pressões parciais nas fases de CRES e TERM que animais suplementados com MON, e não foi observada diferença $(P>0,05)$ entre os aditivos alimentares na fase de ADAP. Os animais recebendo PAP apresentaram maiores $(P<$ $0,05)$ concentrações de BEB nas fases de ADAP e CRES que animais suplementados com MON; mas nenhuma diferença foi observada $(P>0,05)$ entre os aditivos alimentares na fase de TERM. 
Foi observado $(P<0,01)$ efeito principal dos grupos genéticos para a maioria das variáveis do perfil metabólico sanguíneo (Tabela 3), com exceção do $\mathrm{pH}$ do sangue, para o qual foi encontrada interação significativa $(P<0,01)$ com as fases de mensuração (Figura 16). Bovinos BR apresentaram maiores concentrações de BICARB, TCO2, BEB, BEECF e mais elevada PCO2 que animais NE durante o estudo; todavia, foi encontrada maior PO2 para bovinos NE. Ainda, animais BR apresentaram maiores $(P<$ $0,05)$ valores de $\mathrm{pH}$ que bovinos $\mathrm{NE}$ na fase de ADAP, no entanto, não foi observada diferença $(P>0,05)$ entre os grupos genéticos nas fases de CRES e TERM.

Foi observado $(P<0,01)$ efeito principal das fases de mensuração sobre a algumas variáveis do perfil metabólico sanguíneo: PO2, BICARB, TCO2 e BEECF (Tabela 3). Maiores concentrações de BICARB, TCO2 e BEECF foram encontradas na fase de CRES em relação as fases de ADAP e TERM, que não apresentaram diferenças entre si. Já para PO2, foi observada maior pressão parcial nos animais na fase de TERM quando comparados as mensurações nas fases de ADAP e CRES.

\subsection{Flutuação da Ingestão de Matéria Seca}

Não foi observado $(P>0,05)$ efeito principal dos aditivos alimentares sobre a IMS4D (Tabela 4), entretanto foi encontrada $(P<0,01)$ interação entre aditivos alimentares, fases e dias de mensuração (Figura 22). Na fase de CRES, animais que receberam MON não apresentaram diferenças $(P>0,05)$ na IMS4D durante os 4 dias de mensuração; por outro lado, bovinos que foram suplementados com PAP mostraram $(P$ $<0,05)$ IMS4D crescentes nos 4 dias de mensuração, apresentando ainda, maiores $(P<$ 0,05) IMS4D que animais suplementados com MON nos dias 3 e 4. Já na fase de TERM, bovinos que receberam MON apresentaram maiores $(P<0,05)$ IMS4D nos dias

3 e 4 quando comparados aos dias 1 e 2 ; no entanto, foi observado maior $(P<0,05)$ IMS4D no dia 3 quando comparado ao 2 para animais suplementados com PAP, os quais apresentaram maior $(P<0,05)$ IMS4D que animais que receberam MON nos dias 1 e 2 .

Não foi observado $(P>0,05)$ efeito principal dos aditivos alimentares sobre a VIMS (Tabela 4), todavia foram observadas interações $(P<0,01)$ entre aditivos alimentares e fase de mensuração (Figura 17) e aditivos alimentares e dias de mensuração (Figura 18). Animais que receberam PAP apresentaram maior $(P<0,01)$ 
VIMS na fase de CRES que animais suplementados com MON; no entanto, não foi observada diferença $(P>0,05)$ entre os aditivos alimentares na fase de TERM. Ainda, em bovinos alimentados com dietas contendo PAP, foi observado $(P<0,01)$ maior VIMS na fase de CRES em relação a fase de TERM. Já para animais suplementados com MON não foi encontrada diferença na VIMS entre as fases de mensuração. Para a interação entre aditivos alimentares e dias de mensuarção, bovinos recebendo PAP apresentaram maior $(P<0,05)$ VIMS no dia 3 em relação aos dias 1,2 e 4 . Já em animais que foram suplementados com MON foi observada maior VIMS no dia 3, porém este só diferiu do dia $4(P<0,05)$. Não foram encontradas diferenças entres os aditivos alimentares no decorrer dos 4 dias de mensuração $(P>0,05)$.

Não foi observado $(P>0,05)$ efeito principal dos grupos genéticos sobre a IMS4D (Tabela 4), entretanto foi encontrada $(P<0,01)$ interação entre grupos genéticos e fases de mensuração (Figura 19); onde ambos os grupos genéticos avaliados apresentaram maiores $(P<0,01)$ IMS4D na fase de TERM quando comparados a fase de CRES. No entanto, foram encontradas maiores $(P<0,01)$ IMS4D tanto na fase de CRES quanto na de TERM para animais BR em relação aos NE. Não foi observado $(P$ $>0,05)$ efeito principal dos grupos genéticos sobre a VIMS (Tabela 4), todavia foram observadas interações $(P<0,01)$ entre grupos genéticos, fase e dias de mensuração (Figura 23). Na fase de CRES, foi encontrado que animais BR apresentaram maior $(P<$ 0,05) VIMS no dia 3 em relação aos dias 1, 2 e 4; por outro lado, bovinos NE mostraram maior $(P<0,05)$ VIMS no dia 3 também, porém este só diferiu do dia 4. Não houve diferença entre os grupos genéticos durante os 4 dias de mensuração na fase de CRES $(P>0,05)$. Já na fase de TERM, bovinos BR apresentaram maior $(P<0,05)$ VIMS no dia 1 quando comparado ao dia 2 apenas; e não foi observada diferenças $(P>$ $0,05)$ na VIMS para animais NE durante os 4 dias de mensuração. Não houve diferença entre os grupos genéticos durante os 4 dias de mensuração na fase de TERM $(P>0,05)$.

Não foi observado $(P>0,05)$ efeito principal das fases e dos dias de mensuração sobre a IMS4D e a VIMS (Tabela 4).

\subsection{Incidências de Rumenites e Abscessos Hepáticos}

Com relação a incidência de rumenites, não foi encontrado efeito principal dos aditivos alimentares, nem interação significativa $(P>0,05)$ entre grupos genéticos e 
aditivos alimentares. No entanto, bovinos NE mostraram maior $(P<0,05)$ incidência de lesões que animais BR (Figura 20).

Com respeito a incidência de abscessos hepáticos, não foi encontrado efeito principal dos aditivos alimentares, nem interação significativa $(P>0,05)$ entre grupos genéticos e aditivos alimentares. No entanto, bovinos BR mostraram maior $(P<0,01)$ incidência de abscessos que animais NE (Figura 21).

\section{DISCUSSÃO}

\subsection{Aditivos Alimentares}

Com relação ao desempenho em confinamento, foram encontrados GPD e CA similares entre animais recebendo PAP e MON (Tabela 2), o que já havia sido reportado por Millen et al. (2007). Da mesma forma, não houve diferenças entre os aditivos alimentares testados, no tocante às incidências de rumenites e abscessos de fígado (Figuras 20 e 21). Millen et al. (2007) constataram menor incidência de lesões ruminais em animais recebendo PAP, quando comparado àqueles suplementados com MON.

Por outro lado, foi observado redução na IMS em animais que foram alimentados com dietas contendo MON (Tabela 2). Menores IMS em bovinos confinados que receberam MON tem sido reportado em vários estudos (Goodrich et al., 1984; Schelling, 1984; Oliveira et al., 2005). Este efeito pode ter sido devido a menor VIMS encontrada para animais que consumiram MON neste estudo, principalmente na fase de CRES (Figura 17 e Figura 22), logo após o período de 28 dias de ADAP. No entanto, após mais 56 dias na fase de CRES, animais que receberam PAP apresentaram similar VIMS na fase de TERM em relação a bovinos que receberam MON, indicando que talvez a suplementação com MON possa promover melhor adaptação a bovinos confinados depois de 28 dias. Em estudo similar a este, Millen et al. (2008b) não encontraram diferenças na VIMS entre bovinos recebendo PAP ou MON. A menor VIMS e consequente reduzida IMS promovida pela suplementação de MON também pode ser devida em parte a alteração do comportamento ingestivo de bovinos confinados. Mariani (2010) reportou que animais suplementados com MON apresentaram maior número de refeições por dia e menor tempo de alimentação por refeição que animais recebendo PAP, indicando que como a IMS por refeição naquele 
estudo era numericamente menor, animais suplementados com MON foram mais vezes ao cocho, parcelando desta forma a quantidade de carboidratos rapidamente fermentáveis que atingia o rúmen. Assim, a taxa de passagem poderia ser diminuída e o aproveitamento dos nutrientes melhorado, reduzindo-se com isso a IMS.

Ainda, a suplementação com MON promoveu maior Ganho de EGS durante o estudo, e diminuiu o AOL final (Tabela 2), o que implicou em menor Ganho de AOL, principalmente na fase de CRES quando comparados a bovinos que consumiram PAP (Figura 2). Provavelmente devido ao fato de o PAP conter anticorpos contra as 3 maiores bactérias proteolíticas do rúmen (Clostridium sticklandii e aminophilum e Peptostreptococcus) a proteólise tenha sido mais reduzida no rúmen de animais que receberam PAP junto com dieta contendo 18,3\% de farelo de soja e 15,6\% de proteína bruta, aumentando a passagem de proteína verdadeira do rúmen para o intestino, o que pode ter colaborado com o maior ganho de AOL na fase de CRES, onde a exigência de PNDR é maior que em fase de terminação. Esses efeitos em relação a deposição de músculos e gordura na carcaça, também podem estar ligados aos efeitos observados com relação a redução da IMS. Acredita-se que a redução na IMS observada com a suplementação de MON esteja relacionada ao provável aumento no aporte de energia promovido pelo ionóforo. O maior aporte de energia, devido ao aumento do propionato disponível, resultante das mudanças na população microbiana ruminal provocada pelo ionóforo, além de contribuir com a diminuição na IMS (Oliveira et al., 2007), pode também antecipar o início mais pronunciado do depósito de gordura na carcaça. Entretanto, apesar de numericamente superior, não foram encontradas diferenças de EGS final e EGP8 final entre animais que consumiram um ou outro aditivo alimentar (Tabela 2). Do mesmo modo, não foram constatados neste estudo efeito negativo do PAP sobre o rendimento de carcaça (Tabela 2), como já reportado anteriormente em outros estudos nos EUA (DiLorenzo et al., 2008) e no Brasil (Pacheco et al., 2008).

Com respeito ao perfil metabólico sanguíneo, bovinos que receberam PAP mostraram melhor tamponamento do sangue em relação a animais que consumiram MON, pois foram encontradas concentrações mais elevadas de BICARB, TCO2, BEECF (Tabela 3) e de pH sanguíneo somente para animais BR (Figura 12). A suplementação com PAP ainda aumentou o pH do sangue e o BEB na fase de ADAP (Figuras 13 e 15), considerada a mais importante no tocante ao desenvolvimento de 
quadros de acidose (Owens et al., 1998). Durante acidose metabólica a produção excessiva de ácidos pode comprometer a capacidade de tamponamento do bicarbonato, já que o mesmo vai para dentro do rúmen, diminuindo o bicarbonato circulante e consequentemente o pH sanguíneo (Brown et al., 2000). Faverdin et al. (1999) mostraram que a concentração de BICARB foi negativamente correlacionada com a concentração de ácidos graxos de cadeia curta no rúmen, no entanto no presente estudo animais suplementados com PAP e MON apresentaram similares GPD e CA. Em estudo similar a este, Millen et al. (2008a) não observaram diferenças entre PAP e MON para o $\mathrm{pH}$ do sangue, BICARB, TCO2, BEB e BEECF quando os animais foram mudados das dietas de adaptação até a de terminação $(58 \% \rightarrow 73 \% \rightarrow 82 \% \rightarrow 85 \%$ de concentrado). No entanto, apesar do melhor tamponamento do sangue promovido pela suplementação de PAP, todos os valores médios encontrados para todas as variáveis respostas analisadas, estão dentro das faixas consideradas normais (vide Tabela 1; capítulo 1), não havendo constatação de acidose metabólica de acordo com Carlson (1997).

\subsection{Grupos Genéticos}

Bovinos BR, apesar de terem apresentado maiores GPD e GPT que animais NE tanto na fase de CRES quanto na de TERM (Figuras 3 e 4), mostraram CA similar a de bovinos NE (Tabela 2). Isso leva a inferir que o maior GPD e GPT observado em animais BR foram devido a maior IMS desses animais, principalmente na fase de TERM em termos de IMSPV (Figura 6). Esses resultados concordam com os obtidos por Cucki (2006) e Euclides Filho et al. (2003), onde animais com maior proporção de sangue zebuíno apresentaram menor IMS que animais que possuíam maior proporção de sangue taurino. Segundo NRC (1996) e Vaz (1999), a seleção genética para ganho de peso em raças européias produziu animais com maior potencial de IMS. Segundo Barbosa (1998), os animais cruzados Zebu $\times$ Europeus, consomem em média 8\% mais que animais de raças zebuínas puras. No presente estudo, animais BR consumiram 6,5\% a mais que bovinos NE, os quais apresentaram 19\% a menos em termos de GPD. Putrino (2002) encontrou GPD em torno de 20\% maior para animais BR em relação a bovinos NE em todas as dietas do período experimental (20, 40, 60 e 80\% de concentrado), corroborando com os dados obtidos no presente estudo. 
Logo, incrementos para ganho de peso implicam em maior consumo de alimentos. Os dados de desempenho desse estudo com respeito aos grupos genéticos concordam com o estudo de Millen (2008). Desse modo, o maior ganho de peso constatado para bovinos BR pode ter levado à maior deposição de tecido adiposo tanto na EGS quanto EGP8 durante o estudo (Figuras 8 e 11), já que não foram encontradas diferenças entre os grupos genéticos no tocante ao Ganho de AOL (Tabela 2). Como resultado, bovinos BR apresentaram maior PCQ e quantidade de GVS (Tabela 2). Entretanto, mesmo com animais NE apresentando menores EGS, EGP8, peso vivo final e PCQ estes mostraram REND similar ao de bovinos BR, o que pode implicar em REND superior ao de animais com alguma proporção de sangue Europeu quando estes forem abatidos na mesma faixa de peso, como já documentado em alguns estudos (Leme et al., 2000; Cucki, 2006).

Com relação ao perfil metabólico sanguíneo, bovinos BR apresentaram maior tamponamento do sangue em relação aos animais NE, pois BR apresentaram maiores concentrações de BEB, BEECF, BICARB, TCO2 e PCO2 (Tabela 3), e ainda, maior pH sanguíneo na fase de ADAP (Figura 16). No entanto, todos os valores médios encontrados para todas as variáveis respostas analisadas, estão dentro das faixas consideradas normais (vide Tabela 1; capítulo 1), não havendo constatação de acidose metabólica entre os grupos genéticos de acordo com Carlson (1997). Esse desequilíbrio no sangue pode ser um reflexo de uma mobilização progressiva de reservas corporais alcalinas (bases e BICARB) e com isso um tempo maior é requerido para restabelecer essas reservas no sangue quando comparado ao rúmen. Dietas de alto teor de concentrado reduzem a chegada de saliva ao rúmen e, portanto o BICARB do sangue entra para o ambiente ruminal (Counotte et al., 1981), fazendo assim com que a concentração sanguínea de BICARB, e consequentemente o poder tampão do sangue, sejam reduzidos. Desta maneira, a maior incidência de rumenites em animais NE (Figura 20), e consequentemente maior acidificação ruminal, pode ter refletido no perfil metabólico sanguíneo, exaurindo uma parte do BICARB da circulação desses animais em comparação com bovinos BR. A maior incidência de lesões no rúmen em bovinos NE pode, também, ter colaborado para a redução do GPD desses animais durante o estudo. Millen et al. (2007) já haviam relatado que animais NE apresentaram maior 
incidência de rumenites quando comparados a bovinos com algum grau de genótipo europeu, como o Canchim e o Tri-Cross ( $1 / 2 \mathrm{BR}, 1 / 4 \mathrm{NE}, 1 / 4$ Angus).

Por outro lado, mesmo apresentando menor incidência de rumenites e melhor perfil metabólico sanguíneo que bovinos NE, animais BR mostraram maior incidência de abscessos de fígado (Figura 21) e maior VIMS tanto na fase de CRES quanto na de TERM (Figura 23). Mariani (2010) relataram maior IMS por refeição em bovinos BR quando comparados à animais NE, porém sem diferenças entre os grupos genéticos em relação ao número de refeições por dia; o que pode explicar tanto a maior IMS quanto a maior VIMS em bovinos BR no presente estudo. No entanto, Schwartzkopf-Genswein et al. (2004) inferiram que VIMS iguais ou menores que $10 \%$ provavelmente não acarretariam em nenhuma conseqüência negativa para o desempenho de bovinos confinados, corroborando com os presentes resultados, em que todas as médias mostradas apresentaram variações menores que $10 \%$, mesmo se adotando manejo de sobras de 3\%, o que poderia favorecer maiores VIMS quando comparados ao manejo de cocho limpo (Erickson et al., 2003).

Os abscessos hepáticos ocorrem esporadicamente nos ruminantes, especialmente no gado alimentado com dietas contendo altos níveis de concentrado. Pode ocorrer em todas as idades e em todos os tipos de gado, incluindo leiteiro, porém tem seu maior impacto econômico no gado de corte confinado, no qual a incidência vai de $2 \%$ até 90 ou 95\%, apresentando médias de 20 a 30\% na maior parte dos animais confinados nos EUA (Nagaraja et al., 1996), sendo a maior causa de condenação do fígado. No entanto no presente estudo, animais BR, os quais apresentaram maior incidência de abscessos hepáticos foram os que tiveram menor incidência de lesões ruminais; o que pode ser explicado pelo fato da bactéria Fusobacterium necrophorum, maior responsável pela formação dos abscessos, ser encontrada normalmente no ambiente e poder atingir o fígado não apenas por lesões na parede ruminal mas também por via respiratória (Vechiato, 2009). Talvez um fator ainda não claro ou algum fator genético ligado a animais compostos por genótipos Bos taurus possa ser responsável por essa maior incidência de abscessos de fígado em animais BR, mesmo com estes apresentando menor incidência de rumenites.

\subsection{Fases de Mensuração}


Como já era esperado, os animais do presente estudo apresentaram melhor CA na fase de CRES quando comparado à fase de TERM (Tabela 2). Isso ocorre devido à deposição mais acentuada de gordura na carcaça na fase de TERM, onde os animais receberam a dieta mais energética ( $85 \%$ de concentrado), fazendo com que a energia de mantença aumente e a composição do ganho seja na sua maior parte composta por tecido adiposo, o que reduz o GPD e, consequentemente, aumenta a CA (Owens et al., 1993).

Em relação ao perfil metabólico sanguíneo, foram encontrados maiores concentrações de BICARB, TCO2 e BEECF na fase de CRES em relação as fases de ADAP e TERM (Tabela 2). Como as amostras foram coletadas 15 dias após o início de cada fase, pode-se inferir que na fase CRES, depois de 43 dias de alimentação (28 na ADAP + 15 no CRES), os animais já estavam totalmente adaptados a dieta, o que não aconteceu depois de 15 dias na fase de ADAP. Com respeito a fase de TERM, o maior aporte energético (15\% a mais de energia líquida de ganho com relação a fase de CRES), pode ter colaborado para a redução do BICARB, TCO2 e BEECF, já que dietas mais energéticas reduzem a chegada de saliva ao rúmen e, portanto, o BICARB do sangue entra para o ambiente ruminal (Counotte et al., 1981), o que faz com que a concentração sanguínea de BICARB e, consequentemente, o poder tampão do sangue, sejam reduzidos. Goad et al. (1998) constataram redução marcante no BICARB sanguíneo em novilhos alimentados com dietas contendo mais de $80 \%$ de concentrado.

\section{CONCLUSÕES}

A suplementação do preparado de anticorpos policlonais pode ser uma alternativa à monensina sódica, já que bovinos que consumiram o produto que continha anticorpos policlonais no presente estudo apresentaram desempenho similar àqueles que receberam monensina sódica sem afetar negativamente as características de carcaça. Animais suplementados com o preparado de anticorpos policlonais mostraram melhor tamponamento sanguíneo quando estes foram alimentados com dietas de alta energia.

Animais Brangus desempenham melhor em confinamento que animais Nelore, apresentando maior ganho de peso diário e carcaças com maior deposição de gordura subcutânea e de garupa. A menor incidência de rumenites e o melhor tamponamento do 
sangue podem ter colaborado para a maior ingestão de matéria seca e, consequentemente, maior ganho de peso diário apresentado por bovinos Brangus.

\section{REFERÊNCIAS BIBLIOGRÁFICAS}

ASSOCIATION OF OFFICIAL ANALYTICAL CHEMISTS - AOAC. Offical methods of analyses. 16 ed. Washington, D.C. 1997. 1141p.

BARBOSA, P.F. Cruzamentos industriais e a produção de novilhos precoces. In: Simpósio sobre produção intensiva de gado de corte. CYRINO, J.E.P.; MENTEN, J.F.M.; LANNA, D.P.D. et al. (Eds.). Colégio Brasileiro de Nutrição Animal. p.100 - 114. 1998.

BEAUCHEMIN, K.A.; YANG, W.Z.; MORGAVI, D.P. et al. Effects of bacterial direct-fed microbials and yeast on site and extent of digestion, blood chemistry, and subclinical ruminal acidosis in feedlot cattle. Journal of Animal Science, v.81, p.1628-1640, 2003.

BEEFPOINT. Ponto de Encontro da Cadeia da Carne. Notícias. 2010. Disponível em:

http://www.beefpoint.com.br/?noticiaID=59748\&actA=7\&areaID=15\&secaD=16. Acesso em 17/01/2010.

BEVANS, D.W.; BEAUCHEMIN, K.A; SCHWARTZKOPF-GENSWEIN, K.S. et al. Effect of rapid or gradual grain adaptation on subacute acidosis and feed intake by feedlot cattle. Journal of Animal Science, v.83, p.1116 - 1132, 2005.

BIGHAM, M.L.; McMANUS, W.R. Whole Wheat Grain Feeding of Lambs. Effects of Roughage and Wheat Grain Mixtures. Australian Journal of Agricultural Research, v.26, p.1053-1062, 1975.

BLANCH, M.; CALSAMIGLIA, S.; DILORENZO, N. et al. Physiological changes in rumen fermentation during acidosis induction and its control using a multivalent polyclonal antibody preparation in heifers. Journal of Animal Science, v.87, p.1722-1730, 2009. 
BRINK, D.R.; LOWRY, S.R.; STOCK, R.A. et al. Severity of liver abscesses and efficiency of feed utilization of feedlot cattle. Journal of Animal Science, v.68, p.1201-1207, 1990.

BROSSARD, L.; MARTIN, C.; MICHALET-DOREAU, B. et al. Ruminal fermentative parameters and blood acido-basic balance changes during the onset and recovery of induced latent acidosis in sheep. Animal Research, v.52, p. 513-530, CINRA, EDP Sciences, 2003.

BROWN, M. S.; KREHBIEL C. R.; GALYEAN M. L. et al. Evaluation of models of acute and subacute acidosis on dry matter intake, ruminal fermentation, blood chemistry, and endocrine profiles of beef steers. Journal of Animal Science, 78:3155-3168, 2000.

CARLSON, G.P. Fluid, Electrolyte and Acid-Base Balance. In: KANEKO, J.J. (Ed.) Clinical biochemistry of domestic animals. 5.ed. New York: Academic Press. p.485-516, 1997.

CNCPS - Cornell Net Carbohydrate and Protein System. The net carbohydrate and protein system for evaluating herd nutrition and nutrients excretion. Version 5.0. Ithaca, NY. p.237, 2000.

COUNOTTE G.H.M.; PRINS R.A.; JANSSEN R.H.A. et al. Role of Megasphaera elsdenii in the fermentation of DL-[2-13C] lactate in the rumen of dairy cattle, Applied Environmental Microbiology, 42: 649-655, 1981.

CUCKI, T. O. A eficiência do sistema superprecoce com bovinos de diferentes proporções do genótipo Bos indicus. Botucatu: Universidade Estadual Paulista, 2006. p.99. Tese (Doutorado em Zootecnia) - Universidade Estadual Paulista, 2006.

DILORENZO, N. Effects of feeding polyclonal antibody preparations against rumen starch and lactic-fermenting bacteria on target bacteria populations and steer performance. Saint Paul, Minnesota, USA: University of Minnesota, 2004 , p. 101. Master thesis submitted to the faculty of the graduate school of the University of Minnesota, 2004. 
DILORENZO, N.; DIEZ-GONZALEZ, F.; DICOSTANZO, A. et al. Effects of feeding polyclonal antibody preparations on ruminal bacterial populations and ruminal $\mathrm{pH}$ of steers fed high-grain diets. Journal of Animal Science, v.84, p.2178-2185, 2006.

DILORENZO, N.; DAHLEN, C. R.; DIEZ-GONZALEZ, F. et al. Effects of feeding polyclonal antibodies preparations on rumen fermentation patterns, performance, and carcass characteristics of feedlot steers. Journal of Animal Science, v.86, p.3023-3032, 2008.

ERICKSON, G. E.; MILTON, C. T.; FANING, K. C. et al. Interaction between bunk management and monensin concentration during an acidosis challenge with feedlot cattle. Journal of Animal Science, v.81, p.2869-2879, 2003.

EUCLIDES FILHO, K.; FIGUEIREDO, G.R.; EUCLIDES, V.P.B. et al. Desempenho de diferentes grupos genéticos de bovinos de corte em confinamento. Revista Brasileira de Zootecnia, v.32, n.5, p.1114 - 1122, 2003.

FAVERDIN, P; BAREILLE, N. et al. Lipostatic regulation of feed intake in ruminants. In: HEIDE, D. et al. (Eds). Regulation of feed intake. CAB International, p.82 $102,1999$.

GILL, H.S.; SHU, Q.; LENG, R.A. et al. Immunization with Streptococcus bovis protects against lactic acidosis in sheep. Vaccine, v.18, p.2541-2548, 2000.

GOAD, D. W.; GOAD, C. L.; NAGARAJA, T. G. Ruminal microbial and fermentative changes associated with experimentally induced subacute acidosis in steers. Journal of Animal Science, 76:234-241, 1998.

GOERING, H.K., VAN SOEST, P.J. Forage fiber analysis. Agriculture Handbook, Agricultural Research Service. Washington D.C., 1970, 19 p.

GOODRICH, R. D.; GARRETT, J. E.; GAST, D. R. et al. Influence of monensin on the performance of cattle. Journal of Animal Science, v.58, n.6, p.1484-1498, 1984.

LEME, P.R.; BOIN, C.; MARGARIDO, R. C. C. et al. Desempenho em confinamento e características de carcaça de bovinos machos de diferentes cruzamentos abatidos em três faixas de peso. Revista Brasileira de Zootecnia, v.29, n.6, supl.2, p.2347 $-2353,2000$. 
MARIANI, T. M. Suplementação de Anticorpos Policlonais ou Monensina Sódica sobre o Comportamento Ingestivo e Desempenho de Bovinos Brangus e Nelore Confinados. Dissertação (Programa de Pós-Graduação em Zootecnia), Universidade Estadual Paulista Júlio de Mesquita Filho, UNESP. Botucatu. 90p., 2010.

MILLEN, D.D.; PACHECO, R.D.L.; ARRIGONI, M.D.B. et al. Feedlot performance and rumen parakeratosis incidence in Bos indicus type bullocks fed high grain diets and monensin or polyclonal antibodies preparations against rumen bacteria. Journal of Animal Science, v.85, E-Suppl.1, p.552, 2007.

MILLEN, D. D. Desempenho, avaliação ruminal e perfil metabólico sanguíneo de bovinos jovens confinados suplementados com monensina sódica ou anticorpos policlonais. Botucatu: Universidade Estadual Paulista, 2008. Tese (Mestrado em Zootecnia) - Universidade Estadual Paulista, 2008.

MILLEN, D. D.; PACHECO, R. D. L.; ARRIGONI, M. D. B. et al. Blood metabolic profile of feedlot cattle supplemented with monensin or polyclonal antibodies preparations against lactate-producing rumen bacteria during diet step-up. Journal of Animal Science, v.86, (E-suppl.2), p.285, 2008a.

MILLEN, D. D.; PACHECO, R. D. L.; ARRIGONI, M. D. B. et al. Intake fluctuations of feedlot cattle supplemented with monensin or polyclonal antibodies preparations against lactate-producing rumen bacteria during diet step-up. Journal of Animal Science, v.86, (E-supp1.2), p.285, 2008b.

MILlEN, D. D.; PACHECO, R D. L.; ARRIGONI, M. D. B. et al. A snapshot of management practices and nutritional recommendations used by feedlot nutritionists in Brazil. Journal of Animal Science, v.87, p.3427-3439, 2009.

NAGARAJA T. G.; LAUDERT, S. B.; PARROTT, J. C. et al. Liver abscesses in feedlot cattle. Part 1. Causes, pathogenesis, pathology, and diagnosis. Compendium on Continuing Education of Practicing Veterinarian, v.18, p.S230-273, 1996.

NEWBOLD, C.J.; STEWART, C.S.; WALLACE, R.J. et al. Developments in rumen fermentation - The scientist's view. In Recent Advances in Animal Nutrition 
2001. P. C. Garnsworthy and J. Wiseman ed. Nottingham University Press, Nottingham, United Kingdom, p. 251-279, 2001.

NATIONAL RESEARCH COUNCIL. Nutrient requirements of beef cattle. 7.ed. Washington: National Academy Press, 1996. 234p.

OJEU. Official Journal of the European Union. Regulation (EC) No 1831/2003 of the European Parliament and the Council of 22 of September of 2003 on Additives for Use in Animal Nutrition. Pages L268/29-L268/43 in OJEU of 10/18/2003.

OLIVEIRA, M. V. M.; LANA, R. P.; JHAM, G. N. et al. Influência da monensina no consumo e na fermentação ruminal em bovinos recebendo dietas com teores baixo e alto de proteína. Revista Brasileira de Zootecnia, v.34, n.5, p.1763-1774, 2005.

OLIVEIRA, M. V. M.; LANA, R. P.; EIFERT, E. C. et al. Influência da monensina sódica no consumo e na digestibilidade de dietas com diferentes teores de proteína para ovinos. Revista Brasileira de Zootecnia, v.36, n.3, p.643-651, 2007.

OWENS, F. N.; DUBESKI, P.; HANSON, C. F. Factors that alter the growth and development in ruminants. Journal of Animal Science, v.71, p.31 - 38, 1993.

OWENS, F. N.; SECRIST, D. S.; HILL, W. J. et al. Acidosis in cattle: A review. Journal of Animal Science, v.76, p. 275-286, 1998.

PACHECO, R. D. L.; MILLEN, D. D.; CUNHA LEME, T. M. et al. Evaluation of growth, carcass characteristics and meat tenderness of bullocks fed monensin or polyclonal antibodies against lactate-producing rumen bacteria. Journal of Animal Science, v.86 (E-suppl.2), p.200, 2008.

PERKINS, T.L. et al. The use of real time, linear array ultrasound techniques to predict final carcass composition in beef cattle. Ames: Texas Tech University, 1992.

PUTRINO, S. M. Exigências de proteína e energia líquidas para o ganho de peso de tourinhos das raças Nelore e Brangus alimentados com dietas com diferentes proporções de concentrado. Pirassununga: Universidade de São Paulo, 2002. p.82. Dissertação (Mestrado em Zootecnia) - Universidade de São Paulo, USP, 2002. 
SAS. SAS User's Guide: Statistics (Version 5 Ed.). SAS Inst. Inc., Cary, NC, 2003.

SCHELling, G. T. Monensin: mode of action in the rumen. Journal of Animal Science, v.58, n.6, p.1518-1527, 1984.

SCHWARTZKOPF-GENSWEIN, K. S.; BEAUCHEMIN, K. A.; MCALLISTER, T. A. et al. Effect of feed delivery fluctuations and feeding time on ruminal acidosis, growth performance, and feeding behavior of feedlot cattle. Journal of Animal Science, v.82, p.3357-3365, 2004.

VAZ, F.N. Cruzamento alternado das raças Charolês e Nelore: características da carcaça e da carne de novilhos abatidos aos dois anos. Santa Maria: Universidade Federal de Santa Maria, 1999. Dissertação (Mestrado em Zootecnia) - Universidade Federal de Santa Maria, 1999.

VECHIATO, T. A. F. Estudo retrospectivo e prospectivo da presença de abscessos hepáticos em bovinos abatidos em um frigorífico paulista. São Paulo: Universidade de São Paulo, 2009. Dissertação (Mestrado em Clínica Veterinária) - Universidade de São Paulo, 2009.

SHU, Q.; GILL, H.S.; LENG, J.B. et al. Immunization with a Streptococcus bovis vaccine administered by different routes against lactic acidosis in sheep. The Veterinary Journal, v.159, p.262-269, 2000.

SHU, Q.; GILL, H.S.; HENNESSY, D.W. et al. Immunization against lactic acidosis in cattle. Research of Veterinary Science, v.67, p.65-71, 1999. 
Tabela 1. Níveis de inclusão dos ingredientes e conteúdo nutricional das dietas experimentais fornecidas durante o estudo.

\begin{tabular}{lccc}
\hline \hline & \multicolumn{3}{c}{ Nível de Concentrado } \\
\cline { 2 - 4 } Ítem & $55 \%$ & $70 \%$ & $85 \%$ \\
\hline Fases & ADAP & CRES & TERM \\
Dias de Alimentação & 28 & 56 & 56 \\
Ingredientes, \% da MS & & & \\
Feno de Coast Cross & 16,40 & 3,30 & 5,70 \\
Bagaço de Cana Cru & 28,40 & 26,70 & 9,40 \\
Silagem de Grãos Úmidos de Milho & 16,40 & 19,60 & 31,90 \\
Grãos de Milho Seco Quebrados & 10,40 & 15,60 & 8,40 \\
Polpa Cítrica & 9,00 & 15,00 & 32,40 \\
Farelo de Soja & 17,90 & 18,30 & 10,50 \\
Suplemento Mineral com 30\% de Uréia ${ }^{1}$ & 1,50 & 1,50 & 1,70 \\
Conteúdo Nutricional, \% de MS & & & \\
MS (\% da Matéria Natural) & 74,00 & 73,00 & 71,00 \\
NDT ${ }^{2}$ & 69,00 & 72,00 & 78,00 \\
Elg ${ }^{3,5}$ Mcal/kg de MS & 0,99 & 1,08 & 1,24 \\
Carboidratos não fibrosos ${ }^{4}$ & 42,20 & 47,00 & 58,60 \\
Proteína Bruta & 16,80 & 15,60 & 13,20 \\
Proteína Degradável no Rúmen (PDR) ${ }^{5}$ & 72,00 & 75,00 & 76,00 \\
Extrato Etéreo & 3,30 & 3,60 & 3,80 \\
FDN & 36,40 & 30,20 & 20,40 \\
Cálcio & 0,46 & 0,54 & 0,89 \\
Fósforo & 0,34 & 0,35 & 0,32 \\
\hline Suplems
\end{tabular}

${ }^{1}$ Suplemento continha $30 \%$ de uréia, $26,7 \%$ de Ca; $5,3 \%$ de $\mathrm{P} ; 10,9 \%$ de Na; $1,5 \%$ de S; 2600 ppm de Zn; 1300 ppm de Mn; 1032 ppm de Cu; 45,0 ppm de I; 15,0 ppm de Se; 154 ppm de $\mathrm{Cu}$ e 2500 ppm de Fe.

${ }^{2}$ Nutrientes Digestíveis Totais.

${ }^{3}$ Energia Liquida para ganho.

${ }^{4} \mathrm{CNF}=100-($ Proteína bruta + Extrato etéreo + FDN + Cinzas $)$.

${ }^{5}$ Estimado segundo equações do CNCPS (2000), nível 2. 
ลิ

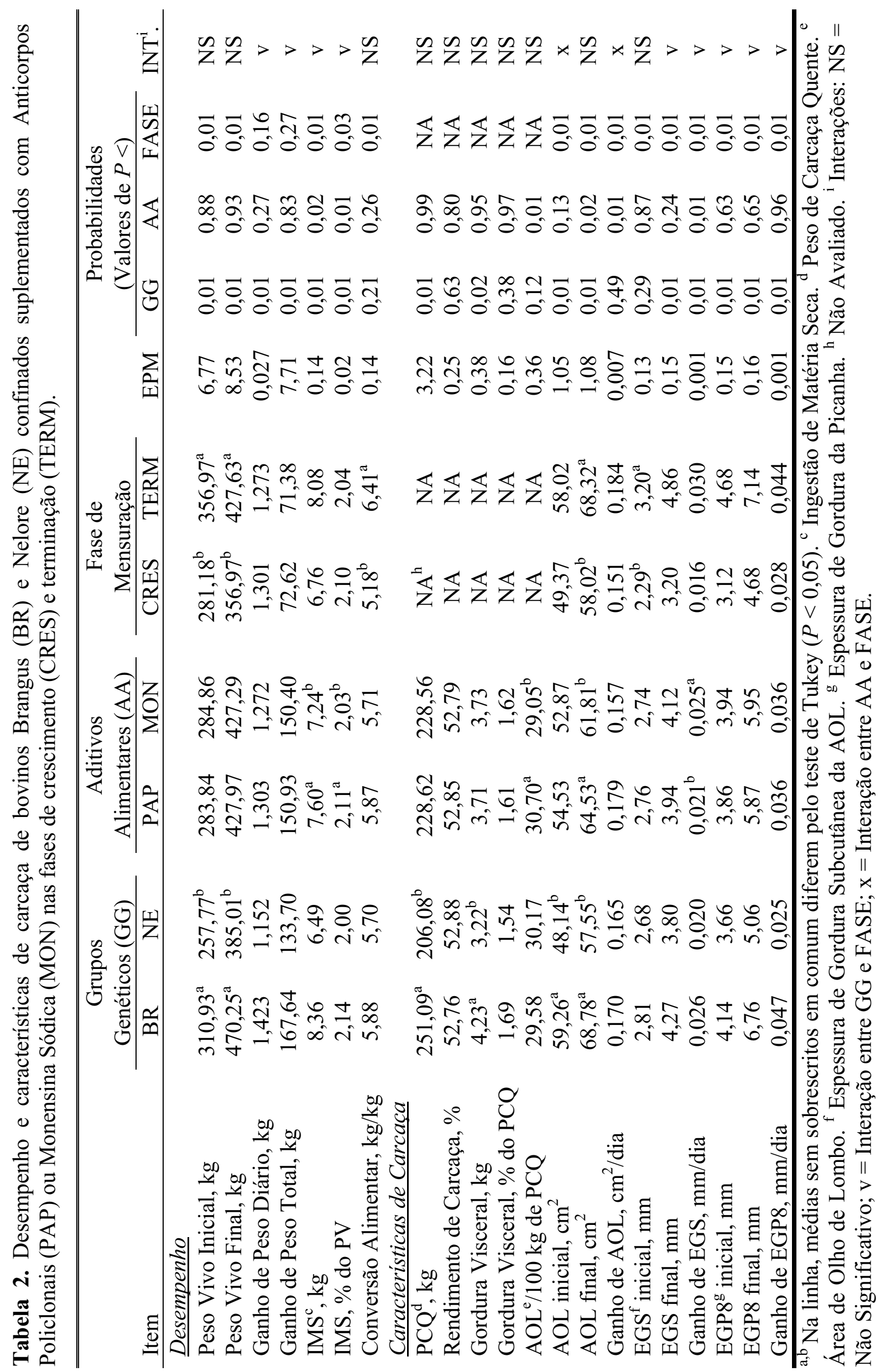




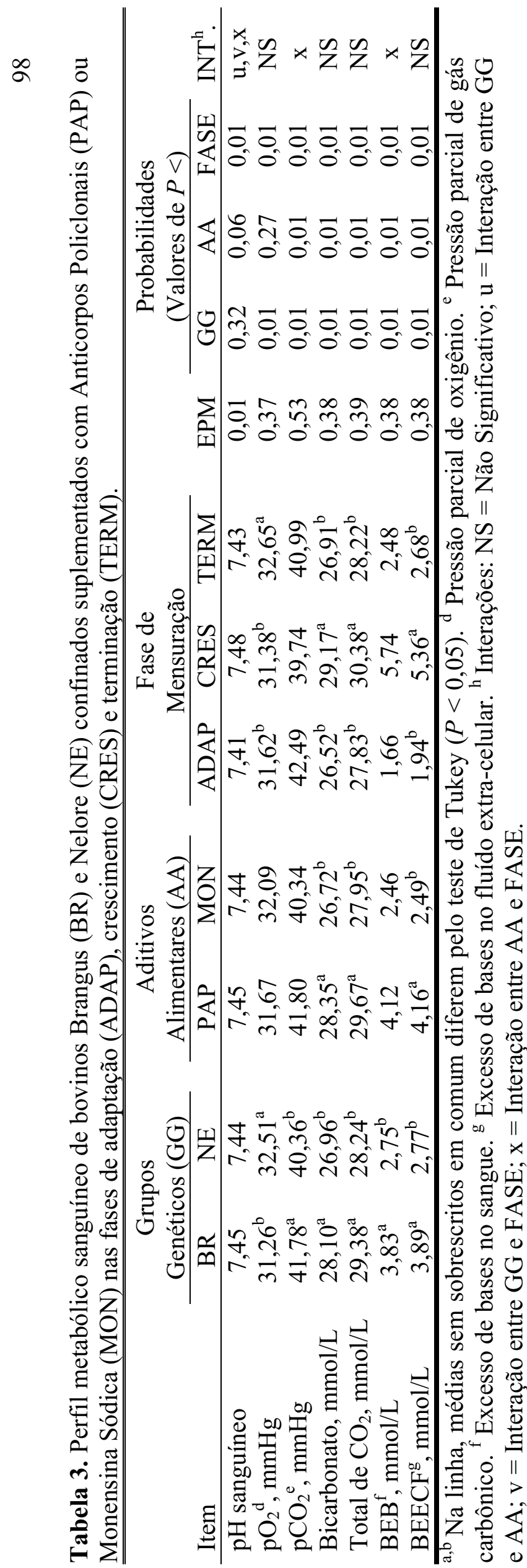


Tabela 4. Flutuação da ingestão de matéria seca de bovinos Brangus (BR) e Nelore (NE) confinados suplementados com Anticorpos Policlonais (PAP) ou Monensina Sódica (MON) nos quatro primeiros dias das fases de crescimento (CRES) e terminação (TERM).

\begin{tabular}{|c|c|c|c|c|}
\hline Item & IMS, $\mathrm{kg}$ & EPM & $\begin{array}{c}\text { Variação da } \\
\text { IMS, kg }\end{array}$ & EPM \\
\hline \multicolumn{5}{|c|}{ Grupos Genéticos $(G G)$} \\
\hline $\mathrm{BR}$ & 7,647 & 0,070 & 0,266 & 0,019 \\
\hline $\mathrm{NE}$ & 6,231 & 0,075 & 0,292 & 0,019 \\
\hline \multicolumn{5}{|c|}{ Aditivos Alimentares (AA) } \\
\hline PAP & 7,141 & 0,069 & 0,288 & 0,021 \\
\hline MON & 6,736 & 0,075 & 0,270 & 0,017 \\
\hline \multicolumn{5}{|c|}{ Fase de Mensuração } \\
\hline CRES & 6,112 & 0,070 & 0,291 & 0,015 \\
\hline TERM & 7,765 & 0,087 & 0,268 & 0,021 \\
\hline \multicolumn{5}{|c|}{ Dias de Mensuração } \\
\hline 1 & 6,699 & 0,057 & 0,253 & 0,024 \\
\hline 2 & 6,825 & 0,057 & 0,247 & 0,024 \\
\hline 3 & 7,073 & 0,057 & 0,380 & 0,024 \\
\hline 4 & 7,158 & 0,057 & 0,237 & 0,024 \\
\hline \multicolumn{5}{|c|}{ Probabilidades (Valores de $P<$ ) } \\
\hline $\mathrm{GG}$ & 0,01 & - & 0,38 & - \\
\hline $\mathrm{AA}$ & 0,01 & - & 0,32 & - \\
\hline FASE & 0,01 & - & 0,28 & - \\
\hline DIAS & 0,01 & - & 0,01 & - \\
\hline INTERAÇÕES $^{\mathrm{d}}$ & $\mathrm{v}, \mathrm{z}$ & - & $\mathrm{x}, \mathrm{y}, \mathrm{w}$ & - \\
\hline
\end{tabular}




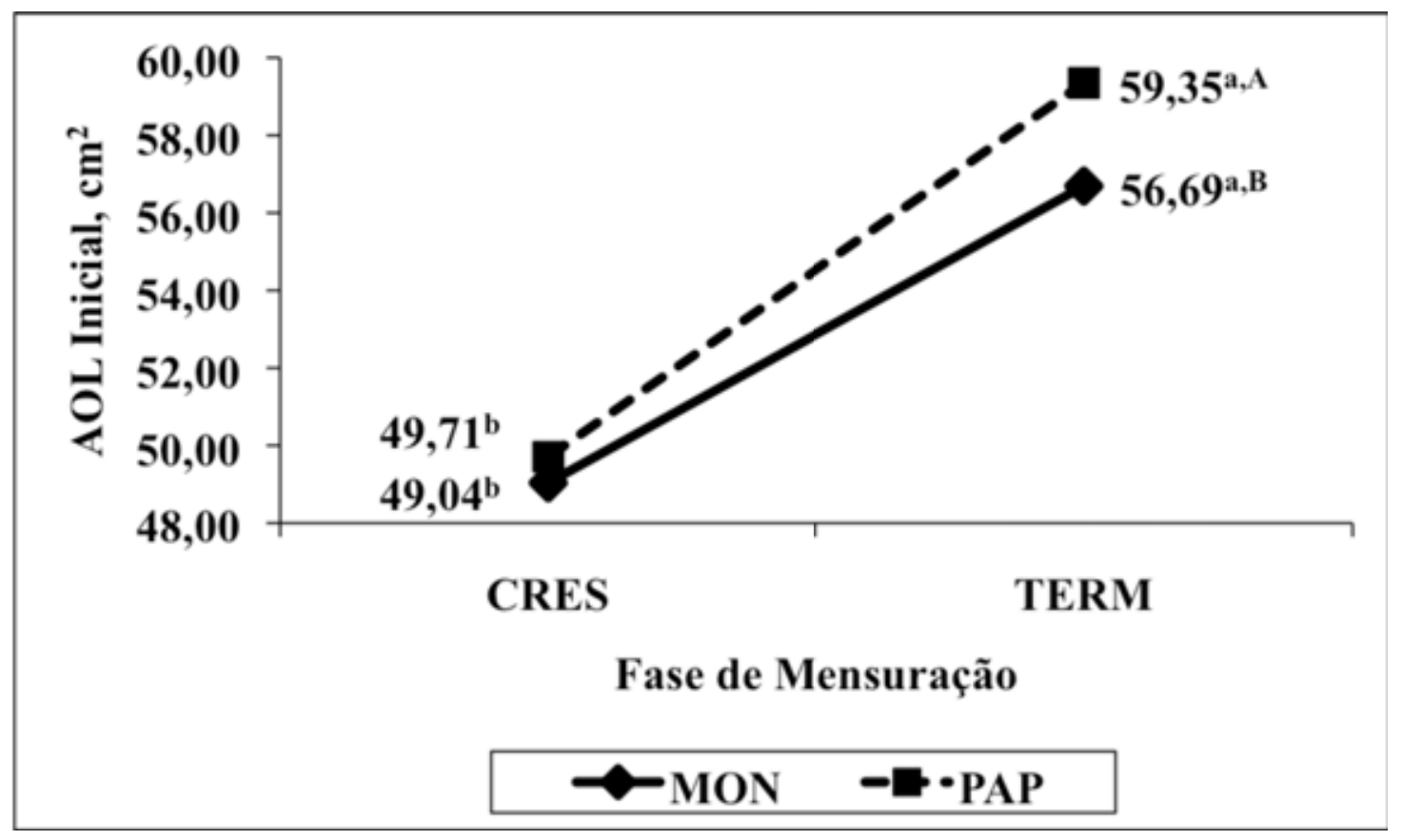

Figura 1. Área de Olho de Lombo (AOL) Inicial dos animais que receberam o Preparado de Anticorpos Policlonais (PAP) ou Monensina Sódica (MON) nas distintas Fases de Mensuração: crescimento (CRES) e terminação (TERM). Foi encontrada interação significativa $(P<0,01)$ entre Aditivos Alimentares e Fases de Mensuração. ${ }^{\mathrm{a}, \mathrm{b}}$ $\mathrm{Na}$ linha, médias sem sobrescritos em comum, diferem $(P<0,01)$. ${ }^{\mathrm{A}, \mathrm{B}} \mathrm{Na}$ coluna, médias sem sobrescritos em comum, diferem $(P<0,05)$. 


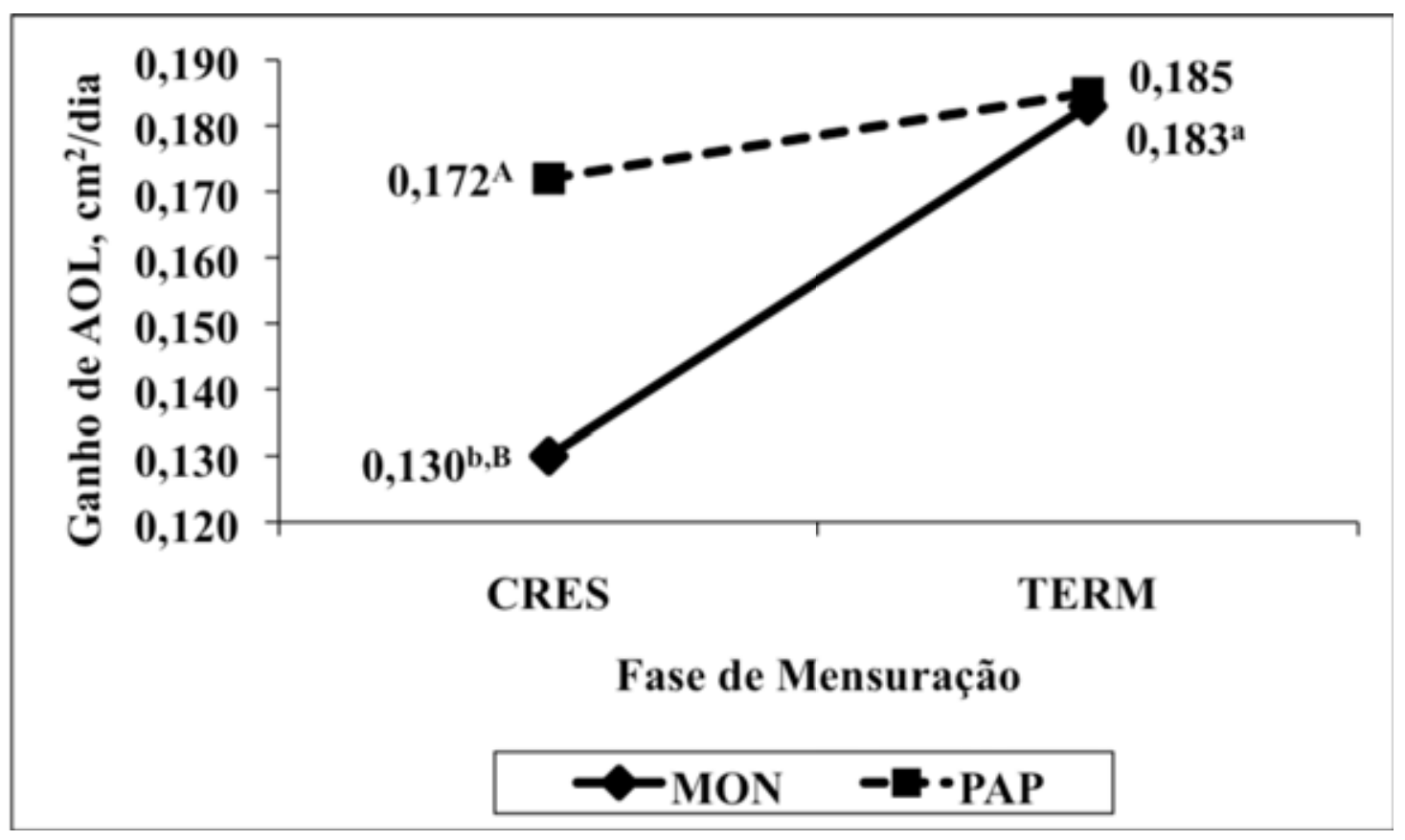

Figura 2. Ganho de Área de Olho de Lombo (AOL) dos animais que receberam o Preparado de Anticorpos Policlonais (PAP) ou Monensina Sódica (MON) nas distintas Fases de Mensuração: crescimento (CRES) e terminação (TERM). Foi encontrada interação significativa $(P<0,05)$ entre Aditivos Alimentares e Fases de Mensuração. ${ }^{\text {a,b }}$ $\mathrm{Na}$ linha, médias sem sobrescritos em comum, diferem $(P<0,01)$. ${ }^{\mathrm{A}, \mathrm{B}} \mathrm{Na}$ coluna, médias sem sobrescritos em comum, diferem $(P<0,01)$. 


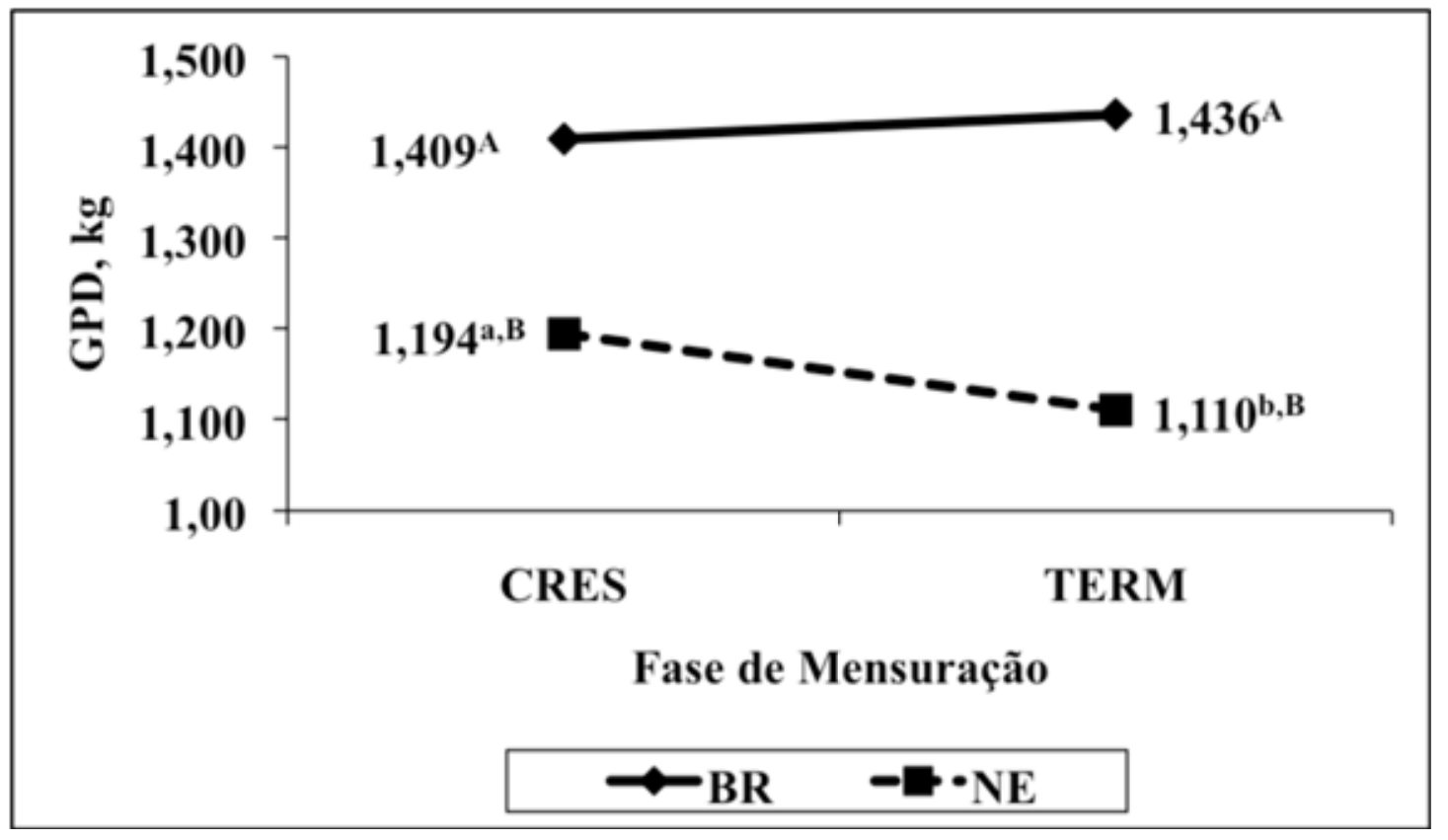

Figura 3. Ganho de peso diário (GPD) dos Grupos Genéticos Brangus (BR) e Nelore (NE) nas distintas Fases de Mensuração: crescimento (CRES) e terminação (TERM). Foi encontrada interação significativa $(P<0,01)$ entre Grupos Genéticos e Fases de Mensuração. ${ }^{\text {a,b }} \mathrm{Na}$ linha, médias sem sobrescritos em comum, diferem $(P<0,01)$. ${ }^{\text {A,B }}$ Na coluna, médias sem sobrescritos em comum, diferem $(P<0,01)$. 


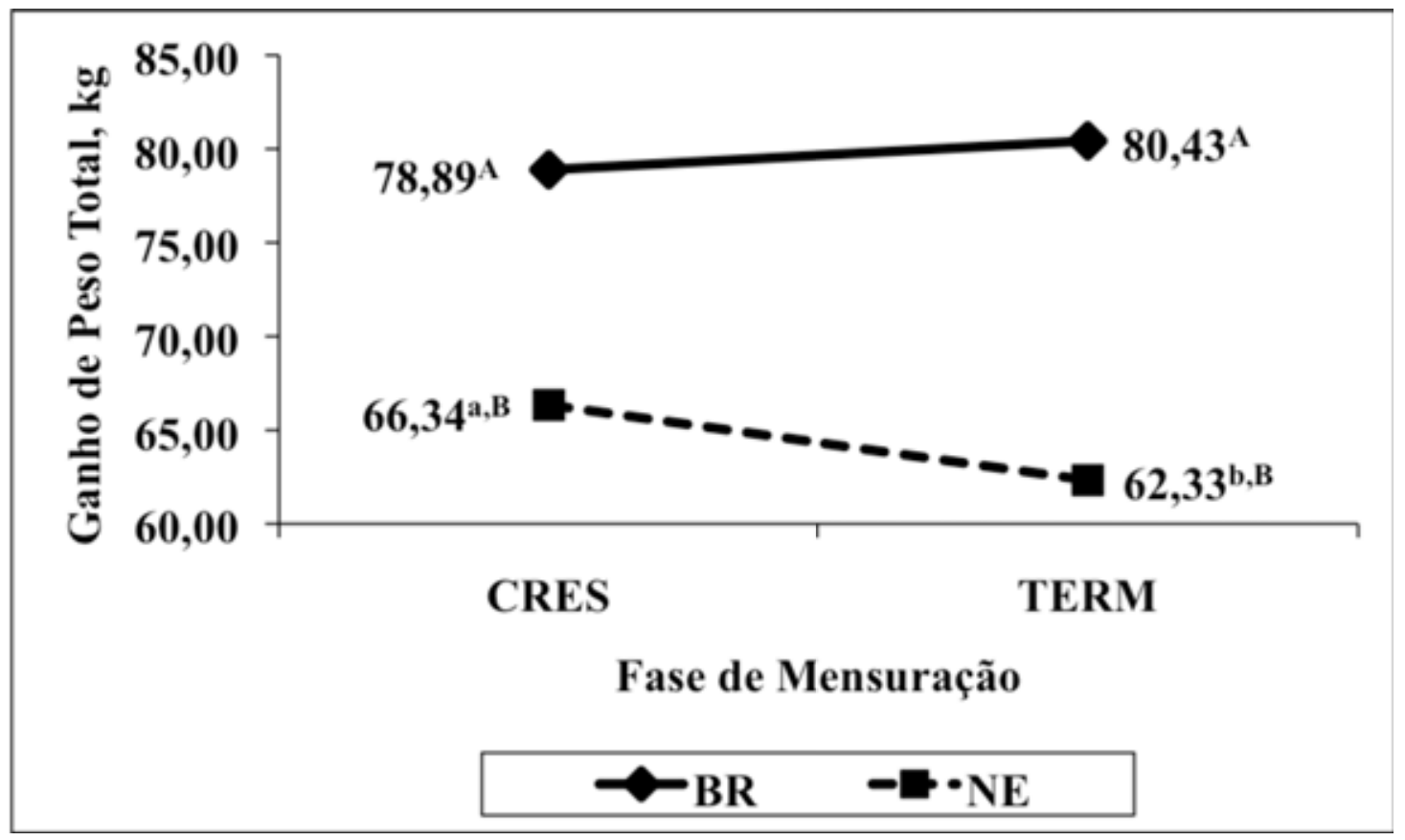

Figura 4. Ganho de Peso Total dos Grupos Genéticos Brangus (BR) e Nelore (NE) nas distintas Fases de Mensuração: crescimento (CRES) e terminação (TERM). Foi encontrada interação significativa $(P<0,05)$ entre Grupos Genéticos e Fases de Mensuração. ${ }^{\mathrm{a}, \mathrm{b}} \mathrm{Na}$ linha, médias sem sobrescritos em comum, diferem $(P<0,01)$. ${ }^{\mathrm{A}, \mathrm{B}}$ Na coluna, médias sem sobrescritos em comum, diferem $(P<0,01)$. 


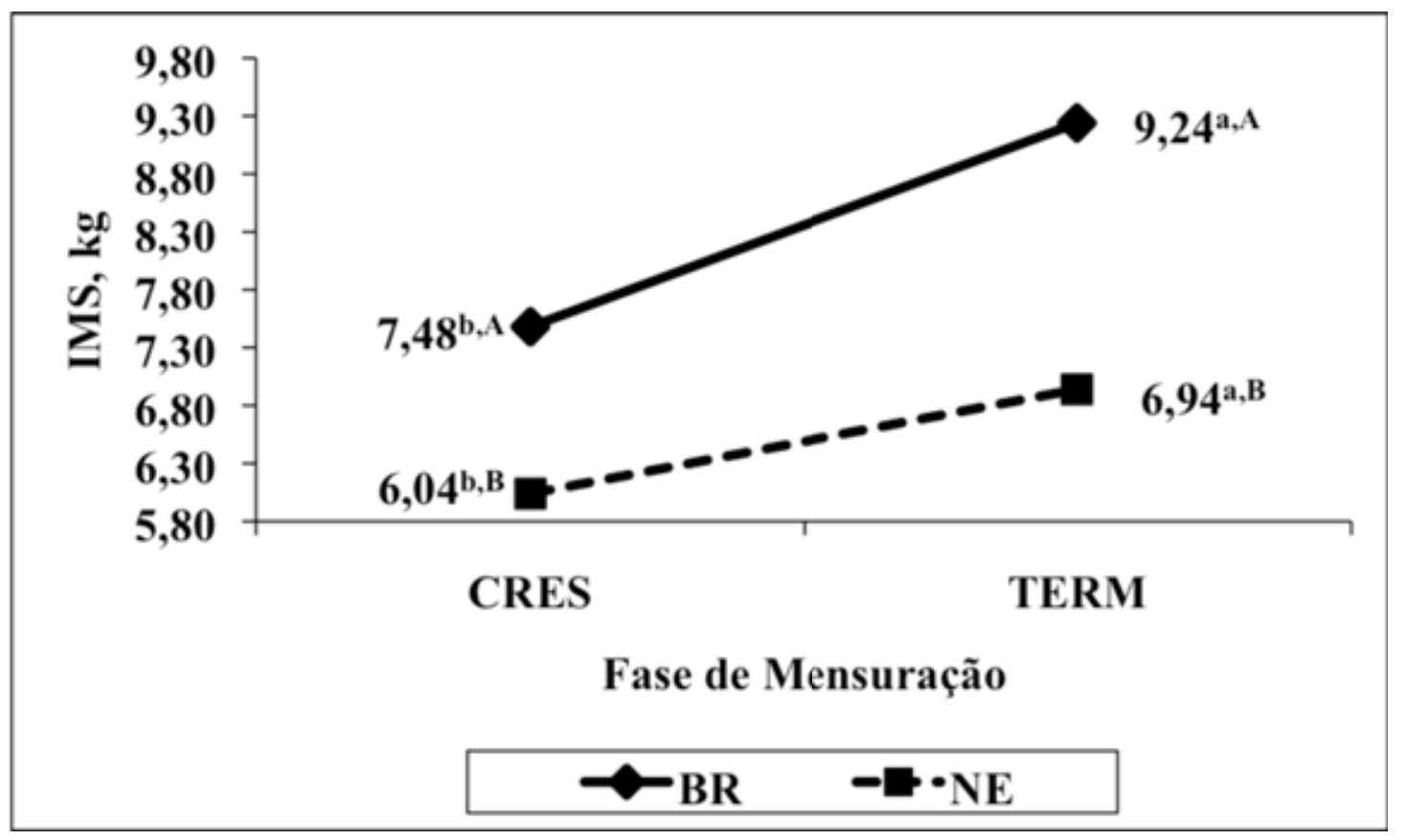

Figura 5. Ingestão de Matéria Seca (IMS) dos Grupos Genéticos Brangus (BR) e Nelore (NE) nas distintas Fases de Mensuração: crescimento (CRES) e terminação (TERM). Foi encontrada interação significativa $(P<0,01)$ entre Grupos Genéticos e Fases de Mensuração. ${ }^{\text {a,b }} \mathrm{Na}$ linha, médias sem sobrescritos em comum, diferem $(P<$ $0,01) .{ }^{\mathrm{A}, \mathrm{B}} \mathrm{Na}$ coluna, médias sem sobrescritos em comum, diferem $(P<0,01)$. 


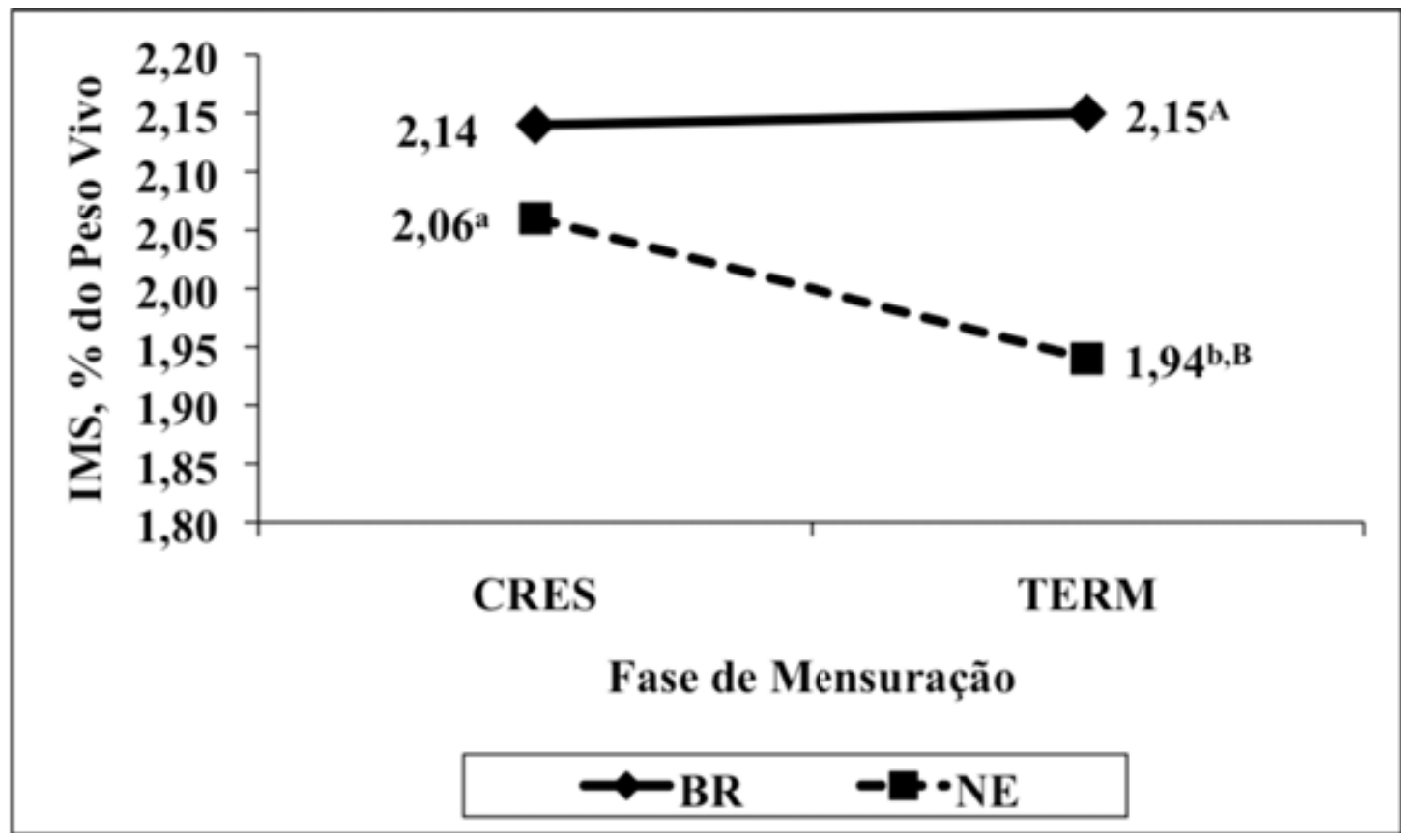

Figura 6. Ingestão de Matéria Seca (IMS) expressa em porcentagem do peso vivo dos Grupos Genéticos Brangus (BR) e Nelore (NE) nas distintas Fases de Mensuração: crescimento (CRES) e terminação (TERM). Foi encontrada interação significativa $(P<$ 0,01) entre Grupos Genéticos e Fases de Mensuração. ${ }^{\mathrm{a}, \mathrm{b}} \mathrm{Na}$ linha, médias sem sobrescritos em comum, diferem $(P<0,01) .{ }^{\mathrm{A}, \mathrm{B}} \mathrm{Na}$ coluna, médias sem sobrescritos em comum, diferem $(P<0,01)$. 


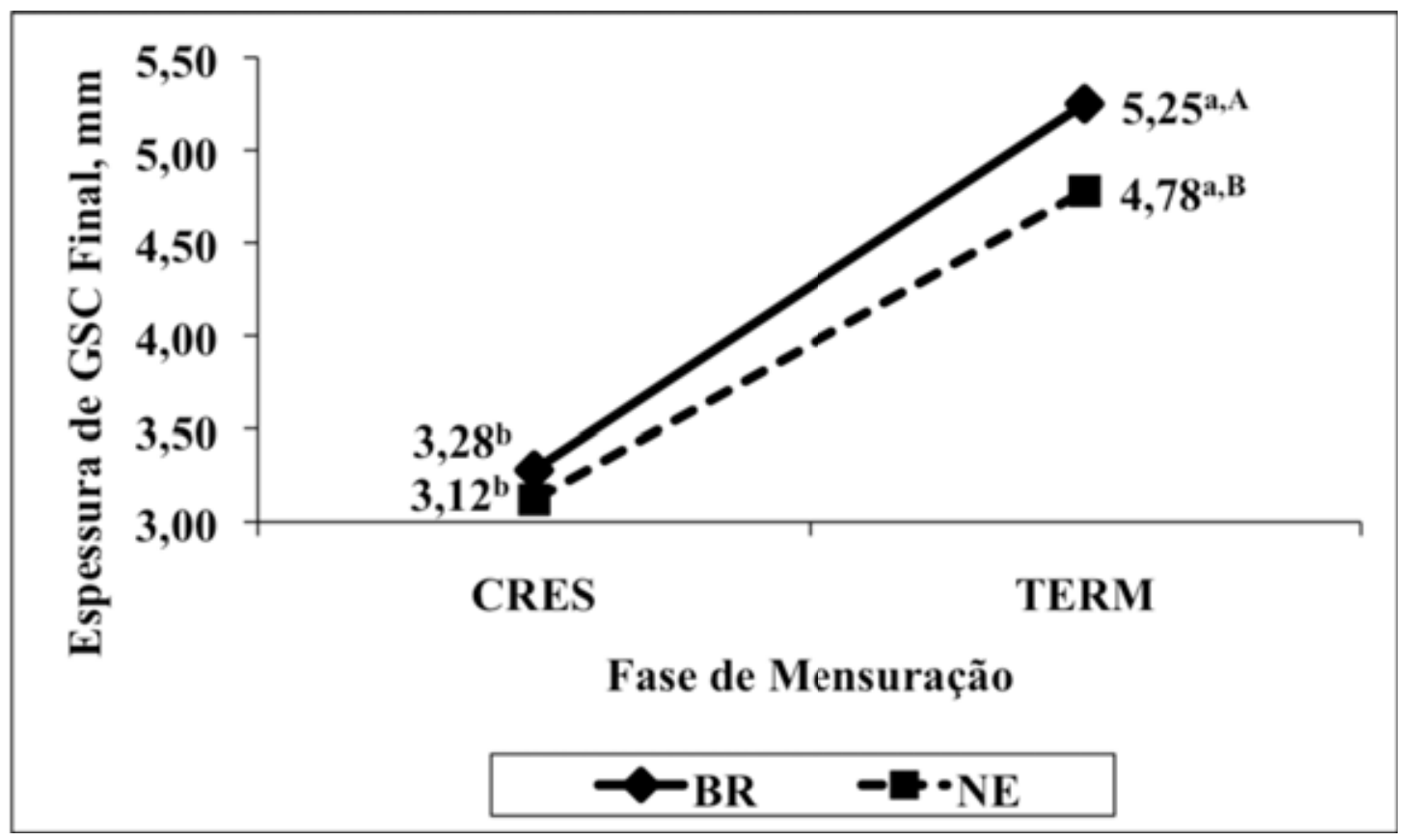

Figura 7. Espessura de Gordura Subcutânea (EGS) Final dos Grupos Genéticos Brangus (BR) e Nelore (NE) nas distintas Fases de Mensuração: crescimento (CRES) e terminação (TERM). Foi encontrada interação significativa $(P<0,01)$ entre Grupos Genéticos e Fases de Mensuração. ${ }^{\mathrm{a}, \mathrm{b}} \mathrm{Na}$ linha, médias sem sobrescritos em comum, diferem $(P<0,01) .{ }^{\text {A,B }}$ Na coluna, médias sem sobrescritos em comum, diferem $(P<$ $0,01)$. 


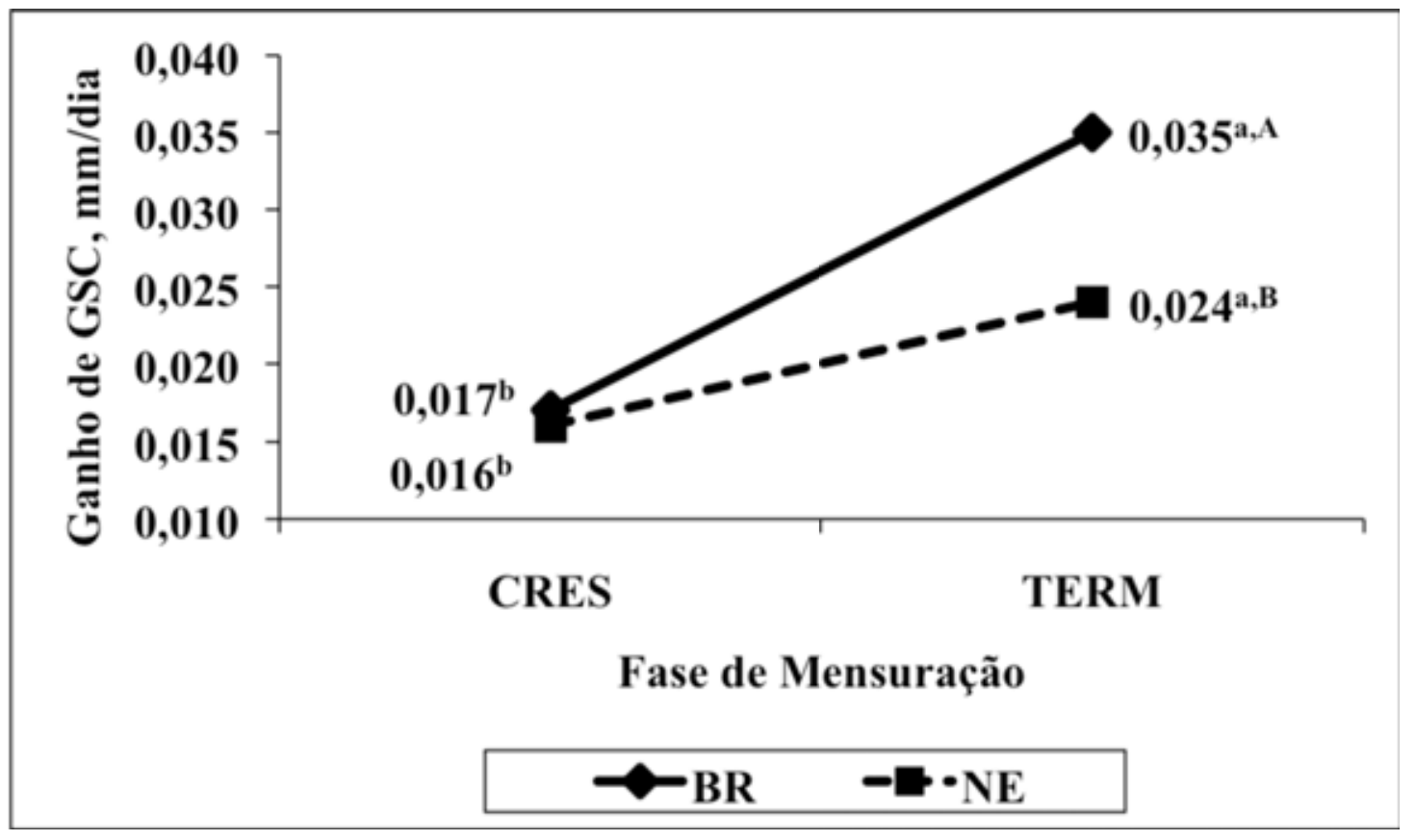

Figura 8. Ganho de Gordura Subcutânea (EGS) dos Grupos Genéticos Brangus (BR) e Nelore (NE) nas distintas Fases de Mensuração: crescimento (CRES) e terminação (TERM). Foi encontrada interação significativa $(P<0,01)$ entre Grupos Genéticos e Fases de Mensuração. ${ }^{\text {a,b }} \mathrm{Na}$ linha, médias sem sobrescritos em comum, diferem $(P<$ $0,01){ }^{\mathrm{A}, \mathrm{B}} \mathrm{Na}$ coluna, médias sem sobrescritos em comum, diferem $(P<0,01)$. 


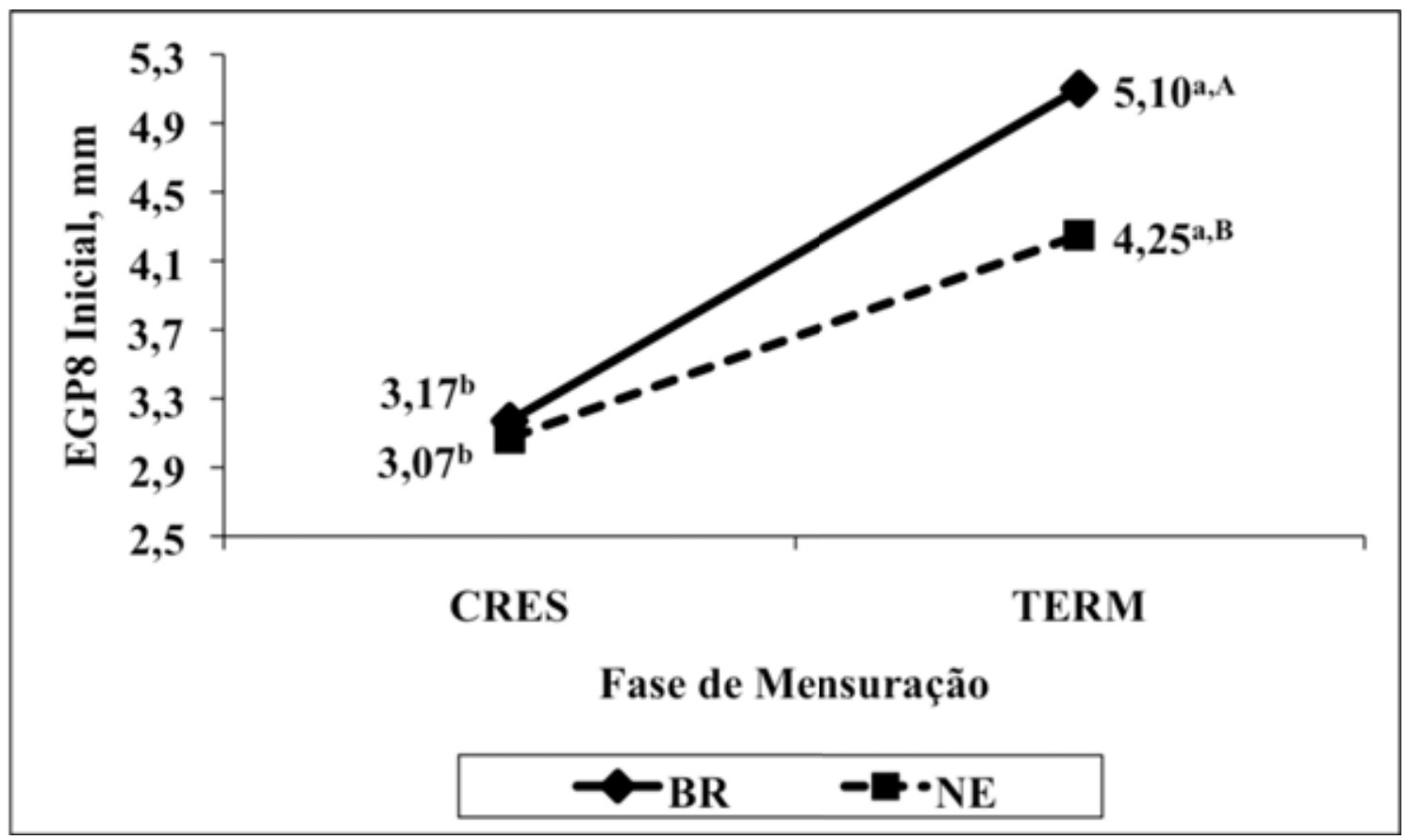

Figura 9. Espessura de Gordura da Picanha (EGP8) Inicial dos Grupos Genéticos Brangus (BR) e Nelore (NE) nas distintas Fases de Mensuração: crescimento (CRES) e terminação (TERM). Foi encontrada interação significativa $(P<0,01)$ entre Grupos Genéticos e Fases de Mensuração. a,b $\mathrm{Na}$ linha, médias sem sobrescritos em comum, diferem $(P<0,01) .{ }^{\text {A,B }} \mathrm{Na}$ coluna, médias sem sobrescritos em comum, diferem $(P<$ $0,01)$. 


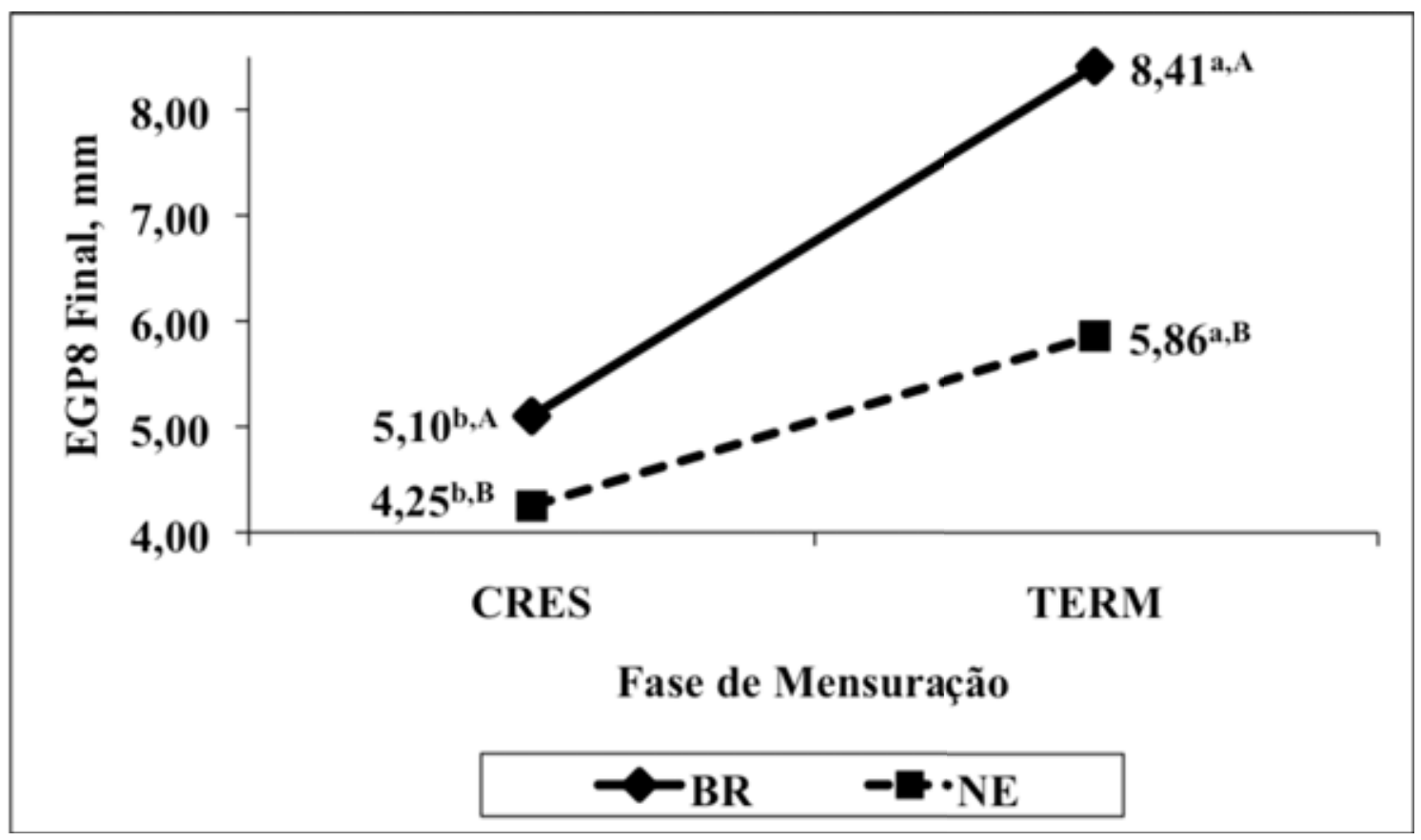

Figura 10. Espessura de Gordura da Picanha (EGP8) Final dos Grupos Genéticos Brangus (BR) e Nelore (NE) nas distintas Fases de Mensuração: crescimento (CRES) e terminação (TERM). Foi encontrada interação significativa $(P<0,01)$ entre Grupos Genéticos e Fases de Mensuração. ${ }^{a, b} \mathrm{Na}$ linha, médias sem sobrescritos em comum, diferem $(P<0,01) .{ }^{\mathrm{A}, \mathrm{B}} \mathrm{Na}$ coluna, médias sem sobrescritos em comum, diferem $(P<$ $0,01)$. 


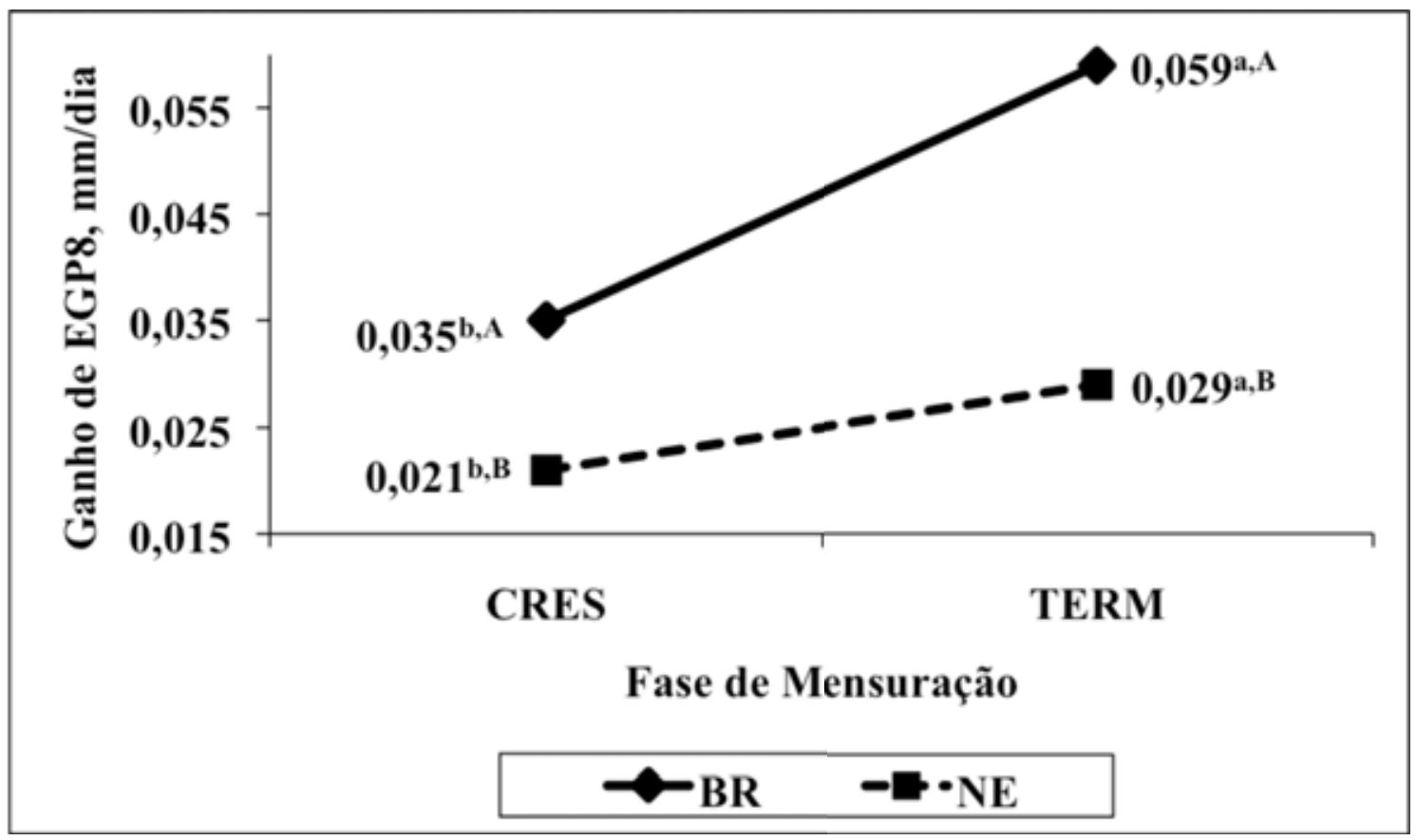

Figura 11. Ganho de Gordura da Picanha (EGP8) dos Grupos Genéticos Brangus (BR) e Nelore (NE) nas distintas Fases de Mensuração: crescimento (CRES) e terminação (TERM). Foi encontrada interação significativa $(P<0,01)$ entre Grupos Genéticos e Fases de Mensuração. ${ }^{\text {a,b }} \mathrm{Na}$ linha, médias sem sobrescritos em comum, diferem $(P<$ $0,01) .{ }^{\mathrm{A}, \mathrm{B}} \mathrm{Na}$ coluna, médias sem sobrescritos em comum, diferem $(P<0,01)$. 


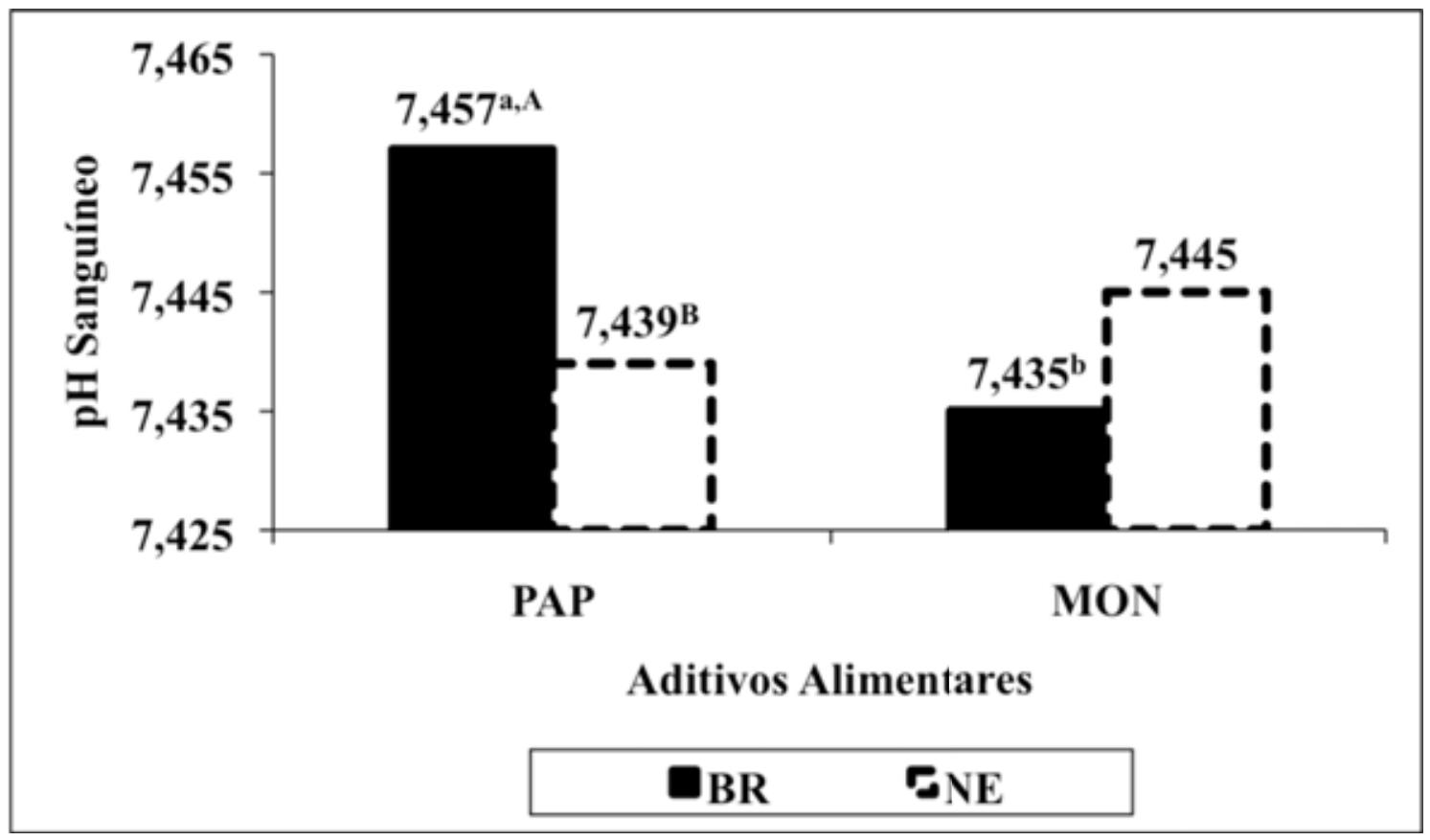

Figura 12. $P H$ do sangue dos Grupos Genéticos Brangus (BR) e Nelore (NE) suplementados com o Preparado de Anticorpos Policlonais (PAP) ou Monensina Sódica $(\mathrm{MON})$. Foi encontrada interação significativa $(P<0,01)$ entre Grupos Genéticos e Aditivos Alimentares. ${ }^{\mathrm{a}, \mathrm{b}}$ Entre colunas escuras, médias sem sobrescritos em comum, diferem $(P<0,01) .{ }^{\mathrm{A}, \mathrm{B}}$ Para cada aditivo alimentar, médias sem sobrescritos em comum, diferem $(P<0,01)$. 


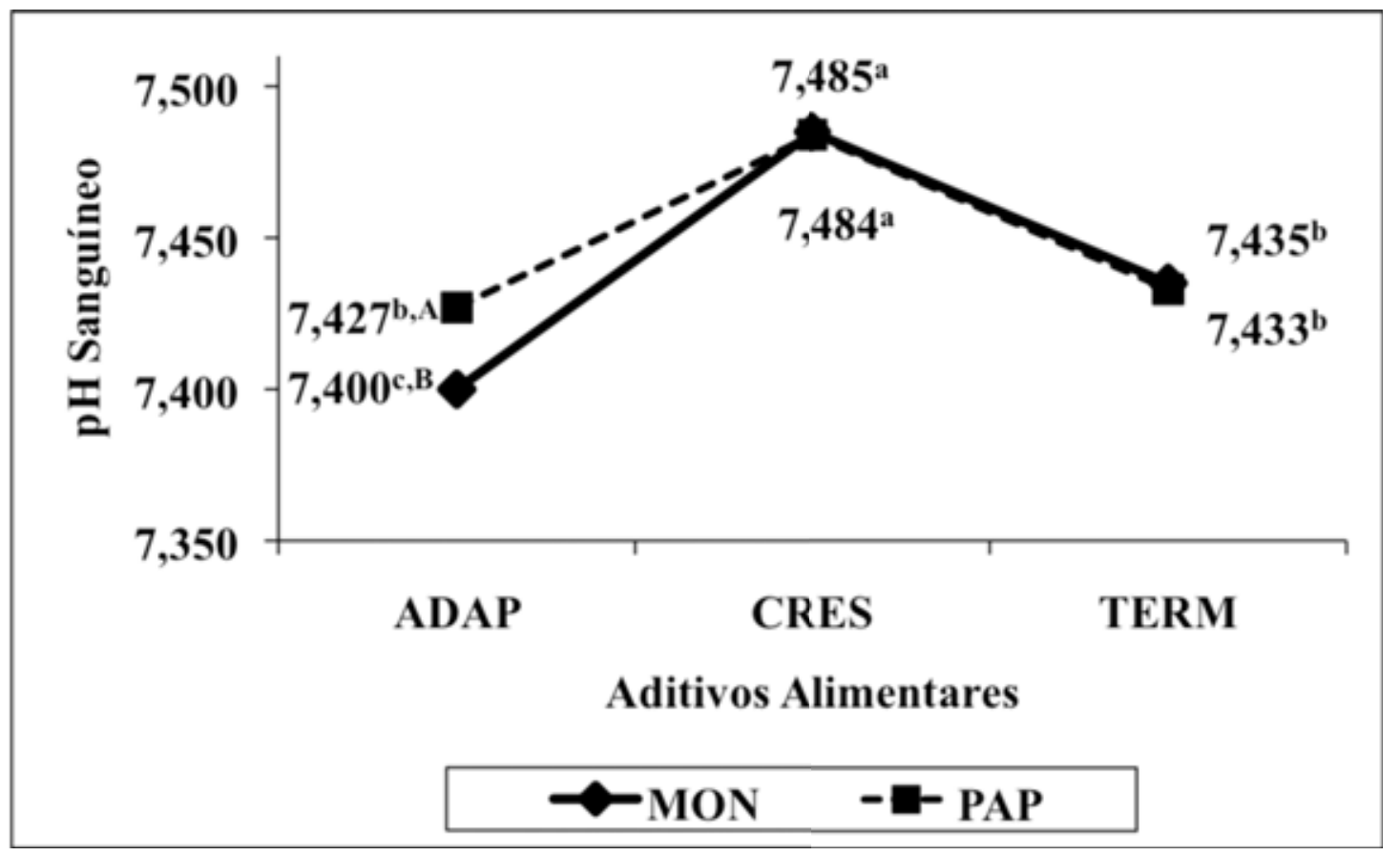

Figura 13. PH do sangue dos animais que receberam o Preparado de Anticorpos Policlonais (PAP) ou Monensina Sódica (MON) nas distintas Fases de Mensuração: adaptação (ADAP), crescimento (CRES) e terminação (TERM). Foi encontrada interação significativa $(P<0,01)$ entre Aditivos Alimentares e Fases de Mensuração. ${ }^{\text {a,b }}$ $\mathrm{Na}$ linha, médias sem sobrescritos em comum, diferem $(P<0,01)$. ${ }^{\mathrm{A}, \mathrm{B}} \mathrm{Na}$ coluna, médias sem sobrescritos em comum, diferem $(P<0,01)$. 


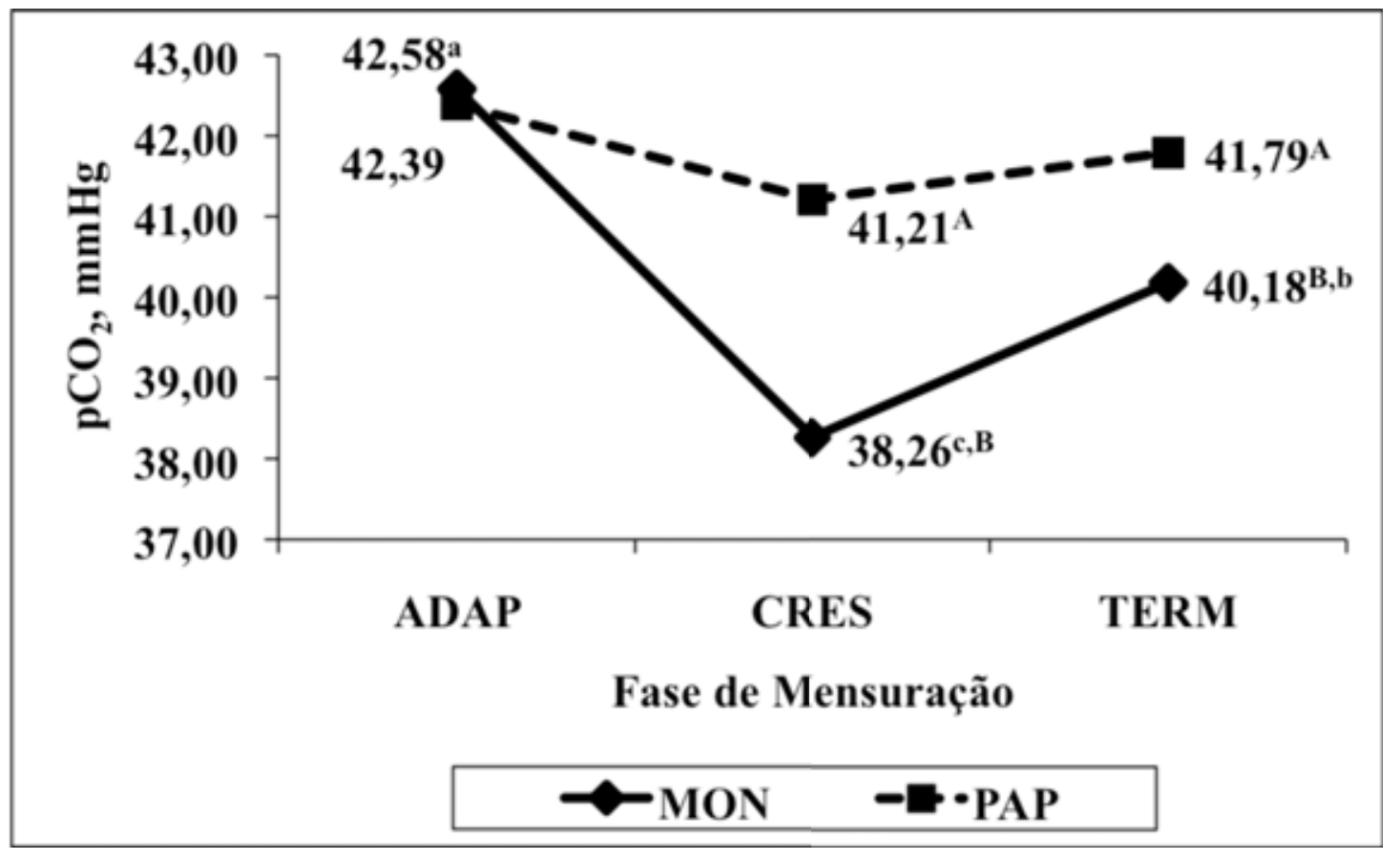

Figura 14. Pressão de gás carbônico $\left(\mathrm{pCO}_{2}\right)$ do sangue dos animais que receberam o Preparado de Anticorpos Policlonais (PAP) ou Monensina Sódica (MON) nas distintas Fases de Mensuração: adaptação (ADAP), crescimento (CRES) e terminação (TERM). Foi encontrada interação significativa $(P<0,05)$ entre Aditivos Alimentares e Fases de Mensuração. ${ }^{\mathrm{a}, \mathrm{b}} \mathrm{Na}$ linha, médias sem sobrescritos em comum, diferem $(P<0,05)$. ${ }^{\mathrm{A}, \mathrm{B}}$ Na coluna, médias sem sobrescritos em comum, diferem $(P<0,05)$. 


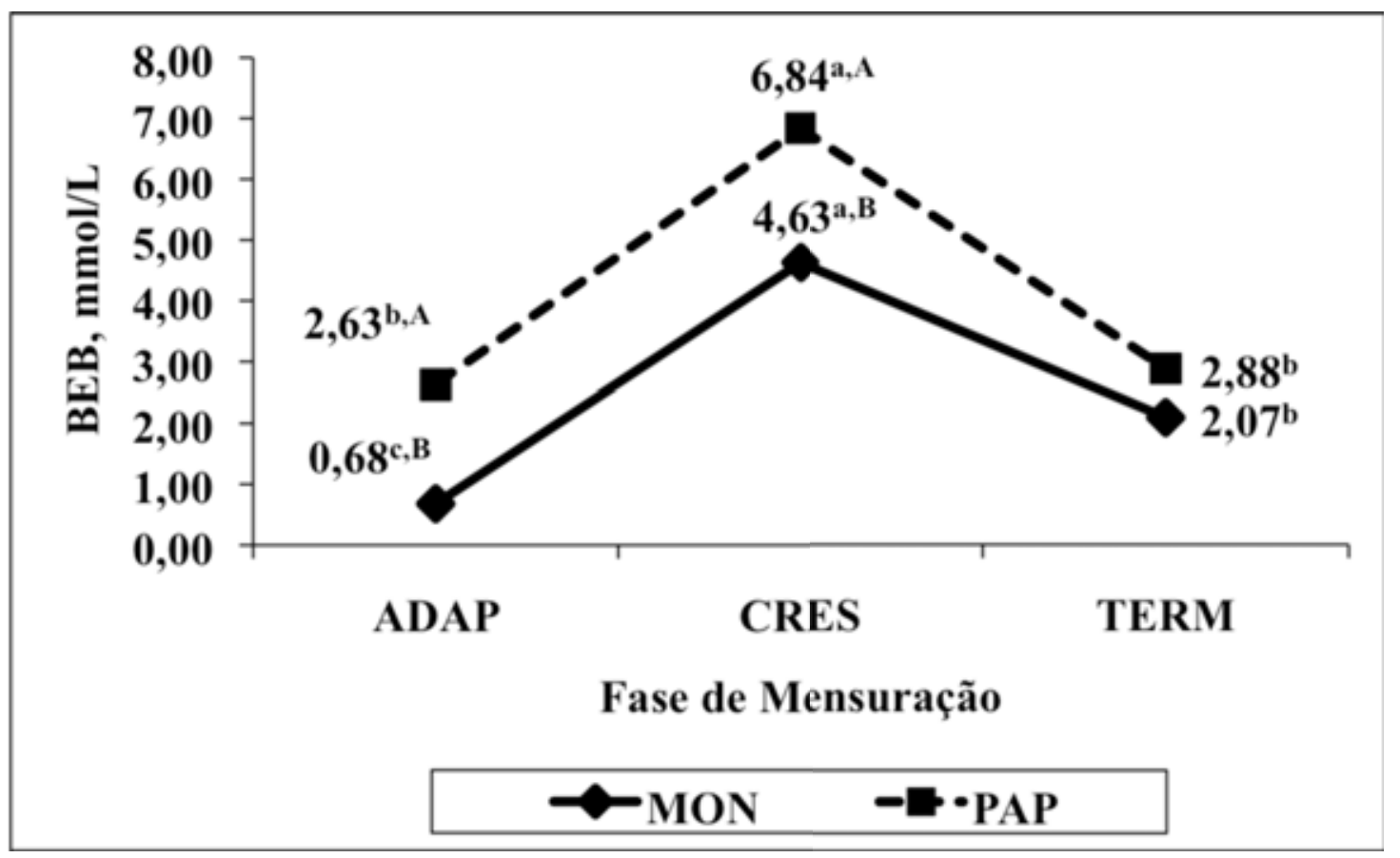

Figura 15. Excesso de Base no Sangue (BEB) dos animais que receberam o Preparado de Anticorpos Policlonais (PAP) ou Monensina Sódica (MON) nas distintas Fases de Mensuração: adaptação (ADAP), crescimento (CRES) e terminação (TERM). Foi encontrada interação significativa $(P<0,05)$ entre Aditivos Alimentares e Fases de Mensuração. ${ }^{\mathrm{a}, \mathrm{b}} \mathrm{Na}$ linha, médias sem sobrescritos em comum, diferem $(P<0,01)$. ${ }^{\mathrm{A}, \mathrm{B}}$ Na coluna, médias sem sobrescritos em comum, diferem $(P<0,05)$. 


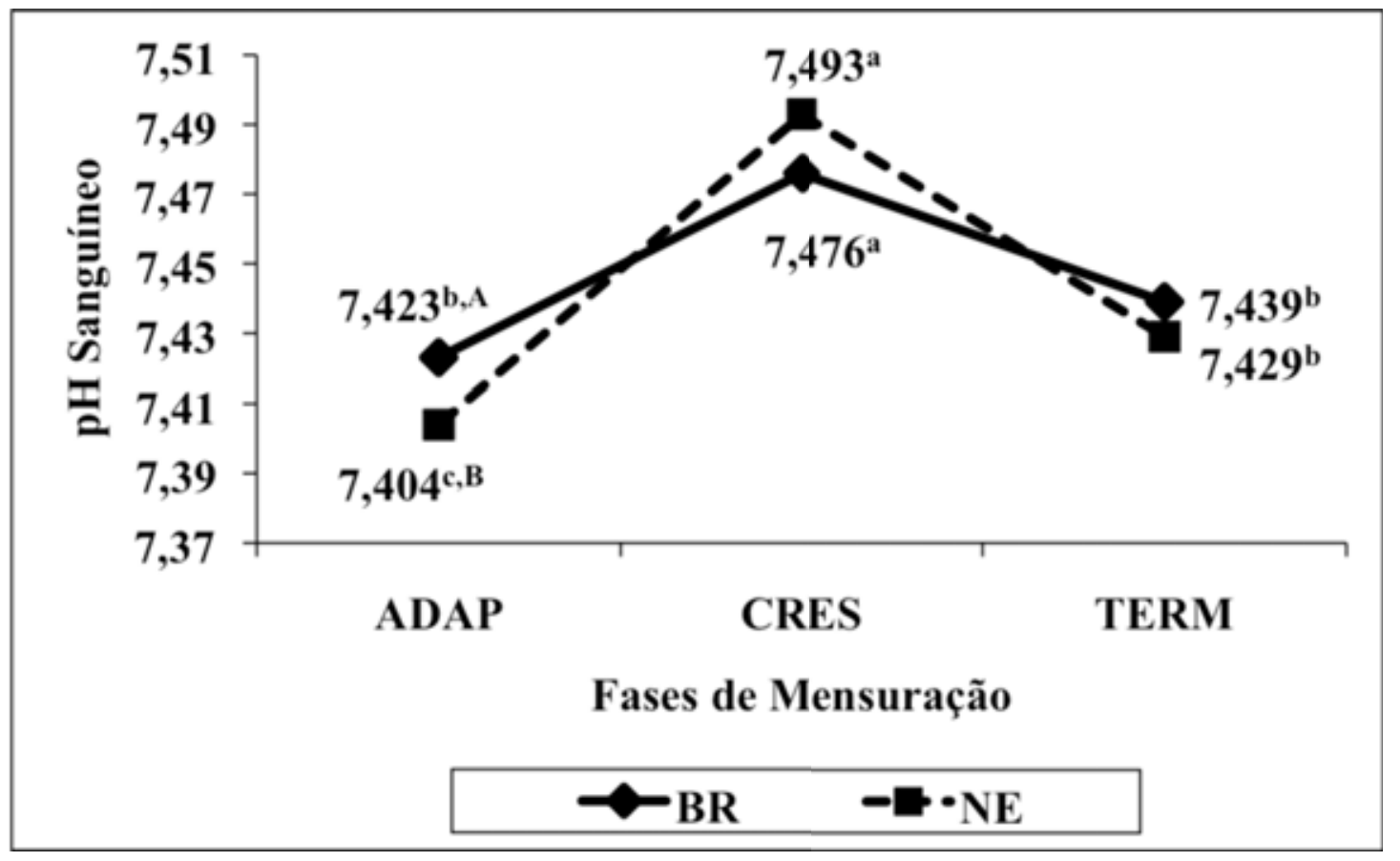

Figura 16. $\mathrm{PH}$ do sangue dos Grupos Genéticos Brangus (BR) e Nelore (NE) nas distintas Fases de Mensuração: adaptação (ADAP), crescimento (CRES) e terminação (TERM). Foi encontrada interação significativa $(P<0,01)$ entre Grupos Genéticos e e Fases de Mensuração. ${ }^{\text {a,b }} \mathrm{Na}$ linha, médias sem sobrescritos em comum, diferem $(P<$ $0,01) .{ }^{\mathrm{A}, \mathrm{B}} \mathrm{Na}$ coluna, médias sem sobrescritos em comum, diferem $(P<0,01)$. 


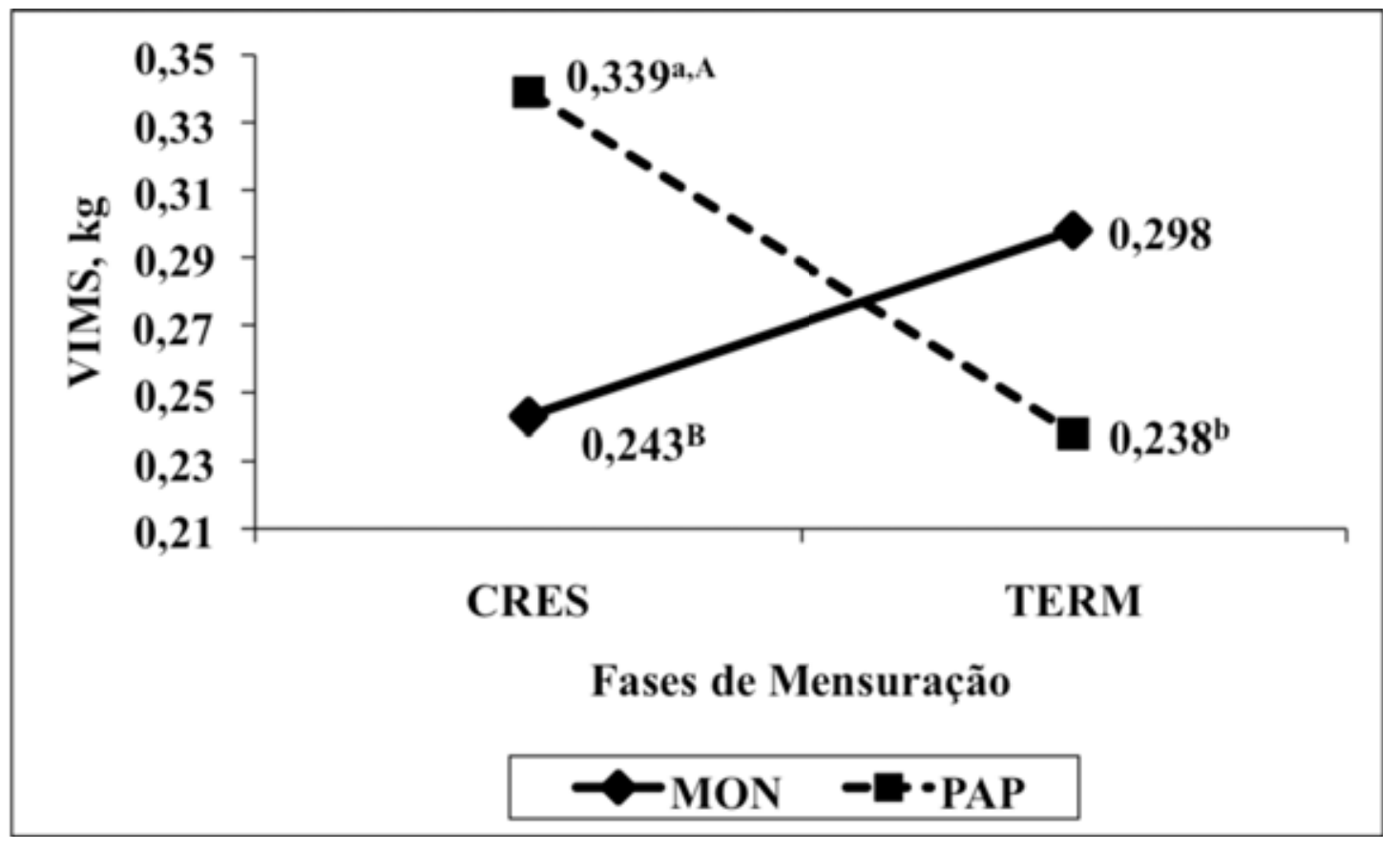

Figura 17. Variação da Ingestão de Matéria Seca (VIMS) dos animais que receberam o Preparado de Anticorpos Policlonais (PAP) ou Monensina Sódica (MON) nos 4 primeiros dias das distintas Fases de Mensuração: crescimento (CRES) e terminação (TERM). Foi encontrada interação significativa $(P<0,01)$ entre Aditivos Alimentares e Fases de Mensuração. ${ }^{\text {a,b }} \mathrm{Na}$ linha, médias sem sobrescritos em comum, diferem $(P<$ $0,01) .{ }^{\mathrm{A}, \mathrm{B}} \mathrm{Na}$ coluna, médias sem sobrescritos em comum, diferem $(P<0,01)$. 


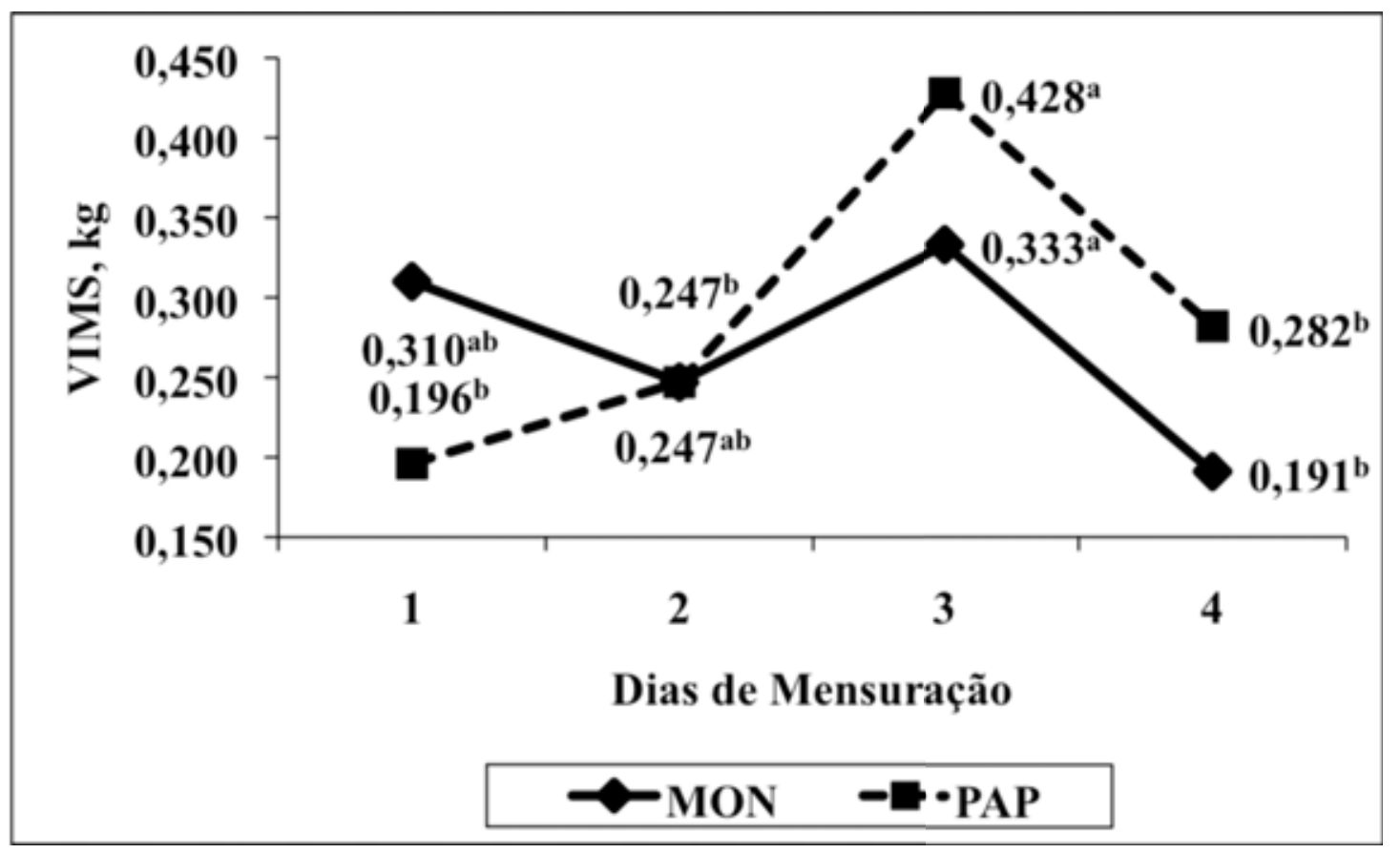

Figura 18. Variação da Ingestão de Matéria Seca (VIMS) dos animais que receberam o Preparado de Anticorpos Policlonais (PAP) ou Monensina Sódica (MON) nos 4 primeiros Dias de Mensuração de cada fase. Foi encontrada interação significativa $(P<$ $0,01)$ entre Aditivos Alimentares e Dias de Mensuração. ${ }^{a, b} \mathrm{Na}$ linha, médias sem sobrescritos em comum, diferem $(P<0,05)$. 


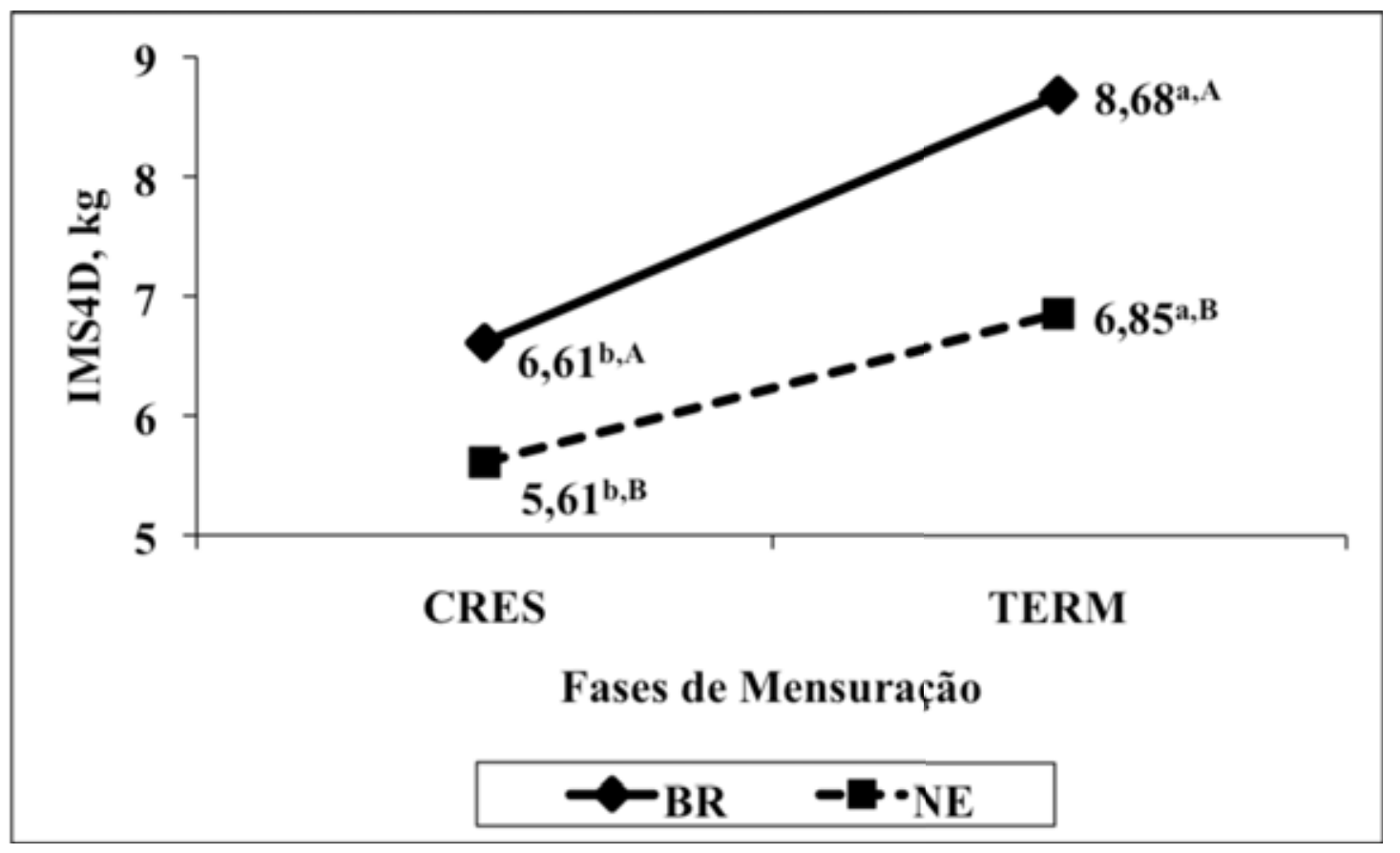

Figura 19. Ingestão de Matéria Seca nos 4 primeiros dias (IMS4D) das distintas Fases de Mensuração: crescimento (CRES) e terminação (TERM) dos Grupos Genéticos Brangus (BR) e Nelore (NE). Foi encontrada interação significativa $(P<0,01)$ entre Grupos Genéticos e Fases de Mensuração. ${ }^{a, b} \mathrm{Na}$ linha, médias sem sobrescritos em comum, diferem $(P<0,01){ }^{\mathrm{A}, \mathrm{B}} \mathrm{Na}$ coluna, médias sem sobrescritos em comum, diferem $(P<0,01)$. 


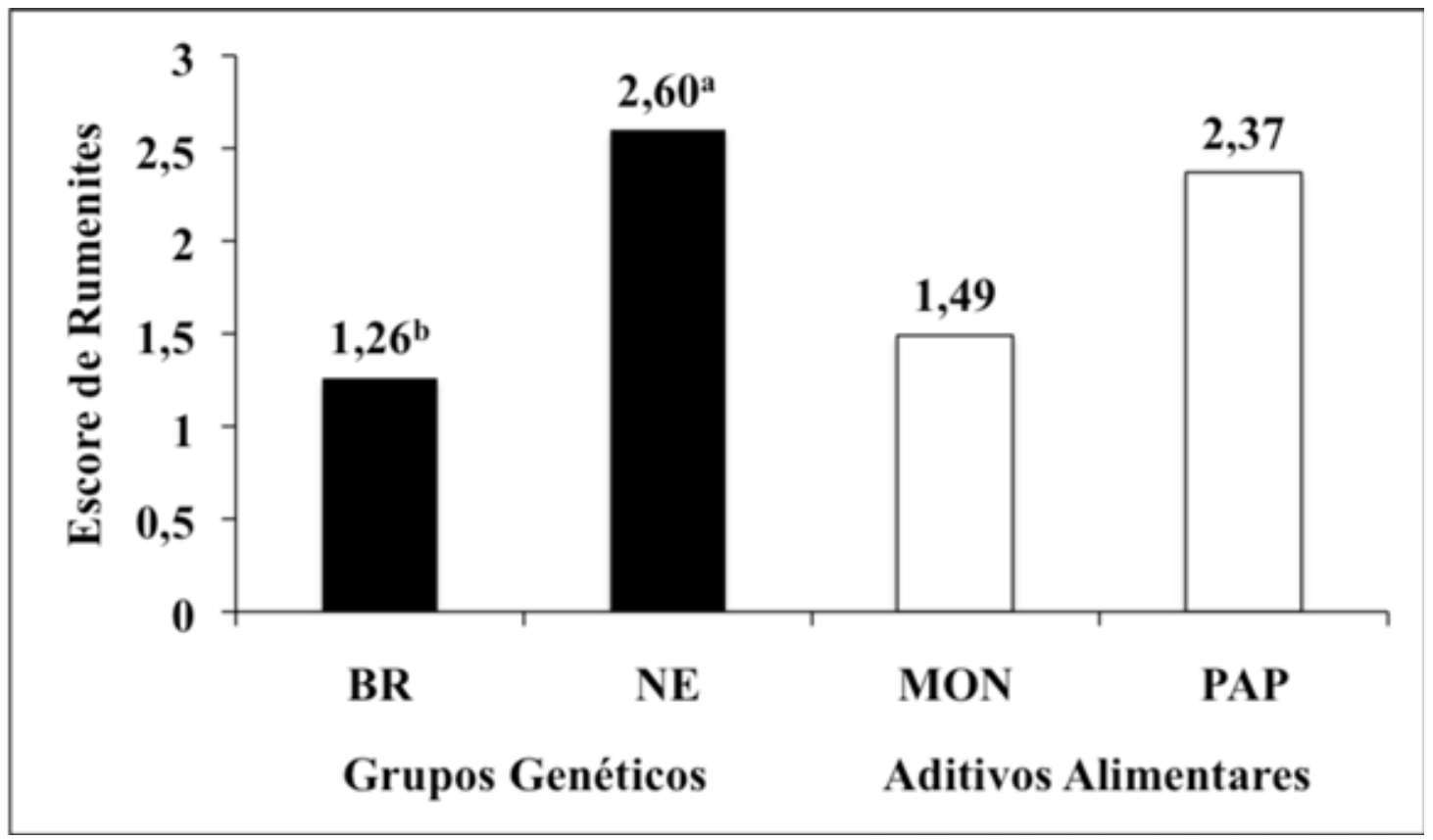

Figura 20. Escore de rumenites nos Grupos Genéticos Brangus (BR) e Nelore (NE), e para suplementação do Preparado de Anticorpos Policlonais (PAP) ou Monensina Sódica (MON). Não foi encontrado efeito principal dos Aditivos Alimentares, nem interação significativa $(P>0,05)$ entre Grupos Genéticos e Aditivos Alimentares. No entanto, bovinos NE mostraram maior $(P<0,05)$ incidência de lesões que animais BR. $\mathrm{EPM}=0,47 .{ }^{\mathrm{a}, \mathrm{b}}$ Para colunas escuras, médias sem sobrescritos em comum, diferem $(P<$ $0,05)$. 


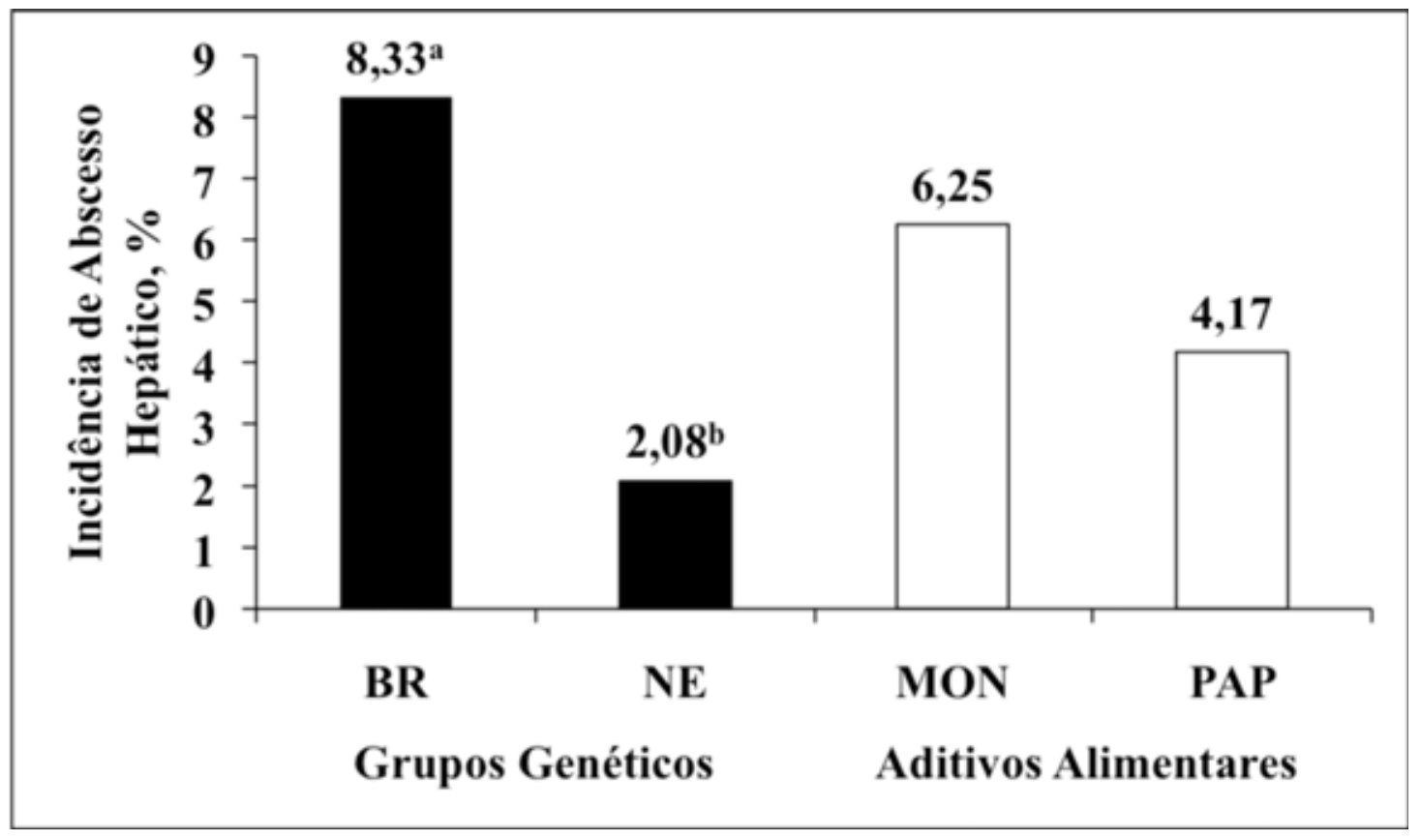

Figura 21. Incidência de abscesso hepático nos Grupos Genéticos Brangus (BR) e Nelore (NE), e para suplementação do Preparado de Anticorpos Policlonais (PAP) ou Monensina Sódica (MON). Não foi encontrado efeito principal dos Aditivos Alimentares, nem interação significativa $(P>0,05)$ entre Grupos Genéticos e Aditivos Alimentares. No entanto, bovinos BR mostraram maior $(P<0,01)$ incidência de abscessos que animais NE. a,b Para colunas escuras, médias sem sobrescritos em comum, diferem $(P<0,01)$. 


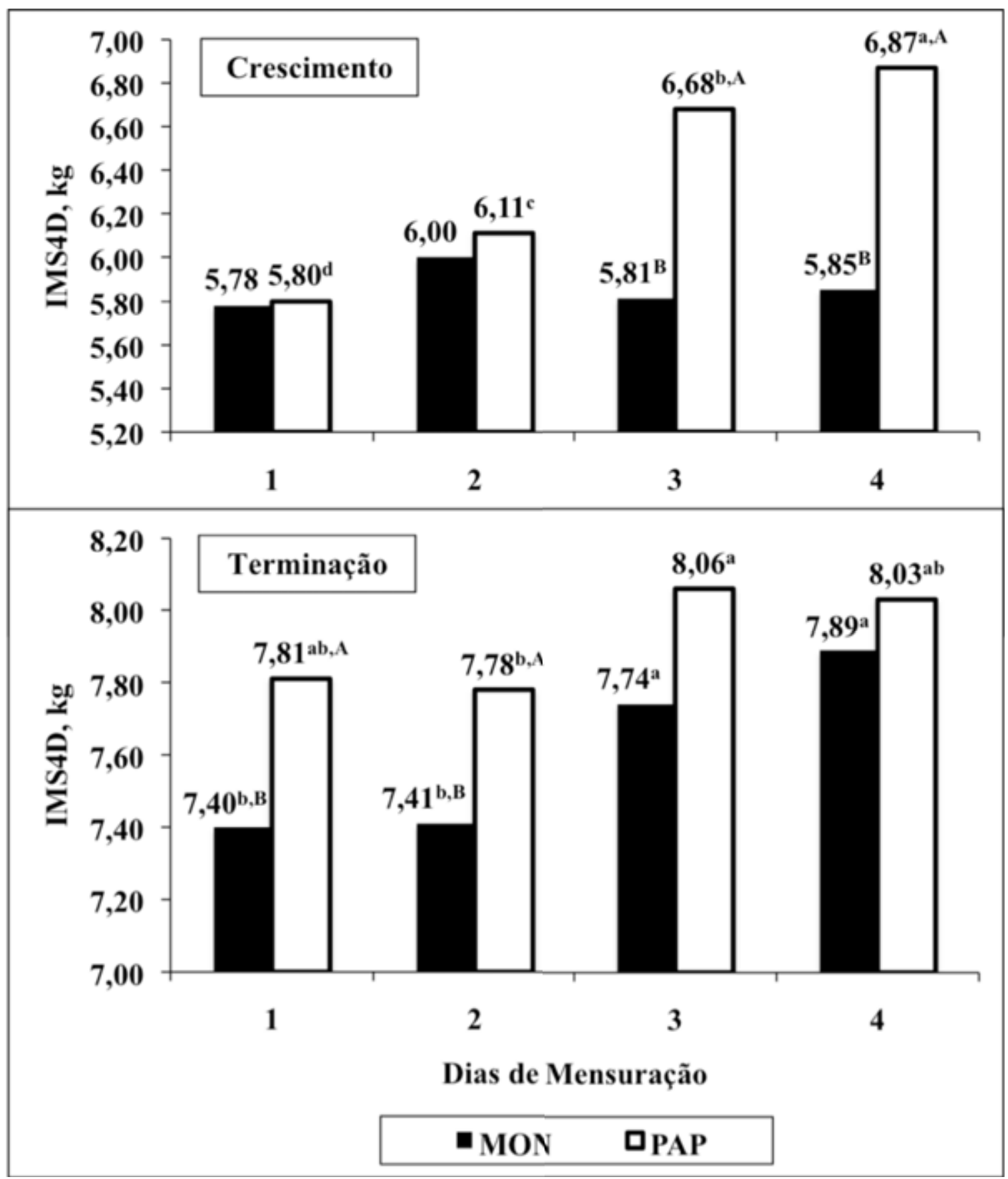

Figura 22. Interação entre Aditivos Alimentares, Fases de Mensuração e Dias de Mensuração para a Ingestão de Matéria Seca (IMS4D) em quilos nos quatro primeiros dias das fases de crescimento e terminação de bovinos confinados recebendo Anticorpos Policlonais (PAP) ou Monensina Sódica (MON). ${ }^{a, b, c, d}$ Entre colunas brancas e entre colunas negras, médias sem sobrescritos em comum diferem $(P<0,05)$. ${ }^{\mathrm{A}, \mathrm{B}}$ Para cada dia, dentro de cada fase, médias sem sobrescritos em comum diferem $(P<0,05)$. 


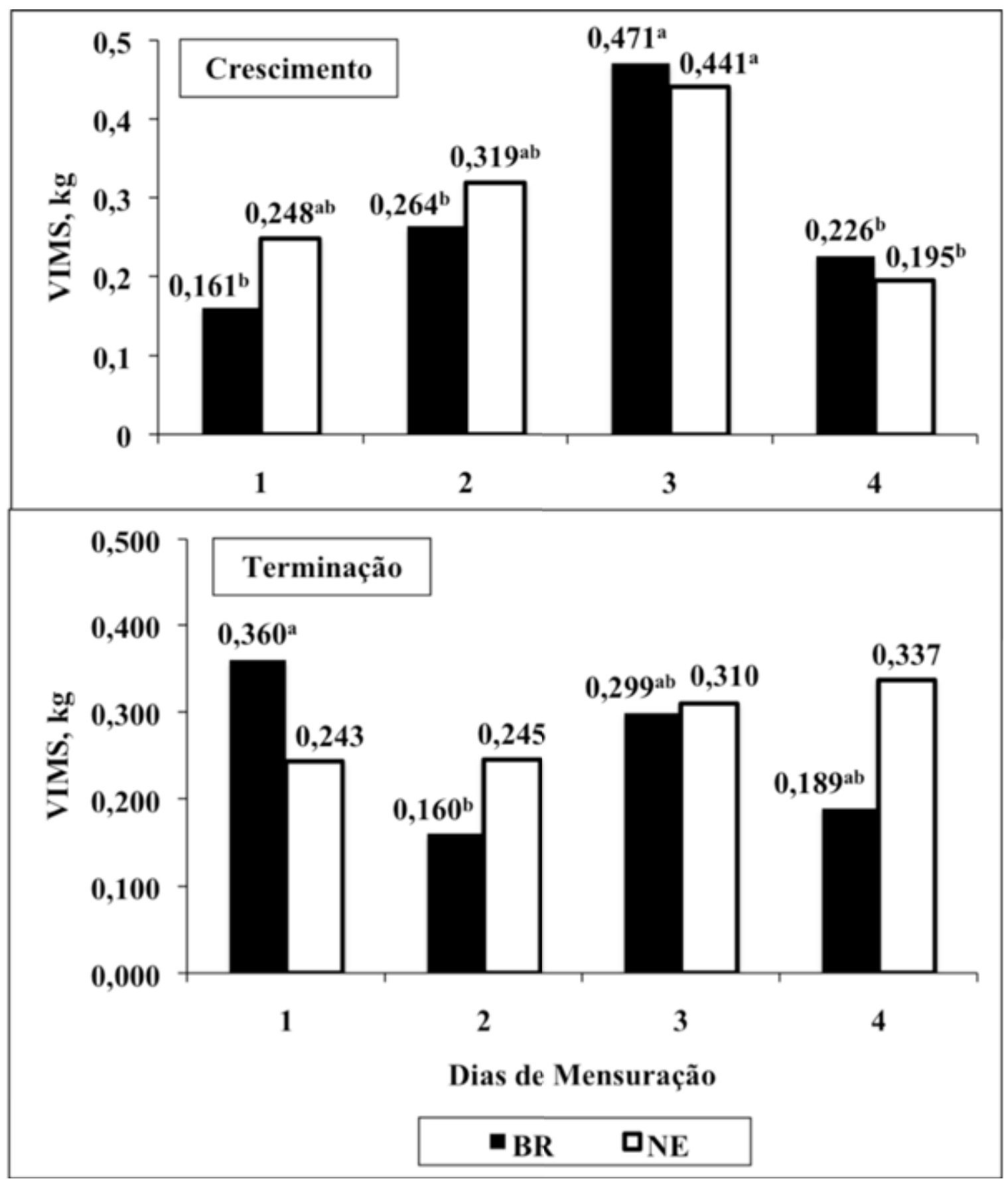

Figura 23. Interação entre Grupos Genéticos, Fases de Mensuração e Dias de Mensuração para Variação da Ingestão de Matéria Seca (VIMS) em quilos nos quatro primeiros dias das fases de crescimento e terminação de bovinos Brangus (BR) e Nelore (NE) confinados. a,b Entre colunas brancas e entre colunas negras, médias sem sobrescritos em comum diferem $(P<0,05)$. 


\section{CAPÍTULO 3}




\section{Anticorpos policlonais ou monensina sódica na alimentação de bovinos jovens}

confinados com dietas de alto concentrado: lipoproteínas sanguíneas e perfil de ácidos graxos da gordura da carcaça de bovinos confinados

O objetivo deste estudo foi avaliar os efeitos da suplementação do preparado de anticorpos policlonais (PAP) ou monensina sódica (MON) sobre a concentração das lipoproteínas sanguíneas e perfil de ácidos graxos da gordura da carcaça. O delineamento experimental foi inteiramente casualizado em arranjo fatorial $2 \times 2$, com seis repetições por tratamento, nos quais 48 bovinos machos inteiros de cada grupo genético (GG) avaliado [Brangus (BR) ou Nelore (NE)] foram alimentados com dietas contendo MON ou PAP fornecidos diariamente na dosagem de 30 e $300 \mathrm{mg} / \mathrm{kg}$ de MS, respectivamente. Foram amostrados 2 animais por baia, sendo considerada a média desses já que a baia foi a unidade experimental. Houve três fases durante o estudo: adaptação, crescimento, e terminação. As dietas fornecidas nestas fases continham 55, 70 e $85 \%$ de concentrado, respectivamente. Após o abate foram coletadas amostras de gordura do tecido adiposo subcutâneo (SUB), intermuscular (IMU) e visceral (VIS). Não foi observado $(P>0,05)$ efeito principal dos aditivos alimentares $(\mathbf{A A})$ sobre a concentração da maioria das lipoproteínas sanguíneas, com exceção à $\operatorname{HDL}(P<0,05)$, onde bovinos recebendo PAP apresentaram maiores concentrações $(59,85$ vs. 54,04 $\mathrm{mg} / \mathrm{dL})$. No tocante aos GG, bovinos NE apresentaram $(P<0,01)$ menor concentração de VLDL. Apesar de apresentaram maior $(P<0,05)$ concentração de ácidos graxos saturados que animais NE suplementados com MON, bovinos NE que receberam PAP também apresentaram maiores $(P<0,05)$ concentrações dos ácidos graxos insaturados C18:2, poliinsaturados (PUFA), ácido linoléico conjugado (CLA; apenas no tecido VIS) e $\omega-3$. Animais BR apresentaram maiores $(P<0,05)$ concentrações de alguns ácidos graxos insaturados que bovinos NE, os quais incluem: C15:1, C16:1, transvaccênico e CLA. Foi constatado maior proporção de ácidos graxos insaturados incluindo os monoinsaturados, PUFA, e o C18:1, no tecido adiposo SUB em relação aos tecidos VIS e IMU. Assim sendo, bovinos que consumiram PAP no presente estudo tiveram aumento da concentração de alguns ácidos graxos insaturados benéficos à saúde humana, o que pode ter elevado a concentração de HDL no sangue.

Palavras-chave: Brangus, HDL, intermuscular, Nelore, subcutâneo, visceral. 


\section{Polyclonal antibodies preparations against rumen bacteria or monensin in high- concentrate diets fed to feedlot cattle: blood lipoproteins concentrations and fatty acid profile of carcass adipose tissues}

This study, conducted at the São Paulo State University feedlot, Botucatu Campus, Brazil, was designed to test monensin (MON) and a polyclonal antibody preparation (PAP) against rumen bacteria on blood lipoproteins concentrations and fatty acid profile of Brangus (BR) and Nellore (NE) cattle. The experiment was designed as a $2 \times 2$ factorial arrangement using repeated measures over time, replicated 6 times (4 bullocks/pen), in which 48 8-mo-old bullocks of each of two breeds (BD) evaluated were fed diets containing either MON at $30 \mathrm{mg} \bullet \mathrm{kg}^{-1}$ or PAP at $300 \mathrm{mg} \bullet \mathrm{kg}^{-1}$ of dry matter (DM) for 112-d. Two bullocks were randomly selected from a population of four in each of 24 pens for sampling. Measures over time were taken according to the phase and level of concentrate fed during the study: 55 (adaptation), 70 (growing) and 85\% (finishing). After slaughter, three different points of carcasses adipose tissue were sampled for future fatty acid profile analysis: subcutaneous (SUB), intermuscular (IMU) and visceral (VIS). No significant $(P>0.05)$ feed additives (FA) main effect was observed for blood lipoproteins, with the exception of HDL $(P<0.05)$, where bullocks receiving PAP had greater concentrations than those fed MON (59.85 vs. 54.04 $\mathrm{mg} / \mathrm{dL})$. With respect to $\mathrm{BD}, \mathrm{NE}$ bullocks presented $(P<0.01)$ lower concentration of VLDL. Despite greater $(P<0.05)$ concentration of saturated fatty acids than NE cattle fed MON, NE bullocks receiving PAP presented greater $(P<0.05)$ concentrations of some unsaturated fatty acids (UFA) including C18:2, poli-UFA (PUFA), conjugated linoleic acid (CLA; only in VIS tissue) and $\omega$-3. In addiotional, BR bullocks had greater $(P<0.05)$ concentrations of some UFA as well, as follows: C15:1, C16:1, transvaccenic and CLA. On the other hand, it was observed $(P<0.05)$ greater concentrations of $\omega-6$ and C18:0 in NE bullocks adipose tissues. Futhermore, greater $(P<0.05)$ proportions of UFA including mono-UFA, PUFA and C18:1 were found in SUB adipose tissue when it was compared to samples collected in IMU and VIS tissues. Thus, feeding PAP increased the concentration of some UFA beneficial to human health, what may have led to greater concentrations of HDL in blood.

Keywords: adipose tissue, Brangus, intermuscular, Nellore, subcutaneous, visceral. 


\section{INTRODUÇÃO}

Ionóforos inibem o crescimento de bactérias gram positivas e muitas dessas estão envolvidas na biohidrogenação no rúmen, incluindo a Butyrivibrio fibrisolvens (Van Nevel e Demeyer, 1995; Fellner et al., 1997). Assim, é esperado que a monensina sódica (MON) aumente a proporção de pelo menos alguns ácidos graxos insaturados na gordura da carcaça de bovinos suplementados, como constatado anteriormente por Sauer et al. (1998) e Eifert (2004).

Tem sido amplamente demonstrado que ácidos graxos poliinsaturados de cadeia longa participam de vários processos metabólicos benéficos à saúde humana (Cook et al., 2001; Varela et al., 2004) e que as gorduras da carne de animais ruminantes, e a própria carne, são fontes naturais de alguns desses ácidos graxos, como os isômeros do ácido linoléico conjugado (CLA), em particular o cis-9, trans-11 (French et al., 2000; Metz et al., 2009); e o ácido linolênico ( $\omega$-3), que age como elemento protetor contra o câncer de mama (Holmes et al., 1999; Sugano e Hirahara, 2000).

No entanto alguns países, particularmente os do continente europeu, baniram o uso de ionóforos como promotores de crescimento por que estes são classificados como antibióticos (OJEU, 2003), os quais despertam a percepção pública de que contribuem para emergência de micro-organismos resistentes a antibióticos (Newbold et al., 2001). Baseado nos fatos que em 2009 o Brasil destinou cerca de 29,3\% de suas exportações para a União Européia (Beefpoint, 2010) e que os ionóforos são os principais aditivos alimentares, sendo utilizados em 100\% dos confinamentos brasileiros (Millen et al., 2009), a busca de novas alternativas para substituir os ionóforos é relevante e pode levar a descoberta de novas técnicas que melhorem os processos de fermentação ruminal e apresentem a mesma eficiência e economicidade dos ionóforos, sem trazer qualquer tipo risco para a saúde humana (DiLorenzo, 2004).

Uma alternativa aos ionóforos que foi avaliada in vivo recentemente é a imunização passiva (DiLorenzo et al., 2008; Blanch et al., 2009). Doses orais de anticorpos contra bactérias ruminais produtoras de lactato têm levado a redução da concentração dos ácidos graxos saturados palmítico (C16:0) e margárico (C17:0) da gordura subcutânea do músculo Longissimus quando comparados a animais que receberam MON (Fossa et al., 2008) e, ainda, a menor incidência de rumenites e desempenho similar a bovinos recebendo MON (Millen et al., 2007). Assim sendo, o 
objetivo deste estudo foi estudar os efeitos do preparado de anticorpos policlonais (PAP), contra as bactérias ruminais Streptococcus bovis, Fusobacterium necrophorum, Escherichia coli, Clostridium aminophilum, Clostridium sticklandii, Peptostreptococcus spp., ou MON sobre a concentração de lipoproteínas sanguíneas e perfil de ácidos graxos da gordura da carcaça coletadas de três distintas regiões de bovinos Brangus e Nelore confinados.

\section{MATERIAL E MÉTODOS}

O trabalho foi conduzido de acordo com as normas da comissão de ética no uso de animais (CEUA) da Faculdade de Medicina Veterinária e Zootecnia, UNESP - Univ. Estadual Paulista, campus de Botucatu.

\subsection{PAP}

Os PAP foram produzidos pela CAMAS Inc., Le Center, MN. O produto comercial contém imunoglobulinas contra Streptococcus bovis (ATCC 9809), Fusobacterium necrophorum (ATCC 27852), Clostridium sticklandii (ATCC 12662), Clostridium aminophilum (ATCC 49906), Peptostreptococcus anaerobius (ATCC 49031), e Escherichia coli O157:H7 (ATCC 43895). Streptococcus bovis é a bactéria que mais produz ácido láctico; Fusobacterium necrophorum é o causador de abscessos hepáticos em animais com acidose; Clostridium sticklandii, Clostridium aminophilum, e Peptostreptococcus anaerobius são bactérias produtoras de amônia; e Escherichia coli O157:H7 é patogênica em humanos e também causadora de acidose.

\subsection{Animais e Local Experimental}

$\mathrm{O}$ estudo foi conduzido na Faculdade de Medicina Veterinária e Zootecnia, UNESP - Univ. Estadual Paulista, campus de Botucatu no confinamento experimental de bovinos de corte, onde foram alocados 96 animais machos, não castrados, com oito meses de idade, pertencentes a dois grupos genéticos [48 da raça Nelore (NE) e 48 da raça Brangus (BR)] e distribuídos aleatoriamente em 24 baias (4 animais/baia). $O$ peso vivo médio inicial foi de $272,60 \pm 9,07$ e $236,63 \pm 15,37 \mathrm{~kg}$ para $\mathrm{BR}$ e $\mathrm{NE}$, respectivamente. Para o presente estudo foram amostrados dois animais por baia, sendo 
considerada a média desses dois animais, já que a baia foi considerada a unidade experimental.

\subsection{Manejo, Arraçoamento e Cuidados com os Animais}

Todos os animais foram submetidos ao mesmo fornecimento de dietas ad libitum, tipo de alojamento e manejo. As baias eram cobertas, protegendo os animais e o alimento do sol e da chuva e com boa facilidade na circulação do ar.

Antes do início do experimento os animais foram pesados, desverminados, vacinados contra doenças virais e bacterianas (rota e coronavírus, tétano, botulismo e sete tipos Clostridium spp.; Pfizer Animal Health, New York, NY) e adaptados às baias e as dietas por período de 28 dias.

Os ingredientes das dietas foram adicionados no próprio vagão distribuidor, aonde foram também misturados. Os animais receberam as dietas duas vezes ao dia: às $8 \mathrm{~h}(40 \%$ do total $)$ e $15 \mathrm{~h}$ ( $60 \%$ do total), sempre com água constante nos bebedouros automáticos $\left(0,89 \mathrm{~m}^{2}\right)$. A ração foi fornecida em cada baia $\left(6,7 \mathrm{~m}^{2} /\right.$ animal) em cocho de $5 \mathrm{~m}$ (1,25 m/animal). A quantidade de ração fornecida diariamente foi ajustada baseada na quantidade de sobras medidas antes do trato da manhã (8h), considerando-se $3 \%$ como nível de sobras. A quantidade de ração fornecida e as sobras foram pesadas diariamente e amostradas semanalmente para análise bromatológica de matéria seca (MS), proteína bruta, extrato etéreo e matéria mineral, os quais foram avaliados segundo o AOAC (1997) e fibra detergente neutro (FDN) segundo Goering e Van Soest (1970). As concentrações de FDN (com $\alpha$-amilase estável sob calor e sulfito de sódio) e FDA foram determinadas usando-se um analisador de fibra (Modelo 200, Ankom Technology, Fairport, NY, EUA).

Os animais foram abatidos quando atingiram $5 \mathrm{~mm}$ de espessura de gordura subcutânea (EGS), mensurada por meio de ultrassonografia seguindo metodologia descrita por Perkins (1992), para alcançar os requerimentos mínimos de gordura de cobertura do mercado brasileiro.

\subsection{Tratamentos e Dietas}

O delineamento experimental foi inteiramente casualizado em arranjo fatorial 2 $\times 2$, com seis repetições por tratamento, nos quais 48 bovinos machos inteiros de cada 
grupo genético avaliado (BR ou NE) foram alimentados com dietas contendo MON (Rumensin, Elanco Animal Health, Indianapolis, IN, EUA) ou PAP (RMT Optimize, CAMAS Inc., Le Center, MN, EUA) fornecidos diariamente via suplemento a doses de 30 e $300 \mathrm{mg} / \mathrm{kg}$ de MS, respectivamente. Como descrito anteriormente, para o presente estudo foram amostrados dois animais por baia, sendo considerada a média desses dois animais, já que a baia foi considerada a unidade experimental, mantendo-se desta forma as 24 unidades experimentais no estudo.

Os animais passaram por três fases durante o estudo: adaptação (ADAP), crescimento (CRES), e terminação (TERM). As dietas fornecidas nestes períodos continham 55, 70 e $85 \%$ de concentrado, respectivamente, e foram compostas por silagem de grãos úmidos de milho, grãos de milho seco quebrados, polpa cítrica peletizada, farelo de soja, bagaço de cana cru, feno de Coast Cross e suplemento mineral e protéico (Tabela 1). A dieta contendo 58\% de concentrado (ADAP) foi fornecida por período de 28 dias para adaptar os animais às dietas subsequentes. Com isso foi considerado o "dia 1" da fase de CRES para o início do experimento. O critério para mudanças de dieta foi baseado na EGS mensurada por meio de ultrassonografia. Quando os animais atingiram média de $3 \mathrm{~mm}$ de EGS sobre o músculo Longissimus dorsi, estes foram passados de 70\% (CRES) para 85\% (TERM) de concentrado. As dietas foram formuladas segundo o sistema Cornell Net Carbohydrate and Protein System 5.0.40 (CNCPS, 2000), cuja formulação está apresentada na Tabela 1, esperando-se ganhos de peso diários (GPD) de 1,300 a 1,600 kg/dia/animal. Os animais permaneceram no experimento por 140 dias antes de serem abatidos, sendo 28, 56 e 56 dias nas fases de ADAP, CRES e TERM; respectivamente.

\subsection{Lipoproteínas no Sangue}

Após 15 dias do início de uma nova fase ou introdução de nova dieta, amostras de sangue foram colhidas através da punção da veia jugular externa dos animais, seguindo a metodologia proposta por Allain et al. (1974), em tubos com vácuo (BD Vacutainer, Franklin Lakes, NJ, EUA) contendo heparina sódica. As amostras coletadas foram armazenadas em isopor com gelo e foram levadas ao laboratório para análises em no máximo $2 \mathrm{~h}$. No laboratório, as amostras foram centrifugadas a velocidade de 3000 rpm por 15 minutos, e uma alíquota de $3 \mathrm{~mL}$ de plasma foi colocada em dois tubos 
eppendorf (MCT-150, Axygen, Union City, CA, EUA) de 1,5 mL cada para posterior análise. De acordo com o proposto, o plasma foi armazenado por no máximo 24 horas até a realização da análise. Para determinação das concentrações de triglicerídeos, colesterol e lipoproteínas de alta densidade (HDL) foram utilizados kits enzimáticos comerciais (Laborlab, Guarulhos, SP, Brasil) e os métodos estão descrito a seguir:

A concentração de triglicerídeos no sangue foi determinada pelo método enzimático no qual três tubos de ensaios foram marcados e utilizados para as três reações (Branco, Padrão e Desconhecido), conforme o quadro:

\begin{tabular}{|l|c|c|}
\hline & Branco & Padrão / Desconhecido \\
\hline Amostra / Padrão & ------ & $20 \mu \mathrm{L}$ \\
\hline Reativo de Trabalho & $2000 \mu \mathrm{L}$ & $2000 \mu \mathrm{L}$ \\
\hline
\end{tabular}

Após isto, as amostras foram homogeneizadas e incubadas à $37^{\circ} \mathrm{C}$ em banhomaria por 15 minutos. Logo após, estas foram retiradas do banho-maria, resfriadas a temperatura ambiente por 5 minutos e então levadas para a leitura em Espectrofotômetro (Cirrus 80MB, Femto, São Paulo, SP, Brasil) calibrado em absorbância de $505 \mathrm{~nm}$, zerando o aparelho com água deionizada. Por fim foi realizado o cálculo da concentração de triglicerídeos de acordo com a seguinte fórmula:

\section{Triglicerídeos, $\mathrm{mg} / \mathrm{dL}=($ Desconhecido - Branco $) \times$ Fator Fator $=200 /($ Padrão - Branco $)$}

Da mesma forma, a concentração de colesterol no sangue também foi analisada pelo método enzimático no qual três tubos de ensaios foram marcados e utilizados para as três reações (Branco, Padrão e Desconhecido), conforme o quadro:

\begin{tabular}{|l|c|c|c|}
\hline & Branco & Padrão & Desconhecido \\
\hline Padrão & ------ & $20 \mathrm{~mL}$ & ------ \\
\hline Desconhecido & ------ & ------ & $20 \mu \mathrm{L}$ \\
\hline Reativo de trabalho & $2000 \mu \mathrm{L}$ & $2000 \mu \mathrm{L}$ & $2000 \mu \mathrm{L}$ \\
\hline
\end{tabular}

Então os três tubos referentes às três reações foram agitados e incubados durante 10 minutos à $37^{\circ} \mathrm{C}$ em banho-maria. Na sequência, foi realizada a leitura em 
espectrofotômetro à absorbância de $505 \mathrm{~nm}$, zerando o aparelho com o Branco. Por fim foi realizado cálculo da concentração de colesterol no sangue de acordo com a seguinte fórmula:

\section{Colesterol, $\mathrm{mg} / \mathrm{dL}=$ Desconhecido $\times$ Fator \\ Fator $=200 /$ Padrão}

As HDL foram separadas seletivamente por precipitação das lipoproteínas de baixa e muito baixa densidade (LDH e VLDL, respectivamente) usando-se o Sulfato de Dextran em presença de íons $\mathrm{Mg}++$. O sobrenadante foi separado por centrifugação e as HDL nele contido quantificadas pelo seu teor de colesterol, utilizando-se o mesmo kit de Colesterol (método enzimático) da Laborlab usado na análise de colesterol propriamente dita.

Então foram colocadas em tubo de ensaio a alíquota de $500 \mu \mathrm{L}$ de amostra e adicionou-se $50 \mu \mathrm{L}$ do Reativo Precipitante como explicado acima. A mistura foi homogeneizada por agitação (sem inverter o tubo) por 20 segundos e depois este foi refrigerado por 40 minutos. Logo após, os tubos foram centrifugados por 15 minutos à 3000 ppm e utilizou-se o sobrenadante límpido como amostra. Três tubos de ensaios foram marcados e utilizados para as 3 reações (Branco, Padrão e Desconhecido), de acordo com o quadro:

\begin{tabular}{|l|c|c|c|}
\hline & Branco & Padrão & Desconhecido \\
\hline Sobrenadante & - & - & $100 \mu \mathrm{L}$ \\
\hline Padrão & - & $20 \mu \mathrm{L}$ & - \\
\hline Reativo de trabalho Colesterol & $2000 \mu \mathrm{L}$ & $2000 \mu \mathrm{L}$ & $2000 \mu \mathrm{L}$ \\
\hline
\end{tabular}

As amostras foram misturadas e incubadas por 15 minutos à $37{ }^{\circ} \mathrm{C}$ em banhomaria. Logo após, os tubos contendo as amostras foram retirados do banho-maria e resfriadas por 5 minutos a temperatura ambiente. Na sequência, as amostras foram levadas para leitura em espectrofotômetro à absorbância de $505 \mathrm{~nm}$, zerando o aparelho com o Branco. O cálculo da concentração de HDL no sangue foi feito com a mesma fórmula utilizada para o cálculo da concentração de colesterol.

A concentração de VLDL no sangue foi calculado conforme a fórmula a seguir: 


\section{VLDL Colesterol, $\mathrm{mg} / \mathrm{dL}=$ Triglicerídeos $/ 5$}

A concentração de LDL no sangue foi determinada de forma indireta por meio da seguinte fórmula:

\section{LDL Colesterol, $\mathrm{mg} / \mathrm{dL}=$ Colesterol total $-($ HDL Colesterol + VLDL Colesterol $)$}

\subsection{Colesterol na Carne}

Após o abate, as carcaças foram resfriadas por 24 horas e posteriormente, amostras do músculo Longissimus dorsi, entre as $12^{\mathrm{a}}$ e $13^{\mathrm{a}}$ costelas, com $2,54 \mathrm{~cm}$ de espessura foram retiradas da meia carcaça esquerda, etiquetadas e congeladas a $-20^{\circ} \mathrm{C}$ para futuras análises laboratoriais de colesterol total na carne. As análises da concentração colesterol no músculo Longissimus dorsi foram realizadas pelo Instituto de Tecnologia de Alimentos (ITAL, Campinas, SP, Brasil) utilizando as metodologias de Folch et al. (1957) e Bohac et al. (1988).

\subsection{Perfil de Ácidos Graxos}

Amostras de aproximadamente $3 \mathrm{~g}$ de gordura visceral (VIS; proveniente dos rins e pelve), gordura subcutânea do músculo Longissimus (SUB) e da gordura intermuscular (IMU) entre os músculos Bíceps femoris (coxão duro + picanha) e Gluteus medius (Alcatra) foram coletadas e acondicionadas em nitrogênio líquido para futura análise do perfil de ácidos graxos.

A extração dos lipídeos, transesterificação e metilação dos ácidos graxos foi realizada no Laboratório de Nutrição e Crescimento Animal da Escola Superior de Agricultura "Luiz de Queiroz" - ESALQ/USP, assim como a análise cromatográfica. A extração e avaliação dos lipídeos totais foram realizadas de acordo com a metodologia modificada de Hara e Radin (1978), com uso de hexano/isopropanol 3:2 (v/v).

Para a transesterificação dos ácidos graxos foi utilizada metodologia descrita por Christie (1982), com modificações, utilizando solução metanólica de metóxido de sódio. Aproximadamente $40 \mathrm{mg}$ de lipídeos foram transferidos para tubo de ensaio, adicionando-se $2 \mathrm{~mL}$ de hexano, seguido de $40 \mu \mathrm{L}$ de metil acetato. Após agitação em 
vortex foram adicionados $40 \mu \mathrm{L}$ de solução de metilação $(1,75 \mathrm{~mL}$ de metano/0,4 $\mathrm{mL}$ de 5,4 mol/L de metóxido de sódio). Em seguida, a mistura foi novamente agitada em vortex durante dois minutos, seguido de descanso durante 10 minutos. Logo após, foram adicionados $60 \mu \mathrm{L}$ de solução reagente de terminação (1 g ácido oxálico/30 mL dietil éter) e agitados em vortex por 30 segundos. No mesmo processo foi adicionado $200 \mathrm{mg}$ de cloreto de cálcio, mantendo a solução em repouso por 1 hora, seguido de centrifugação $(5700 \mathrm{G})$ durante 5 minutos à $5^{\circ} \mathrm{C}$. Após centrifugação, o sobrenadante foi transferido para frascos específicos para realização da cromatografia gasosa.

A análise cromatográfica foi feita em cromatógrafo Thermo Finnigan, modelo Trace com detector de ionização de chama (FID), utilizando coluna capilar de sílica fundida de $100 \mathrm{~m}$ de comprimento, 0,25 $\mathrm{mm}$ diâmetro e 0,2 $\mu \mathrm{m}$ de espessura (Supelco SP-2560, Bellefonte, PA, EUA). O gás de arraste utilizado foi hélio a 1,2 mL/min. Para injeção foi utilizado $1 \mu \mathrm{L}$ de amostra em modo split, com razão de divisão $1 / 21 \mathrm{e}$ temperatura de $250^{\circ} \mathrm{C}$. A temperatura inicial do forno foi de $70^{\circ} \mathrm{C}$ durante 4 minutos, elevando a $170^{\circ} \mathrm{C}$ com proporções de $13^{\circ} \mathrm{C} / \mathrm{min}$, e finalmente para $250^{\circ} \mathrm{C}$ a $35^{\circ} \mathrm{C} / \mathrm{min}$ por 5 minutos. A temperatura do detector foi de $300^{\circ} \mathrm{C}$ e o fluxo dos gases de $450,40 \mathrm{e}$ $45 \mathrm{~mL} / \mathrm{min}$ para o ar sintético, hidrogênio e nitrogênio, respectivamente. A identificação e taxa de recuperação dos ésteres metílicos dos ácidos graxos foi feita através da comparação com os tempos de retenção e as concentrações dos ácidos graxos de um padrão conhecido (Supelco Inc., Bellefonte, PA, EUA).

\subsection{Delineamento Experimental e Análise Estatística}

O delineamento experimental foi inteiramente casualizado e as baias foram consideradas unidades experimentais. Foram realizados testes de normalidade e de heterogeneidade de variâncias antes de se proceder a análise de variância e quando necessário, os dados foram transformados. Para todas as variáveis respostas em que foram realizadas medidas repetidas no tempo, foram testadas as seguintes estruturas de covariância: AR(1), ARH(1), ANTE(1), CS, CSH, TOEP, TOEPH, UN, UNR e HF. A estrutura que rendeu menor valor de AIC (Akaike Bayesian Criterion) para cada variável resposta, foi escolhida para análise por acomodar melhor os dados. Resultados foram considerados significantes a $\mathrm{P}<0,05$. 
Os dados de colesterol no músculo Longissimus dorsi foi analisado como arranjo fatorial $2 \times 2$, em que os efeitos de dois grupos genéticos (BR e NE) e de dois aditivos alimentares (PAP e MON) foram avaliados utilizando-se o PROC MIXED do SAS (2003) de acordo com o modelo 1 abaixo.

\section{MODELO 1:}

$Y_{i j k}=\mu+G G_{i}+T_{j}+G G^{*} T_{i j}+e_{i j k}$;

em que:

- $\mathrm{Y}_{\mathrm{ijk}}$ é a observação na $\mathrm{k}^{\text {ésima }}$ baia, no $\mathrm{j}^{\text {ésimo }}$ tratamento e no $\mathrm{i}^{\text {ésimo }}$ grupo genético;

- $\mu$ é a média geral;

- $\mathrm{GG}_{\mathrm{i}}$ é o efeito do $\mathrm{i}^{\text {ésimo }}$ grupo genético, sendo $\mathrm{i}=1$ : NE e 2: BR;

- $\mathrm{T}_{\mathrm{j}}$ é o efeito do jésimo aditivo alimentar, sendo $\mathrm{j}=1$ : MON e 2: PAP;

- GG* $\mathrm{T}_{\mathrm{ij}}$ é a interação entre o $\mathrm{i}^{\text {śimo }}$ grupo genético e o jésimo aditivo alimentar;

- $\mathrm{e}_{\mathrm{ijk}}$ é o erro experimental associado a observação $\mathrm{Y}_{\mathrm{ijk}}\left(0 ; \sigma_{e}^{2}\right)$.

Os dados de lipoproteínas do sangue foram analisados como arranjo fatorial $2 \times$ 2 com medidas repetidas no tempo, em que os efeitos de dois grupos genéticos (BR e $\mathrm{NE}$ ) e de dois aditivos alimentares (PAP e MON) foram avaliados em duas fases de mensurações (CRES e TERM) utilizando-se o PROC MIXED do SAS (2003) de acordo com o modelo 2 abaixo e teste de Tukey para comparação entre médias.

\section{MODELO 2:}

$Y_{i j k l}=\mu+G G_{i}+T_{j}+G G^{*} T_{i j}+\gamma_{i j l}+F_{k}+G G^{*} F_{i k}+T^{*} F_{j k}+G G^{*} T^{*} F_{i j k}+e_{i j k l} ;$

em que:

- $Y_{\mathrm{ijkl}}$ é a observação na $\mathrm{l}^{\text {ésima }}$ baia, no $\mathrm{j}^{\text {ésimo }}$ tratamento, no $\mathrm{i}^{\text {ésimo }}$ grupo genético e $\mathrm{k}^{\text {ésima }}$ fase de mensuração;

- $\mu$ é a média geral;

- $\mathrm{GG}_{\mathrm{i}}$ é o efeito do $i^{\text {ésimo }}$ grupo genético, sendo $\mathrm{i}=1$ : NE e 2: BR;

- $\mathrm{T}_{\mathrm{j}}$ é o efeito do $\mathrm{j}^{\text {ésimo }}$ aditivo alimentar, sendo $\mathrm{j}=1$ : MON e 2: PAP;

- GG* $\mathrm{T}_{\mathrm{ij}}$ é a interação entre o $\mathrm{i}^{\text {śimo }}$ grupo genético e o jésimo aditivo alimentar;

- $\gamma_{\mathrm{ijl}}$ é o erro experimental “a” associado a observação $\mathrm{Y}_{\mathrm{ijl}}\left(0 ; \sigma_{\gamma}^{2}\right)$; 
- $\mathrm{F}_{\mathrm{k}}$ é o efeito da $\mathrm{k}^{\text {ésima }}$ fase, sendo $\mathrm{k}=1$ : CRES e 2: TERM;

- GG* $\mathrm{F}_{\mathrm{ik}}$ é a interação entre o $\mathrm{i}^{\text {śimo }}$ grupo genético e a $\mathrm{k}^{\text {ésima }}$ fase;

- $\mathrm{T}^{*} \mathrm{~F}_{\mathrm{jk}}$ é a interação entre o $\mathrm{j}^{\text {śimo }}$ aditivo alimentar e a $\mathrm{k}^{\text {ésima }}$ fase;

- GG* $T^{*} \mathrm{~F}_{\mathrm{ijk}}$ é a interação entre o $\mathrm{i}^{\text {ésimo }}$ grupo genético, o jésimo aditivo alimentar e a $\mathrm{k}^{\text {ésima }}$ fase;

- $\mathrm{e}_{\mathrm{ijkl}}$ é o erro experimental "b" associado a observação $\mathrm{Y}_{\mathrm{ijkl}}\left(0 ; \sigma_{e}^{2}\right)$.

Já os dados referentes ao perfil de ácidos graxos do tecido adiposo foram analisados como arranjo fatorial $2 \times 2$ com medidas repetidas no espaço, em que os efeitos de dois grupos genéticos (BR e NE) e de dois aditivos alimentares (PAP e MON) foram avaliados em três distintas regiões de amostragem (SUB, VIS e IMU) utilizandose o PROC MIXED do SAS (2003) de acordo com o modelo 3 abaixo e teste de Tukey para comparação entre médias.

MODELO 3:

$Y_{i j k l}=\mu+G G_{i}+T_{j}+G G^{*} T_{i j}+\gamma_{i j l}+R E_{k}+G G^{*} R E_{i k}+T^{*} R E_{j k}+G G^{*} T^{*} R E_{i j k}+e_{i j k l} ;$

em que:

- $Y_{\mathrm{ijkl}}$ é a observação na $1^{\text {ésima }}$ baia, no $\mathrm{j}^{\text {ésimo }}$ tratamento, no $\mathrm{i}^{\text {simo }}$ grupo genético e $\mathrm{k}^{\text {ésima }}$ região de mensuração;

- $\mu$ é a média geral;

- $\mathrm{GG}_{\mathrm{i}}$ é o efeito do $i^{\text {ésimo }}$ grupo genético, sendo $\mathrm{i}=1$ : NE e 2: BR;

- $\mathrm{T}_{\mathrm{j}}$ é o efeito do jésimo aditivo alimentar, sendo $\mathrm{j}=1$ : MON e 2: PAP;

- GG* $T_{i j}$ é a interação entre o $i^{\text {ésimo }}$ grupo genético e o jésimo aditivo alimentar;

- $\gamma_{\mathrm{ijl}}$ é o erro experimental “a” associado a observação $\mathrm{Y}_{\mathrm{ijl}}\left(0 ; \sigma_{\gamma}^{2}\right)$;

- $\mathrm{RE}_{\mathrm{k}}$ é o efeito da $\mathrm{k}^{\text {ésima }}$ região de mensuração, sendo $\mathrm{k}=1$ : SUB, 2: VIS e 3: IMU;

- GG*RE $E_{\mathrm{ik}}$ é a interação entre o $\mathrm{i}^{\text {ésimo }}$ grupo genético e a $\mathrm{k}^{\text {ésima }}$ região;

- T* $\mathrm{RE}_{\mathrm{jk}}$ é a interação entre o $\mathrm{j}^{\text {ésimo }}$ aditivo alimentar e a $\mathrm{k}^{\text {śima }}$ região;

- GG*T*RE $\mathrm{E}_{\mathrm{ijk}}$ é a interação entre o $\mathrm{i}^{\text {ésimo }}$ grupo genético, o jésimo aditivo alimentar e a $\mathrm{k}^{\text {ésima }}$ região;

- $\mathrm{e}_{\mathrm{ijkl}}$ é o erro experimental "b" associado a observação $\mathrm{Y}_{\mathrm{ijkl}}\left(0 ; \sigma_{e}^{2}\right)$. 


\section{RESULTADOS}

\subsection{Lipoproteínas do Sangue e Colesterol na Carne}

Não foi observado $(P>0,05)$ efeito principal dos aditivos alimentares sobre a concentração de colesterol na carne e sobre a maioria das lipoproteínas sanguíneas, com exceção à HDL $(P<0,05)$, onde bovinos que receberam PAP apresentaram maior concentração $(59,85$ vs. 54,04 mg/dL) que animais suplementados com MON (Tabela 2).

Com relação aos grupos genéticos, foi encontrado efeito principal apenas sobre a concentração dos Triglicerídeos e VLDL $(P<0,01)$, onde bovinos NE apresentaram maiores concentrações (Tabela 2).

No tocante às fases de mensuração, foram observados $(P<0,01)$ efeito principal apenas sobre o colesterol sanguíneo e LDL, onde maiores concentrações foram encontradas na fase de CRES (Tabela 2).

\subsection{Perfil de Ácidos Graxos}

Não foi observado $(P>0,05)$ efeito principal dos aditivos alimentares sobre a concentração da maioria dos ácidos graxos mensurados nas diferentes regiões de amostragem, com exceção dos ácidos graxos de cadeia curta (AGCC), ácido Transvaccênico (TVA) e ácidos graxos não identificados (AGNI), onde bovinos que receberam MON apresentaram $(P<0,01)$ maiores concentrações de TVA e menores concentrações de AGCC e AGNI (Tabela 3).

Foram encontradas interações significativas $(P<0,01)$ entre aditivos alimentares e grupos genéticos para os ácidos graxos: Mirístico (C14:0), Palmítico (C16:0), Heptadecenóico (C17:1), Oléico (C18:1), Linoléico (C18:2), Saturados (AGS), Insaturados (AGI), Monoinsaturados (MUFA), Poliinsaturados (PUFA) e para as relações MUFA:AGS e PUFA:MUFA. Os animais BR que receberam MON apresentaram maiores $(P<0,01)$ concentrações de C14:0 e C16:0 que $\mathrm{NE}$ suplementados com MON. No entanto, não foi observada diferença $(P>0,05)$ entre os grupos genéticos quando estes receberam PAP. Ainda, quando foram alimentados com dietas contendo PAP, bovinos NE apresentaram maior $(P<0,01)$ concentração de C14:0 e C16:0 do que quando estes foram suplementados com MON (Figuras 1 e 2). 
Para os C17:1, AGI, MUFA e MUFA:AGS, animais BR recebendo PAP apresentaram maiores $(P<0,01)$ concentrações de que NE suplementados com PAP. No entanto, não foi observada diferença $(P>0,05)$ entre os grupos genéticos quando estes receberam MON. Ainda, quando foram alimentados com dietas contendo MON, bovinos NE apresentaram maiores $(P<0,01)$ concentrações de C17:1, AGI, MUFA e MUFA:AGS do que quando estes foram suplementados com PAP (Figuras 3, 4, 5 e 6). Animais BR recebendo PAP apresentaram maiores $(P<0,01)$ concentrações de C18:1 que NE suplementados com PAP. No entanto, quando as dietas continham MON foi observado $(P<0,01)$ maior concentração de C18:1 no tecido adiposo de animais NE. Ainda, quando foram alimentados com dietas contendo $\mathrm{MON}$, bovinos NE apresentaram maior $(P<0,01)$ concentração de $\mathrm{C} 18: 1$ do que quando estes foram suplementados com PAP (Figura 7).

Para o C18:2, animais NE que receberam PAP apresentaram maiores $(P<0,05)$ concentrações que BR suplementados com PAP. No entanto, quando as dietas continham MON foi observado $(P<0,01)$ maior concentração de C18:2 no tecido adiposo de animais BR. Ainda, quando foram alimentados com dietas contendo MON, bovinos NE apresentaram menor $(P<0,01)$ concentração de $\mathrm{C} 18: 2$ do que quando estes foram suplementados com PAP (Figura 8). Quando foram alimentados com dietas contendo MON, bovinos NE apresentaram menor $(P<0,01)$ concentração de AGS do que quando estes foram suplementados com PAP. Já bovinos BR não mostraram diferença $(P>0,05)$ na concentração de AGS nos tecidos adiposos quando PAP e MON foram fornecidos. Ainda, Animais NE recebendo PAP apresentaram maiores $(P<0,05)$ concentrações de AGS que BR suplementados com PAP. No entanto quando as dietas continham MON, não foi observado $(P>0,05)$ diferenças entre os grupos genéticos (Figura 9).

Quando foram alimentados com dietas contendo MON, bovinos NE apresentaram menores $(P<0,05)$ concentrações de PUFA e PUFA:MUFA do que quando estes foram suplementados com PAP. Por outro lado, bovinos BR mostraram redução $(P<0,01)$ na concentração de PUFA e de PUFA:MUFA nos tecidos adiposos quando receberam PAP. Ainda, Animais BR recebendo PAP apresentaram menores $(P$ $<0,01)$ concentrações de PUFA e de PUFA:MUFA que bovinos NE suplementados com PAP. No entanto quando as dietas continham MON, foram observados $(P<0,01)$ 
menores concentrações de PUFA e de PUFA:MUFA nos tecidos adiposos de animais NE (Figuras 10 e 11).

Também foram observadas interações $(P<0,05)$ entre aditivos alimentares, grupos genéticos e regiões de amostragem para os ácidos graxos: Miristoléico (C14:1), Pentadecanóico (C15:0), Esteárico (C18:0), Linoléico Conjugado (CLA), Linolênico n-

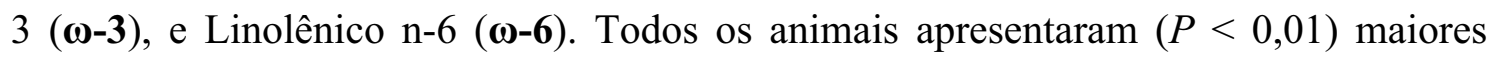
concentrações de C14:1 no tecido adiposo na seguinte ordem: SUB > IMU > VIS. Quando os grupos genéticos foram suplementados com PAP, animais BR apresentaram maiores concentrações de C14:1 nos tecidos adiposos IMU e SUB que bovinos NE, no entanto não foi observada diferença $(P>0,05)$ entre os grupos genéticos quando se amostrou o tecido adiposo VIS. Por outro lado, quando os grupos genéticos foram suplementados com MON, não foram detectadas $(P>0,05)$ diferenças nas distintas regiões de amostragem. Ainda, não foi observada diferença $(P>0,05)$ entre bovinos $\mathrm{BR}$ suplementados com PAP e MON nas diferentes regiões de amostragem, sendo o mesmo observado $(P>0,05)$ para os animais NE para o C14:1 (Figura 12). Com relação ao C15:0, todos os animais apresentaram $(P<0,01)$ maiores concentrações de C15:0 nos tecidos adiposos VIS e IMU, com exceção de animais NE que receberam MON, os quais apresentaram $(P<0,05)$ concentrações descrescentes de C15:0 de acordo com a região de amostragem: IMU > VIS $>$ SUB.

Quando os grupos genéticos foram suplementados com MON, animais BR aprentaram maiores $(P<0,05)$ concentrações de C15:0 em todos os tecidos adiposos amostrados que bovinos NE. Por outro lado, quando os grupos genéticos foram suplementados com PAP, não foram detectadas $(P>0,05)$ diferenças nas distintas regiões de amostragem. Ainda, não foi observada diferença $(P>0,05)$ entre bovinos $\mathrm{BR}$ suplementados com PAP e MON nas diferentes regiões de amostragem. Entretanto, bovinos NE apresentaram maiores $(P<0,05)$ concentrações de C15:0 nos tecidos adiposos SUB e VIS quando estes receberam PAP, porém não foram detectadas diferenças $(P>0,05)$ no tecido adiposo IMU (Figura 13).

Os animais apresentaram $(P<0,01)$ maiores concentrações de C18:0 no tecido adiposo, de acordo com a região de amostragem, na seguinte ordem: VIS > IMU > SUB. Quando os grupos genéticos foram suplementados com MON, animais NE aprentaram maiores $(P<0,01)$ concentrações de C18:0 que bovinos BR no tecido 
adiposo VIS, mas nenhuma diferença $(P>0,05)$ foi constatada nos outros tecidos amostrados. Por outro lado, quando os grupos genéticos foram suplementados com PAP, animais NE apresentaram maiores $(P<0,01)$ concentrações de C18:0 que bovinos BR no tecido adiposo SUB, mas nenhuma diferença $(P>0,05)$ foi constatada nos outros tecidos amostrados. Ainda, não foi observada diferença $(P>0,05)$ entre bovinos BR suplementados com PAP e MON nas diferentes regiões de amostragem. Entretanto, para bovinos NE que receberam PAP e MON, foram observadas maiores $(P<0,01)$ concentrações de C18:0 no tecido adiposo VIS quando estes receberam MON, porém não foram detectadas diferenças $(P>0,05)$ nos tecidos adiposos IMU e SUB (Figura 14).

Com respeito ao CLA, todos os animais apresentaram $(P<0,05)$ menores concentrações no tecido adiposo VIS. Quando os grupos genéticos foram suplementados com MON, animais BR apresentaram maiores $(P<0,05)$ concentrações de CLA em todos os tecidos adiposos amostrados, com exceção do SUB, que bovinos NE (Figura 15). Por outro lado, quando os grupos genéticos foram suplementados com PAP, foram encontradas $(P<0,05)$ maiores concentrações de CLA apenas no tecido adiposo SUB de animais BR quando estes foram comparados aos NE. Ainda, não foi observada diferença $(P>0,05)$ entre bovinos BR suplementados com PAP ou MON nas diferentes regiões de amostragem. Entretanto, para bovinos NE, foram observadas maiores $(P<0,05)$ concentrações de CLA no tecido adiposo VIS quando estes receberam PAP, porém não foram detectadas diferenças $(P>0,05)$ entre os aditivos alimentares nos tecidos adiposos IMU e SUB (Figura 15).

Para o $\omega-3$, quando os animais dos diferentes grupos genéticos foram suplementados com MON, animais BR aprensentaram maiores $(P<0,05)$ concentrações de $\omega-3$ nos tecidos adiposos IMU e VIS que bovinos NE. Por outro lado, quando os grupos genéticos foram suplementados com PAP, foram encontradas $(P<$ 0,05) maiores concentrações de $\omega-3$ apenas nos tecidos adiposos IMU e VIS de animais NE quando estes foram comparados aos BR. Ainda, bovinos BR suplementados com MON apresentaram maiores $(P<0,05)$ concentrações de $\omega$-3 nos tecidos IMU e VIS do que BR recebendo PAP. Ao contrário para bovinos NE, foram observadas maiores $(P<$ $0,05)$ concentrações de $\omega-3$ em todos os tecidos amostrados de animais que receberam PAP, quando comparados aos suplementados com MON (Figura 16). Enfim, todos os 
animais apresentaram $(P<0,01)$ maiores concentrações de $\omega-6$ no tecido adiposo VIS. Quando os grupos genéticos foram suplementados com MON, animais NE aprensentaram maiores $(P<0,05)$ concentrações de $\omega-6$ nos tecidos adiposos IMU e VIS que bovinos BR. Por outro lado, quando os grupos genéticos foram suplementados com PAP, foi encontrado $(P<0,05)$ maiores concentrações de $\omega-6$ apenas no tecido adiposo SUB de animais NE quando estes foram comparados aos BR. Ainda, bovinos BR suplementados com MON apresentaram maiores $(P<0,05)$ concentrações de $\omega-6$ no tecido SUB do que animais BR recebendo PAP. Ao contrário para bovinos NE, foi observado maiores $(P<0,05)$ concentrações de $\omega-6$ nos tecidos adiposos IMU e VIS de animais que receberam MON, quando comparados aos suplementados com PAP (Figura 17).

Não foi observado $(P>0,05)$ efeito principal dos grupos genéticos sobre a concentração da maioria dos ácidos graxos mensurados nas diferentes regiões de amostragem, com exceção dos ácidos graxos Pentadecenóico (C15:1), Palmitoléico (C16:1) e TVA, onde bovinos BR apresentaram maiores $(P<0,01)$ concentrações que animais NE (Tabela 3).

No tocante às regiões de mensuração, foi observado $(P<0,01)$ efeito principal sobre todos os ácidos graxos mensurados, com exceção $(P>0,05)$ do C14:1, C15:0, C18:0, CLA, $\omega-3$ e $\omega-6$ (Tabela 3). Amostras das regiões VIS e IMU apresentaram $(P<$ 0,05) maiores concentrações de AGCC, C14:0 e C17:0 que a região SUB. Por outro lado, amostras da região SUB apresentaram $(P<0,05)$ concentrações mais elevadas de C15:1, C16:1, C17:1, C18:1, AGI, MUFA e MUFA:AGS em relação à região IMU, a qual apresentou maiores $(P<0,05)$ concentrações que a região VIS, para os mesmos ácidos graxos. Amostras do tecido adiposo SUB ainda apresentaram $(P<0,05)$ maiores concentrações de C18:2, PUFA:AGS e AGNI que amostras das regiões VIS e IMU. Maiores concentrações de C16:0 e PUFA:MUFA foram encontradas $(P<0,05)$ nos tecidos IMU e VIS, respectivamente. Já para TVA, AGS e PUFA, maiores concentrações foram observadas $(P<0,05)$ nos tecidos IMU, VIS e SUB, respectivamente, e menores concentrações $(P<0,05)$ nos tecidos SUB, SUB e IMU, respectivamente.

\section{DISCUSSÃO}




\subsection{Aditivos Alimentares}

Apesar de apresentaram maior concentração de AGS que animais NE suplementados com MON (Figura 9), bovinos NE que receberam PAP apresentaram maiores concentrações dos ácidos graxos insaturados C18:2, PUFA, PUFA:MUFA, CLA (apenas no tecido VIS) e $\omega$-3 que NE que consumiram MON (Figuras 8, 10, 11, 15 e 16; respectivamente). Tem sido amplamente demonstrado que ácidos graxos poliinsaturados de cadeia longa participam de vários processos metabólicos benéficos à saúde humana (Cook et al., 2001; Varela et al., 2004) e que as gorduras da carne de ruminantes são fontes naturais de alguns desses ácidos graxos, como os isômeros do CLA (French et al., 2000; Metz et al., 2009) e o $\omega$-3, que age como elemento protetor contra o câncer de mama (Holmes et al., 1999; Sugano e Hirahara, 2000). Assim, animais que receberam PAP apresentaram menor relação $\omega-6 / \omega-3$ que animais que receberam MON (1,14 vs. 1,29), indicativo de gordura mais saudável (Bartsch et al., 1999). Esses efeitos observados podem estar ligados ao fato de que animais que consumiram PAP durante o estudo apresentaram maiores concentrações de HDL no sangue (Tabela 2). Ácidos graxos saturados como os C14:0 e C16:0 são transportados pelas VLDL e LDL do sangue, porém ácidos graxos insaturados (C18:2, $\omega$-3 e o CLA) são transportados, na sua maior parte, pela HDL (Souza, 2005). Entretanto, bovinos BR que receberam PAP apresentaram menores concentrações de PUFA, PUFA:MUFA e $\omega$ 3 que àqueles suplementados com MON, o que poderia ser explicado pela menor biohidrogenação promovida pela MON (Van Nevel e Demeyer, 1995), indicando que talvez um fator, ainda não claro ligado a raça NE, possa estar afetando positivamente as concentrações de C18:2, PUFA, PUFA:MUFA, CLA e $\omega$-3 quando estes receberam PAP.

Em contrapartida, bovinos $\mathrm{NE}$ recebendo $\mathrm{MON}$ apresentaram maiores concentrações dos ácidos graxos insaturados AGI, MUFA, MUFA:AGS, C18:1 e $\omega-6$ (tecidos IMU e VIS) que NE que consumiram PAP (Figuras 4, 5, 6, 7 e 17; respectivamente). Ainda, bovinos BR suplementados com MON mostraram maiores concentrações de $\omega-6$ no tecido SUB que BR que consumiram PAP. Foi observado ainda efeito principal da MON em elevar a concentração de TVA (Tabela 3). Eifert (2004) verificou que a proporção de ácidos graxos insaturados do leite foi mais alta em 
vacas recebendo dietas com MON. Tanto a suplementação com MON quanto a maior incidência de lesões no rúmen levam a diminuição da biohidrogenação e, consequentemente, ao maior acúmulo de ácidos graxos insaturados nos tecidos adiposos (Van Nevel e Demeyer, 1995; Fellner et al., 1997). Como animais NE apresentaram maior incidência de rumenites no presente estudo, isso permite atribuir em parte que: o acúmulo dos ácidos graxos insaturados citados acima nos tecidos adiposos amostrados pode estar ligado a maior acidificação ruminal sofrida pelos animais da raça NE.

Ainda, animais NE suplementados com PAP apresentaram maiores concentrações de C14:0 e C16:0 (Figuras 1 e 2) e menores concentrações de C18:0 (Figura 14) que bovinos que consumiram MON. Como a MON promove o efeito de redução na biohidrogenação (Fellner et al., 1997), já era esperado que animais recebendo PAP apresentassem maiores concentrações de alguns ácidos graxos saturados. No entanto, bovinos que receberam PAP não apresentaram aumento na concentração das lipoproteínas sanguíneas VLDL e LDL (Tabela 2), as quais são as responsáveis pelo transporte dos C14:0 e C16:0 para os tecidos (Ochoa e Marchello, 1991), mas animais NE apresentaram maior concentração de VLDL o que pode ter colaborado com o aumento (Tabela 2). Por outro lado, Fossa et al. (2008) encontraram maiores concentrações dos ácidos graxos C16:0 e C17:0 na gordura subcutânea de animais suplementados com MON quando estes foram comparados àqueles que receberam PAP, não corroborando com os achados do presente estudo.

\subsection{Grupos Genéticos}

No presente estudo animais BR apresentaram maiores concentrações de alguns ácidos graxos insaturados nos tecidos adiposos que bovinos NE, os quais incluem: C15:1, C16:1, TVA e CLA (Tabela 3 e Figura 15). No entanto, foi observado nos tecidos adiposos de animais NE, maiores concentrações de $\omega-6$ e C18:0 (Figuras 17 e 14, respectivamente) e de AGS quando suplementados com PAP (Figura 9). Animais NE, ainda, apresentaram maiores concentrações da lipoproteína VLDL (Tabela 2), as quais são responsáveis pelo transporte de ácidos graxos saturados como o C14:0 e C16:0 (Mattson e Grundy, 1985) até os tecidos. Todavia, não foram encontrados diferenças nas concentrações dos ácidos graxos C14:0 e C16:0 nos tecidos adiposos de animais NE e BR que receberam PAP, sendo observada maiores concentrações desses 
ácidos graxos em animais BR, quando ambos os grupos genéticos receberam MON (Figuras 1 e 2). Esse resultados não concordam com os dados obtidos por Fossa et al. (2008), que observaram maiores concentrações de C18:1, CLA, AGI, MUFA, PUFA:AGS, MUFA:AGS, e menores concentrações de C16:0, C17:0 e C18:0 no tecido adiposo SUB de bovinos da raça NE em relação a animais Canchim e Tri-Cross ( $1 / 2$ BR, $1 / 4$ Angus, $1 / 4$ NE). No estudo de Fossa et al. (2008) foi inferido que a maior incidência de lesões ruminais em bovinos da raça $\mathrm{NE}$, pode ter levado à redução da biohidrogenação e o consequente aumento de ácidos graxos insaturados no tecido adiposo SUB desses animais. Da mesma forma, no presente estudo, foi observado maior incidência de rumenites em bovinos NE. No entanto, essa maior incidência foi menor $(2,6)$ quando comparado ao estudo de Millen et al. (2007) que foi de 4,29. A pesquisa da microbiologia ruminal de animais Zebu é muito escassa, e sendo a biohidrogenação ruminal um processo essencialmente microbiano, não se sabe se existem diferenças nas populações microbianas entre animais compostos por genótipos Bos indicus e Bos taurus. Deste modo, mais estudos necessitam ser conduzidos para se esclarecer de melhor maneira, a relação entre as lesões ruminais e o perfil de ácidos graxos dos tecidos adiposos de bovinos de diferentes grupos genéticos que consomem dietas contendo altos níveis de concentrado.

\subsection{Fases e Regiões de Mensuração}

Com respeito as fases de mensuração para as lipoproteínas do sangue, foi encontrado maior concentração de colesterol e LDL na fase de CRES em relação a de TERM (Tabela 2). Esses dados concordam com os achados de Ochoa e Marchello (1991), em que reduções lineares tanto de LDL quanto de colesterol foram encontradas à medida que bovinos jovens avançaram no desenvolvimento até serem abatidos. DiMarco et al. (1981) também encontraram redução no colesterol sanguíneo à medida que os animais cresceram e se aproximaram do ponto de abate. Ochoa e Marchello (1991) por outro lado encontraram aumentos lineares do HDL enquanto os animais se desenvolveram, porém este resultado não foi observado no presente estudo (Tabela 2).

Em relação as regiões de mensuração foi constatado maior proporção de ácidos graxos insaturados incluindo o MUFA, PUFA, C18:1, AGI e outros, no tecido adiposo SUB em relação aos tecidos VIS e IMU (Tabela 3). É claro que, por outro lado, foram 
encontrados nos tecidos adiposos IMU e VIS maiores concentrações de ácidos graxos saturados. Assim, podemos inferir que a gordura do contra-filé (SUB) possui perfil de ácidos graxos mais insaturado que a gordura IMU localizada entre o alcatra e a picanha.

A relação volumoso:concentrado, adições de tampões, alimentação restrita e o estágio de crescimento das pastagens são fatores que podem influenciar o conteúdo de CLA e de ácidos graxos insaturados na carne e na gordura de ruminantes. Outro fator bastante estudado para o aumento na concentração de CLA e de ácidos graxos insaturados na carne é a adição de óleos à dieta (Mir et al. 2004; Eiffert, 2004). No entanto, a biohidrogenação ruminal e a incidência de rumenites parecem não ser os únicos responsáveis pela composição do perfil de ácidos graxos da gordura da carcaça de bovinos de corte confinados. Algum outro fator que ainda não está claro parece estar envolvido na alteração da composição dos ácidos graxos da carcaça de bovinos confinados. Como não há na literatura estudos anteriores que tenham mensurado a concentração dos ácidos graxos em diferentes tecidos adiposos da carcaça de bovinos, se torna mais difícil fazer alguma inferência com relação aos resultados obtidos. Assim sendo, mais estudos similares a este em relação ao perfil de ácidos graxos devem ser conduzidos para que se possa entender os mecanismos pelos quais o tecido adiposo SUB contém maior proporção da maioria dos ácidos graxos insaturados em relação aos tecidos adiposos IMU e VIS.

\section{CONCLUSÕES}

Bovinos Nelore que consumiram o preparado de anticorpos policlonais no presente estudo, apesar de apresentarem menores concentrações totais de ácidos graxos insaturados nos tecidos adiposos amostrados, aumentaram a concentração de alguns ácidos graxos insaturados benéficos à saúde humana como os ácidos linoléico (C18:2) e linoléico conjugado (CLA) e total de ácidos graxos poliinsaturados (PUFA), elevando assim a concentração de HDL no sangue.

Com relação as distintas regiões de amostragem, amostras do tecido adiposo subcutâneo mostraram incrementos de $15 \%$ e $28 \%$ no teor de ácidos graxos insaturados em relação aos tecidos adiposos intermuscular e visceral, respectivamente. 


\section{REFERÊNCIAS BIBLIOGRÁFICAS}

ALLAIN, C. C.; POON, L. S.; CHAN, C. S. G. et al. Enzymatic determination of total serum cholesterol. Clinical Chemistry, v. 20, n. 4, p. 470-475, 1974.

ASSOCIATION OF OFFICIAL ANALYTICAL CHEMISTS - AOAC. Offical methods of analyses. 16 ed. Washington, D.C. 1997. 1141p.

BARTSCH, H.; NAIR, J.; OWEN, R.W. Dietary polyunsaturated fatty acids and cancers of the breast and colorectum: emerging evidence for their role as risk modifiers. Carcinogenesis, v. 20, p. 2209-2218, 1999.

BEEFPOINT. Ponto de Encontro da Cadeia da Carne. Notícias. 2010. Disponível em: http://www.beefpoint.com.br/?noticiaID=59748\&actA=7\&areaID=15\&secaD=16. Acesso em 17/01/2010.

BLANCH, M.; CALSAMIGLIA, S.; DILORENZO, N. et al. Physiological changes in rumen fermentation during acidosis induction and its control using a multivalent polyclonal antibody preparation in heifers. Journal of Animal Science, v.87, p.1722-1730, 2009.

BOHAC, C. E.; RHEE, K. S.; CROSS, H. R. et al. Assessment of methodologies for colorimetric cholesterol assay of meats. Journal of Food Science, v. 53, p.1642$1644,1988$.

CNCPS - Cornell Net Carbohydrate and Protein System. The net carbohydrate and protein system for evaluating herd nutrition and nutrients excretion. Version 5.0. Ithaca, NY. p.37, 2000.

COOK, M .E.; WHIGHAM, L. D.; YANG, M. et al. CLA inhibitis the induction of prostaglandin and leukotriene synthesis. A natural substitute for non-steroidal andti-inflammaory drugs? In: INTERNATIONAL CONFERENCE ON CLA, 1. Proceedings. Alesund: NATURAL ASA, 2001, p. 6-7, 2001.

CHRISTIE, W.W. Simple produce for rapid transmethy lation of glycerolipids and cholesteryl esters. Journal of lipid research, v.23, p.1-4, 1982.

DILORENZO, N. Effects of feeding polyclonal antibody preparations against rumen starch and lactic-fermenting bacteria on target bacteria populations 
and steer performance. Saint Paul, Minnesota, USA: University of Minnesota, 2004, p.101. Master thesis submitted to the faculty of the graduate school of the University of Minnesota.

DILORENZO, N., DAHLEN, C. R.; DIEZ-GONZALEZ, F. et al. Effects of feeding polyclonal antibodies preparations on rumen fermentation patterns, performance, and carcass characteristics of feedlot steers. Journal of Animal Science, v.86, p.3023-3032, 2008.

DIMARCO, N. M.; BEITZ, D. C.; WHITEHURST, G. B. Effect of Fasting on Free Fatty Acid, Glycerol and Cholesterol Concentrations in Blood Plasma and Lipoprotein Lipase Activity in Adipose Tissue of Cattle. Journal of Animal Science, v.52, p.75-82, 1981.

EIFERT, E. C. Fontes de carboidratos, óleo de soja e monensina para vacas lactantes: Desempenho, digestibilidade, parâmetros ruminais e perfil de ácidos graxos do leite. 117f. Tese (Doutorado em Zootecnia) - Universidade Federal de Viçosa, 2004.

FELLNER, V.; SAUER, F. D.; KRAMER, J. K. G. Effect of nigercin, monensin, and tetronasin on biohydrogenation in continuous flow-through ruminal fermenters. Journal of Dairy Science, 80:921-928, 1997.

FOLCH, J.; LEES, M.; SLOANE-STANLEY, G.H. A simple method for the isolation and purification of total lipids from animal tissues. The Journal of Biological Chemistry, v.226, p.497-509, 1957.

FOSSA, M.V.; PACHECO, R.D.L.; MILLEN, D.D. et al. Fatty acid profile, meat cholesterol and total lipids of Bos indicus based types bullocks fed monensin or polyclonal antibodies against lactate-producing rumen bacteria. Journal of Animal Science, v.86 (E-suppl.2), p.200, 2008.

FRENCH, P.; STANTON C.; LAWLESS F. et al. Fatty acid composition, including conjugated linoleic acid, of intramuscular fat from steers offered grazed grass, grass silage, or concentrate-based. Journal of Animal Science, v.78, p.28492855,2000 . 
GOERING, H. K.; VAN SOEST, P. J. Forage fiber analysis. Agriculture Handbook, Agricultural Research Service. P.19.; Washington D.C., 1970.

HARA, A.; HADIN, N. S. Lipid extraticion of tissues with a low toxicity solvent. Analytical Biochemistry, v.90, p.420-426, 1978.

HOLMES, M. D.; HUNTER, D. J.; COLDITZ, G. A. et al. Association of dietary intake of fat and fatty acids with risk of breast cancer. The Journal of the American Medical Association, v.281(10), p.914-920, 1999.

MATTSON F.H., GRUNDY S. M. Comparison of effects of dietary saturated, monounsaturated, and polyunsaturated fatty acids on plasma lipids and lipoproteins in man. Journal of Lipid Research, v.26, p.194-202, 1985.

METZ, P. A. M.; MENEZES, L. F. G.; SANTOS, A. P. et al. Perfil de ácidos graxos na carne de novilhos de diferentes categorias e grupos genéticos, terminados em confinamento. Revista Brasileira de Zootecnia, v. 38, p.523-531, 2009.

MILLEN, D.D.; PACHECO, R.D.L.; ARRIGONI, M.D.B. et al. Feedlot performance and rumen parakeratosis incidence in Bos indicus type bullocks fed high grain diets and monensin or polyclonal antibodies preparations against rumen bacteria. Journal of Animal Science, v.85, E-Suppl, p.552, 2007.

MILlEN, D. D.; PACHECO, R D. L.; ARRIGONI, M. D. B. et al. A snapshot of management practices and nutritional recommendations used by feedlot nutritionists in Brazil. Journal of Animal Science, v.87, p.3427-3439, 2009.

MIR, P. S.; MCALLISTER, T. A.; SHANNON, S. et al. Conjugated linoleic acid enriched beef production. American Journal of Clinical Nutrition, v.79(Suppl), n.3, p.1207-1211, 2004.

NEWBOLD, C. J.; STEWART, C. S.; WALLACE, R. J. et al. Developments in rumen fermentation - The scientist's view. In Recent Advances in Animal Nutrition 2001.p.251-279. P. C. Garnsworthy and J. Wiseman ed. Nottingham University Press, Nottingham, United Kingdom, 2001.

OCHOA, M. F., MARCHELLO, J. A. Bovine lipoprotein and apolipoprotein profiles as influenced by sex and growth. Journal of Animal Science, 69: 4030-4038, 1991. 
OJEU. Official Journal of the European Union. Regulation (EC) No 1831/2003 of the European Parliament and the Council of 22 of September of 2003 on Additives for Use in Animal Nutrition. Pages L268/29-L268/43 in OJEU of 10/18/2003.

PERKINS, T.L. The use of real time, linear array ultrasound techniques to predict final carcass composition in beef cattle. Ames: Texas Tech University, 1992.

SAS. SAS User's Guide: Statistics (Version 5 Ed.). SAS Inst. Inc., Cary, NC, 2003.

SAUER, F. D.; FELLNER, V.; KINSMAN, R.; KRAMER, J. K. G. et al. Methane output and lactation response in Holstein cattle with Monensin or unsaturated fat added to the diet. Journal of Animal Science, Champaign, v.76, p.906-914, 1998.

SOUZA, A. A. Perfil de ácidos graxos e concentração de CLA no tecido adiposo de bovinos de corte de diferentes grupos genéticos no modelo biológico superprecoce. Botucatu. Tese (Doutorado)-Faculdade de Medicina Veterinária e Zootecnia, Universidade Estadual Paulista, Botucatu. 73p., 2005.

SUGANO, M.; HIRAHARA, F. Polyunsaturated fatty acids in the food chain in Japan. American Journal of Clinical Nutrition, v.71(1 Suppl), p.189-196, 2000.

VAN NEVEL, C. J.; DEMEYER, D. I. Lipolysis and biohydrogenation of soybean oil in the rumen in vitro: Inhibition by antimicrobials. Journal of Dairy Science, 78:2797-2806, 1995.

VARELA, A.; OLIETE, B.; MORENO, T. et al. Effect of pasture finishing on the meat characteristics and intramuscular fatty acid profile of steers of the Rubia Gallega breed. Meat Science, v.67, p.515-522, 2004. 
Tabela 1. Níveis de inclusão dos ingredientes e conteúdo nutricional das dietas experimentais fornecidas durante o estudo.

\begin{tabular}{lccc}
\hline \hline & \multicolumn{3}{c}{ Nível de Concentrado } \\
\cline { 2 - 4 } Ítem & $55 \%$ & $70 \%$ & $85 \%$ \\
\hline Fases & ADAP & CRES & TERM \\
Dias de Alimentação & 28 & 56 & 56 \\
Ingredientes, \% da MS & & & \\
Feno de Coast Cross & 16,40 & 3,30 & 5,70 \\
Bagaço de Cana Cru & 28,40 & 26,70 & 9,40 \\
Silagem de Grãos Úmidos de Milho & 16,40 & 19,60 & 31,90 \\
Grãos de Milho Seco Quebrados & 10,40 & 15,60 & 8,40 \\
Polpa Cítrica & 9,00 & 15,00 & 32,40 \\
Farelo de Soja & 17,90 & 18,30 & 10,50 \\
Suplemento Mineral com 30\% de Uréia ${ }^{1}$ & 1,50 & 1,50 & 1,70 \\
Conteúdo Nutricional, \% de MS & & & \\
MS (\% da Matéria Natural) & 74,00 & 73,00 & 71,00 \\
NDT ${ }^{2}$ & 69,00 & 72,00 & 78,00 \\
Elg ${ }^{3,5}$ Mcal/kg de MS & 0,99 & 1,08 & 1,24 \\
Carboidratos não fibrosos ${ }^{4}$ & 42,20 & 47,00 & 58,60 \\
Proteína Bruta & 16,80 & 15,60 & 13,20 \\
Proteína Degradável no Rúmen (PDR) ${ }^{5}$ & 72,00 & 75,00 & 76,00 \\
Extrato Etéreo & 3,30 & 3,60 & 3,80 \\
FDN & 36,40 & 30,20 & 20,40 \\
Cálcio & 0,46 & 0,54 & 0,89 \\
Fósforo & 0,34 & 0,35 & 0,32 \\
\hline Suplem
\end{tabular}

${ }^{1}$ Suplemento continha $30 \%$ de uréia, $26,7 \%$ de Ca; $5,3 \%$ de $\mathrm{P} ; 10,9 \%$ de $\mathrm{Na} ; 1,5 \%$ de $\mathrm{S}$; 2600 ppm de Zn; 1300 ppm de Mn; 1032 ppm de Cu; 45,0 ppm de I; 15,0 ppm de Se; $154 \mathrm{ppm}$ de $\mathrm{Cu}$ e $2500 \mathrm{ppm}$ de Fe.

${ }^{2}$ Nutrientes Digestíveis Totais.

${ }^{3}$ Energia Liquida para ganho.

${ }^{4} \mathrm{CNF}=100-($ Proteína bruta + Extrato etéreo + FDN + Cinzas $)$.

${ }^{5}$ Estimado segundo equações do CNCPS (2000), nível 2. 


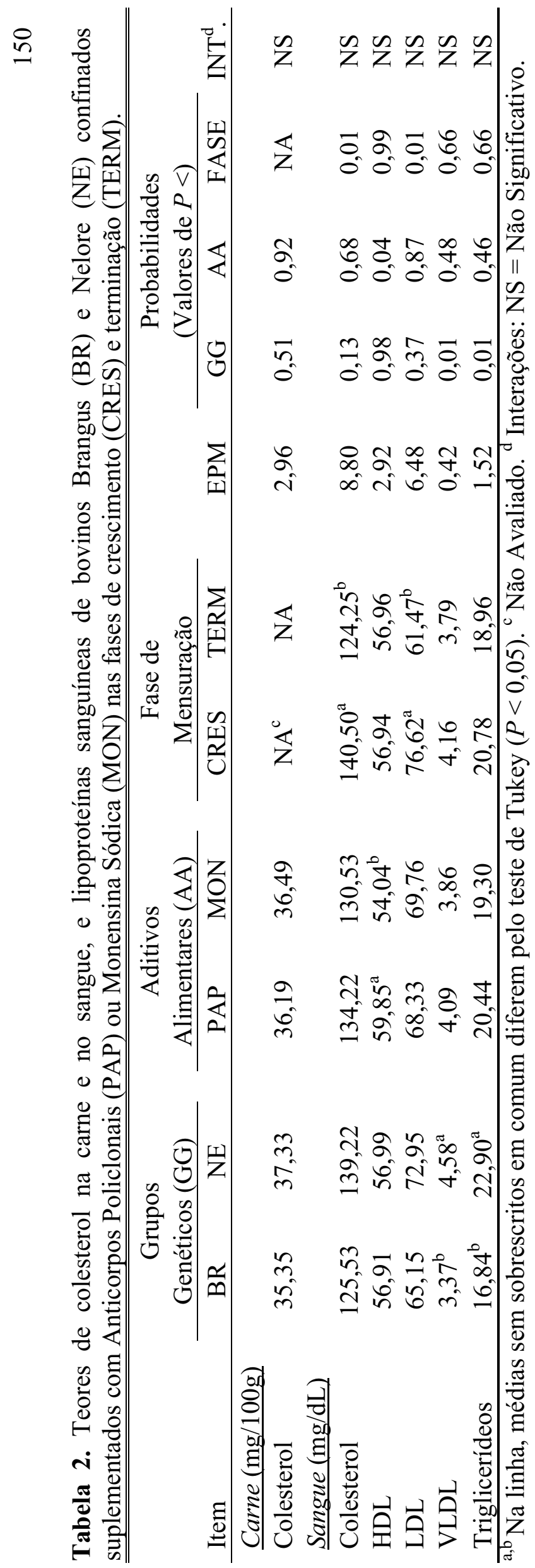




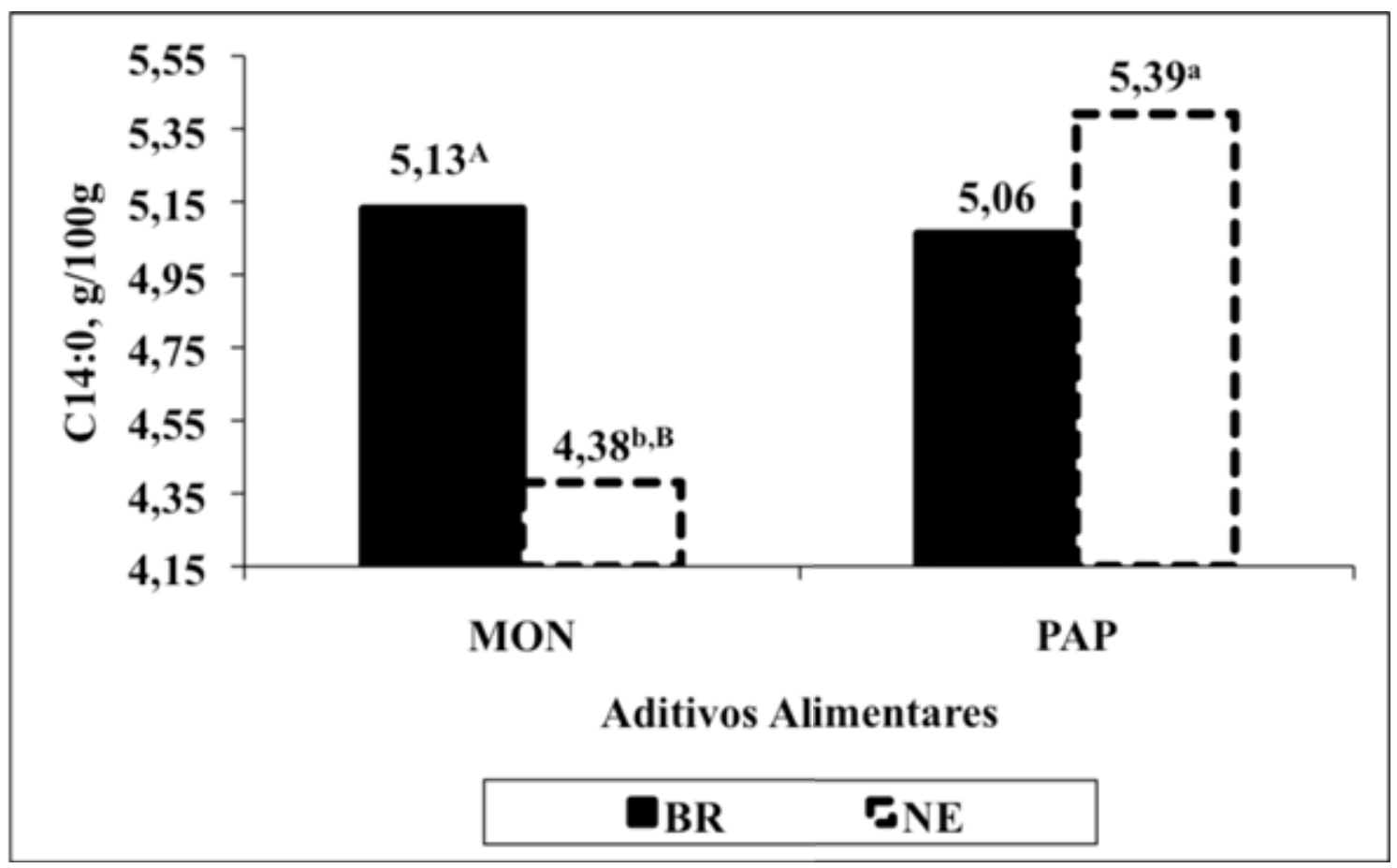

Figura 1. Concentração de Ácido Mirístico (C14:0) do tecido adiposo dos Grupos Genéticos Brangus (BR) e Nelore (NE) suplementados com o Preparado de Anticorpos Policlonais (PAP) ou Monensina Sódica (MON). Foi encontrada interação significativa $(P<0,01)$ entre Grupos Genéticos e Aditivos Alimentares. ${ }^{\mathrm{a}, \mathrm{b}}$ Entre colunas brancas, médias sem sobrescritos em comum, diferem $(P<0,01)$. A,B Para cada aditivo alimentar, médias sem sobrescritos em comum, diferem $(P<0,01)$. 


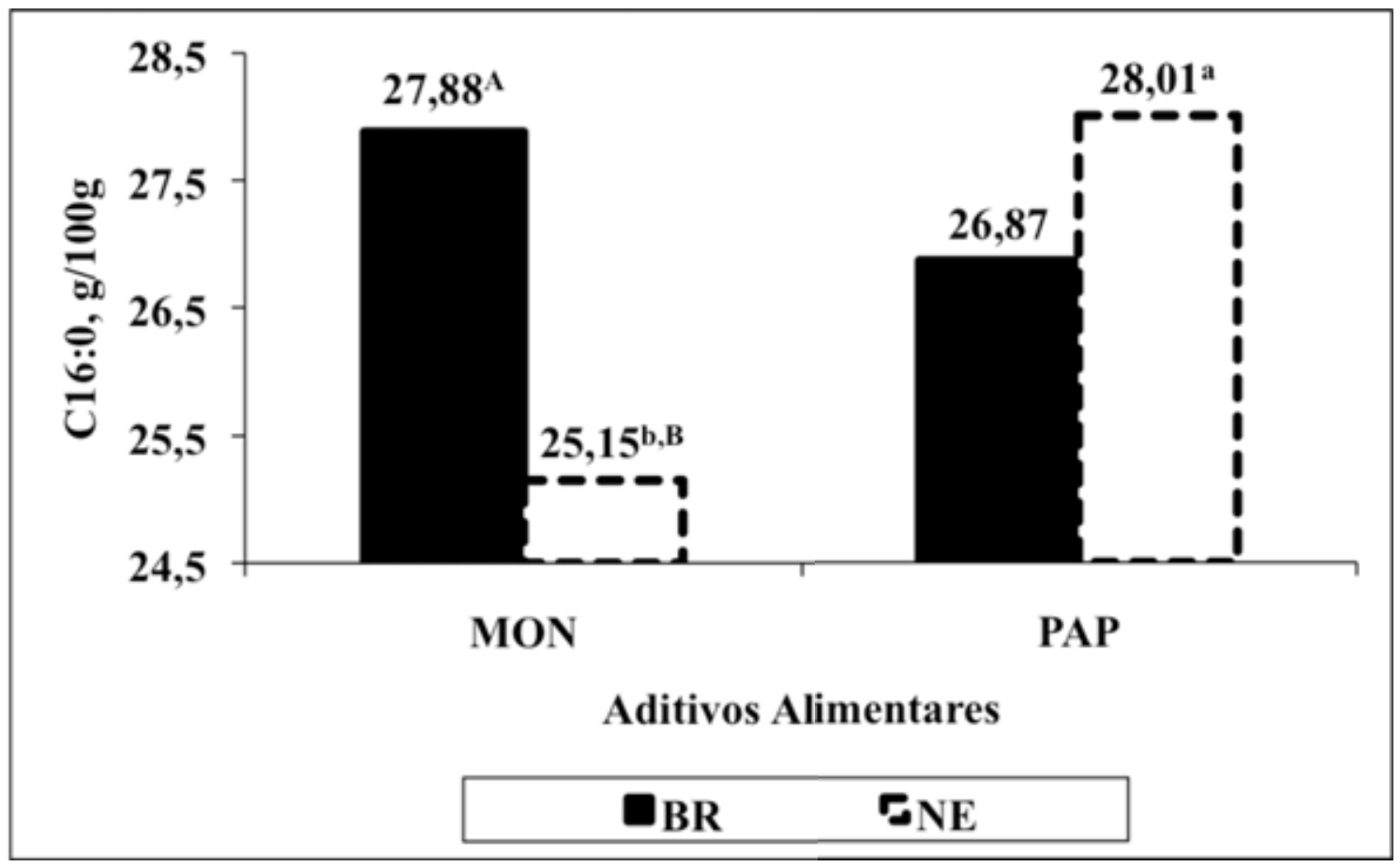

Figura 2. Concentração de Ácido Palmítico (C16:0) do tecido adiposo dos Grupos Genéticos Brangus (BR) e Nelore (NE) suplementados com o Preparado de Anticorpos Policlonais (PAP) ou Monensina Sódica (MON). Foi encontrada interação significativa $(P<0,01)$ entre Grupos Genéticos e Aditivos Alimentares. ${ }^{\mathrm{a}, \mathrm{b}}$ Entre colunas brancas, médias sem sobrescritos em comum, diferem $(P<0,01) .{ }^{\mathrm{A}, \mathrm{B}}$ Para cada aditivo alimentar, médias sem sobrescritos em comum, diferem $(P<0,01)$. 


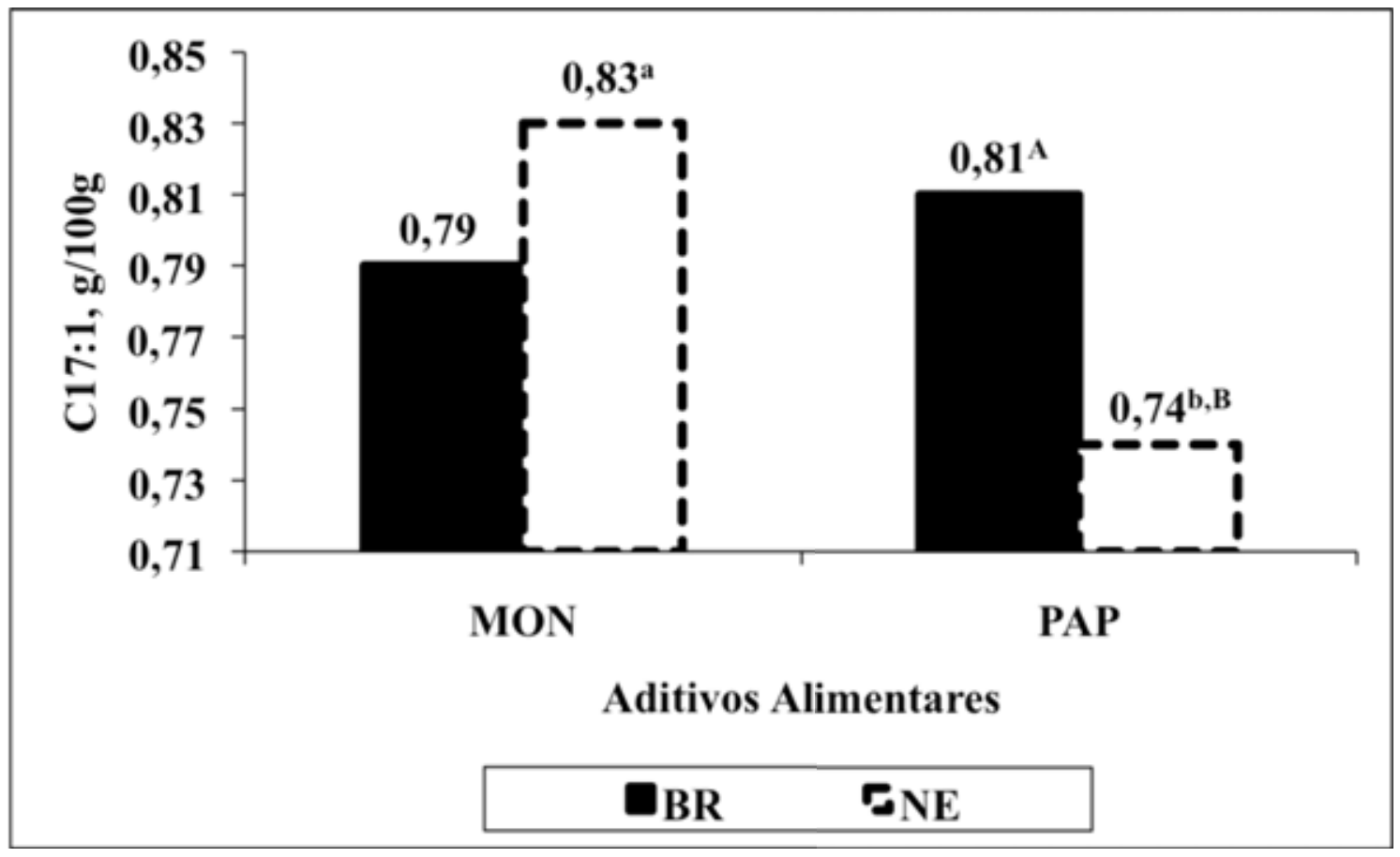

Figura 3. Concentração de Ácido Heptadecenóico (C17:1) do tecido adiposo dos Grupos Genéticos Brangus (BR) e Nelore (NE) suplementados com o Preparado de Anticorpos Policlonais (PAP) ou Monensina Sódica (MON). Foi encontrada interação significativa $(P<0,01)$ entre Grupos Genéticos e Aditivos Alimentares. ${ }^{\mathrm{a}, \mathrm{b}}$ Entre colunas brancas, médias sem sobrescritos em comum, diferem $(P<0,01)$. ${ }^{\mathrm{A}, \mathrm{B}}$ Para cada aditivo alimentar, médias sem sobrescritos em comum, diferem $(P<0,05)$. 


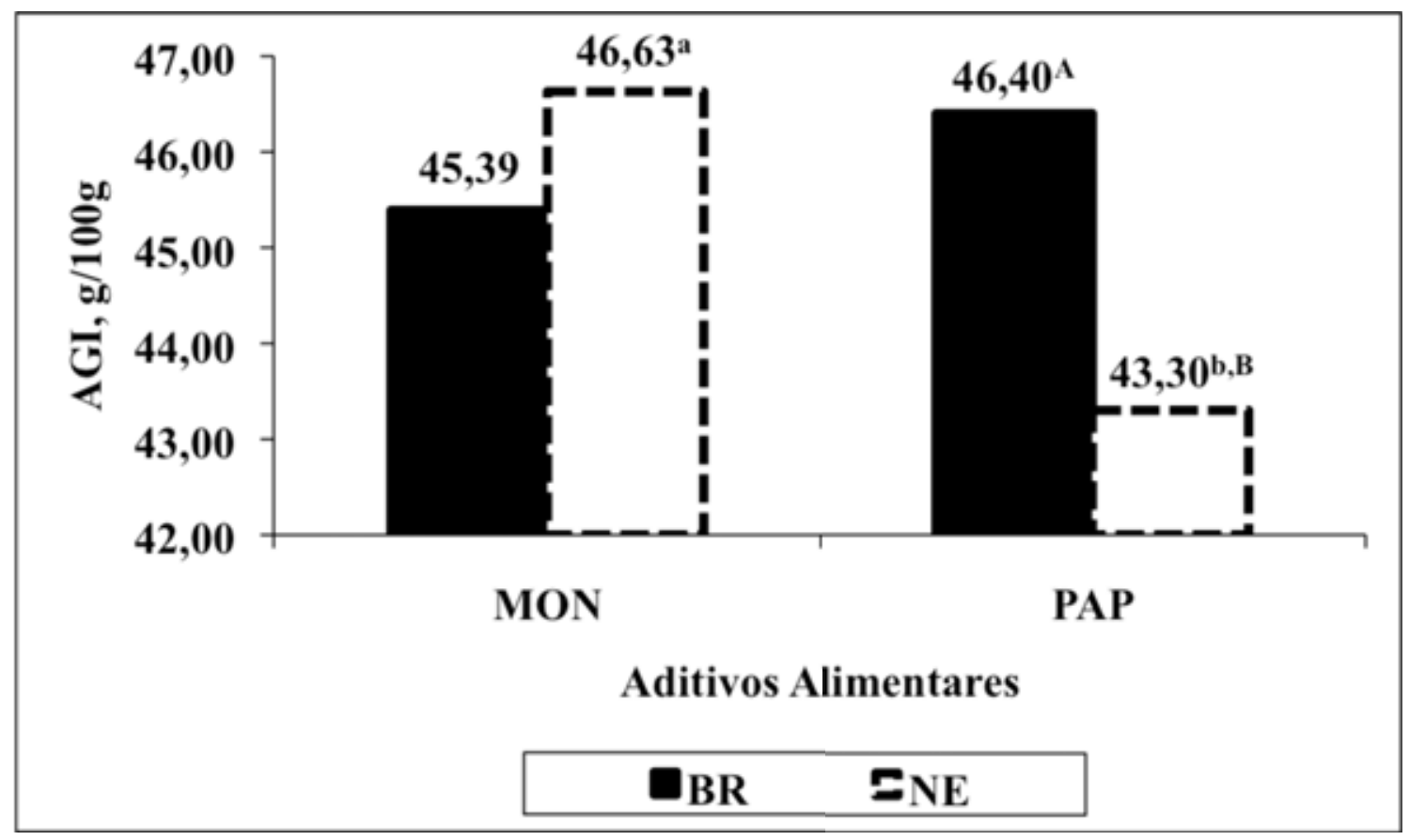

Figura 4. Concentração de Ácido Graxos Insaturados (AGI) do tecido adiposo dos Grupos Genéticos Brangus (BR) e Nelore (NE) suplementados com o Preparado de Anticorpos Policlonais (PAP) ou Monensina Sódica (MON). Foi encontrada interação significativa $(P<0,01)$ entre Grupos Genéticos e Aditivos Alimentares. ${ }^{\mathrm{a}, \mathrm{b}}$ Entre colunas brancas, médias sem sobrescritos em comum, diferem $(P<0,01)$. ${ }^{\mathrm{A}, \mathrm{B}}$ Para cada aditivo alimentar, médias sem sobrescritos em comum, diferem $(P<0,05)$. 


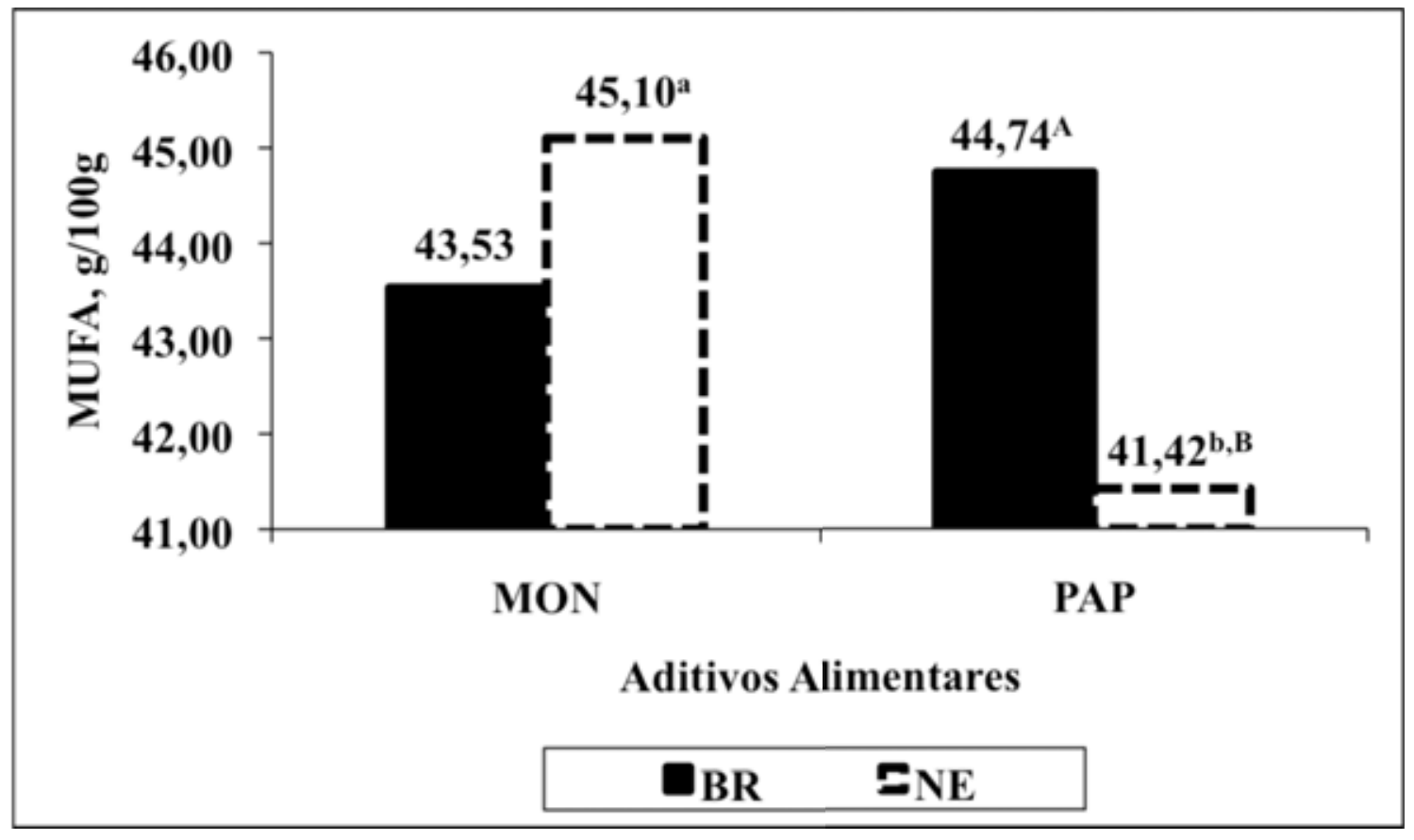

Figura 5. Concentração de Ácido Graxos Mono-Insaturados (MUFA) do tecido adiposo dos Grupos Genéticos Brangus (BR) e Nelore (NE) suplementados com o Preparado de Anticorpos Policlonais (PAP) ou Monensina Sódica (MON). Foi encontrada interação significativa $(P<0,01)$ entre Grupos Genéticos e Aditivos Alimentares. ${ }^{\mathrm{a}, \mathrm{b}}$ Entre colunas brancas, médias sem sobrescritos em comum, diferem $(P<0,01)$. ${ }^{\mathrm{A}, \mathrm{B}}$ Para cada aditivo alimentar, médias sem sobrescritos em comum, diferem $(P<0,01)$. 


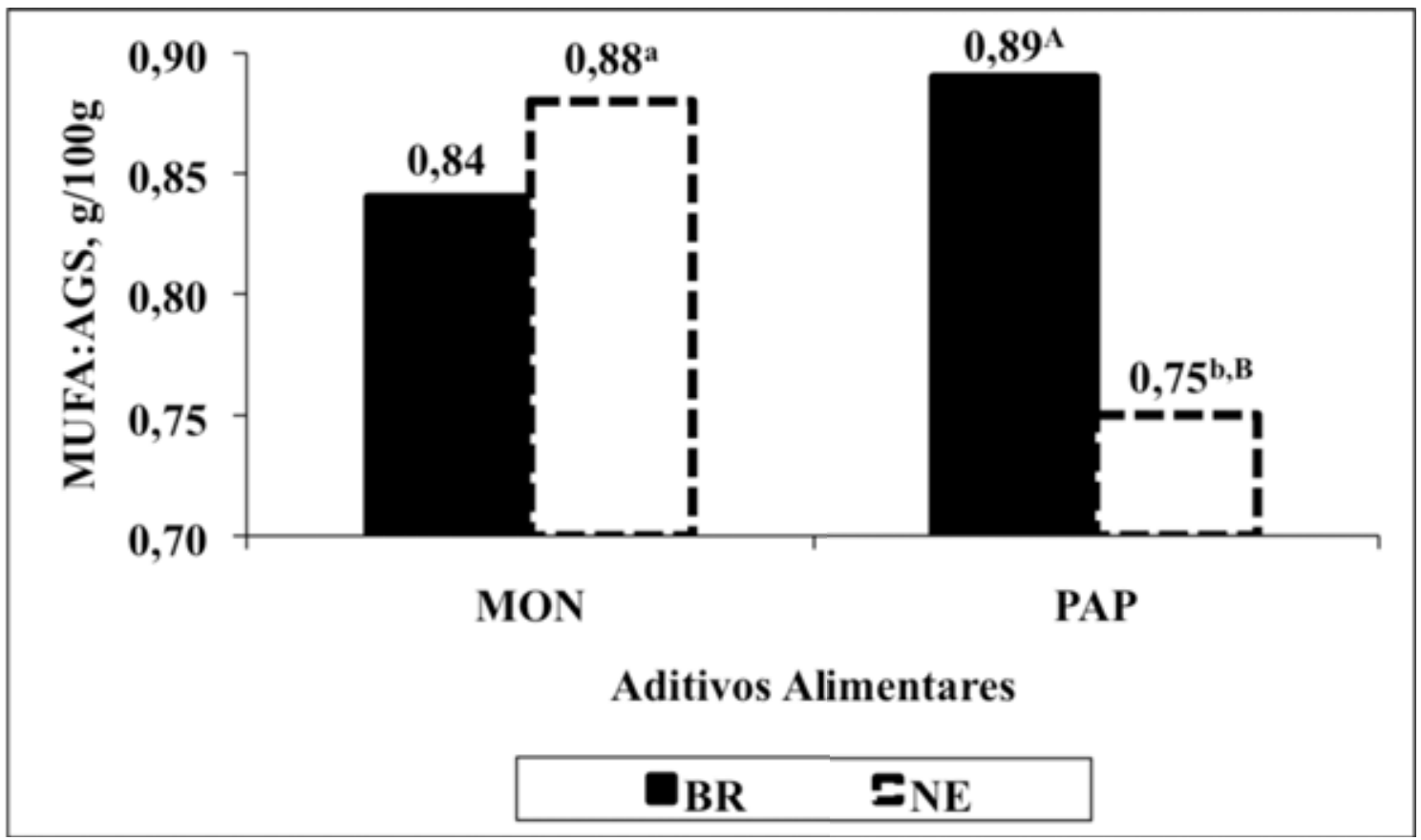

Figura 6. Relação entre ácidos graxos mono-insaturados e ácidos graxos saturados (MUFA:AGS) do tecido adiposo dos Grupos Genéticos Brangus (BR) e Nelore (NE) suplementados com o Preparado de Anticorpos Policlonais (PAP) ou Monensina Sódica $(\mathrm{MON})$. Foi encontrada interação significativa $(P<0,01)$ entre Grupos Genéticos e Aditivos Alimentares. ${ }^{\mathrm{a}, \mathrm{b}}$ Entre colunas brancas, médias sem sobrescritos em comum, diferem $(P<0,01) .{ }^{\mathrm{A}, \mathrm{B}}$ Para cada aditivo alimentar, médias sem sobrescritos em comum, diferem $(P<0,01)$. 


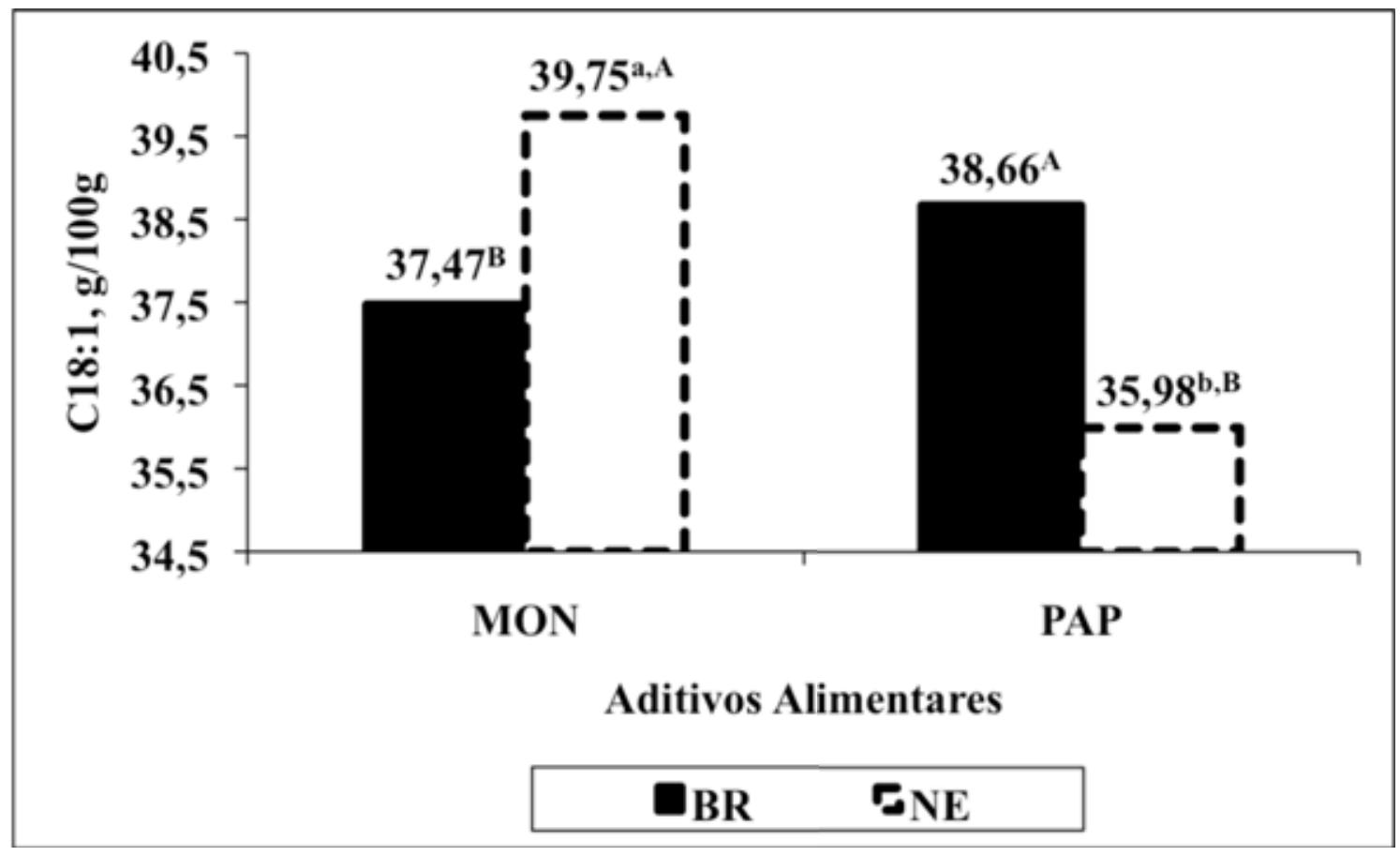

Figura 7. Concentração de Ácido Oléico (C18:1) do tecido adiposo dos Grupos Genéticos Brangus (BR) e Nelore (NE) suplementados com o Preparado de Anticorpos Policlonais (PAP) ou Monensina Sódica (MON). Foi encontrada interação significativa $(P<0,01)$ entre Grupos Genéticos e Aditivos Alimentares. ${ }^{\mathrm{a}, \mathrm{b}}$ Entre colunas brancas, médias sem sobrescritos em comum, diferem $(P<0,01)$. ${ }^{\mathrm{A}, \mathrm{B}}$ Para cada aditivo alimentar, médias sem sobrescritos em comum, diferem $(P<0,01)$. 


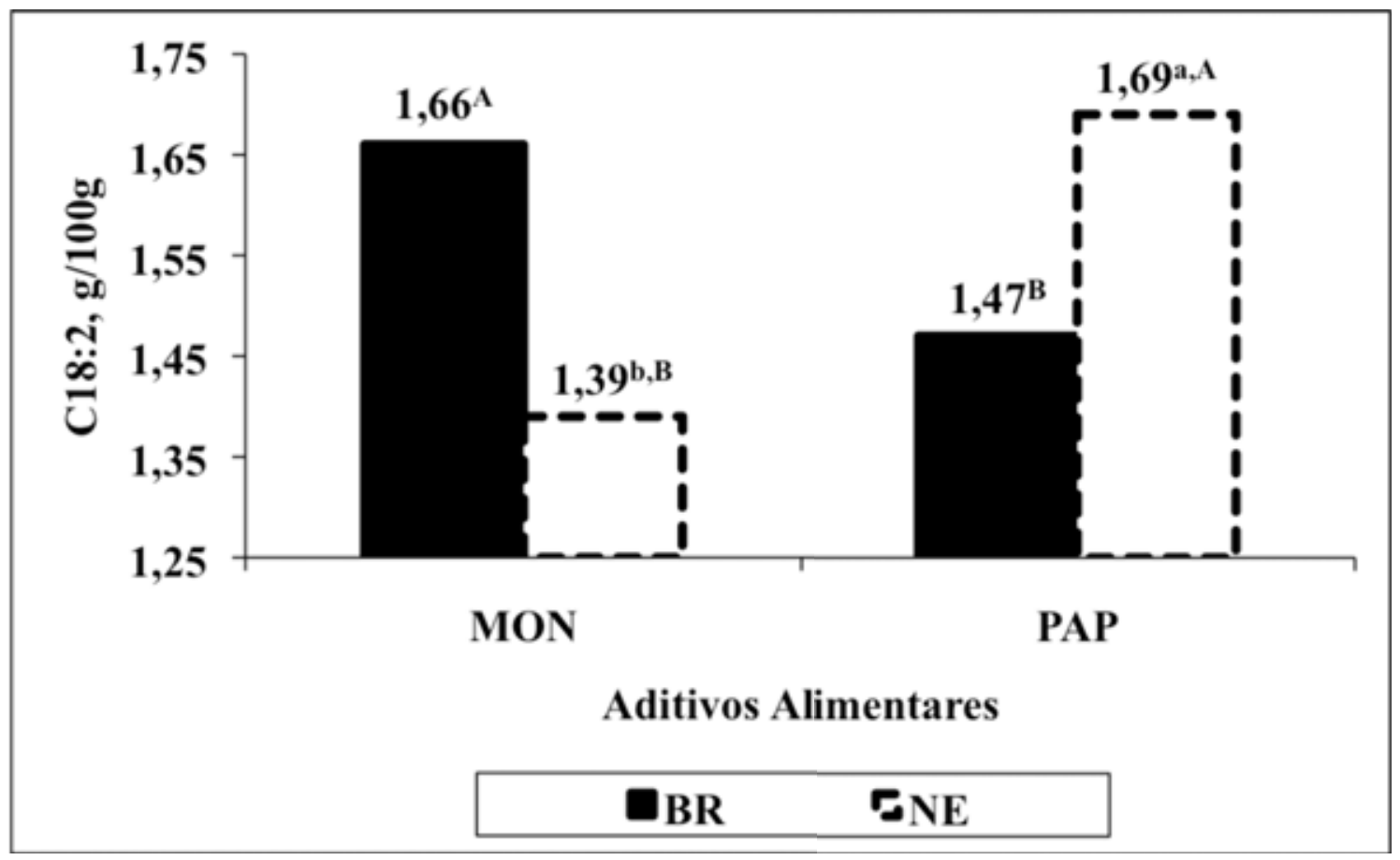

Figura 8. Concentração de Ácido Linoléico (C18:2) do tecido adiposo dos Grupos Genéticos Brangus (BR) e Nelore (NE) suplementados com o Preparado de Anticorpos Policlonais (PAP) ou Monensina Sódica (MON). Foi encontrada interação significativa $(P<0,01)$ entre Grupos Genéticos e Aditivos Alimentares. ${ }^{\mathrm{a}, \mathrm{b}}$ Entre colunas brancas, médias sem sobrescritos em comum, diferem $(P<0,01)$. A,B Para cada aditivo alimentar, médias sem sobrescritos em comum, diferem $(P<0,05)$. 


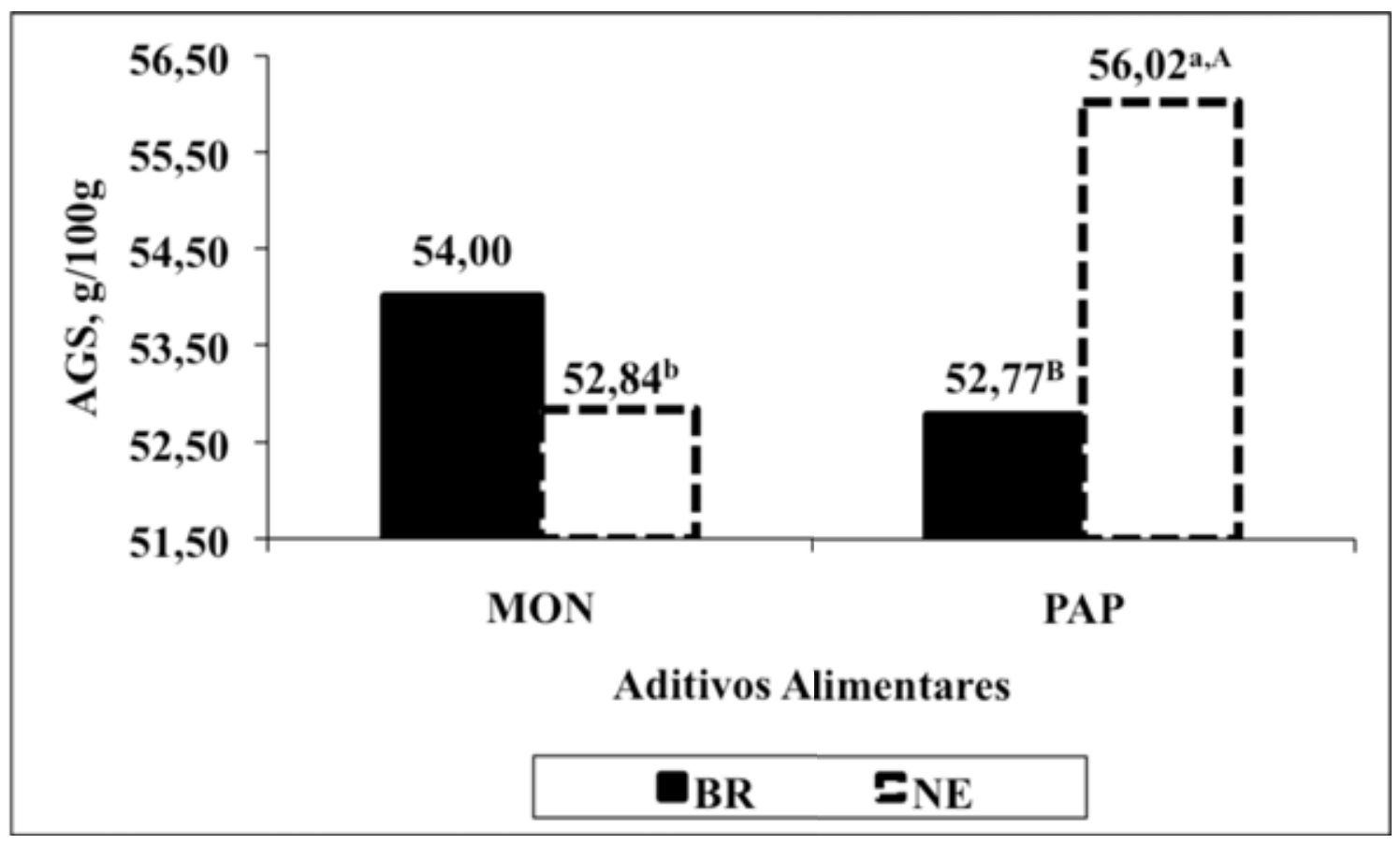

Figura 9. Concentração de Ácido Graxos Saturados (AGS) do tecido adiposo dos Grupos Genéticos Brangus (BR) e Nelore (NE) suplementados com o Preparado de Anticorpos Policlonais (PAP) ou Monensina Sódica (MON). Foi encontrada interação significativa $(P<0,01)$ entre Grupos Genéticos e Aditivos Alimentares. ${ }^{\mathrm{a}, \mathrm{b}}$ Entre colunas brancas, médias sem sobrescritos em comum, diferem $(P<0,01) .{ }^{\mathrm{A}, \mathrm{B}}$ Para cada aditivo alimentar, médias sem sobrescritos em comum, diferem $(P<0,05)$. 


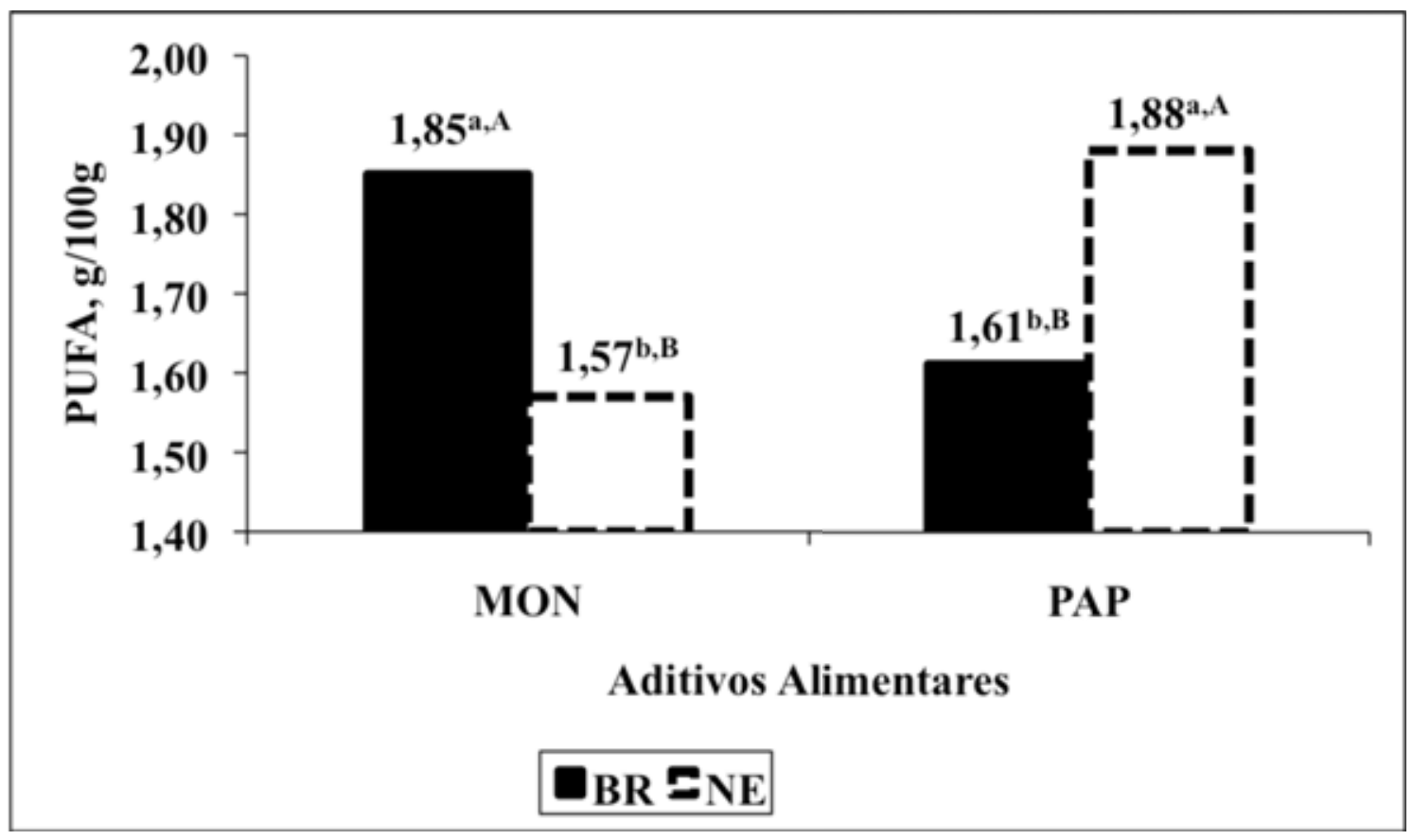

Figura 10. Concentração de Ácido Graxos Poli-Insaturados (PUFA) do tecido adiposo dos Grupos Genéticos Brangus (BR) e Nelore (NE) suplementados com o Preparado de Anticorpos Policlonais (PAP) ou Monensina Sódica (MON). Foi encontrada interação significativa $(P<0,01)$ entre Grupos Genéticos e Aditivos Alimentares. ${ }^{\mathrm{a}, \mathrm{b}}$ Entre colunas brancas e entre colunas negras, médias sem sobrescritos em comum, diferem $(P<0,05)$. ${ }^{\mathrm{A}, \mathrm{B}}$ Para cada aditivo alimentar, médias sem sobrescritos em comum, diferem $(P<0,01)$. 


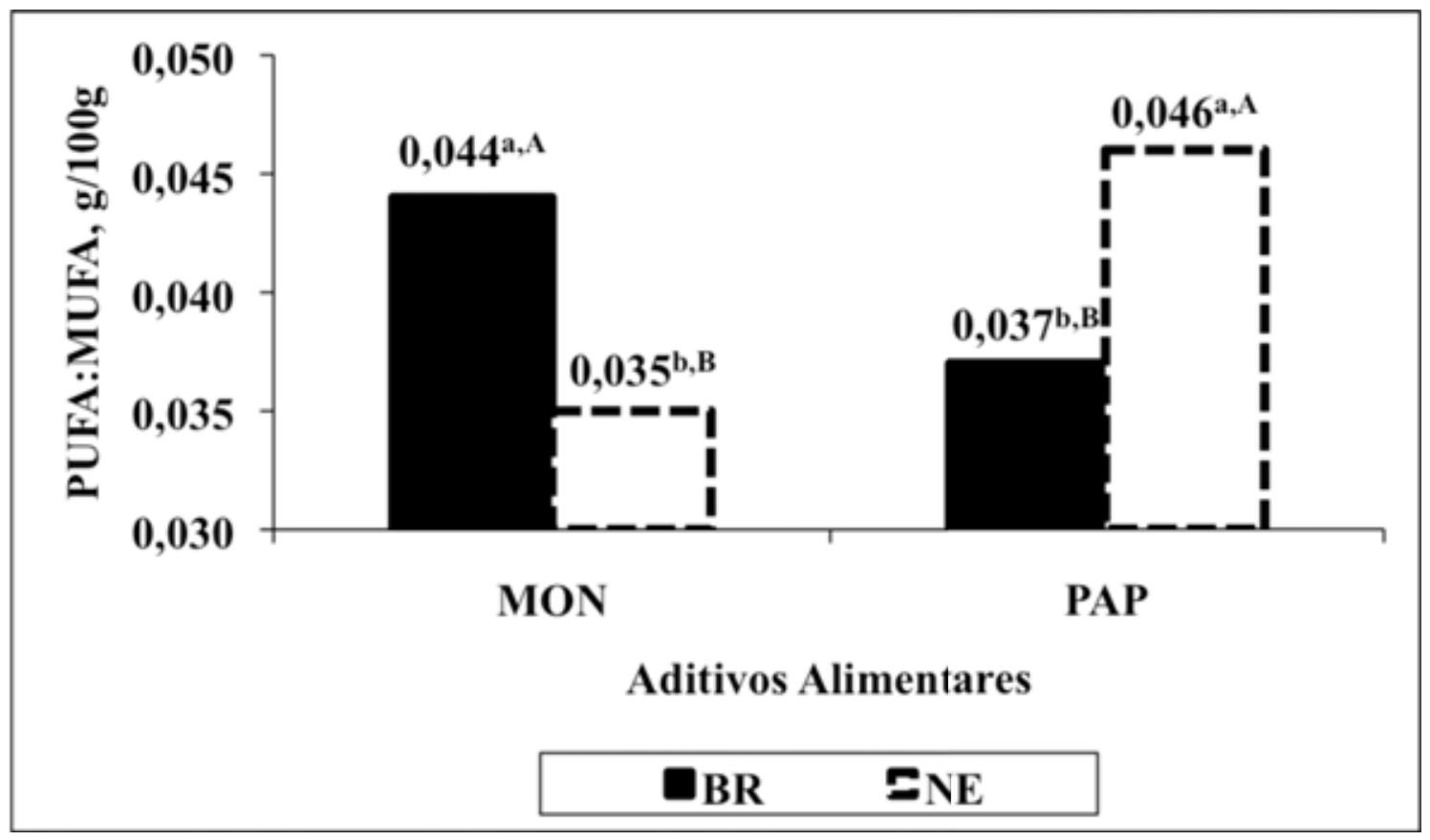

Figura 11. Relação entre ácidos graxos poli-insaturados e mono-insaturados (PUFA:MUFA) do tecido adiposo dos Grupos Genéticos Brangus (BR) e Nelore (NE) suplementados com o Preparado de Anticorpos Policlonais (PAP) ou Monensina Sódica $(\mathrm{MON})$. Foi encontrada interação significativa $(P<0,01)$ entre Grupos Genéticos e Aditivos Alimentares. ${ }^{\mathrm{a}, \mathrm{b}}$ Entre colunas brancas e entre colunas negras, médias sem sobrescritos em comum, diferem $(P<0,05) .{ }^{\mathrm{A}, \mathrm{B}}$ Para cada aditivo alimentar, médias sem sobrescritos em comum, diferem $(P<0,01)$. 


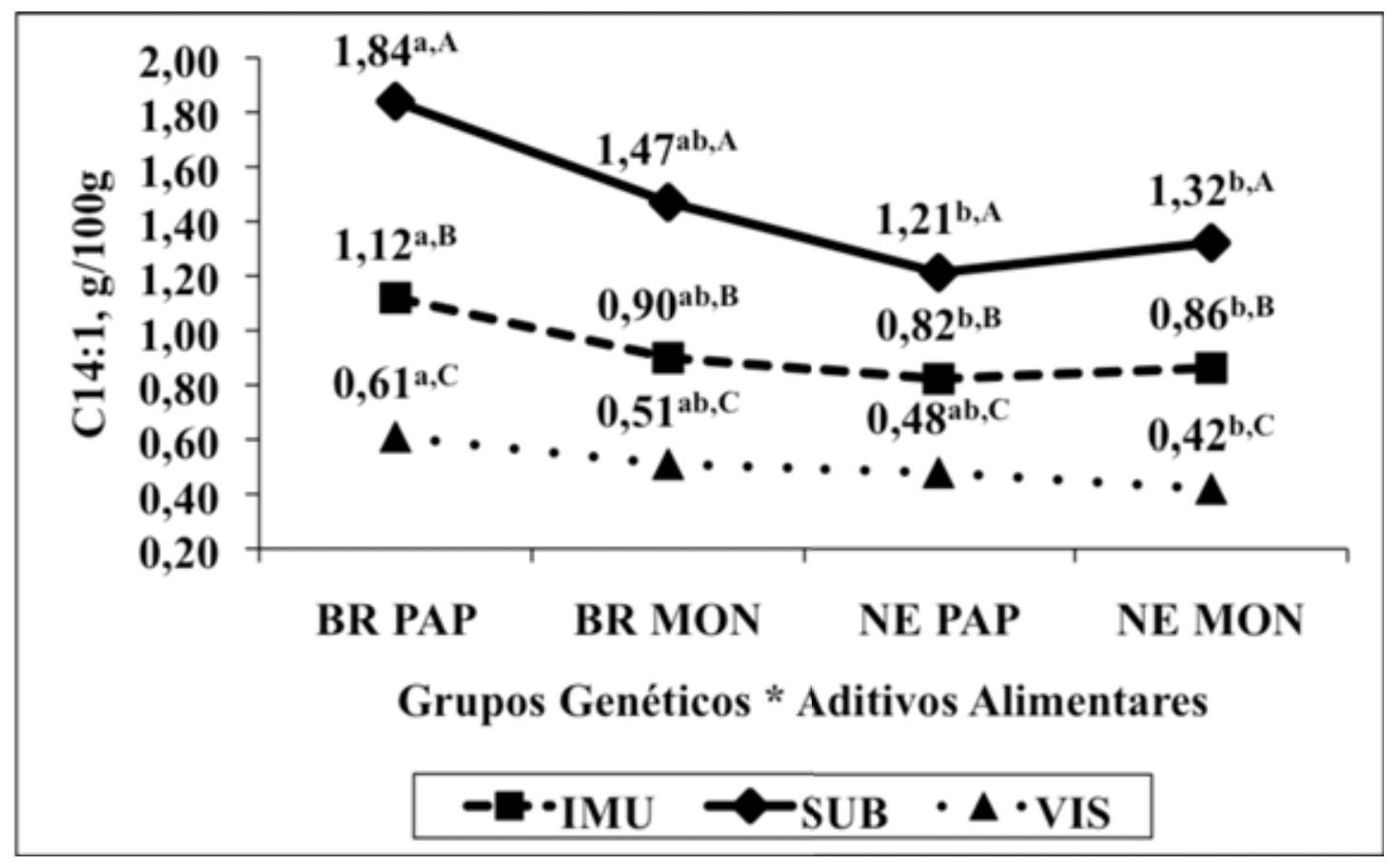

Figura 12. Concentração de Ácido Miristoléico (C14:1) do tecido adiposo amostrados em 3 distintas regiões: Intermuscular (IMU), Subcutânea (SUB) e Visceral (VIS) dos Grupos Genéticos Brangus (BR) e Nelore (NE) suplementados com o Preparado de Anticorpos Policlonais (PAP) ou Monensina Sódica (MON). Foi encontrada interação significativa $(P<0,01)$ entre Grupos Genéticos, Aditivos Alimentares e Região de Amostragem. ${ }^{\mathrm{a}, \mathrm{b}} \mathrm{Na}$ linha, médias sem sobrescritos em comum, diferem $(P<0,05)$. ${ }^{\mathrm{A}, \mathrm{B}, \mathrm{C}}$ Na coluna, médias sem sobrescritos em comum, diferem $(P<0,01)$. 


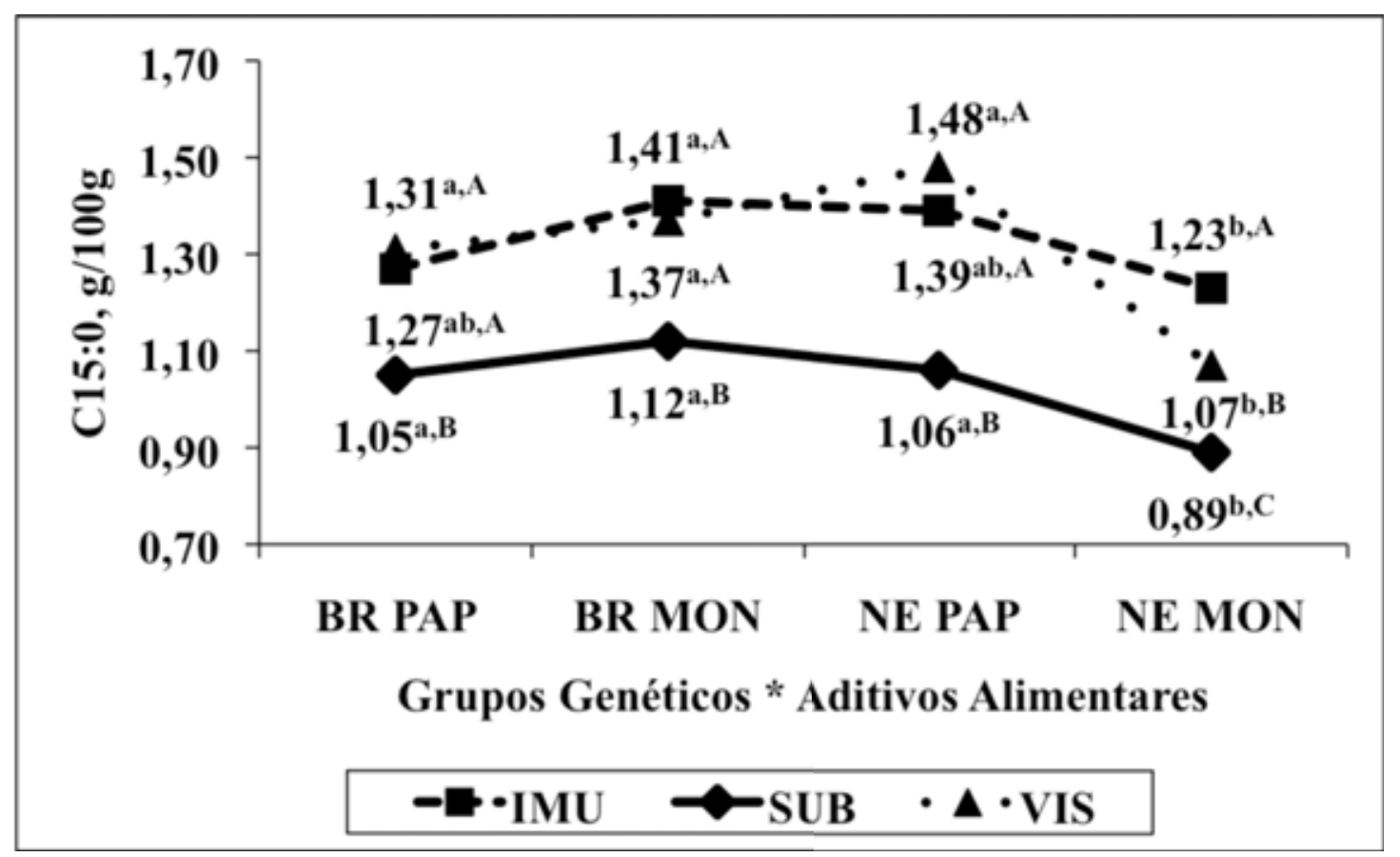

Figura 13. Concentração de Ácido Pentadecanóico $(\mathrm{C} 15: 0)$ do tecido adiposo amostrados em 3 distintas regiões: Intermuscular (IMU), Subcutânea (SUB) e Visceral (VIS) dos Grupos Genéticos Brangus (BR) e Nelore (NE) suplementados com o Preparado de Anticorpos Policlonais (PAP) ou Monensina Sódica (MON). Foi encontrada interação significativa $(P<0,05)$ entre Grupos Genéticos, Aditivos Alimentares e Região de Amostragem. ${ }^{\text {a,b }} \mathrm{Na}$ linha, médias sem sobrescritos em comum, diferem $(P<0,05)$. ${ }^{\text {A,B,C }} \mathrm{Na}$ coluna, médias sem sobrescritos em comum, diferem $(P<$ $0,05)$. 


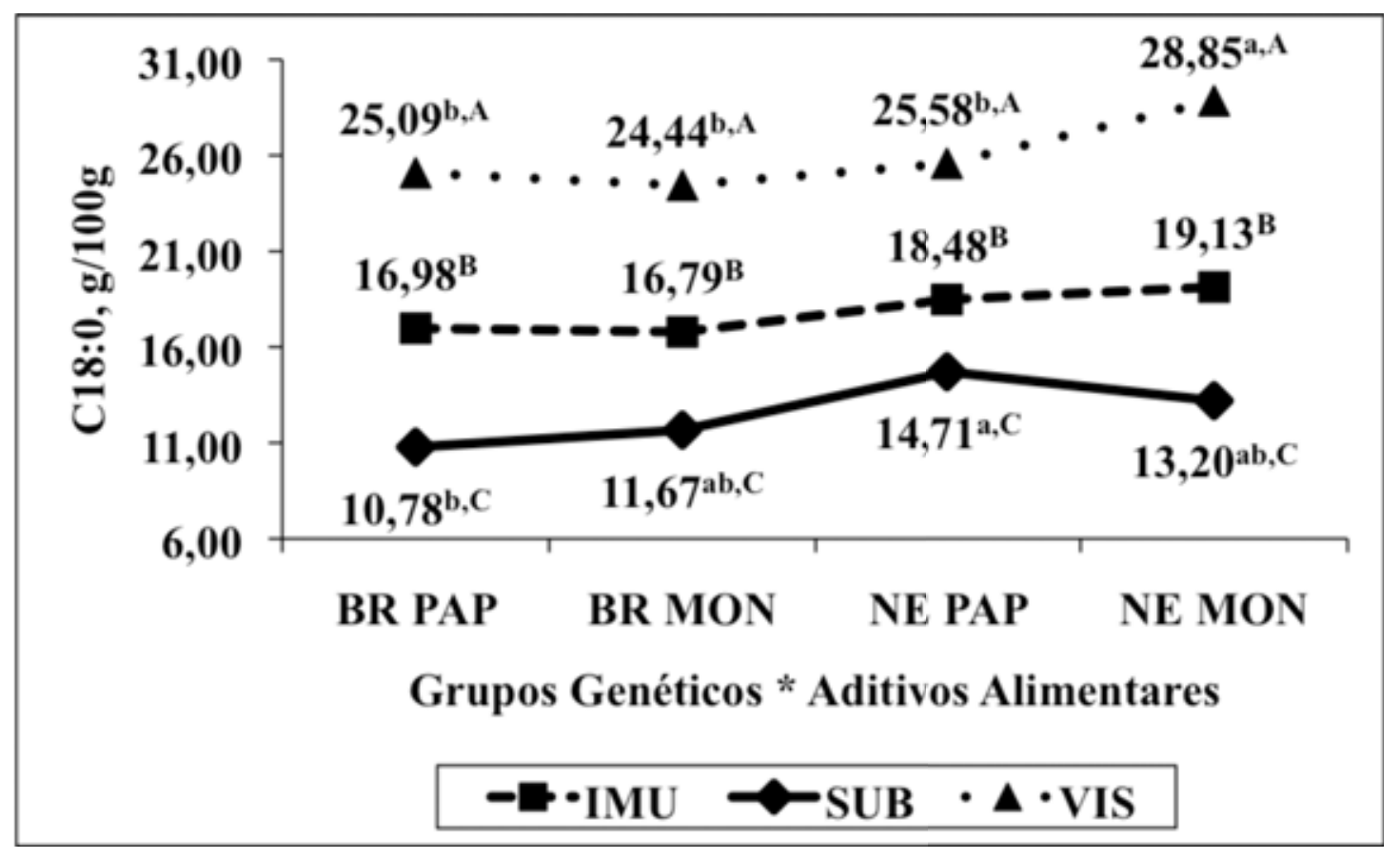

Figura 14. Concentração de Ácido Esteárico (C18:0) do tecido adiposo amostrados em 3 distintas regiões: Intermuscular (IMU), Subcutânea (SUB) e Visceral (VIS) dos Grupos Genéticos Brangus (BR) e Nelore (NE) suplementados com o Preparado de Anticorpos Policlonais (PAP) ou Monensina Sódica (MON). Foi encontrada interação significativa $(P<0,01)$ entre Grupos Genéticos, Aditivos Alimentares e Região de Amostragem. ${ }^{\mathrm{a}, \mathrm{b}} \mathrm{Na}$ linha, médias sem sobrescritos em comum, diferem $(P<0,01)$. ${ }^{\mathrm{A}, \mathrm{B}, \mathrm{C}}$ Na coluna, médias sem sobrescritos em comum, diferem $(P<0,01)$. 


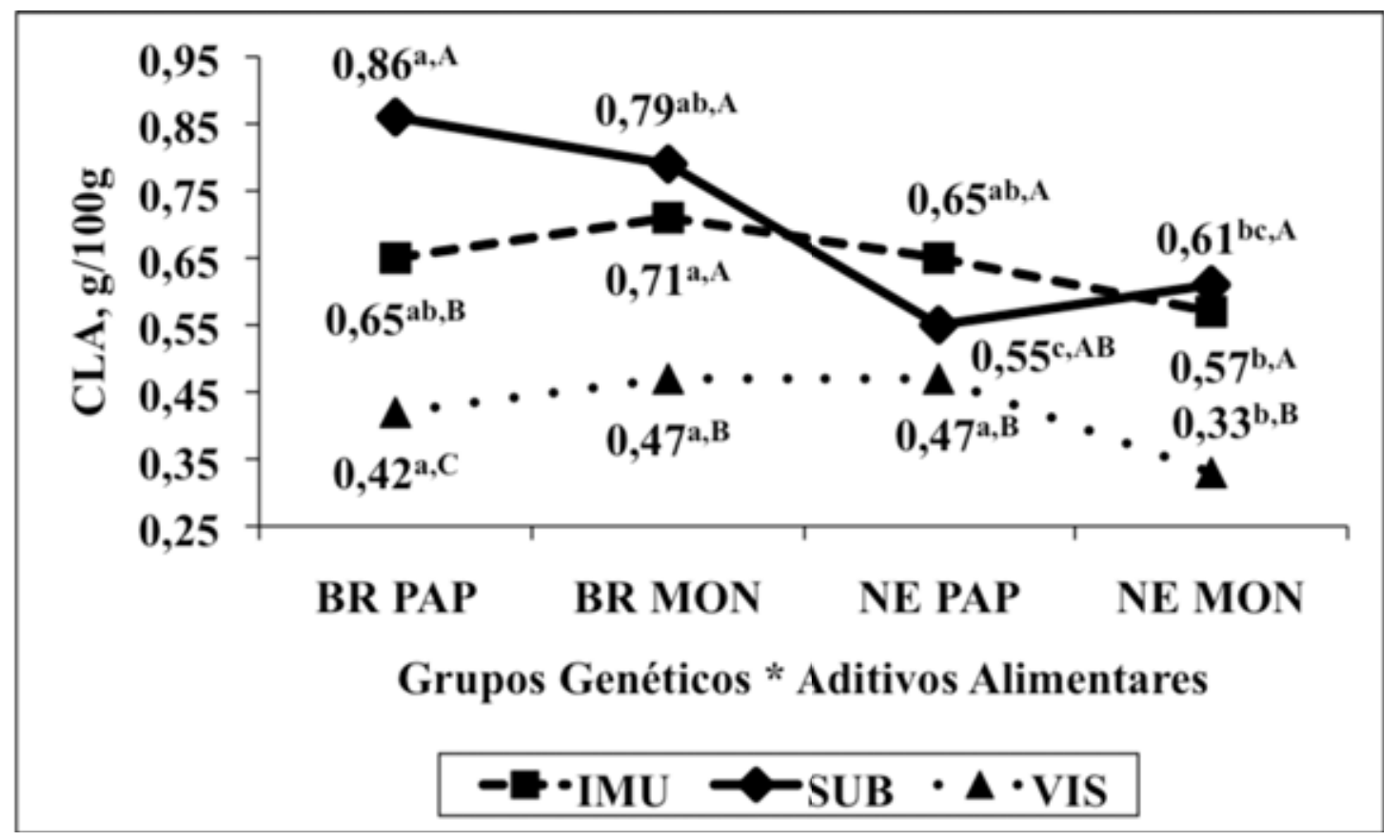

Figura 15. Concentração de Ácido Linoléico Conjugado (CLA; C18:2 cis-9, trans-11) do tecido adiposo amostrados em 3 distintas regiões: Intermuscular (IMU), Subcutânea (SUB) e Visceral (VIS) dos Grupos Genéticos Brangus (BR) e Nelore (NE) suplementados com o Preparado de Anticorpos Policlonais (PAP) ou Monensina Sódica $(\mathrm{MON})$. Foi encontrada interação significativa $(P<0,01)$ entre Grupos Genéticos, Aditivos Alimentares e Região de Amostragem. ${ }^{\mathrm{a}, \mathrm{b}, \mathrm{c}} \mathrm{Na}$ linha, médias sem sobrescritos em comum, diferem $(P<0,05) .{ }^{\mathrm{A}, \mathrm{B}, \mathrm{C}} \mathrm{Na}$ coluna, médias sem sobrescritos em comum, diferem $(P<0,05)$. 


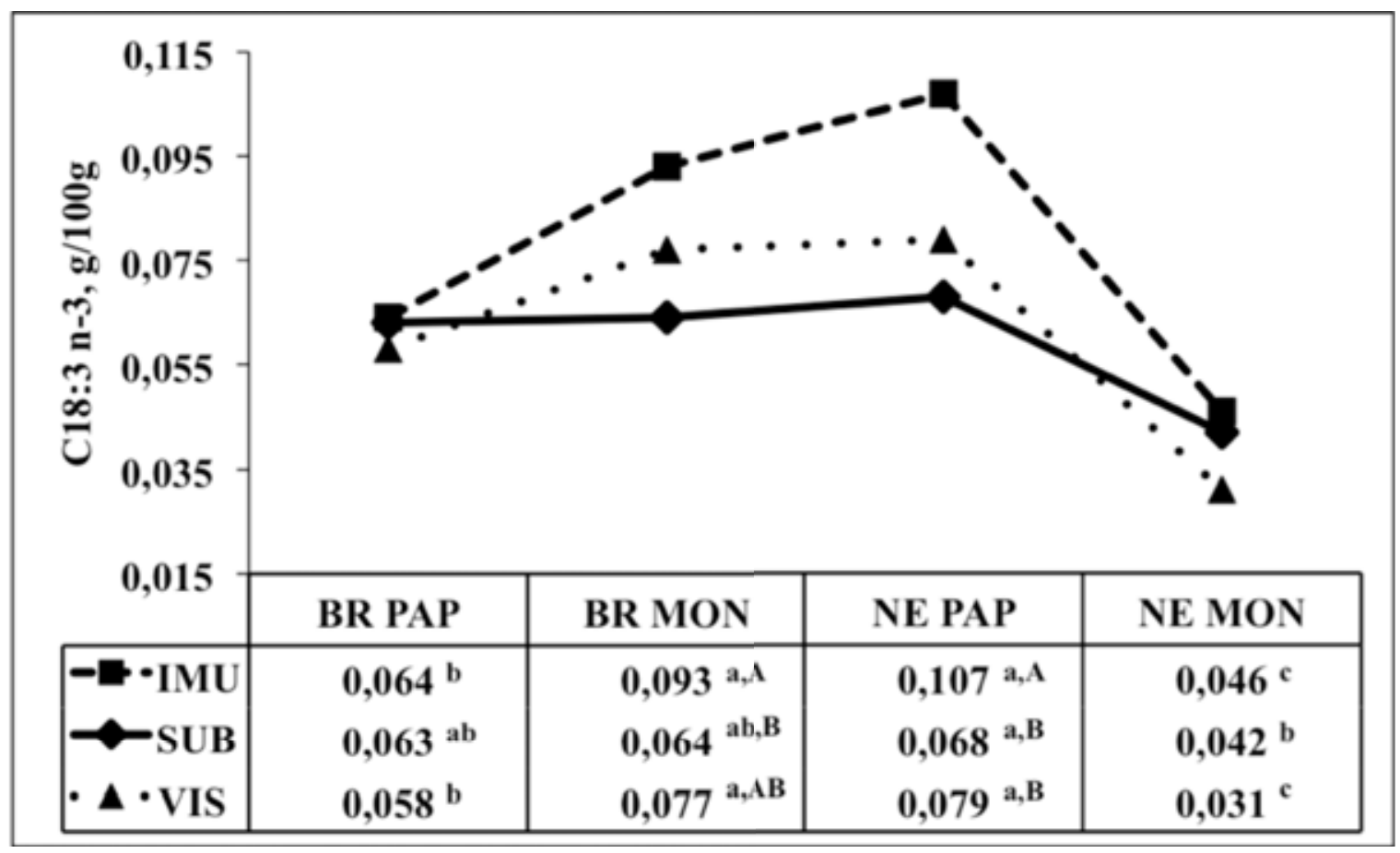

Figura 16. Concentração de Ácido Linolênico Omega-3 (C18:3 n-3) do tecido adiposo amostrados em 3 distintas regiões: Intermuscular (IMU), Subcutânea (SUB) e Visceral (VIS) dos Grupos Genéticos Brangus (BR) e Nelore (NE) suplementados com o Preparado de Anticorpos Policlonais (PAP) ou Monensina Sódica (MON). Foi encontrada interação significativa $(P<0,01)$ entre Grupos Genéticos, Aditivos Alimentares e Região de Amostragem. ${ }^{\text {a,b,c }} \mathrm{Na}$ linha, médias sem sobrescritos em comum, diferem $(P<0,05){ }^{\mathrm{A}, \mathrm{B}} \mathrm{Na}$ coluna, médias sem sobrescritos em comum, diferem $(P<0,01)$. 


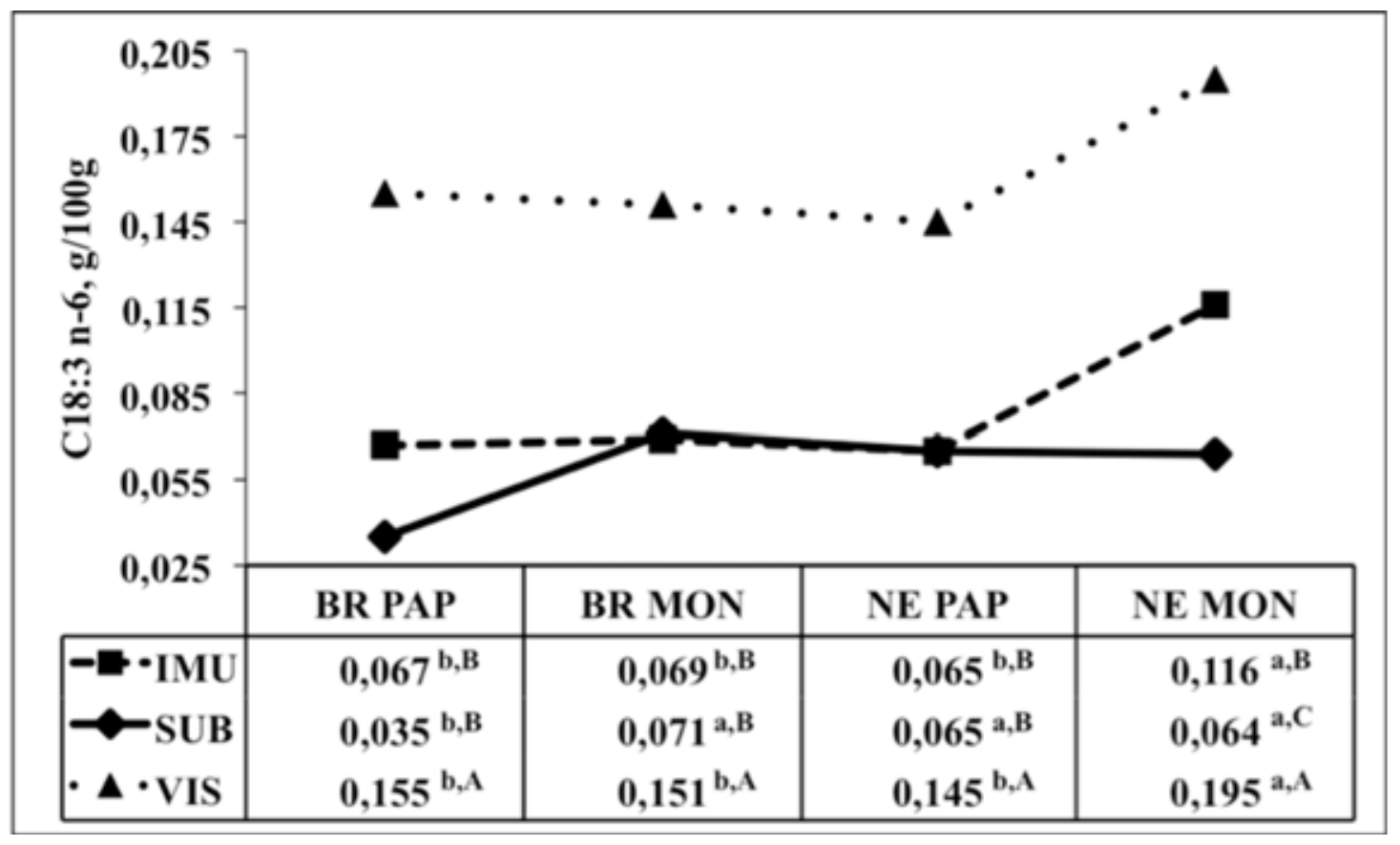

Figura 17. Concentração de Ácido Linolênico Omega-6 (C18:3 n-6) do tecido adiposo amostrados em 3 distintas regiões: Intermuscular (IMU), Subcutânea (SUB) e Visceral (VIS) dos Grupos Genéticos Brangus (BR) e Nelore (NE) suplementados com o Preparado de Anticorpos Policlonais (PAP) ou Monensina Sódica (MON). Foi encontrada interação significativa $(P<0,01)$ entre Grupos Genéticos, Aditivos Alimentares e Região de Amostragem. ${ }^{\text {a,b }} \mathrm{Na}$ linha, médias sem sobrescritos em comum, diferem $(P<0,05)$. ${ }^{\text {A,B,C }}$ Na coluna, médias sem sobrescritos em comum, diferem $(P<$ $0,01)$. 


\section{CAPÍTULO 4}




\section{IMPLICAÇÕES}

A técnica de imunização para controlar populações específicas de microorganismos ruminais surge como nova tecnologia que tem grande potencial, especialmente quando consideramos futuras linhas na produção animal e a proibição de antibióticos, resultante da preocupação pública em relação ao uso excessivo destes na produção animal. O uso de imunização passiva via oral parece ser uma ferramenta nutricional que, num futuro próximo, poderia ser largamente utilizada. No presente estudo, apesar de o produto se apresentar na forma seca, este pode ter atingido o objetivo, contrariando outros estudos nos quais o preparado de anticorpos policlonais na forma seca foi fornecido. No entanto, necessita-se de mais pesquisas em relação ao preparado de anticorpos policlonais, principalmente para se determinar os mecanismos pelos quais seus efeitos são atingidos e a dosagem ótima de inclusão do produto nas dietas de bovinos confinados. Em estudos futuros envolvendo delineamentos experimentais similares a este, a inclusão de controle negativo como um dos tratamentos seria extremamente útil.

Estudos mais aprofundados são necessários para determinar os mecanismos pelos quais os efeitos benéficos são atingidos assim como o ajustamento das doses que devem ser usadas e o desenvolvimento de novos anticorpos contra outros tipos de bactérias ruminais que podem afetar o desempenho de bovinos confinados. A suplementação em conjunto com a monensina sódica, especialmente no período de adaptação às dietas de alto concentrado, quando o animal é realmente desafiado em termos de acidose ruminal, revela novo campo para pesquisa com essa nova tecnologia. No entanto, outros enfoques para o uso do preparado de anticorpos policlonais deveriam ser explorados, pois existe ainda grande incerteza em torno da "real" proibição do uso de ionóforos em dietas de ruminantes, por se tratar de uma decisão muito mais política do que técnica.

O modelo de confinamento experimental adotado poderia ser substituído por um ciclo mais curto (60-90 dias) com animais zebuínos puros desafiados com dietas contendo altos teores de concentrado, pois dessa forma haveria menos tempo para os animais se adaptarem às dietas e simularia, de melhor maneira, as condições encontradas nos confinamentos brasileiros. 
Mais estudos são necessários para se esclarecer as razões pelas quais bovinos Zebu apresentam menor consumo de alimentos que animais com alguma proporção do genótipo Bos taurus quando dietas de altos teores de concetrado são fornecidas e, assim, elaborar estratégias para que esse problema de ganho de peso reduzido, seja solucionado. Estudos com relação a sensitividade de animais zebuínos à dietas altamente energéticas também devem ser conduzidos, já que os protocolos de adaptação utilizados no Brasil nos dias de hoje, foram desenvolvidos para bovinos de genótipo Europeu.

Atenção especial deveria ser dada para se esclarecer as diferenças encontradas em termos de teores de ácidos graxos saturados e insaturados entre os tecidos adiposos subcutâneo, intermuscular e visceral amostrados, e os mecanismos pelos quais esses ácidos graxos são depositados na gordura das carcaças de bovinos de corte. 